Portland State University

PDXScholar

\title{
A Collaborative Approach to Cultural Resource Risk Assessment, Preservation, and Prioritization: A Case Study from Sauvie Island, Oregon
}

Phillip James Daily

Portland State University

Follow this and additional works at: https://pdxscholar.library.pdx.edu/open_access_etds

Part of the Environmental Studies Commons, and the Other History of Art, Architecture, and Archaeology Commons

Let us know how access to this document benefits you.

\section{Recommended Citation}

Daily, Phillip James, "A Collaborative Approach to Cultural Resource Risk Assessment, Preservation, and Prioritization: A Case Study from Sauvie Island, Oregon" (2021). Dissertations and Theses. Paper 5817. https://doi.org/10.15760/etd.7688

This Thesis is brought to you for free and open access. It has been accepted for inclusion in Dissertations and Theses by an authorized administrator of PDXScholar. Please contact us if we can make this document more accessible: pdxscholar@pdx.edu. 
A Collaborative Approach to Cultural Resource Risk Assessment, Preservation, and Prioritization:

A Case Study from Sauvie Island, Oregon

\title{
by
}

Phillip James Daily

A thesis submitted in partial fulfillment of the requirements for the degree of

\author{
Master of Science \\ in \\ Anthropology
}

Thesis Committee:

Virginia L. Butler, Chair

Douglas C. Wilson

Jeremy Spoon

Portland State University

2021 
(C) 2021 Phillip James Daily 


\begin{abstract}
New and increasing threats to cultural heritage resources have pushed archaeologists, land managers, and Indigenous peoples to develop strategies to identify at-risk resources, determine condition, vulnerabilities, and value of said resources, and then provide mitigation and preservation prioritizations and recommendations for the future. One such strategy is the risk assessment approach. Typically, to guide ongoing and future management of vulnerable cultural resources, risk assessments consider preexisting archaeological data, alongside geomorphological and hydrological landform characteristics, to prioritize sites for preservation. While such assessments have been conducted around the globe, they have not been widely applied on the Lower Columbia of Oregon and Washington (U.S.A.), nor has a localized methodology been developed, particularly one that incorporates the perspectives and values of descendent communities, through a collaborative partnership.

My research took such a collaborative approach to risk assessment, via a case study of the western shoreline of Sauvie Island, located on the Lower Columbia River, in partnership with one of several tribes with strong ties to the river, the Confederated Tribes of the Grand Ronde. My project examined an area of cultural significance to develop a baseline prioritization assessment, using the novel strategy of waterborne survey via kayak to access my study area. I posed two primary research questions: - 1) What forces negatively impacted cultural heritage resources? 2) How did tribal partners prioritize cultural resources for preservation?
\end{abstract}


To address these questions, I conducted fieldwork over the course of several months along the $\sim 34 \mathrm{~km}$ western shoreline of Sauvie Island, recording 18 archaeological sites, including 8 previously recorded sites and 10 newly identified ones. Using GIS capable devices and geotagged photography, I recorded nearly 2,000 artifacts, as well as in situ cultural deposits, dateable features, and diagnostic artifacts. These elements of the physical archaeological assemblage factored into a series of six variables defining archaeological value. I also recorded factors which put each site at risk, such as erosion and modern cultural impacts. To obtain tribal input about their views of value, I had seven collaborative meetings with staff members of the Tribal Historic Preservation Office (THPO) from the Confederated Tribes of the Grand Ronde. Through an iterative process of editing and review, we identified six variables that communicated how the Grand Ronde value cultural resources. Together, archaeological and tribal values and risk assessment scores were joined to create prioritization preservation scores for each of the 18 sites recorded during my project.

The application of the prioritization assessment process identified two sites scoring "Very High", four sites scoring "High", four sites scoring "Medium", seven sites scoring "Low", and one site placed in the "Very Low" group. The assessment process showed where archaeological and tribal values overlapped, largely in areas of proximity to ethnographic locations and rare characteristics of the site. The assessment also showed where sites diverged, where tribal values recognized the potential of a site over the observed physical assemblage, and where, most importantly, sites retained reconnectivity, or an aspect that the tribe could reengage with, be it through land access, 
the activities that could be conducted at the site, or the context of other sites and ethnographic locations around it. Additionally, the assessment also highlighted ways sites are vulnerable to loss from erosion. Fifteen of the 18 sites have some combination of sheer eroding banks, slumping, undercutting, or sheer beach edge. Sediment starvation due to upstream river dams and boat wake are the main forces of erosion along the shoreline.

My project has several values. First, I have provided an up-to-date overview of cultural resources along the western shoreline of Sauvie Island for the Oregon State Historic Preservation Office and other agencies, such as the Oregon Department of Fish and Wildlife. This alone will be useful for management purposes. Second, I have created a preservation prioritization process which allows for a systematic review of archaeological values, tribal values, and risk factors. This process could be applied both in the Lower Columbia and elsewhere. Third, through a collaborative effort with my Grand Ronde tribal partners, I have identified a number of tribal values that reflect how a descendant community views cultural resources. This case study has produced a risk assessment template based not only on archaeological value, but also value to descendent communities. Future work should expand the assessment to include perspectives from other tribes with ties to Sauvie Island. 


\section{Acknowledgements}

At the start, the scope of a thesis is difficult to judge, and the odds are good that things will be much larger and stranger than expected. As such, it takes a team to support such an endeavor and my thesis is no exception, with far too many friends, family, peers, colleagues, and academic advisers to list individually here. Here are just a few people who truly were instrumental in my work.

To my adviser, Virginia Butler, who has stuck with me throughout my years here at Portland State and worked overtime to point me to the right literature, contact the right people, and make the right academic choices. She has been patient and dedicated, through all the ups and downs, through a project that has evolved quite dramatically over the course of its lifetime. She has spent countless hours offering valuable feedback, helping to shape this thesis into what it is today. Its success would not have been possible without her as my adviser. Virginia, along with the rest of the Anthropology Department's academic faculty, particularly my committee, Doug Wilson, and Jeremy Spoon, have served to ensure that my time here at Portland State has been enriching and my endeavors have been supported. Thank you all.

To our tribal partners at the Grand Ronde Tribal Historic Preservation Office, Chris Bailey, Cheryl Pouley, and Briece Edwards, who's guidance was the impetus for this project. These three individuals dedicated a significant amount of their time, as well as their resources, to not only help shape the overall scope and direction of this project, but to help me understand the relationship that the Grand Ronde tribe has to cultural resources on the landscape. It was always the goal of this project to center tribal 
perspectives, and these three individuals added that perspective, which simply could not be found elsewhere. Their contribution has, I hope, made this research project more equitable, more considerate, and most importantly, valuable for all local tribal communities, through the emphasis on a tribal perspective.

To Madeline Robin, my loving partner, unfailing research assistant, and patient driver. From her emotional support to her practical contributions in the field, Madeline was my rock during some truly grueling days slogging along the Sauvie Island beaches. Her background in biology also made her a key part of floral and faunal identification in the field. This thesis could not have been completed without her, and I will be forever grateful for her assistance.

To Mark Nebeker, Daniel Pettit, and the rest of the Oregon Department of Fish and Wildlife staff on Sauvie Island, as well as staff from other agencies, such as the Oregon Parks and Recreation Department and Metro. These folks put up with my requests, expedited permits, cheerfully facilitated access, and provided useful information on the land being surveyed. It is my hope that the information I have collected will be of great use to them in the coming years as they work with local tribes to protect Sauvie Island's rich cultural heritage.

To Dennis Torresdal, who provided a home for my kayaks during my survey fieldwork. Long a friend of the department, Dennis' freely given assistance dramatically reduced travel time and made my work on Sauvie Island infinitely more accessible. Dennis was also kind enough to take me out on a jetboat ride on the Multnomah Channel, 
where he shared his extensive knowledge of the island with me. Without Dennis' contributions, the field portion of my project may well have not been possible.

To Chris Bullard, at the Portland State Outdoor Program, who provided the kayaks for my project at a significant discount to the department, for an uncharacteristically extended period of time. Chris went out of his way to make a key logistical portion of my work affordable and accessible, a testament to his commitment to the Portland State mission, "Let Knowledge Serve the City".

There are so many others. Carolyn Reynolds, a descendent of the Douglas Family, graciously allowed access to her property, where the Sunken Village site is located. Tim Couch, from Sauvie Island Drainage Improvement, who helped identify and contact private landowners on the island. The Harbormaster, who's name remains unknown, at McCuddy's Marina, who graciously allowed me to park for no charge while launching boats in the vicinity. John Pouley, at the Oregon State Historic Preservation Office, who provided me access to the SHPO database and helped to guide me in the right direction as I created my site forms. 


\section{Table of Contents}

Abstract..........................................................................

Acknowledgements....................................................................iv

List of Tables.......................................................................

List of Figures.....................................................................

Chapter 1. Introduction..............................................................1

Chapter 2. Background.............................................................6

Risk Assessments: Procedures, Terminology, and Case Studies Around the Globe.....6

The Changing Environment of the Lower Columbia: Overview of Geologic History..21

The Changing Environment of the Lower Columbia: Localized Risk Factors...........24

Climate Change Impacts on Sauvie Island Cultural Heritage .............................34

An Overview of Lower Columbia Cultural Heritage ..................................... 36

The Cultural Record: Ethnohistory and Ethnography ...............................38

A Brief History of Archaeology and Themes of the Portland Basin .......................39

Sauvie Island: A Place of Shared Meaning and Value .................................42

Archaeology of the Western Sauvie Island Shoreline ...................................51

Perspectives from Lower Columbia Indigenous Stakeholders ...........................57

Chapter 3. Research Design and Methods.........................................60

Tribal Collaboration ........................................................... 61

Study Area Selection ..............................................................63

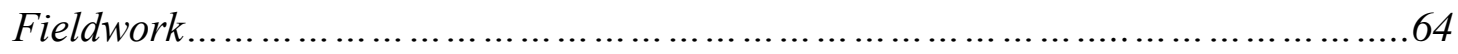

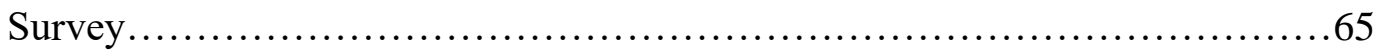


Field Recording..................................................71

Developing a Prioritization Assessment .........................................76

Archaeological Value............................................... 76

Tribal Value............................................................ 78

Risk Factors........................................................ 84

Summary of Assessment Process.......................................86

Chapter 4. Results..................................................................87

Summary of Survey Results .................................................. 87

Overview of Cultural Resources.................................................. 90

Prioritization Scoring ...................................................... 101

Archaeological Value................................................... 101

Tribal Value...................................................... 105

Comparing and Contrasting Archaeological and Tribal Value.................112

Risk Factors....................................................116

Overall Prioritization................................................ 125

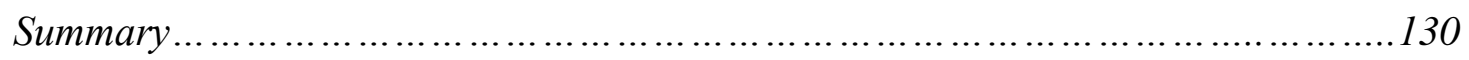

Chapter 5. Discussion, Conclusions, and Future Research.........................131

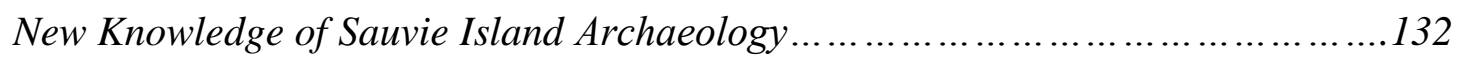

The Benefits of Collaboration and the Lessons Learned .............................135

The Future and Broader Applications of Prioritization Assessments .................. 139

Future Research and Engagement on Sauvie Island ............................. 142

Incorporating Views of Other Lower Columbia Tribes......................142 
Visiting Sauvie Island with Tribal Staff and Members

Expanding Prioritization Assessment to Greater Sauvie Island................144

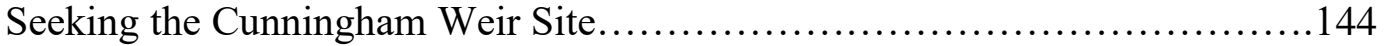

Dating and Documentation at PJD002............................... 145

Relocating Fort William...............................................146

Assessing the Fazio Parcel............................................ 146

Relocating the Pumphouse Site..................................... 147

Bringing in Additional Professional and Academic Experts.....................148

A New Perspective ............................................................. 150

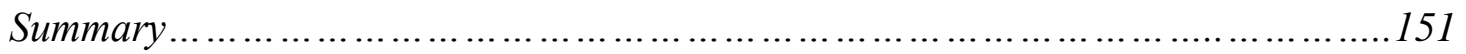

References Cited...............................................................153

Appendices........................................................................176

Appendix A: Prospectus......................................................176

Appendix B: Example SHPO Site Form...........................................179

Appendix C: Baseline Site Form Used in Assessment.............................180

Appendix D: Prioritization Assessment Form.....................................195

Appendix E: Anderson Assessment Form.......................................198

Appendix F: General Site Overviews and Photos................................202

Appendix G: Collaborative Process for Assessment................................250

Appendix H: Site Condition Overview.............................................269 


\section{List of Tables}

Table 2.1. National Register of Historic Places (NRHP) evaluation process.............13

Table 2.2. A risk assessment utilizing NRHP determination of significance.............14

Table 2.3. Previously recorded sites along the western Sauvie Island shoreline...........55

Table 3.1. Scoring process for archaeological value...............................77

Table 3.2. Scoring process for tribal value.................................. 80

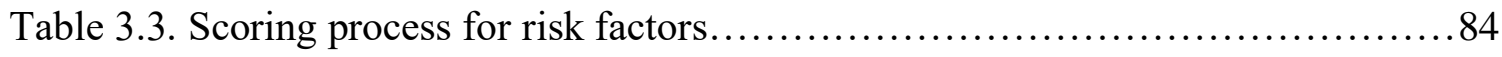

Table 3.4. Final outline of preservation prioritization scoring process..................86

Table 4.1. Overview of archaeological sites recorded in project area.................92

Table 4.2. Archaeological value scores for surveyed sites........................103

Table 4.3. Tribal value scores for surveyed sites.............................. 107

Table 4.4. Comparison between archaeological and tribal value scores...............114

Table 4.5. Risk factor scores for surveyed sites.............................. 117

Table 4.6. Risk factor comparison across recorded sites.........................119

Table 4.7. Comparison of site conditions for previously recorded sites...............125

Table 4.8. Overall scores for all sites........................................ 127 


\section{List of Figures}

Figure 1.1. Satellite horizon view of study area, western shoreline of Sauvie Island........4

Figure 2.1. Progression of bottom-up vs. top-down risk assessment approaches..........18

Figure 2.2. The organization and process of a bottom-up risk assessment.............20

Figure 2.3. A map of Sauvie Island's two primary levees............................28

Figure 2.4. A view from the "Big Dike", primary levee...........................29

Figure 2.5. Map of bank protection added by the USACE to Sauvie Island.............30

Figure 2.6. Aerial photograph of a 1955 logging boom along shoreline..................32

Figure 2.7. A modern gravel barge traversing the Multnomah Channel..................33

Figure 2.8. Map of Lower Columbia cultural area and study area....................37

Figure 2.9. Map and list of ethnographically recorded villages near study area..........44

Figure 2.10 . Previously recorded village sites near study area......................45

Figure 2.11. Wapato fields on Sauvie Island....................................46

Figure 2.12. Lewis and Clark map of Willamette and Columbia River confluence.......47

Figure 2.13. Wilkes Survey map of Sauvie Island................................48

Figure 2.14. Basketry from the Sunken Village site.............................53

Figure 2.15. A beach view of Sunken Village site and bank erosion..................53

Figure 2.16. Timeline of recording for previously identified sites...................56

Figure 2.17. Grand Ronde understanding of cultural resource value...................58

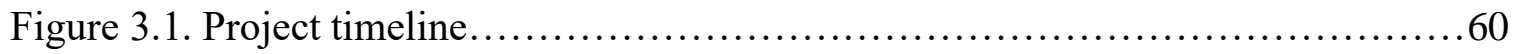

Figure 3.2. ODFW land ownership map of Sauvie Island.........................68

Figure 4.1. Survey status of western shoreline of Sauvie Island $\ldots \ldots \ldots \ldots \ldots \ldots \ldots \ldots \ldots 88$ 
Figure 4.2. Exposed cut-bank at site 35MU62................................95

Figure 4.3. Diagnostic projectile point at site PJD010.............................. 96

Figure 4.4. Side-notched preform netweight at site PJD004......................97

Figure 4.5. Diagnostic ceramic fragment at site PJD002 .........................98

Figure 4.6. Diagnostic ceramic fragment at site PJD002............................. 99

Figure 4.7. Exposed hearth feature at site 35MU62 ............................ 100

Figure 4.8. Distribution of archaeological value variables........................ 104

Figure 4.9. Distribution of tribal value variables.............................. 108

Figure 4.10. Comparing and contrasting archaeological and tribal value scores........113

Figure 4.11. Example of slumping bank at site PJD002 ........................ 120

Figure 4.12. Example of sheer, exposed bank at site PJD002........................121

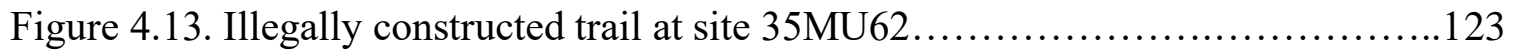

Figure 4.14. Range and grouping of prioritization scores across recorded sites..........128

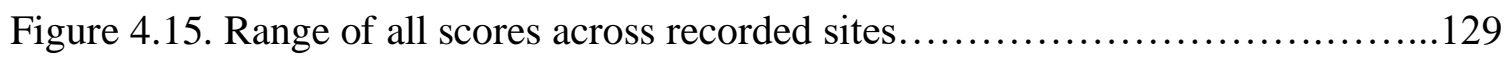




\section{Chapter 1. Introduction}

Overwhelming evidence and near unanimous consensus from the scientific community indicates that global climate change is the most pressing environmental concern facing humanity (Ripple et al. 2017). The adverse impacts of this anthropogenic crisis on human habitation, development, and infrastructure are well established (IPCC 2015; USGCRP 2018). Under these conditions, cultural heritage is increasingly vulnerable in the face of sea-level rise, greater storm frequency/severity, erosion, and habitat change/destruction (Erlandson 2008; 2012; FitzGerald et al. 2008; C. Johnson and Germano 2020; Markham 2017; NRC 2012; Pilkey and Cooper 2004; Rockman et al. 2016; UNESCO 2007; USGCRP 2018; Yu et al. in press; Zhang et al. 2004). These impacts have prompted researchers to develop strategies for identifying and mitigating cultural heritage loss in a rapidly changing climate. In the context of my thesis, cultural heritage represents both the tangible and intangible elements and values of a cultural resource.

One such strategy that has been developed to identify the loss of cultural heritage resources due to climate change is the risk assessment approach (e.g., S. Anderson 2016; Hambly 2017a; A. Johnson et al. 2015; Reeder et al. 2012; Reeder-Myers 2015). Typically, to guide management and preservation of vulnerable cultural resources, risk assessments consider preexisting archaeological data, alongside geomorphological and hydrological landform characteristics. Assessments use interagency database overlay

(e.g., Bickler et al. 2004; D. Anderson et al. 2017), geographic information systems (e.g., Canuti et al. 2000; Dupont and Eetvelde 2013; Melnick et al. 2016), and regional 
modelling of the impacts of climate change (e.g., A. Johnson et al. 2015; Westley et al. 2011) to achieve this.

While these elements of the risk assessment approach are common, due to the imminence and severity of climate change, they may not take a holistic view of the diverse landscapes and resources that make up cultural heritage (Melnick 2015). Risk assessments operating from preexisting archaeological data may not include the knowledge, values, and input of descendant communities, who may have differing preservation priorities (Carmichael et al. 2018). Moreover, there may be opportunities for synergies drawing from these perspectives. For assessment purposes, lack of Indigenous input can limit the definition or value of cultural heritage prioritized for preservation, leaving out consideration of such things as landscape, plant communities, places of spiritual meaning, and locations recalled in oral histories and traditions. Risk assessments can address this by incorporating Indigenous priorities for preservation, as well as a holistic definition of cultural heritage that improves the value and scope of the assessment for researchers and community members alike (Carmichael et al. 2018).

My research takes this approach to risk assessment, via a case study along the Lower Columbia River (Oregon, U.S.A.) in partnership with the Confederated Tribes of the Grand Ronde Community of Oregon, a descendent community with deep ties to the river. Through systematic field survey, my project examines cultural heritage on the western shoreline of Sauvie Island (Figure 1.1), an area that was selected during consultation with Grand Ronde Tribal Historic Preservation Office (THPO) staff. My project addresses several gaps in the literature on the Lower Columbia: 1) the lack of a 
baseline assessment process for threatened cultural resources, 2) the lack of an assessment process that incorporates tribal input, and 3) the lack of a systematic survey of the western shoreline of Sauvie Island. I pose two research questions regarding my project area - 1) What forces are negatively impacting cultural heritage, encompassing these tangible and intangible phenomena? and 2) How do tribal partners value and prioritize cultural resources for preservation? I addressed these questions in my thesis, first through a field-based survey, where I documented the physical archaeology, and the impacts of erosion and other forces negatively affecting the shoreline. Then, through seven in-depth meetings with members of the Grand Ronde cultural resources staff, I gained the perspectives and priorities of descendent communities regarding cultural resources. My project generated three deliverables - 1) A process for establishing a baseline assessment for cultural heritage resources, useful for planning and deciding outcomes on the Lower Columbia, 2) An assessment that incorporates Indigenous community knowledge into a collaborative process that can be applied along the Lower Columbia, and 3) An up-to-date overview of cultural resources along the western shoreline of Sauvie Island. Through this, I contribute to and expand the regional knowledge of cultural history and cultural resource vulnerability, assisting tribal partners, land managers, and archaeologists with a risk assessment based not only on archaeological value, but also value to descendent communities. 


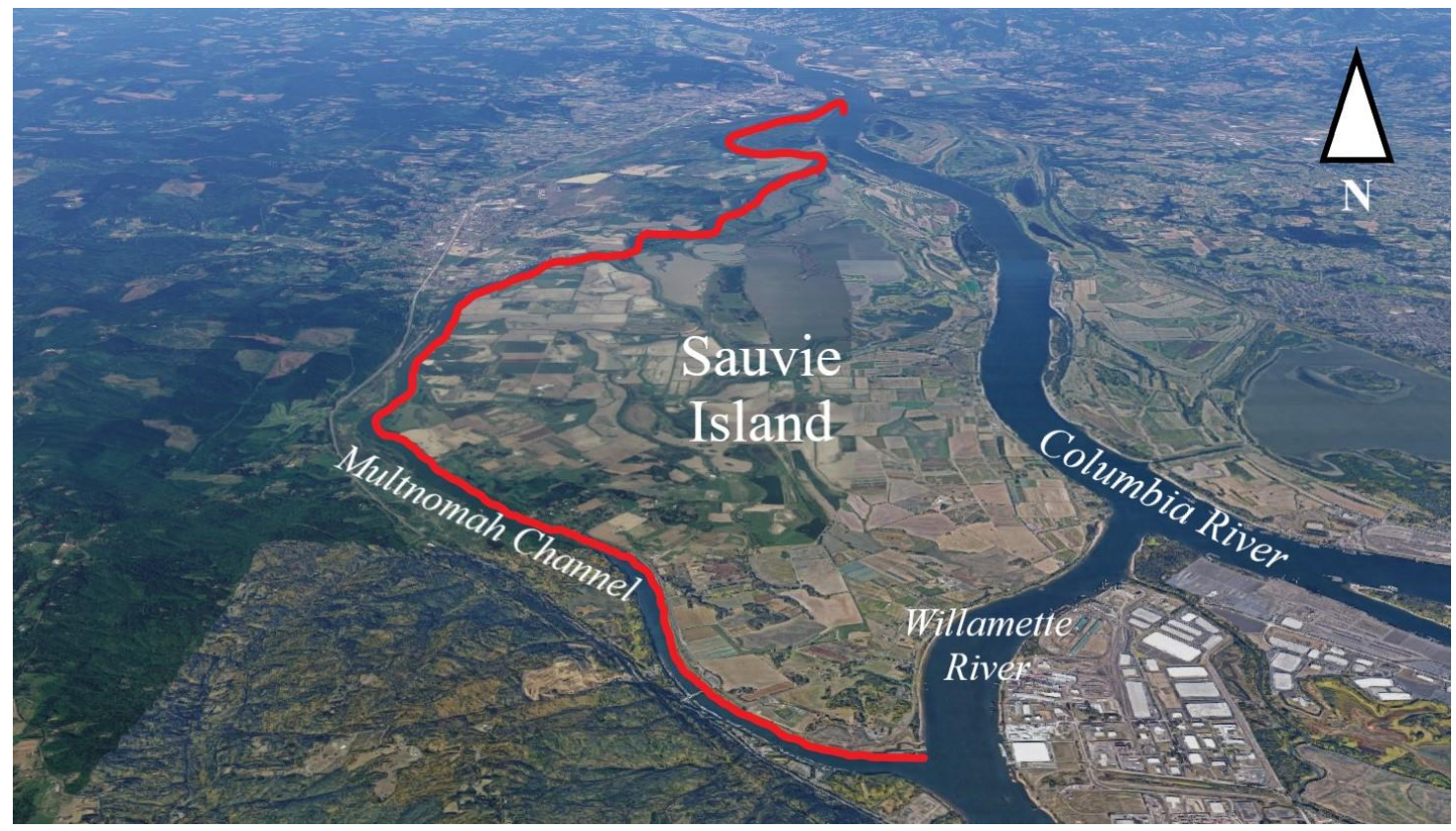

Figure 1.1. Satellite horizon view of my study area on Sauvie Island, highlighted in red, with major waterways labeled in white. Map modified from Google Maps (2020).

While concern over climate change was the impetus for my original project, fieldwork identified several other anthropogenic related risk factors with a more imminent impact on Sauvie Island cultural heritage. Damming upriver has led to sediment starvation along the Sauvie Island shoreline, with natural and anthropogenic erosion removing soil deposits that are not being replaced. Euro-American agricultural development on Sauvie Island and subsequent concern over seasonal flooding has also led to the construction of a levee system, maintenance of which can disturb existing sites while also accelerating erosion by redirecting currents towards the opposing shoreline. Finally, the wake from commercial and recreational boating has increased the speed and intensity of natural wave-action, exacerbating ongoing erosion, particularly during highwater periods. These and other impacts noted in my fieldwork ultimately became the primary concern of my research and the risk assessment approach. 
I organized my thesis into five chapters. In my background, Chapter 2, I provide an overview of archaeological risk assessment responses to site degradation around the globe. I outline several case studies and the various methodologies used to address the loss of cultural heritage. I provide an archaeological overview of my study area, as well as an overview of the hydrological and geomorphological landscape of the Lower Columbia, with attention to agents that negatively impact site condition. In Chapter 3, I provide an overview of the methodological underpinnings for my research, including project area selection, data collection goals, assessment strategies, recording procedures, prioritization process, and qualifying factors for consideration. In Chapter 4, I review results from field work and summarize the assessment and prioritization scores, including the forces that degrade shoreline sites, and I consider the outcomes from my collaboration with the Confederated Tribes of the Grand Ronde. In my discussion and conclusion, Chapter 5, I consider the broader implications of my project, including suggestions for future preservation of cultural heritage on Sauvie Island, how my baseline assessment procedure can be applied elsewhere on the Lower Columbia and beyond, and the value added by collaborating with tribal partners. I also consider directions for future research. 


\section{Chapter 2. Background}

In this chapter, I first explore the process of risk assessment for cultural heritage around the globe, detailing various methodologies used, as well as hallmark case studies that illustrate the diverse practical applications of the risk assessment and site prioritization process. I also explore common terminology utilized in risk assessment literature, as well as features typical to most assessments. Second, I detail the changing environment of the Lower Columbia, including geomorphological and hydrological forces, natural or otherwise, that threaten cultural heritage, with a focus on agents of change specific to or applicable to the Lower Columbia cultural region and Sauvie Island in particular. Third, I detail the current understanding and significance of cultural heritage along the Lower Columbia and Sauvie Island, from an archaeological and broader cultural standpoint, including the importance of the area to descendent communities, both as a resource rich landscape and a place of gathering.

\section{Risk Assessments: Procedures, Terminology, and Case Studies Around the Globe}

At a time when anthropogenic climate change and other human driven impacts pose an immediate threat to cultural resources that may already be at-risk, researchers face an increasing pressure to respond quickly and efficiently to ongoing and near-future degradation of cultural heritage (Hollesen et al. 2018; Nimura et al. 2017; Reeder-Myers and Rick 2019). The loss of cultural heritage, in the form of resources that may be archaeologically or culturally significant, prompts efforts to mitigate ongoing degradation, and support the preservation of at-risk heritage (Harvey and Perry 2015). To do this, cultural heritage resources must be understood, evaluated, and prioritized based 
on their meaning and significance to various stakeholders, including not only researchers, agencies, and land managers, but also descendent communities and the general public (G. Smith et al. 2018). One common way to prioritize site preservation involves the development of a risk assessment.

Risk assessments of cultural heritage are derived from long-standing procedures used to assess damage after disasters (Canuti et al. 2000) and as such, borrow basic structural elements, such as hazard and risk, while adding methodology and terminology tailored to the study of cultural heritage. In and of itself, cultural heritage is a key overarching term, and it refers broadly to interconnected cultural resources that have sociocultural meaning to various peoples and communities (Nimura et al. 2017). Cultural heritage includes cultural resources such as archaeological sites, landscapes, traditional plant communities, landmarks, or places of religious significance, as well as objects and actions associated with them, such as artifacts or traditional practices like basketry construction (Yu et al., in press). Risk assessments are a way of identifying the significance or value of cultural heritage, or resources therein, to stakeholders, and then pairing this with the risk factors that threaten cultural heritage (C. Johnson and Germano 2020).

Risk (sometimes referred to as exposure) in an assessment typically reflects an aggregation of hazardous forces that impact the landform holding the cultural resource and the vulnerability, or degree of loss, experienced as a result (C. Johnson and Germano 2020; Melnick et al. 2016; Yu et al. in press). As noted above, this terminology draws from the broader literature on disaster management and various research uses these terms 
selectively or adds additional terms as needed (Canuti et al. 2000; R.N. Jones and Preston 2011; S. Anderson 2016). Sub-categories of risk often include terms like hazard, referring to the event(s) that puts resources at risk (and the probability that it will occur), sensitivity, a focus on the degree to which a resource is prone to loss, and vulnerability, referring to the degree of loss that will be experienced because of that event (Canuti et al. 2000; C. Johnson and Germano 2020; S. Anderson 2016). Vulnerability is also sometimes used as a synonym for the overarching sum of risk factors ( $\mathrm{Yu}$ et al. in press) but will not be used in that capacity for my research. Further sub-categories may express finer-grained aspects of risk, with severity and time frame (imminence) often used together to express resource vulnerability (e.g., Melnick et al. 2016; Melnick and Quiroz 2017; S. Anderson 2016). Examples of hazards include erosion and sea-level rise (e.g., Melnick and Quiroz 2017; S. Anderson 2016), while examples of vulnerability include the amount of site area that overlaps with an area which is projected to have significant levels of inundation, erosion, or other impacts (e.g., Bickler et al. 2004; Canuti et al. 2000). Recent work in cultural resources management has also incorporated adaptive or management capacity, or the ability of land managers and others to adapt to or reduce risk factors (Daly 2014; C. Johnson and Germano 2020; Yu et al. in press). In sum, the risk element of an assessment aims to encompass all of the factors that can threaten a resource, the probability that they will cause damage, and the degree to which the resource will be impacted. In this way, assessments meld descriptive language common to any damaging force with definitions fitted to cultural heritage. 
The archaeological or cultural value that archaeologists assign to a resource is typically, but not always, grounded in archaeological site boundaries and western scientific conventions, emphasizing elements such as importance (data characteristics), ubiquity (rarity), condition, amount, and cost of salvage or excavation (e.g., money and/or time) of the site (Hambly 2017a). In a recent large-scale assessment conducted along the Scottish coast, settlements and middens, large, relatively uncommon sites with data-rich deposits, were assigned high archaeological value (Hambly 2017a). In a recent study across three United States coastal locations, equal value was given to resources simply by virtue of being archaeological sites, with prioritization based solely on a slew of risk factors related to shoreline geomorphology and land-use (Reeder-Myers 2015). Common in the United States is the use of the National Register of Historic Places (NRHP) criteria to assign significance, a process covered later on in this section. Another study assessing two Irish sites relied on already established World Heritage values, which considered archaeological characteristics, nature of archaeological deposits, and the position of the archaeological site in the broader cultural pattern (Daly 2014). These values may quantify the importance of the physical elements of a cultural resource, but used alone, they neglect other stakeholder voices and values that are less tangible.

For descendent communities, the value of cultural heritage resources emphasizes a definition and meaning that may extend beyond what is assigned by academic researchers, agencies, and other land managers (Newland et al. 2017), as was the case with Indigenous rangers in Australia (Carmichael et al. 2017b). Cultural resources, as defined by Indigenous peoples, can include bounded archaeological sites, but may also 
include places of spiritual significance, first food plant communities, or locations mentioned in oral histories (Carmichael et al. 2017b; Edwards 2018). Resources may have indigenous value because of the connection to the identity, lifeways, and ideas of ancestors (Carmichael et al. 2017b). In the United States, where policy has created a system of tribal entities, we might call such characteristics tribal values. Resources that are of value to descendent communities may or may not be encompassed by or associated with archaeological site boundaries. In one example of a risk assessment from Australia, places of ritual importance, such as burials and rock art, had a high cultural value to Indigenous communities, in a manner that expanded beyond that of the associated physical archaeology (Carmichael et al. 2018). These values may also be conditioned by how a descendent community views the degradation of resources in question (Newland et al. 2017). As part of a preliminary assessment of the risk factors threatening cultural heritage along the California coastline and the values placed on those resources by stakeholders, tribal groups highlighted a distinction between resources lost to natural processes and resources lost to anthropogenic processes (Newland et al. 2017). Under certain risk factors, it may be acceptable for a resource to be lost, at least in the physical sense, as part of a cycle of renewal and rebirth laid out in a tribe's spiritual beliefs (Newland et al. 2017). This perspective highlights the importance of gathering descendent community input and partnership in matters involving cultural heritage.

The Pacific Northwest has many examples of archaeologists partnering with descendent communities to incorporate their input into discussions of cultural heritage. Gonzalez et al. (2018) use a Community-Based Participatory Research (CBPR) approach 
(Atalay 2006; 2008; 2012) in their work with the Confederated Tribes of the Grand Ronde. A community embedded field school has been established (Gonzalez and Kretzler 2017; Gonzalez and Edwards 2020) on the principles of tribally-informed needs/methods, compensation of community participants, tribal ownership over research process, and a collaborative relationship that builds community capacity.

Another example of stakeholder partnership between archaeologists and descendent communities is the Cathlapotle Plankhouse Project, located within the Ridgefield Wildlife Refuge, approximately $50 \mathrm{~km}$ north of Portland (Daehnke 2005; 2007; 2013; 2017). The Cathlapotle plankhouse village site (45CL1) was excavated over several field seasons in the 1990's (e.g., Ames et al. 1999; 2017a; 2017b; 2017c), as part of a partnership between Portland State University, the U.S. Fish and Wildlife Service, and the Chinook Indian Nation, a tribe that continues to fight for formal recognition by the United States Government (Daehnke 2017; Fisher and Jetté 2017; T. Johnson 2013; 2017). The partnership led to the construction of a new cedar plankhouse at the Refuge in the mid-2000's, providing a place for Chinook peoples to gather and carry out ceremony, demonstrating their continued existence and legitimacy as a tribal entity, while also supporting a wide range of public educational programs related to cultural and environmental history of the region (Daehnke 2017).

A final example of partnership with Indigenous peoples in the Pacific Northwest is found at the Fort Vancouver National Historic Site, managed by the National Park Service (NPS). The Fort is home to a historic-era cemetery and due to the Fort's role as an important nexus of early post-contact interaction between Euro-Americans and 
Indigenous peoples, work at the site led to consultation with 19 tribes as part of a repatriation effort (Wilson 2015). This culminated not just in the return of Indigenous remains, but in the building of a friendly and supportive space for tribal members (Finegan 2021; Wilson 2015). This included incorporation of the location into canoe journeys, educational programs, and joint public archaeology endeavors, while partnerships with Indigenous artists helped to shape renovations at the Fort's visitor center (Finegan 2021; Kretzler 2015; Wilson 2015). The positive outcome to this complex case of repatriation was owed largely to the establishing of an open line of communication and willingness to invest in relationships built on mutual respect and trust (Kretzler 2015).

In the United States, one common strategy that agencies use to assess the value of a cultural resource is the National Register of Historic Places (NRHP) eligibility process (Table 2.1), a federal and legal framework for recognizing cultural resources that have significance (Hardesty and Little 2009; King 2013; Neumann and Sanford 2010; Neumann et al. 2010). Drawing from the archaeological, ethnographic, and ethnohistorical record, the NRHP process identifies the criteria, integrity, age, significance levels, and special exceptions for a cultural resource. The four criteria used to classify the significance of resources include: A) association with notable events, B) association with important individuals, C) distinctive characteristics, and D) data yielding valuable information on the past (Hardesty and Little 2009; King 2013). These criteria may apply singularly or in combination. Integrity is key to NRHP eligibility and 
generally refers to how intact a resource is when compared to its original context and similar resources (Hardesty and Little 2009).

Table 2.1. NRHP evaluation process, table courtesy of Hardesty and Little (2009).

Eligibility Step 1. Categorize the property.

Eligibility Step 2. Determine which historic context(s) the property represents and how property types relate to the archaeological resources.

Eligibility Step 3. Evaluate significance under National Register criteria A-D.

Eligibility Step 4. Apply criteria considerations.

Eligibility Step 5. Determine if property retains sufficient integrity to convey its significance.

One example of how NRHP measures of significance are used in the context of a risk assessment is outlined in S. Anderson's (2016) work on archaeological sites in Alaska that were not only NRHP eligible but had been determined to be significant enough to be classified as National Historic Landmarks (NHL). This study used qualitative archaeological values (significance) derived from an NRHP evaluation process, multiplied against various risk factors, to produce a total site preservation score (Table 2.2). 
Table 2.2. An example of a risk assessment utilizing NRHP determination of significance applied to the Ipiutak (XPH-3) National Historic Landmark site in Alaska. The assessment scores various risk factors (denoted in bold text) and multiples them against the high significance value (3) of the Ipiutak site. Table modified from S. Anderson (2016).

\begin{tabular}{|c|c|c|c|c|c|}
\hline & \multicolumn{5}{|c|}{ Ipiutak National Register Archaeological Site - Alaska } \\
\hline & Score & 3 & 2 & o $+2+5$ & $\begin{array}{l}\text { Totals } \\
\text { (Sum or } \\
\text { Multiply) }\end{array}$ \\
\hline \multirow{4}{*}{ Risk Factors: } & Hazard & High & Moderate & Low & +3 \\
\hline & $\begin{array}{c}\text { Site } \\
\text { Vulnerability }\end{array}$ & High & Moderate & Low & +3 \\
\hline & $\begin{array}{l}\text { Aggregated } \\
\text { Hazard Time } \\
\text { Frame }\end{array}$ & $\begin{array}{l}\text { Imminent } \\
\text { (or } \\
\text { unknown) }\end{array}$ & $\begin{array}{c}\text { Moderate } \\
\text { Term }\end{array}$ & Long term & +3 \\
\hline & Site Condition & Good & Fair & Poor/Destroyed & +2 \\
\hline \multirow[b]{2}{*}{$\begin{array}{c}\text { Archaeological } \\
\text { Value: }\end{array}$} & & & & $\begin{array}{l}\text { Overall Site } \\
\text { Risk: }\end{array}$ & $=11$ \\
\hline & $\begin{array}{c}\text { Site } \\
\text { Significance } \\
\text { (NRHP) }\end{array}$ & $\begin{array}{l}\text { High (or } \\
\text { unknown) }\end{array}$ & Moderate & Low & $* 3$ \\
\hline & & & & $\begin{array}{c}\text { Total Site } \\
\text { Prioritization } \\
\text { Score: }\end{array}$ & $=33$ \\
\hline
\end{tabular}

In acknowledgement of an evolving understanding of cultural heritage that includes more than bounded physical archaeology, federal agencies undertaking the NRHP process are exploring and applying new methodologies to broaden the view of significance (e.g., S. Anderson 2016, Hardesty and Little 2009; C. Johnson and Germano 2020; Wilson 2015; Yu et al. in press). This has included new considerations of the meaning of integrity and who best determines that meaning, as well as expanding the understanding and use of the first three NRHP criteria in the case of resources that may have traditionally been evaluated largely on their relationship to the fourth criteria, or the 
degree to which a resource yields data about the past (King 2013). Other strategies include recognition of traditional cultural properties, which refer to resources that are culturally significant due to an ongoing association with a community that also stretches into the past (Barcalow and Spoon 2018; Hardesty and Little 2009; King 2013). These cultural properties may include places mentioned in oral histories, locations of religious significance, or areas of first food cultivation. Increasingly, the landscape approach is also being used to acknowledge the shared connection of multiple archaeological sites or features to a cultural pattern or practice (Hardesty and Little 2009). Whereas a single site may not be regarded as significant, when connected into a holistic understanding of the activity or cultural pattern involved, such a site may become part of a significant cultural landscape.

In a risk assessment, the end goal is to recommend mitigation and preservation priorities to researchers, land managers, descendent communities, and other stakeholders in a manner that reflects the importance of the resources and the degree of risk. To accomplish this, quantitative and qualitative values are calculated and summed, to express an overall numerical value of cultural significance and risk, ultimately forming the preservation priority score in an assessment. How this calculation occurs varies widely among researchers. Some assessments minimize quantification in the assessment and prioritization process, qualitatively assessing sites based on project goals (e.g., Quilliam et al. 2014). Some assessments use ranked-scale classifications, to characterize site significance or the severity of site damage (e.g., Hambly 2017a). For example, a site may be given a higher archaeological value based on its precontact use or contribution to 
research (i.e., village site $=3$, task site $=1$ ). The site may also be given a higher risk score because of its proximity to water and subsequent vulnerability to wave-action (i.e., $100 \mathrm{~m}$ from water $=1,25 \mathrm{~m}$ from water $=3$ ). Other assessments use multipart and sometimes weighted equations to represent outsized impacts unique to a site or region (e.g., Reeder et al. 2012; Reeder-Myers 2015). A risk assessment that focuses on the impacts of sea level rise may weight vulnerable geomorphological characteristics accordingly, with less emphasis towards inland threats. Ultimately, these quantitative or qualitative values are compiled in a matrix or index from which preservation priorities can emerge (Melnick et al. 2016; Melnick and Quiroz 2017).

Beyond the commonalities and differences in terminology and in how values and risk factors are scored, most researchers take one of two general structural approaches to risk assessment (Figure 2.1), which can be categorized as top-down and bottom-up (Carmichael 2015; R.N. Jones and Preston 2011). Top-down approaches are often driven by the legal and regulatory duties required of agencies or land managers, and use preexisting archaeological and physiographic data to predictively model risk and prioritize accordingly (S. Anderson 2016; Yu et al. in press). The use of preexisting data in this approach can reduce the time and money spent assessing cultural resources, speeding preservation efforts for imperiled sites. A recent assessment of climate change impacts along the Gulf of Mexico and Atlantic coasts of the southeastern United States is one example (D. Anderson et al. 2017). This study assessed loss due to sea level rise for tens of thousands of archaeological sites in nine states, linking data from numerous regional, state, and local repositories. Another assessment conducted in Rhode Island was 
a response to agency obligations created in the wake of Hurricane Sandy, which exposed many archaeological sites to severe degradation (Ives et al. 2018). An assessment in Brittany, France, began with a synthesis of available archaeological and geographical data, designed to separate types of archaeological sites based on their assemblages and position on the landscape (Shi et al. 2012). Other work in that area has focused on the use of a wide range of archival data in desk analysis, including historic maps, photographs, art, charts, and paleoenvironmental data (Momber et al. 2017). These examples of topdown approaches demonstrate ways that these risk assessments rely on preexisting data and the forms that data takes. 


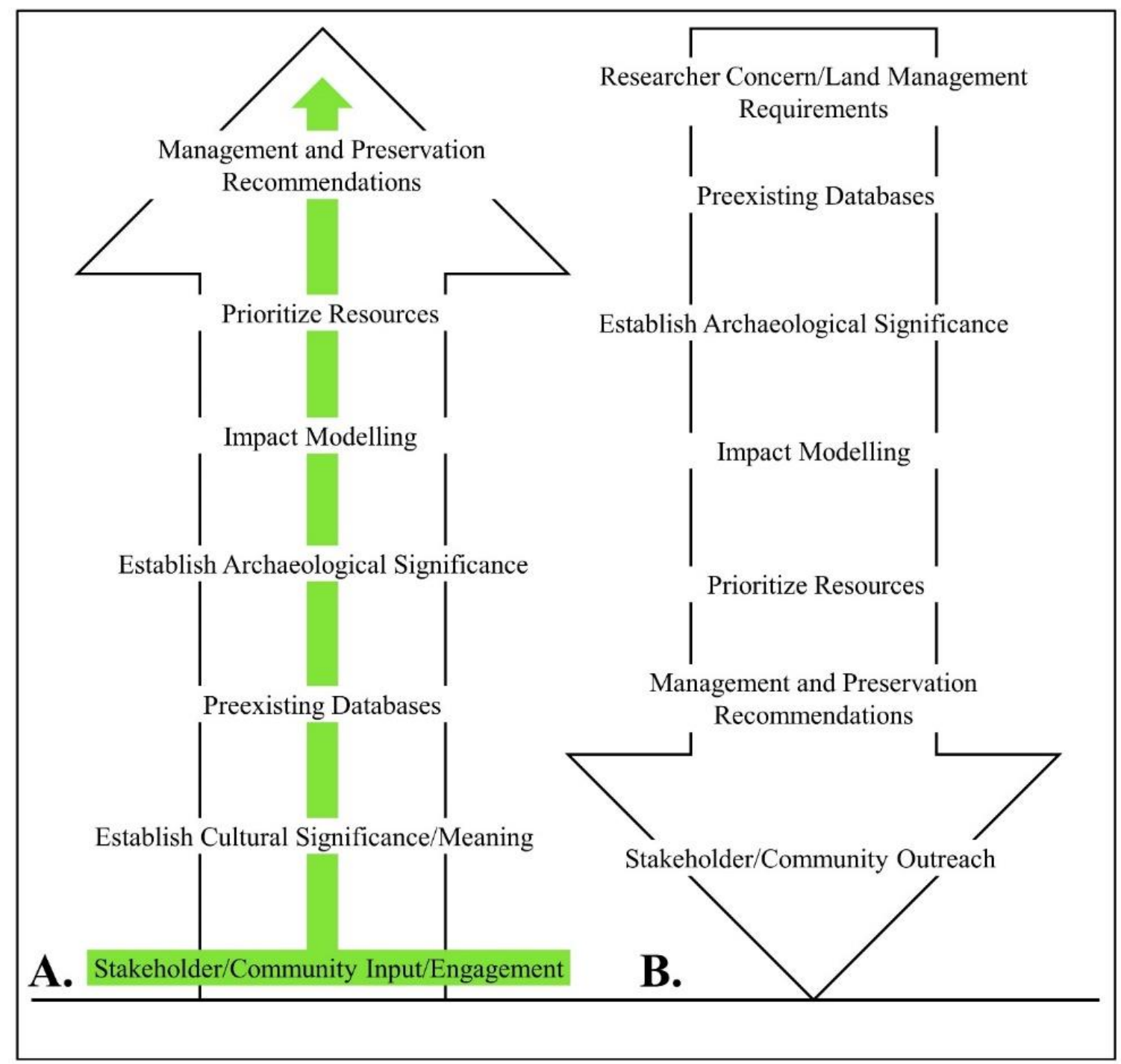

Figure 2.1. The general research progression of bottom-up (A) and top-down (B) risk assessment approaches. Green is used to communicate the ongoing role that stakeholders play in each stage of a bottom-up approach.

In contrast, bottom-up approaches are collaborative efforts with communities, who initiate, dictate, and fully participate in the assessment. In these assessments, data are often generated through site-level fieldwork conducted with the assistance of Indigenous stakeholders (Carmichael et al. 2018; S. Anderson 2016; Yu et al. in press). A recent assessment in Australia (Figure 2.2) is one example (Carmichael 2015; Carmichael et al. 2017a; 2017b; 2018). The project began with a descendent community raising 
concerns about the impacts of climate change on their cultural heritage. Archaeologists then worked with the stakeholders to select a methodology, record community knowledge, and model the impacts of climate change on cultural resources in the region. Based on the regional environment and the nature of resources involved, risk, or the likelihood of loss, was sub-categorized into sensitivity and exposure to impacting factors. Indigenous knowledge and values were used to assess these resources, which were defined and prioritized not only by physical archaeology and physiography but also by the importance and meaning the resources had to the community. Much of this involved emphasizing ritual and belief, over the presence of physical archaeology. This study demonstrates the value, to descendent communities and researchers alike, of expanding the definition of cultural resources through a collaborative, holistic, bottom-up approach to risk assessment. 


\begin{tabular}{|c|c|c|c|c|}
\hline \multicolumn{4}{|c|}{ Likelihood of loss or damage } & Consequence \\
\hline EXPOSURE & score & & & \\
\hline Town/outstation & .6 & & & \\
\hline Tourism/hunting & .2 & & & \\
\hline Graded road/track & .6 & & & \\
\hline From tidal zone & 1 & & & \\
\hline Above tidal zone & .6 & SENSITIVITY & score & \\
\hline Gorge & .2 & Ochre type & 1 & \\
\hline Feral damage & .2 & Rock hardness & .6 & \\
\hline Native damage & .6 & Rock overhang & .6 & CULTURAL \\
\hline Fire hazard & 1 & Fence & .2 & SIGNIFICANCE score \\
\hline Weathering & .6 & Legal gazette & .6 & \multirow{2}{*}{$\begin{array}{l}\text { Pictures of spirits/ } \\
\text { ceremony; site has a class } 3 \\
\text { Dreaming story. }\end{array}$} \\
\hline Total Exposure. & 5.6 & Total_Sensitivit & 3.0 & \\
\hline
\end{tabular}

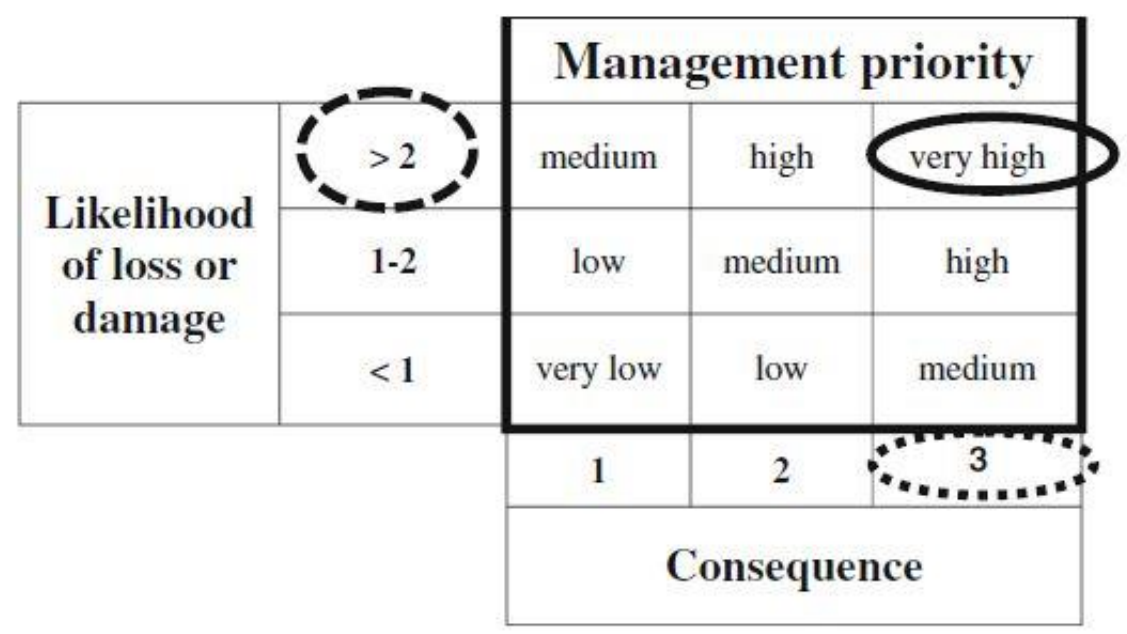

Figure 2.2. One example of bottom-up risk assessment process. Cultural or tribal value (significance) score is developed with and tailored for the Indigenous community. Risk is expressed in the form of exposure and sensitivity. Risk scores (dotted line circles, left) are cross-referenced with cultural significance (consequence) scores (dotted line circles, right) to determine a management priority (circled in black). Table courtesy of Carmichael et al. (2018).

Some recent risk assessments have successfully blended aspects of the top-down and bottom-up approaches by beginning with preexisting data and predictive modelling, followed by a degree of site-level fieldwork, collaboration, and outreach with community stakeholders (e.g., Hambly 2017a; S. Anderson 2016; S. Anderson and Cody 2019; 
Wragg et al. 2017; Yu et al. in press). Recent research in Scotland, is one example of this (Dawson 2013; 2015). The assessment drew from large-scale modelling of climate change impacts and relied on preexisting data from a nationwide archaeological survey. The assessment then evolved to include community participation through citizen science, with volunteers conducting fieldwork to verify previous findings and document the ongoing erosion of coastal sites (Dawson et al. 2017; Hambly 2017a, 2017b, 2018), a strategy that has been repeated in several other assessments (e.g.; Bonsall and Moore 2017; Wragg et al. 2017). Another example of this blended work comes from the Alaskan study previously discussed, where an assessment process was developed for the National Park Service (NPS) using climate change modelling and site records, combined with sitelevel analysis and a multi-faceted community outreach program, used to bridge the gap between the set process of determining NRHP eligibility and the values of descendent communities (S. Anderson 2016; S. Anderson and Cody 2019). These examples suggest how large-scale predictive modelling and agency databases can be incorporated with fine-grained, locally specific research that involves descendent community input. My project on the Lower Columbia also takes a blended approach to developing a cultural heritage risk assessment, hereafter referred to as a prioritization assessment, to reflect its holistic nature.

\section{The Changing Environment of the Lower Columbia: Overview of Geologic History}

The Lower Columbia is an area of unique geomorphologic and hydrologic change, where forces of nature and human intervention have led to a series of dramatic landscape shifts that continue into the present day (O’Connor 2004). The region sits 
within the greater Pacific Northwest and is dominated by the Columbia River, which drains nearly 700,000 square kilometers of North America, the largest discharge of its kind into the Pacific (Cannon 2015; Naik and Jay 2005). The region is dominated by a massive floodplain, marked by large-scale sediment deposition ranging between a peak of $1.5 \mathrm{~cm} /$ year (11-9,000 years ago) to $0.3 \mathrm{~cm} /$ year in places like the Portland Basin (Evarts et al. 2016). This deposition has been driven not only by regular river movement, but by cataclysmic forces, such as the +40 late-glacial Missoula floods between 20,000 and 15,000 years ago or the more recent Bonneville Landslide, less than 600 years ago (Benito and O’Connor 2003; Orr and Orr 2000). These powerful forces have filled, modified, and built-up landforms throughout the Lower Columbia. These landscape changes have affected the lifeways of Indigenous inhabitants and Euro-American colonizers alike (Bourdeau 2004; Cannon 2015; Peterson et al. 2011).

Of particular interest to my project is the Portland Basin, a topographic feature that includes the Columbia River and associated floodplain, between the Sandy River to the east and the Lewis River to the northwest (Cannon 2015; Evarts et al. 2009; 2016; Peterson et al. 2011). The Portland Basin also includes the northern stretch of the Willamette River, where it joins the Columbia. Serving as the center point of the PugetWillamette Lowlands and a gateway to the greater Willamette Valley to the south and the Columbia Gorge to the east, the Portland Basin marks one of the few instances of a large river intersecting an active volcanic range (Cannon 2015; Evarts et al. 2009). The Basin is over $2000 \mathrm{~km}^{2}$ in total area and oriented from northwest to southwest, a roughly rectangular area bordered by areas of uplift and faulting, with the sediment deposition on 
the Basin floor extending up to $400 \mathrm{~m}$ below sea level (Evarts et al. 2009; 2016). Initial formation of the Basin likely occurred sometime after $20 \mathrm{Ma}$, but changes due to basalt flows around 16-15 Ma helped create the path and sedimentary deposition that the Lower Columbia follows today. Much of the basin was sculpted by the Missoula Floods (Cannon 2015; Evarts et al. 2009; 2016).

One landform within the Portland Basin is Sauvie Island, which has experienced many of the landscape changes that are common throughout the Lower Columbia. The island is an alluvial deposition that sits just north of the confluence of the Willamette and Columbia Rivers, at the western edge of the Portland Basin, some $140 \mathrm{~km}$ from the mouth of the Columbia River (Evarts et al. 2016; O'Connor 2004; Orr and Orr 2000). The largest island in Oregon, Sauvie Island is 24,000 acres in total area, $24.3 \mathrm{~km}$ long and $7.3 \mathrm{~km}$ wide, with over $34 \mathrm{~km}$ of western shoreline along the Multnomah Channel alone (Canniff 2014; Stewart 1950). The landform that would become Sauvie Island is thought to have built up some 2,500 years ago, when a natural bend in the Columbia River decreased water velocity, allowing sediment to collect against an outcropping of Columbia River Basalt now called Warrior Point (Cannon 2015; Evarts et al. 2009; Long 2007; Saleeby 1983; Spencer 1950; E. Strong 1967). Eventually, the Willamette River split into a primary channel heading northeast directly into the Columbia River and into the distributary Multnomah Channel, which meandered northwest towards the Columbia, cutting off the western side of Sauvie Island from the mainland (Bourdeau 2004). Prior to Euro-American occupation, the island was a regularly inundated, heavily vegetated 
wetland, marked by floodplain bars, backswamps, and crossed by a series of natural levees (Bourdeau 2004).

\section{The Changing Environment of the Lower Columbia: Localized Risk Factors}

There are several imminent and ongoing anthropogenic risk factors that negatively impact the cultural heritage of Sauvie Island. As was the case for all of the Lower Columbia, dam construction in the greater Columbia River Basin has radically altered Sauvie Island's natural hydrogeologic processes by changing river flow and sediment deposition rates. Localized risk factors such as agricultural land modification, commercial boat traffic, dredging, and recreation have all compounded the dramatic changes brought on by the dams. These anthropogenic factors indirectly or directly exacerbate or add to natural erosional forces on the island, which negatively impact the condition of cultural resources located along the shoreline.

The anthropogenic factor that has had the greatest negative impact on Sauvie Island cultural heritage is the Columbia River Basin (CRB) hydroelectric power grid. The CRB system includes 250 reservoirs, 150 hydroelectric projects, and 18 mainstem dams, the majority of which are maintained by the U.S. Army Corps of Engineers (USACE) and other United State government entities (USACE 2012). This system is arrayed across five states and extends into Canada, for the purposes of power production and flood mitigation, as well as agricultural and municipal water supply (USACE 2012). On the Lower Columbia alone, the USACE has constructed three massive mainstem hydroelectric dams, the closest of which, Bonneville (built in 1937), is only 40 miles upstream from Sauvie Island (Long 2007; USACE 2012; Willingham 2018). Dams at 
The Dalles (built in 1957) and John Day (built in 1971) also sit in close proximity (USACE 2012; Willingham 2018). Not only have these dams and other anthropogenic modifications throughout the CRB inundated archaeological sites and greatly disrupted anadromous fish runs on the Lower Columbia, but, most relevant to my research, these modifications have exacerbated natural erosional processes on shorelines throughout the river system, including along the western shoreline of Sauvie Island.

The negative impact of CRB anthropogenic modifications on erosional processes is not often discussed in overviews of Lower Columbia River cultural heritage but is of critical importance to the condition of shoreline cultural resources. Naturally, or exacerbated anthropogenically, river flow erodes shoreline sediments as it passes by. Offsetting this, rivers naturally transport and deposit loads of sediment from upstream, and the Columbia River is no exception. Under natural pre-development flow conditions, the Columbia River deposits the majority of its sediment load during periods of peak river flow and during major flooding events that occur primarily in spring with snow melt (Babcock 1989; Long 2007). However, after nearly 200 years of Euro-American agricultural development and land modification, centered around CRB dam construction, the Columbia River is experiencing a $\sim 15 \%$ reduction in average flow, a $45 \%$ average reduction in the magnitude of spring freshet peak flows, increased water temperatures, and increased flows during the latter portion of the year, contributing to the current mean discharge of $\sim 7500 \mathrm{~m}^{3} / \mathrm{sec}^{-1}$ (Bourdeau 2004; Helaire et al. 2019; Jay et al. 2011; Naik and Jay 2005; Templeton and Jay 2013). Formerly, powerful peak flow seasons and flood events sent nutrient-loaded water into resource rich floodplains, such as those that once 
existed on Sauvie Island. Most relevant to shoreline cultural resources, these peak flows and flooding events also deposited sediment to offset bank erosion in these areas (Helaire et al. 2014; Long 2007). However, with dam construction to the east, these important hydrological events are greatly stymied, and the river lacks the ability to carry the necessary sediment supply downstream (Helaire et al. 2019; Templeton and Jay 2013).

In conjunction with this reduction in river flow, the availability of sediment is also greatly reduced by dam construction. Not only has flow greatly decreased, but much of the sediment the river once carried is now trapped behind dam walls or in low-energy reservoirs (Long 2007; Templeton and Jay 2013). By trapping this sediment load, dams accelerate ongoing natural and anthropogenic erosional forces downstream by starving landforms of the sediment needed to replace soil lost to erosional processes that operate beyond the dams (USACE 1983; 1986; 2012; Evarts et al. 2016; Long 2007). In summary, the two-pronged problem is the river's decreasing sediment load and an inability to adequately carry what sediment remains to its destination (Templeton and Jay 2013). A landform like Sauvie Island, which was formed by and has long depended on regular sediment deposition, now faces unprecedented levels of erosion, which threatens the condition and stability of shoreline cultural resources.

Besides the regional impact of Columbia River dams on sediment deposition, Sauvie Island faces a number of localized impacts to cultural heritage, one of which is the island's large levee system. This levee system was constructed to support Euro-American agriculture, which has existed on the island for over 150 years but is poorly suited for the natural cycles of flooding and sediment deposition that have characterized the island 
since it was first formed (Spencer 1950). As such, in response to 43 flood events between 1858 and 1930 (Saleeby 1983) and in anticipation of particularly severe events like the Vanport Flood of 1948, the island was fortified with an extensive levee system to guard against the spring freshets (Canniff 2014; Dudley 2019; Spencer 1950) that had made the island so productive for Indigenous peoples prior to contact, as explored below, in my overview of the island's cultural heritage.

The Sauvie Island levee system (Figure 2.3) was constructed with the assistance of the USACE, following the Flood Control Act of 1936. Such efforts by the USACE have been dictated by Congressional mandate since the 1820's, through successive Flood Control Acts that required the improvement of navigable rivers and harbors, as well as further $20^{\text {th }}$ century expansion into the general development of water resources (Canniff 2014; Spencer 1950; Willingham 2018). On Sauvie Island, USACE efforts merged existing natural levees that run across the island with artificial ones strategically designed to protect the 12,000 acres of agricultural land that make up the southern half of the island, as well as a smaller 1,600-acre portion to the north (USACE 1983; 1986; Dudley 2019; Long 2007; Spencer 1950). Initial efforts by local residents had produced a small southern dike, completed in 1921, but due to failure and swamping in the 1930's, construction began on the island's primary levee, the Big Dike (Figure 2.4), which was completed in 1941 (Canniff 2014; Long 2007; Spencer 1950). At a height of around $10 \mathrm{~m}$ and combined with the smaller North Dike built shortly thereafter, this system withstood the Vanport Flood of 1948 and enabled Euro-American residents to dramatically expand agricultural activities on the island (Canniff 2014; Long 2007). In keeping with various 
Flood Control Acts, the USACE has maintained this expansive series of levees, dikes, and protective revetments (Figure 2.5) throughout the greater Sauvie Island area for the last 70 years. This maintenance has included a period of bank protection projects throughout the 1980's (e.g., USACE 1983; 1986) and the more recent levee stabilization projects that spurred the comprehensive excavation of Sauvie Island's best-known archaeological site, Sunken Village (35MU4), in the late 2000's (e.g., Croes et al. 2009).

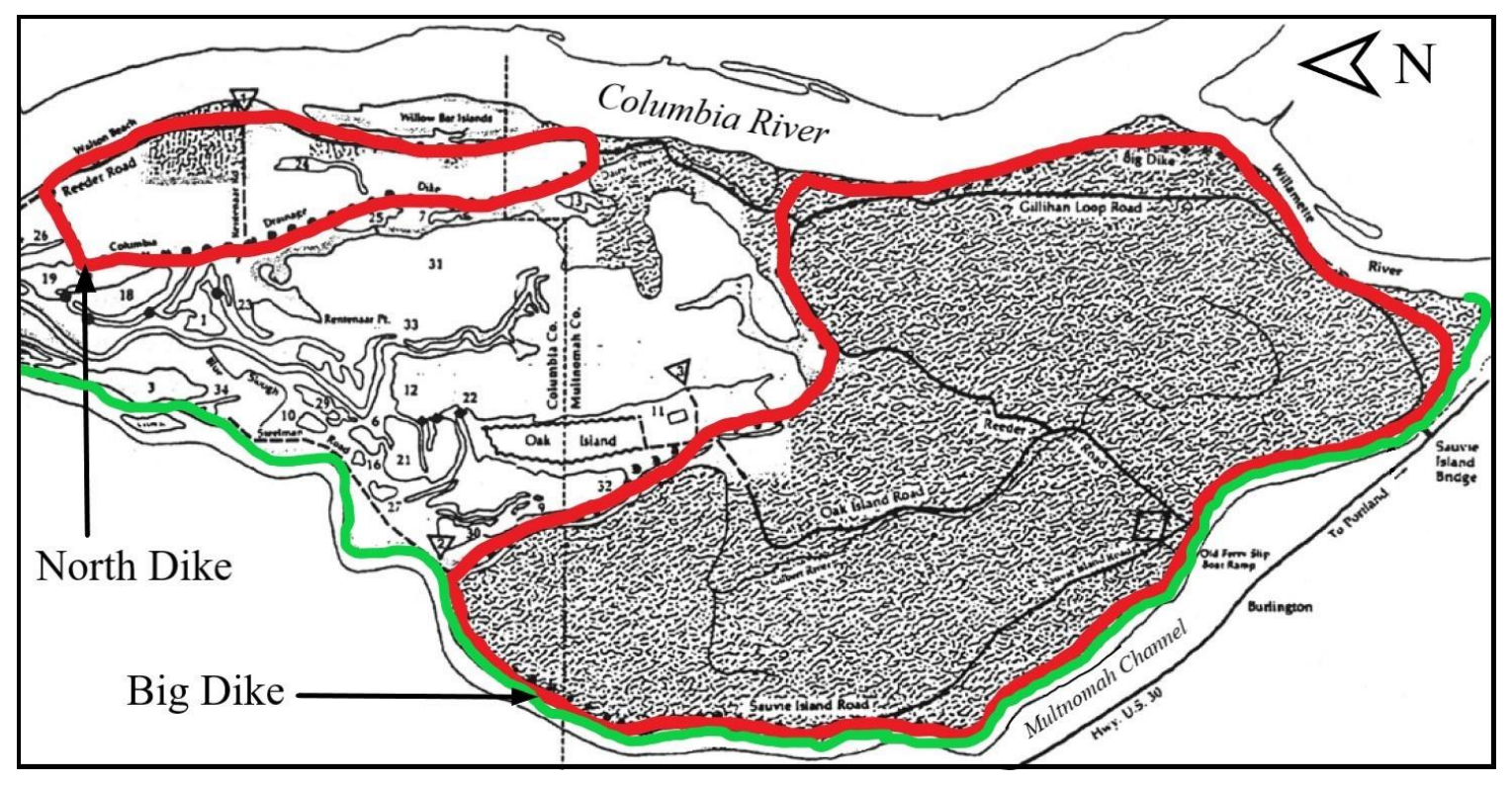

Figure 2.3. Map showing Sauvie Island's two primary levees, marked in red, which bound over 12,000 acres of agricultural land. My study area, which runs along the western edge of the Big Dike, is denoted in green. The most northern section of Sauvie Island, which remains largely undeveloped, is not shown. Map modified from the Oregon Department of Fish and Wildlife. 


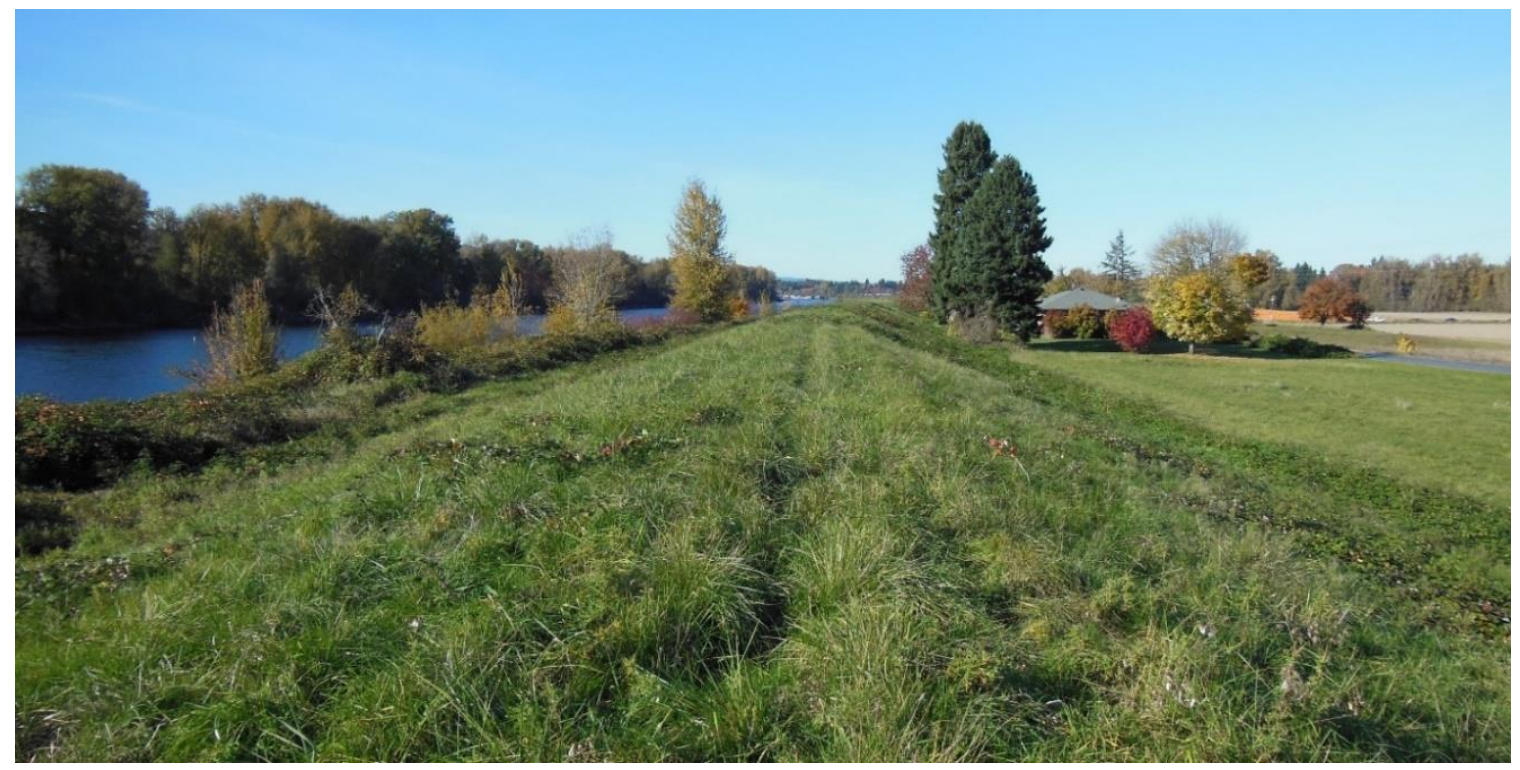

Figure 2.4. A view facing north, looking down the "Big Dike" or the primary levee, along the western shoreline of Sauvie Island, along the Multnomah Channel. The Sunken Village site (35MU4) sits on the beach to left and extends into the bank and levee. Photograph by author, taken in October 2019. 


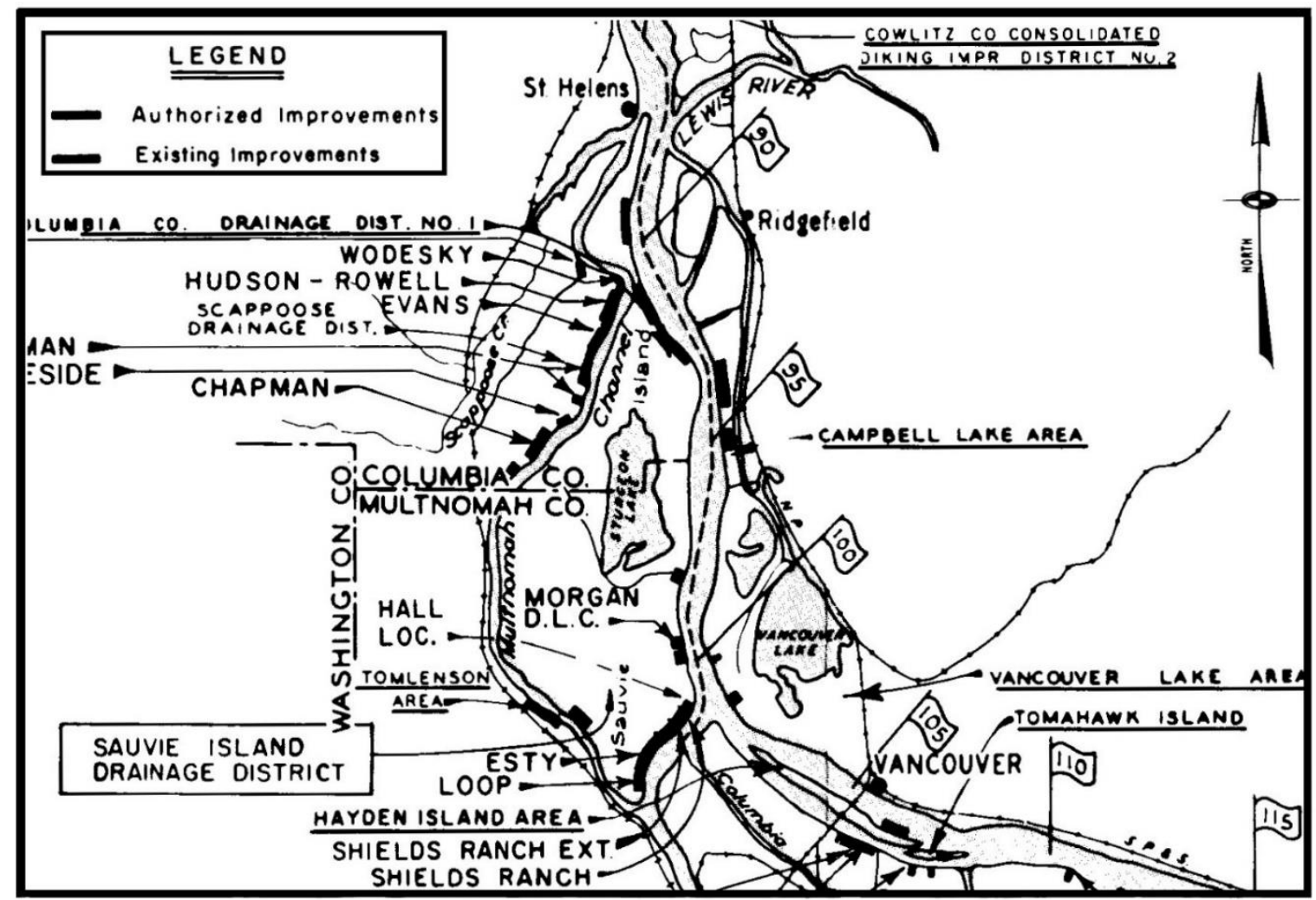

Figure 2.5. Bank protection added by the USACE to Sauvie Island and surrounding area as of April 1983. Note the thick dark lines marking existing and authorized improvements at the time of publication. At the time of publication, these modifications included levees, sediment redistribution, and riprapping. Map modified from U.S. Army Corps of Engineers (1983).

The construction and maintenance of these levees disturbs cultural heritage through initial land clearing, then earthmoving, and placement of riprap to protect against ongoing erosion. The levees, by definition, prevent seasonal flooding from distributing much needed sediment across the island, forming another obstacle to the replacement of sediment lost due to erosion. Levee maintenance can also involve riprapping, which often has the effect of redirecting the river current towards the opposite unprotected shoreline with greater than normal force, thereby increasing erosion there (Long 2007; USACE 1983; 1986). Maintenance can also involve the redistribution of dredge spoils, which can 
create sediment traps that starve areas further downstream (USACE 1983; 1986). Even in the areas where levee stabilization efforts take place, results are mixed. Poor application of riprapping for example, can do more harm than good, simply changing erosional patterns as opposed to preventing them (Long 2007; USACE 1983; 1986).

Another major factor that has the potential to affect Sauvie Island cultural heritage is commercial boat traffic. The Multnomah Channel, along the west side of the island, has seen extensive commercial traffic throughout the historic and modern eras. Early industry in the area involved extensive logging booms being moved or stored along the island shoreline (Figure 2.6), a practice that continued into the late 1990's. Related to this extensive logging, multiple industries existed along the Sauvie Island shoreline, the Multnomah Channel and neighboring waterways and shorelines. These included sawmills, loading docks, paper mills, creosote plants, and other timber processing facilities in the Sauvie Island vicinity, with industry established by the mid- $19^{\text {th }}$ century in the nearby community of St. Helens to the northwest, and on the mainland just across the Multnomah Channel from Sauvie Island (Perrin 2014). Most notably associated with the island proper, the early- $20^{\text {th }}$ century Island Lumber Company mill had an extensive dock and wharf complex surrounding Warrior Point, now recorded with the Oregon SHPO as site 35CO66 (Perrin 2014; Roulette and Finley 2009a; 2009b). Today, the Multnomah Channel still sees significant commercial traffic. Due to gravel deposits along the Willamette, to the south, and in Scappoose, across from Sauvie Island on the mainland to the north, barge shipments (Figure 2.7) are the most common commercial vessels utilizing the Multnomah Channel today (USACE 1983). These vessels create 
waves that strike the shoreline at a much greater height and strength than wind-driven waves in an anthropogenic impact that exacerbates both natural and artificial erosion (USACE 1983; 1986; Long 2007). The Multnomah Channel is also home to many houseboats, at least a dozen private boat moorages, and is a popular location for recreational boating, with two publicly owned boat ramps on the western shoreline of Sauvie Island, a publicly-owned mainland ramp near Rocky Point, and numerous private ramps, some of which are also publicly accessible. Anthropogenic wave-action from all of these sources, commercial and recreational, exacerbates natural erosional impacts from wind-drive wave action.

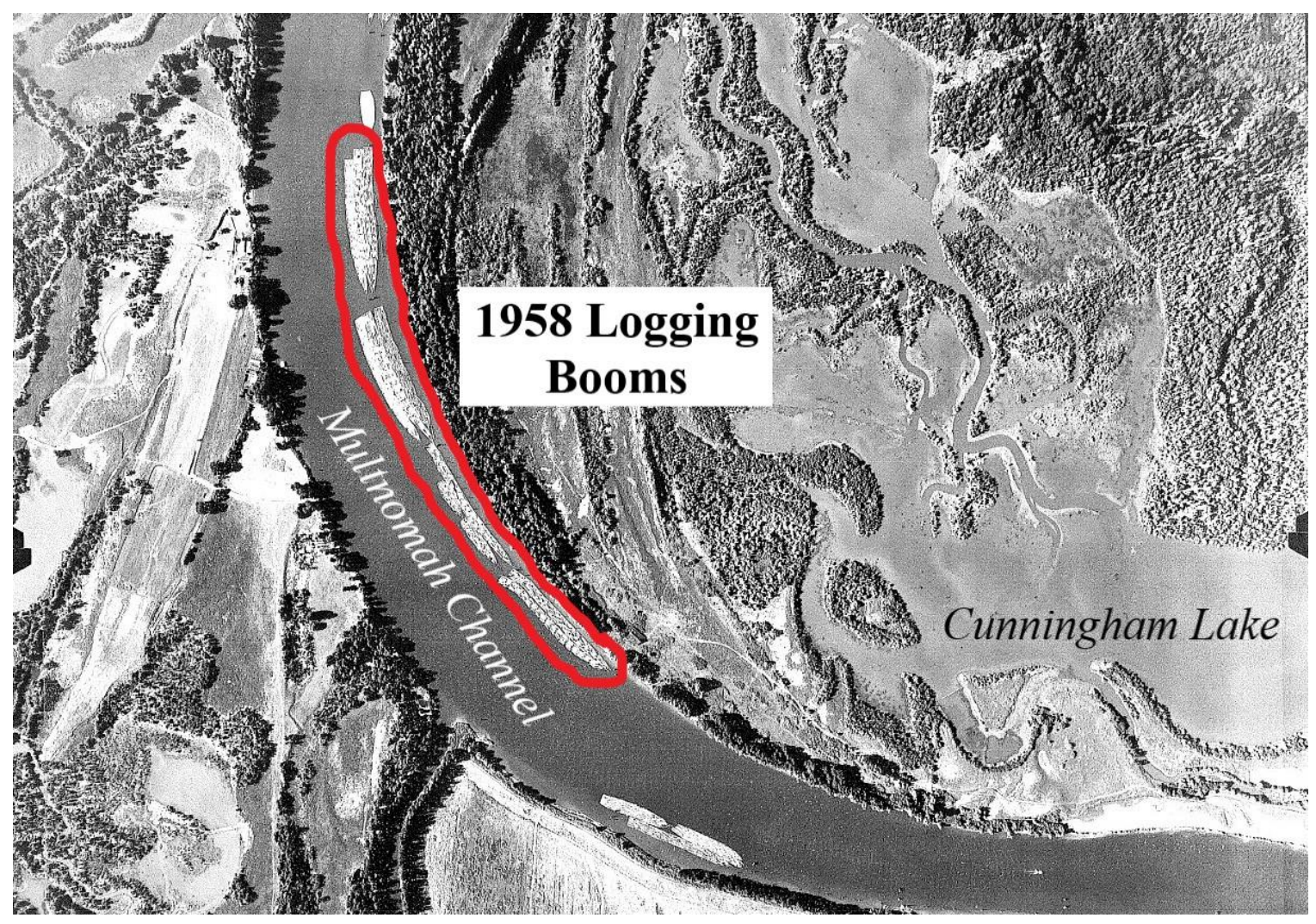

Figure 2.6. A 1958 Oregon Department of Fish and Wildlife aerial photograph of logging booms along the Multnomah Channel and Sauvie Island shoreline, just south of Cunningham Lake, near the north end of the island. Photo courtesy of ODFW (1958). 


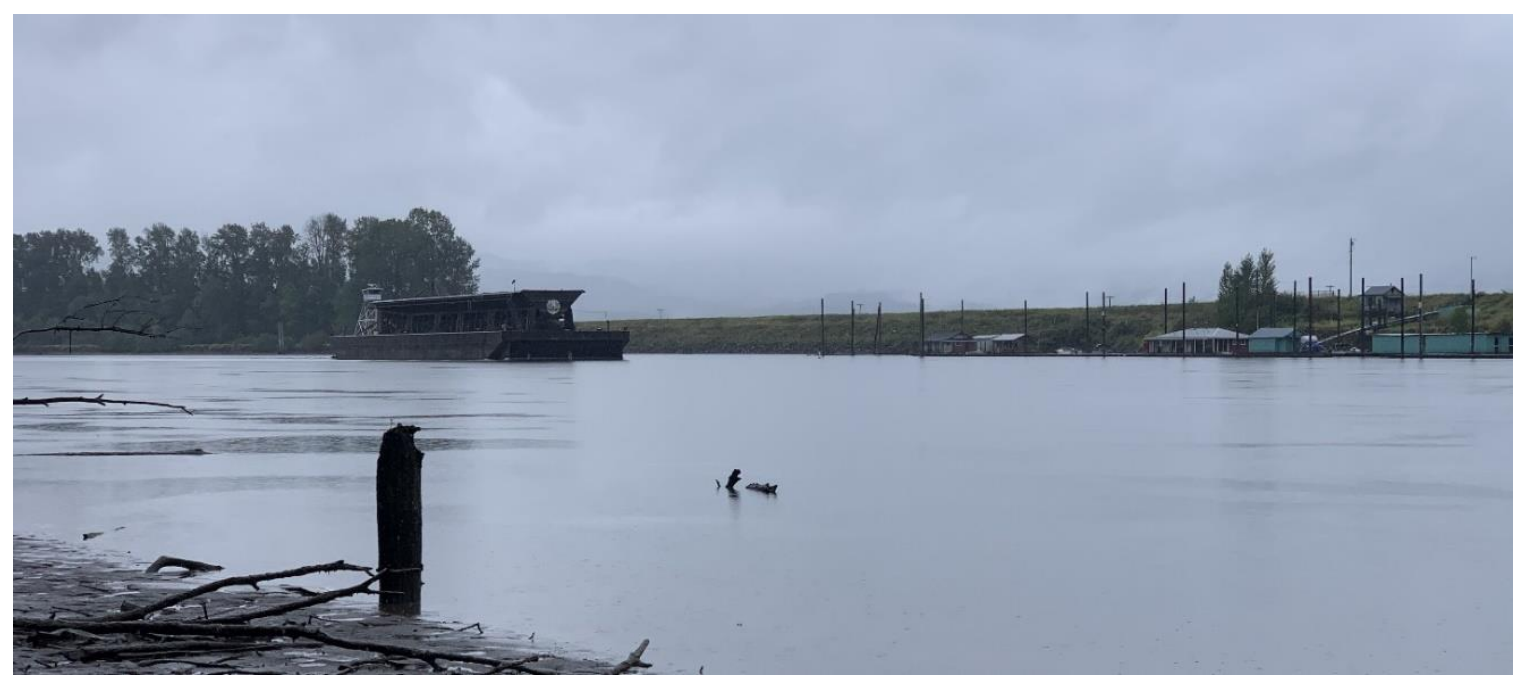

Figure 2.7. A modern commercial barge (upper left) carrying gravel up the Multnomah Channel, towards Scappoose Bay and the Columbia River, as seen from the Sauvie Island western shoreline. Note the line of private houseboat moorages (upper right). Photograph by author, taken in September 2019.

Another anthropogenic factor potentially affecting shoreline cultural resources related to commercial shipping along the channel is dredging, which is conducted and/or authorized by the USACE (1986). The size of modern gravel barges and other vessels require channels that are deeper than the natural depth, both for navigation and for smooth travel. This commercial shipping need has prompted expansive and repeated dredging and deepening of the Multnomah Channel, the Willamette River, and the Columbia River (Long 2007; Templeton and Jay 2013). Dredging has occurred since the 1870's on the Willamette (Wallick et al. 2007) and began in 1895 on the Lower Columbia (USACE 1986) and continues into the modern era (Long 2007). Dredging further altered the Sauvie Island environment and contributed to erosion through the production of spoils, or sediment scraped from the channel bottom (Long 2007). These spoils, when distributed haphazardly, create artificial sediment traps that prevent naturally flowing sediment from reaching locations further downstream, causing 
sediment starvation (USACE 1983; Long 2007). The deepening of the Multnomah Channel through dredging may have also affected the ease of access by people to the Island, as early Euro-American reports suggested that Indigenous peoples may have been able to cross the Multnomah Channel on foot during seasonally low water in the fall (R.F. Jones 1978).

A final agent of archaeological site disturbance on Sauvie Island is livestock, which were first introduced when the Hudson's Bay Company constructed dairy farms to establish claim over the territory in the 1840's (Canniff 2014; Seaman 1967; Spencer 1950; E. Strong 1967). Today, the southern half of the island is now mostly devoted to crops, but open cattle grazing still occurs at several locations on the northern half of the island, where watering holes and gently sloping bank areas provide access to the beach along the Multnomah Channel.

In summary, a complex array of compounding anthropogenic factors could negatively affect Sauvie Island cultural heritage, especially though erosion of the shoreline. The key factors causing erosion include upstream dam construction, which has depleted the sediment budget, dredging, riprap emplacement, livestock trampling, and wave action from boat traffic.

\section{Climate Change Impacts on Sauvie Island Cultural Heritage}

Beyond forces linked to historic and contemporary development localized around Sauvie Island and the Lower Columbia River, we can add the broad-scale impacts of climate change. Presenting a pressing concern for researchers, climate change is an 
inevitable near-future threat to both natural and cultural resources on Sauvie Island and along the greater Lower Columbia (e.g., Glick et al. 2007; IPCC 2015; LCEP 2015; Mote et al. 1999; 2005; NRC 2004). Hazards like rising sea levels, higher temperatures, changing precipitation, and increasing storm intensity have already been observed (Mote et al. 2014; LCEP 2015; Snover et al. 2003; Talke et al. 2018). Predicted temperature rises of $0.2-1.0^{\circ} \mathrm{F}$ per decade and concurrent global sea-level rise of $0.5-1.5 \mathrm{~m}$ by 2100 will likely put tens of thousands of acres of low-lying land at risk of inundation (Glick et al. 2007; Mote et al. 2005; Rahmstorf 2007). Increasing salinization and acidification threatens culturally important plant communities by interfering with photosynthesis (Delesalle and Blum 1994; Pezeshki et al. 1987). Destruction of protective landforms and native plant communities is likely to increase coastal erosion (Feagin et al. 2005;

FitzGerald et al. 2008). Summer streamflow will decrease with warming temperatures (Mote et al. 2014) while warmer winters will temporarily lead to increased rainfall, with unexpected runoff, erosion, and flooding (Chang and Jung 2010; Payne et al. 2004). Tidal variation will increase along with sea level, putting low lying areas at risk of erosion (Devlin et al. 2017).

These factors are undoubtedly significant, and some are already impacting the Lower Columbia, particularly at the mouth of the estuary. However, modelling on the matter remains in its preliminary stages, particularly as it relates to my study area on Sauvie Island. An initial Geographic Information Systems (GIS) bathtub model created by the Confederated Tribes of the Grand Ronde has provided some insight into how future sea level rises might impact the island, but finer grained predictions and timelines 
are challenging to produce. Variables like isostatic rebound off the Oregon Coast produce background noise that clutters existing models, complicating how results are understood. It is highly likely the impacts of climate change will be felt broadly across the Lower Columbia and factors related to climate change are undoubtedly already at work.

However, through my background research and fieldwork on Sauvie Island, it became apparent that the negative impacts from development present a more immediate, ongoing, and severe threat to cultural resources on the island than climate change. Therefore, my thesis project shifted to focus on ways these forces imperil cultural resources.

\section{An Overview of Lower Columbia Cultural Heritage}

My overview focuses on the portion of the Lower Columbia extending from The Dalles to the river's mouth, a distance of $315 \mathrm{~km}$ (Figure 2.8). Owing to the young age of the floodplain, Lower Columbia archaeological sites date to within the last 2,500 years, with most sites dating to the last 1,000 years (Sobel et al. 2013). By this time, during what is known regionally as the Middle Pacific Period (1800 BC - AD 200/500), lifeways common to the Northwest Coast are thought to have emerged, although the nature of the Lower Columbia record is still temporally spotty during this time (Sobel et al. 2013). Despite this, the Lower Columbia record allows archaeologists to address many questions of human mobility, subsistence, and land use. 


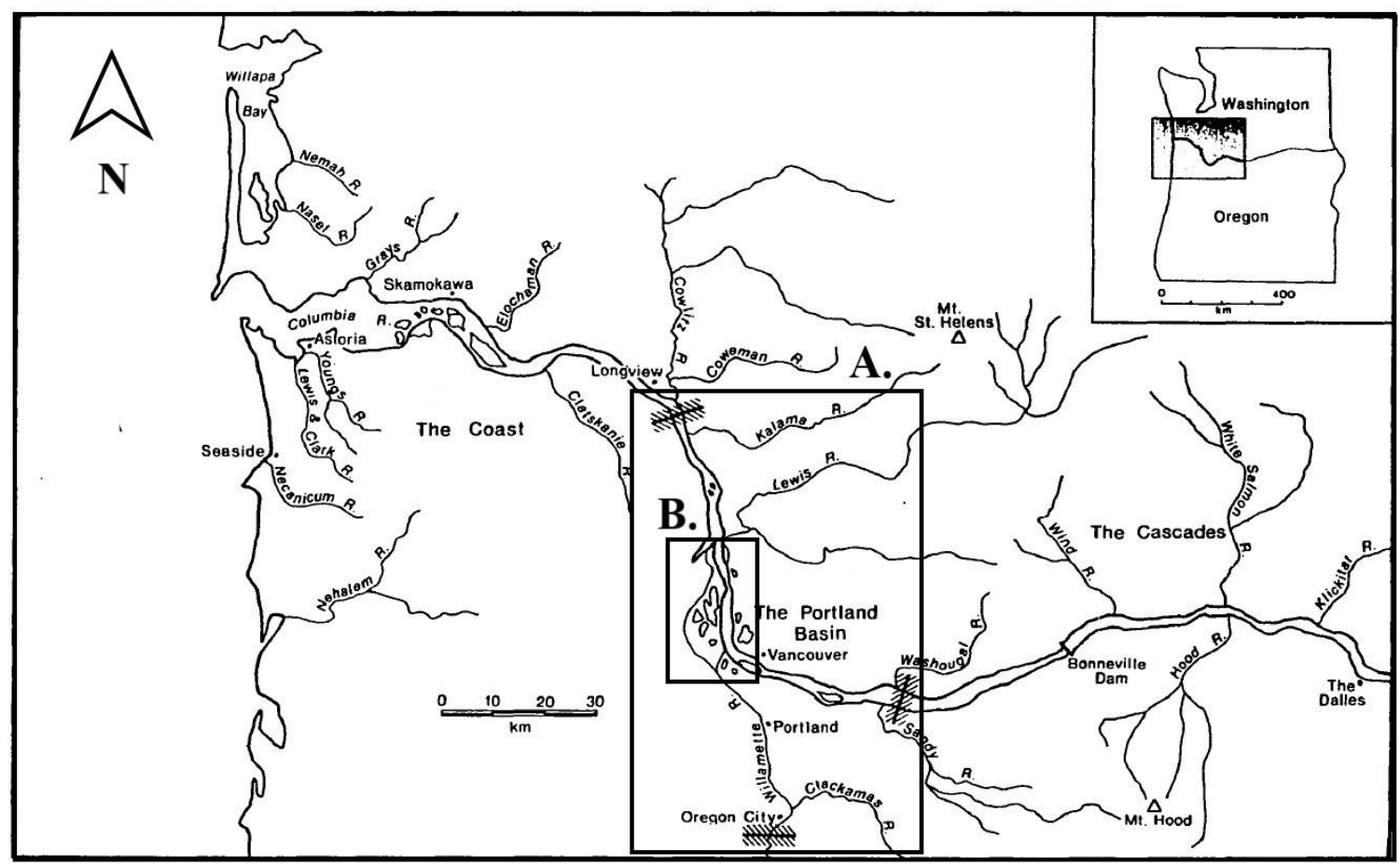

Figure 2.8. The Lower Columbia cultural area, with the Portland Basin (A) and Sauvie Island (B), the study area, indicated within. Map modified from Saleeby (1983).

Consistent with the Northwest Coast Culture Area, Lower Columbia Indigenous cultures are characterized by social stratification, permanent residences, high population density, and sedentism (Ames 1994; 2004; Gahr 2013; Suttles 1990). Extensive travel, trade, and communication networks were afforded by waterborne transport, while diverse subsistence strategies took advantage of both the highly productive aquatic resources and the abundant terrestrial resources surrounding the river. At the time of first EuroAmerican contact, Lower Columbia peoples were practicing large-scale landscape and resource management, paired with a storage backed economy (Sobel et al. 2013). Like other areas of the Northwest Coast, Lower Columbia technology relied heavily on organic material and involved extensive use of wood for houses, storage, and transportation, while fiber from a variety of plants provided materials for basketry, 
cordage, and nets. Our knowledge of this record comes from the work of academic and professional archaeologists, from ethnohistorical accounts, from ethnographers and cultural anthropologists, and from the Indigenous peoples who have inhabited the region. Drawing on Western science, this stretches back nearly 2500 years (e.g., Ames 1992; Ellis 2013; Jacobs 1945; R.F. Jones 1972; Pettigrew 1977; E. Strong 1967), but from an Indigenous perspective, occupation extends to time immemorial (T. Johnson 2017).

\section{The Cultural Record: Ethnohistory and Ethnography}

Euro-American accounts at contact provide the earliest record of Lower Columbia Chinookan culture. The accounts begin in the late $18^{\text {th }}$ century with observations of Indigenous places and lifeways by Euro-American explorers and early naturalists, especially those associated with the development of the fur trade (e.g., Boit 1921; Franchere 1854; Kane 1971; Ray 1938; Swan 1857; Vancouver 1798; Wilkes 1849a; $1849 \mathrm{~b} ; 1958 ; 2009)$. In the late $19^{\text {th }}$ and $20^{\text {th }}$ centuries, cultural anthropologists worked in the region, recording aspects of language, religion, folklore, and oral histories (e.g., Boas 1894; 1901; French 1958; Gatschet 1877; Jacobs 1945; Kenoyer 2017; Sapir 1907; 1909; Suttles and Lang 2013). Most recently, anthropologists have used these ethnographic accounts, along with ethnohistorical records, to study cultural geography on the Lower Columbia (Ellis 2013; Silverstein 1990; Zenk 1990), seasonal population movement (Boyd and Hajda 1987; Saleeby and Pettigrew 1983), social organization (Hajda 1984), placenames of Indigenous significance (Boyd 2011; Ellis et al 2013; Zenk 1994; Zenk et al. 2016), the impact of disease (Boyd 2013), post-contact fisheries (Butler and Martin 
2013; Martin 2006), and post-contact resilience (Daehnke 2017; Deur 2012; 2016; Minor and Burgess 2009).

\section{A Brief History of Archaeology and Themes of the Portland Basin}

Within the Lower Columbia, the Portland Basin sits along the southwest border of the Lower Columbia cultural area, a gateway to the greater Willamette Valley cultural area to the south and the Columbia Plateau cultural area to the east. Knowledge of the Portland Basin archaeological record comes from a diverse array of sources, including academics, professionals, and amateurs (Ames 1992). Ames (1992) and Pettigrew (1977; 1981) have summarized the history of archaeological research in the area, divided into a lengthy phase of amateur collecting and the subsequent growth of professional approaches, divided into four distinct periods: the Early Amateur Period (contact-1923), the Early Professional Period (1924-1950), the Reservoir Salvage Period (1951-1965), and the Recent or Developed Professional Period (1966-Present).

These divisions are helpful in laying out the general progression of Portland Basin archaeological work, but it should be noted that the exact parameters are likely more complicated. This is due to work such as the first excavations in 1947 at Fort Vancouver, under Caywood (Wilson 2015) as well as work that has emerged throughout the $21^{\text {st }}$ century, such as that described prior, at locations such as Grand Ronde, Cathlapotle, and Fort Vancouver (e.g.; Daehnke 2017; Gonzalez and Edwards 2020; Kretzler 2015). Given the increasing role of Indigenous perspectives in cultural resources management decisions, it may well be time to mark a new era, which recognizes this consequential shift in authority. 
Our earliest knowledge of the Lower Columbia archaeological record comes from a long period of amateur work throughout the Portland Basin and the broader cultural area. This work centers on the early-20 $0^{\text {th }}$ century rise of collectors (e.g., R.F. Jones 1972; Seaman 1967; E. Strong 1967), who scoured the Lower Columbia for artifacts and recorded cursory details on the sites and artifacts they encountered (Butler 2007; Sobel 2004). However, this mostly involved the wholesale removal of archaeological deposits by collectors primarily interested in artifacts for personal and aesthetic reasons. Later on, collective entities like the Oregon Archaeological Society (OAS) provided organizational structure and methodology for member-led excavations, which increased in size and scope, but many problems remained, as artifacts were lost, and reporting was minimal (e.g. Foreman and Foreman 1977; Hibbs and Starkey 1974; R.F. Jones 1972; Slocum and Matsen 1972). Since the 1970's, the OAS has undergone extensive change in its approach to archaeology, supporting stewardship and public outreach (Butler 2007).

In the 1970's and 1980's, archaeological investigations in the Portland Basin began to transition to academic and professional work, with the research of Pettigrew $(1977 ; 1981)$ and Saleeby (1983), who worked with the OAS, drawing on member's personal artifact collections and using volunteers to excavate at several key Sauvie Island sites. These included the Cholick (35MU1), Pumphouse (35CO7), Lyons (35MU6), Merrybell (35MU9), and unnamed 35CO3 sites, among others in the general vicinity of the island, such as the Meier (35CO5) site. Pettigrew's work resulted in the development of a chronological culture history for the Portland Basin, using projectile points and other artifact types, such as netweights. Saleeby (1983) explored hunter-gatherer subsistence 
and mobility shifts, demonstrating a diversity of animal use through the area's first zooarchaeological analysis and challenging previously accepted ideas of seasonal movement, concluding that instead of a residential, camp-to-camp pattern, Portland Basin peoples were sedentary forager-collectors.

Over the course of nearly two decades, from the late 1980's to the mid-2000's, Kenneth Ames conducted work at the Cathlapotle (45CL1) and the Meier (35CO5), two seminal Pacific Northwest archaeological sites, as part of the Wapato Valley Archaeological Project (WVAP). His projects explored questions of regional chronology, socioeconomic structure, household organization, mobility patterns, and subsistence strategies. Cathlapotle is a village site with as many as eleven plankhouse dwellings, part of a continuous occupation spanning over 1,000 years, with stratified deposits extending 2-4m in depth (Ames et al. 1999). Research began in the early 1990's to locate the site and continued for over two decades (Ames and Sobel 2009), with the final reporting having only recently been completed (e.g., Ames et al. 2017a; 2017b; 2017c). Home to nearly 1,000 people at its peak, the Cathlapotle site provided a highly diverse and abundant artifact assemblage (Ames et al. 1999). The Meier site is another plankhouse village, albeit with only a single large dwelling, which was excavated from 1987-1991, also under the direction of Kenneth Ames (Sobel 2004). The village was inhabited continuously for at least four centuries and is perhaps most notable for its immense root storage cellars, which likely held wapato (Sagittaria latifolia), an aquatic tuber, which was extremely abundant in the wetlands of Sauvie Island, located just across the Multnomah Channel from Meier. 
Another research theme in Lower Columbia archaeology is the exploration of socioeconomic issues in Lower Chinookan society, an area of study pioneered by Ames and his student and colleagues, through work on large Lower Columbia plankhouse sites. Sobel $(2004 ; 2006)$ utilizes the Lower Columbia record to shed light on economic and household organization expressed in inequality, slavery, stratification, and labor. Their work argued for multi-generational corporate households vying for position in a prestige hierarchy, with each household utilizing different strategies and intensities of subsistence and production to gain or maintain prestige (Sobel 2006). The study also highlighted clear shifts in the gaining and maintaining of prestige after Euro-American contact, which destabilized existing hierarchies, allowing households with lower prestige to close the gap (Sobel 2006). C. Smith $(2006 ; 2008)$ explores socio-economic organization and site formation via the spatial distribution of artifacts, features, and task areas around plankhouses, most notably at the Cathlapotle and Meier sites. Ames and Shepard (2019) and Shepard (2014) examine the resources, labor, and time involved in plankhouse construction and maintenance.

Beyond this and much other existing research, questions remain about the earliest occupation of the Lower Columbia, the development of recent cultural patterns, the impacts of Euro-American contact, and the role of Lower Columbia peoples in the broader Pacific Northwest cultural area (Sobel et al. 2013).

\section{Sauvie Island: A Place of Shared Meaning and Value}

An area of shared cultural value to archaeologists and Indigenous peoples alike is Sauvie Island (Bright 2004; Deur 2012; McArthur and McArthur 2003; M. Newman 
1991; W. Strong et al. 1930; T. Newman and McNassar 1977). Prior to Euro-American contact, Sauvie Island's highly productive wetland resource area supported a large population, playing a significant role in the subsistence strategies of the densely populated, socially stratified Chinookan society. Ethnographic records suggest that at least 16 villages (Figure 2.9) were located on or around the island near the time of EuroAmerican contact, with up to 6 villages on the island itself, although some of these may have been temporary residential sites (Boyd 2011b; Ellis et al. 2013; Zenk et al. 2016). Archaeological work has been conducted at multiple sites (Figure 2.10). Three of these, the Cholick (35MU1), Merrybell (35MU9), and Pump House (35CO7) sites, are shown adjacent to the Multnomah Channel but are actually slightly inland and were not included in my survey. 


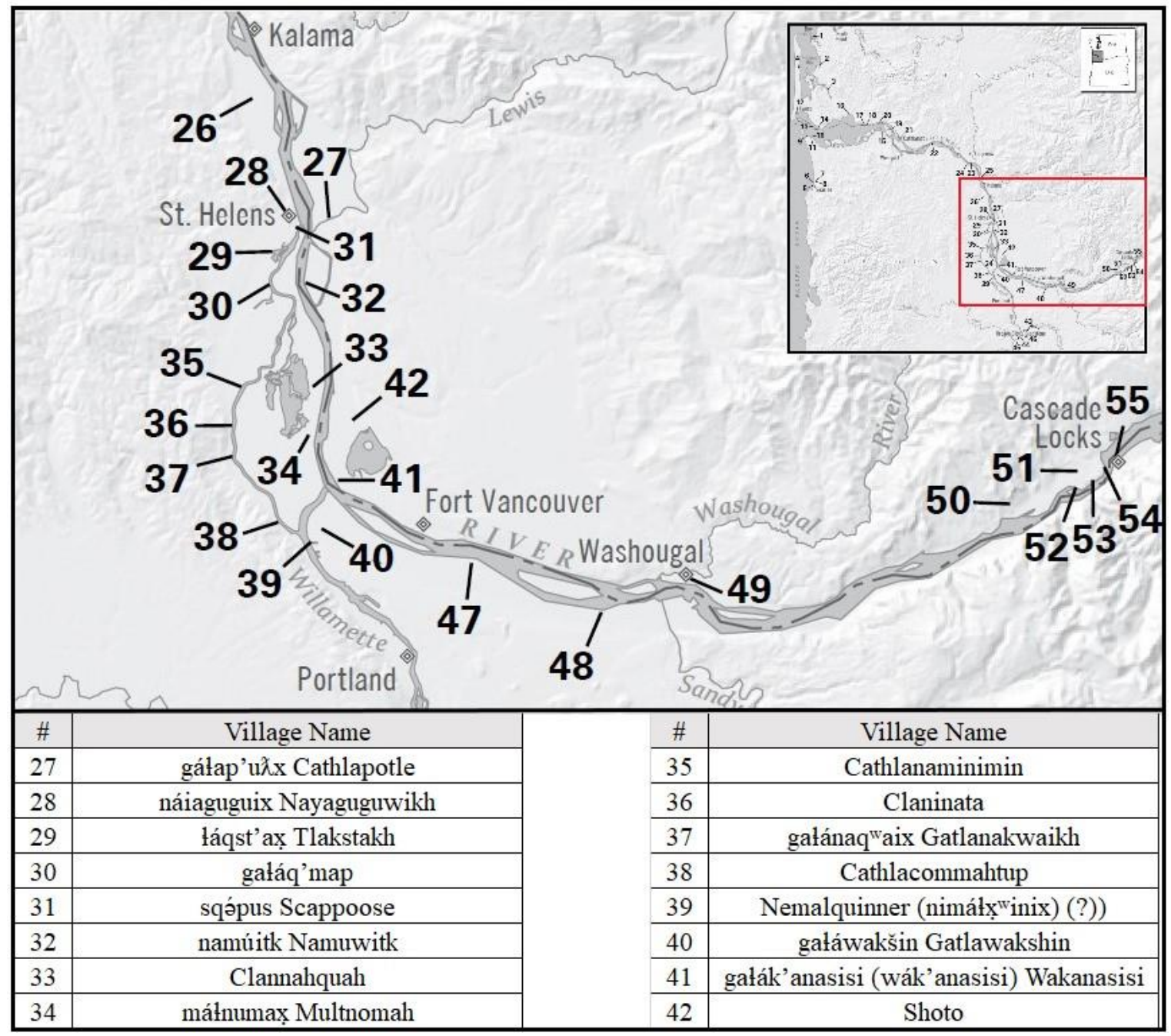

Figure 2.9. Mid-19 $9^{\text {th }}$ century villages on and near Sauvie Island, with villages $29,30,31$, $35,36,37$, and 38 found along either the western shoreline of the island or immediately across Multnomah Channel. Village locations beyond the Sauvie Island area are shown but not named. Map modified from Zenk et al. (2016). 


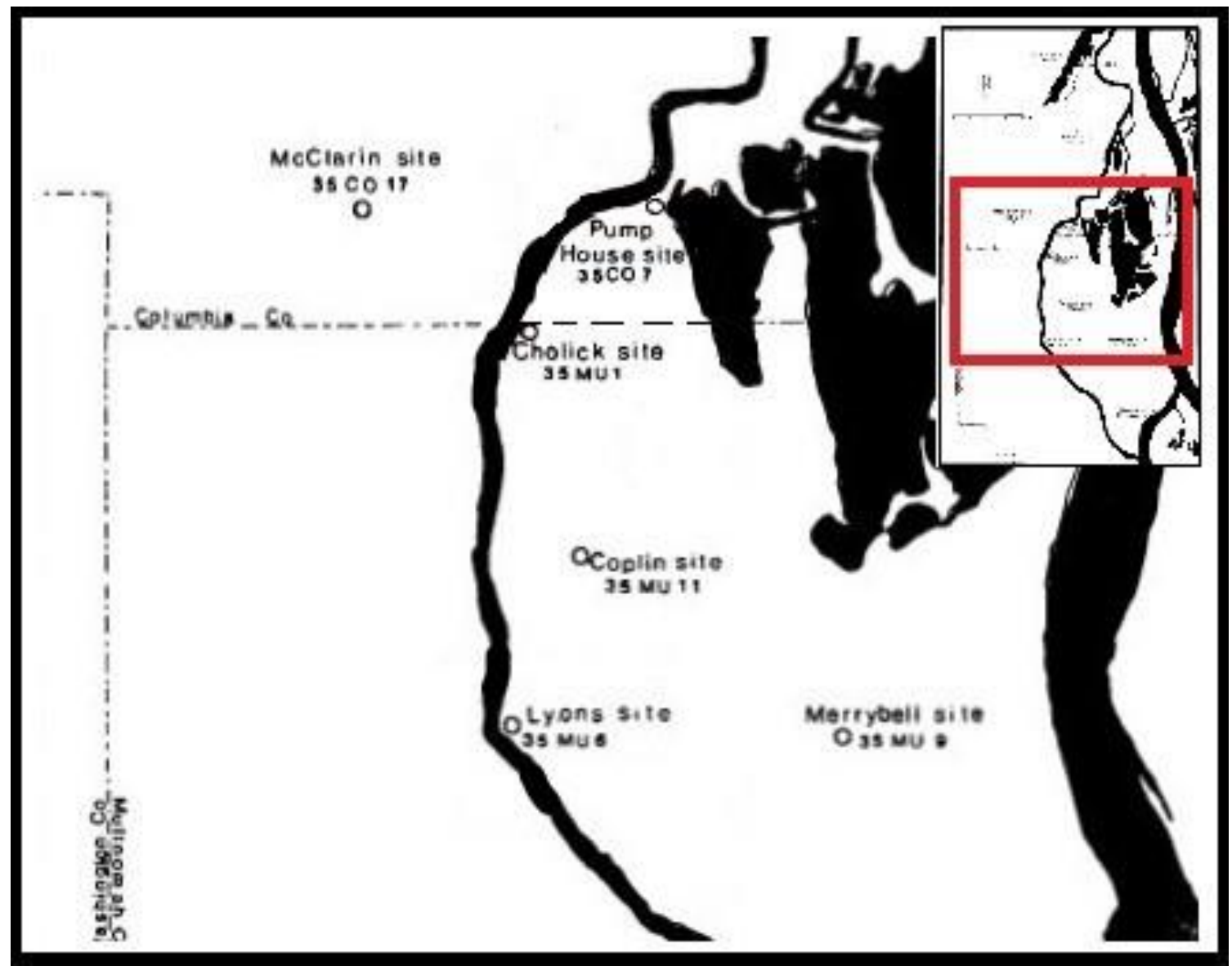

Figure 2.10. Previously excavated archaeological sites near the western shoreline of the island. Note that the Pump House (35CO7), Cholick (35MU1), and Lyons (35MU6) sites are slightly inland from the Multnomah Channel and were not part of the survey area. Map modified from Pettigrew (1981).

These sites, along with the massive acorn processing site at Sunken Village (35MU4), on the southwestern shoreline of the island (Croes 1988; Croes et al. 2007; 2009; Fagan 2004; M. Newman 1991; T. Newman and McNassar 1977) suggest a diverse subsistence base that incorporated plant resources such as acorns and wapato in addition to typical terrestrial and aquatic resources (Darby 2002; Gahr 2013; Pettigrew 1981).

Early Euro-Americans made note of the island as a major place of Indigenous subsistence and gathering, with Lewis and Clark designating it Wappato Island, after the aquatic tuber that was a key element of Chinookan lifeways (Boyd 2011; Cutright 2003; Darby 
2002; Moulton 1983b). In addition to intensive plant-management across Sauvie Island's immense wapato fields (Figure 2.11), the island was also rich in other plants, such as reeds (Phragmites australis), rushes (Juncus), willows (Salix), and hazel (Corylus cornuta), which provided material for basketry, while yampah (Perideridia gairdneri) and acorns (Quercus garryana) were important foods (Darby 1996; 2002).

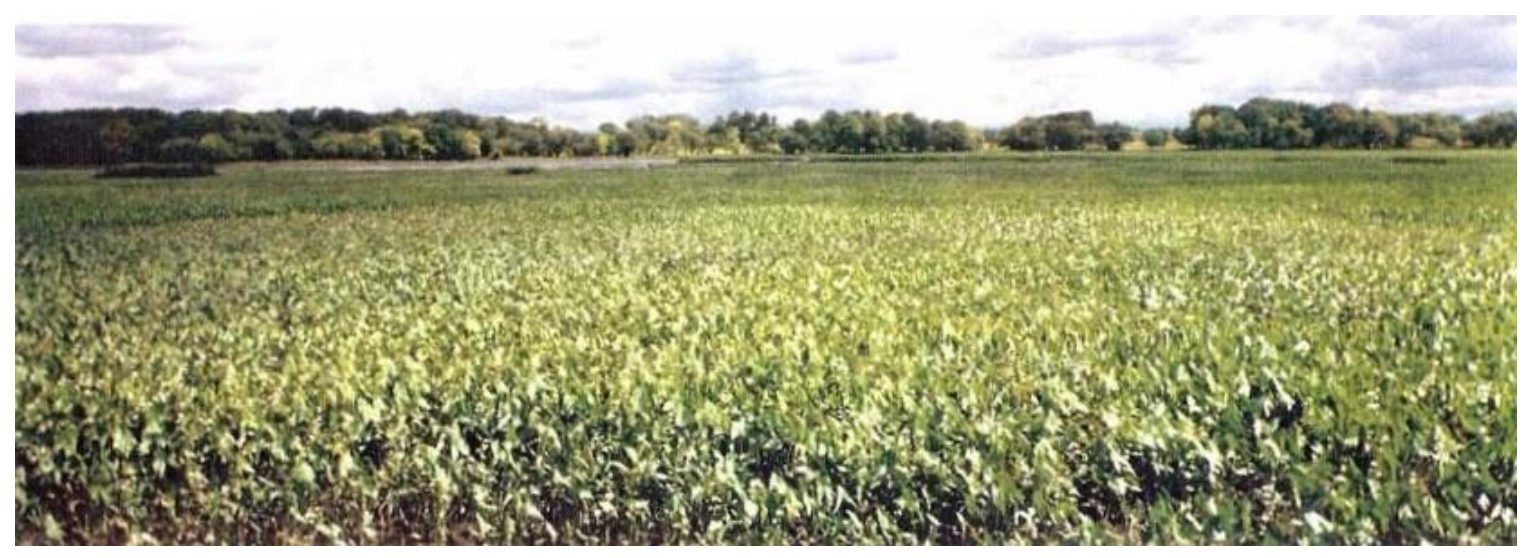

Figure 2.11. A wapato field at Crane Lake, northwest Sauvie Island. Photo courtesy of Darby (1996).

The island which came to be known as Sauvie Island is first mentioned in 1792, when William R. Broughton, part of George Vancouver's survey excursion up the Lower Columbia, recorded an interaction with Indigenous peoples at what would be called Warrior Point, the northernmost tip of the island (Spencer 1950; Vancouver 1798). Lewis and Clark would follow in 1805, making cursory maps (Figure 2.12) and notes on the island's inhabitants, flora, and fauna (Cutright 2003; Moulton 1983a; 1983b). Other brief mentions of the island are made in the survey accounts of Gabriel Franchère (1854), James Swan (1857), and David Thompson (1914; 1916) as well as historical accounts like those of Robert Greenhow (1844). 


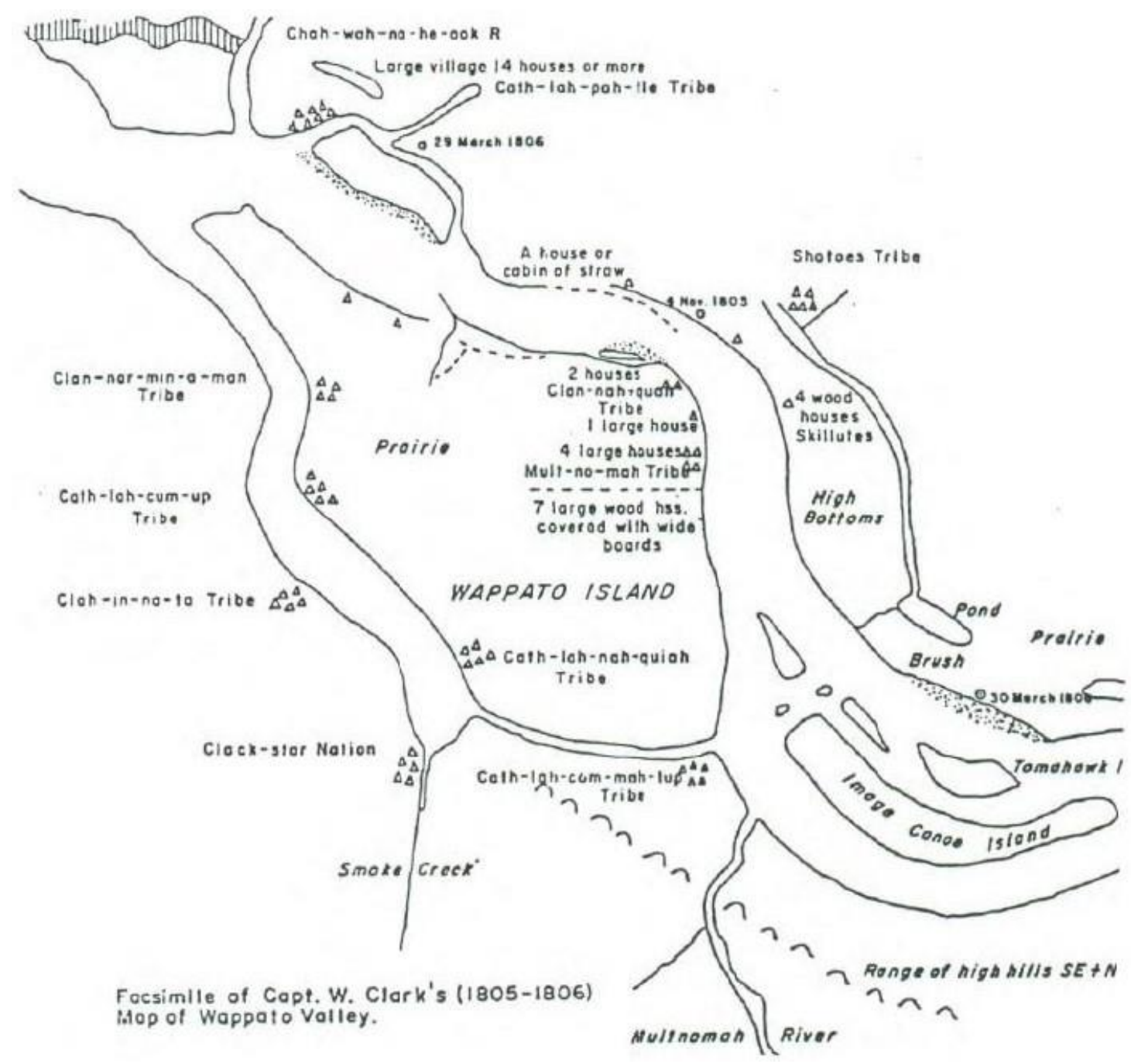

Figure 2.12. Captain Clark's map of the Willamette and Columbia River confluence and Sauvie Island (then called Wappato Island), with villages and some physiographic features detailed, map courtesy of M. Newman (1991).

In addition to being exceptionally brief, these accounts struggled to accurately describe the role or place of the Multnomah Channel along the western shoreline of the island, likely due to its shallowness at that time, which may have obscured the extent to which it separated the island from the mainland (e.g., Thompson 1914), or an inability to distinguish between the channel and the Willamette River proper (e.g., Cox 1832). The first relatively detailed geographic account of the island (Figure 2.13) was made in 1841, 
as part of a large survey by Charles Wilkes $(1849 \mathrm{a} ; 1849 \mathrm{~b} ; 1958 ; 2009)$ that mapped a substantial portion of Pacific Northwest Coast waterways. By the time of the Wilkes mapping however, most of the large island population and villages had been devastated by disease (Boyd 2011b; Deur 2012). A wave of smallpox in the 1780's had preceded first recorded European contact and then a wave of malaria had followed after the 18241825 construction of Fort Vancouver to the southeast, the first permanent Euro-American presence in the area (Boyd 2011b; Deur 2012). It was this wave that led to the abandonment of Cathlapotle in the mid-1800's (Daehnke 2005). As such, Wilkes' relatively detailed accounts and maps made little mention of the once thriving villages and processing sites that Lewis and Clark had observed in 1805.

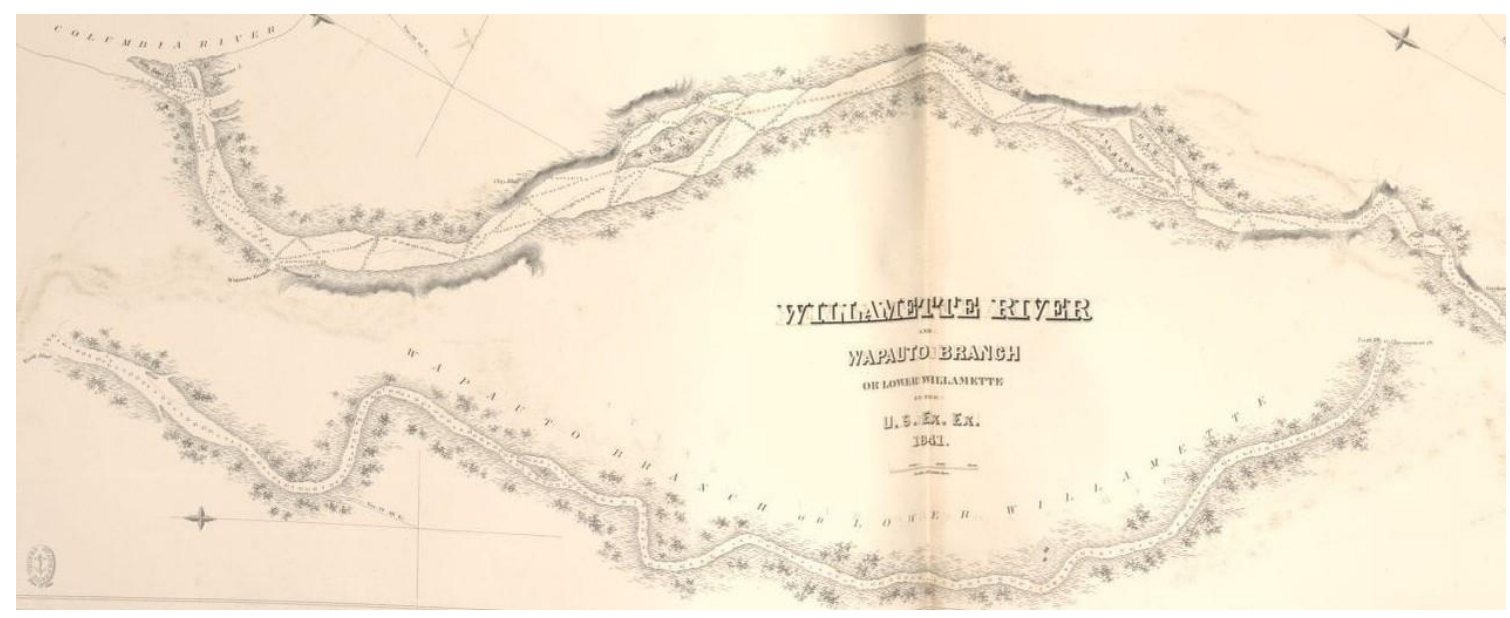

Figure 2.13. The 1841 Wilkes survey map of Sauvie Island, with Multnomah Channel termed the Wapato Branch of the Willamette River. Note incomplete geography at northern and southern ends of the island, as well as the mistaken placement of the Willamette, which Wilkes thought to extend around the eastern shoreline of Sauvie Island. Map courtesy of Wilkes (1849b).

Sauvie Island has an early and extensive record of Euro-American occupation, in the form of agriculture and commercial activity. Initially ignored by the Hudson's Bay Company due to regular flooding, Sauvie Island was first occupied by Euro-Americans in 
1834, when Nathaniel Wyeth, an aspiring fur trader, established the short-lived Fort William, located on the western shoreline (Canniff 2014; Greenhow 1844; Spencer 1950). Although the island briefly took on Wyeth's name due to his failed venture, the Hudson's Bay Company would establish the island's first successful Euro-American industry shortly thereafter, a series of dairy farms that would operate well into the $20^{\text {th }}$ century (Spencer 1950) and today form a significant part of one of the island's primary historical archaeological components at the Logie/HBC Dairy (35MU136) site, just to the southeast of the likely location of Fort William (Stenger 1987). The island's current name derives from one of the first overseers of these farms, a Hudson's Bay employee named Laurent Sauvé (Spencer 1950; Watson 2010).

Importantly, while Indigenous populations greatly declined after the 1830's due to disease, with the populations on Sauvie Island devastated in kind (Deur 2012), their connection to the island continued into the post-contact period. Deur (2012) notes ethnohistoric accounts of marked graves across the island after the epidemics, as well as later task-oriented visits to the area by displaced peoples who had been pushed further downstream. Intermarriage also created complex post-contact lineages, such as that of Sauvé, who had two Indigenous wives over the course of his lifetime (Boyd 2011; Spencer 1950; Watson 2010). The Logie family, who took over management of the island's dairies after Sauvé retired, was said to have offered medical care to both EuroAmerican and Indigenous residents of the island (Spencer 1950). Indigenous peoples from numerous tribal groups also formed much of the working class at the nearby Fort Vancouver (Wilson 2015). These accounts highlight the overlap between Indigenous and 
Euro-American use of the island and the complexity of assigning ethnicity to cultural resources dating to the $19^{\text {th }}$ century.

Euro-American land and waterway modifications had early beginnings on Sauvie Island. At the south end of the island, a series of dikes and dams (35MU242) from the mid- $19^{\text {th }}$ century extend into the Multnomah Channel, remnants of some of the first attempts by the USACE to facilitate agriculture on the island by reducing flooding (Pfandler 2013). At the north end of the island, the remains of the Island Lumber Company (site 35CO66, Roulette and Finley 2009b) surround the entirety of Warrior Point. The Island Lumber Company was one of many waterway-based industries that were built up in the area with the advent of modern pile construction in the late- $19^{\text {th }}$ century (Roulette and Finley 2009a). This allowed for large-scale commercial enterprises to extend into waterways, providing easy access to shipping lanes. These historic-era commercial activities have greatly influenced the nature of known historical site components along the Sauvie Island shoreline, many of which are recorded as historic refuse and debris scatters. In the interior, the Bybee-Howell site is a well-preserved example of a historic home from the first wave of dedicated Euro-American agriculturalists (Spencer 1950), built in the 1850's and now maintained by Portland Metro (Wulf 2016). Until the construction of the modern levee system in the mid- $20^{\text {th }}$ century, dairy was a key island industry, as cattle could be ferried to the mainland during flooding events (Canniff 2014; Dudley 2019; Spencer 1950). Remains of the historic island ferry, the only means to access the island until the Sauvie Island Bridge was built in 1949, can be observed at the Sauvie Island Boat Ramp, another Metro managed 
property (Dudley 2019). All along the shoreline are the remains of smaller private docks, both modern and historic, as well as large historic trash scatters, from years of commercial and recreational activity along the shoreline.

Since Euro-American contact, vandalism, looting, pothunting, and amateur work on Sauvie Island has been a threat to cultural resources (Croes 1988; Pettigrew and Lebow 1987; Fagan 2004). Pettigrew’s early site reports (1973a; 1973b; 1973c; 1973d) noted the extent of the pothunting at many Sauvie Island sites and also noted the private collections that held chronologically important artifacts $(1977 ; 1981)$. Seaman $(1967)$, an early $20^{\text {th }}$ century collector, provides locations and instructions for other "collectors" while speaking openly about the immense looting that occurred at sites on the east side of the island. Although such large-scale collecting has ceased, sites along the shoreline remain vulnerable to opportunistic looting by hunters, recreationalists, illegal fishers, and private landowners.

\section{Archaeology of the Western Sauvie Island Shoreline}

The western shoreline and immediate bank of Sauvie Island is home to 35MU4, or Sunken Village. This site is listed on National Register of Historic Places (NRHP) as a National Historic Landmark (NHL), one of only 17 in Oregon (NPS 2020) and is the most extensively recorded and studied archaeological site on the island. While it has been the target of multiple field efforts, the most recent work involved extensive excavation to mitigate impacts from disturbance due to the repair of the levee that bisects the site (Croes et al. 2009; Fagan 2004; T. Newman and McNassar 1977; Pettigrew 1973a; Pettigrew and Lebow 1987). The area was briefly alluded to in ethnographic accounts 
(Croes et al. 2009), first described in amateur accounts (R.F. Jones 1972; E. Strong 1967), and first recorded by Pettigrew in the early 1970's (Pettigrew 1973a). Sunken Village is a well preserved wet site, chiefly known for the $\sim 110$ hemlock lined puts dug into the intertidal zone along the shoreline, that functioned to leach tannins from acorn meat. It provided intact basketry (Figure 2.14), as well as wood, bone, and a rich floral assemblage, with stratified cultural deposits extending into the bank and levee (Croes 1988; Croes et al. 2009; Fagan 2004; M. Newman 1991). The site is the largest acorn processing site in North America and has drawn global attention due to the preservation level of organic cultural materials (Croes et al. 2007; 2009). The assemblage of basketry at the site, an extremely diverse and well-preserved demonstration of Indigenous crafting techniques, is of great cultural significance to Lower Columbia tribal communities (Connolly and Byram 1997). As such, major excavations in the late 2000's were conducted with the partnership and cooperation of tribal governments from the Grand Ronde, Siletz, and Warm Springs (Croes et al. 2009). The Sunken Village leaching pits are located on the beach proper, although site deposits extend into the bank and levee, which has seen extensive erosion, as noted during past recordings (Figure 2.15). As such, this significant site of great cultural importance falls within my project area and is assessed in later chapters. 


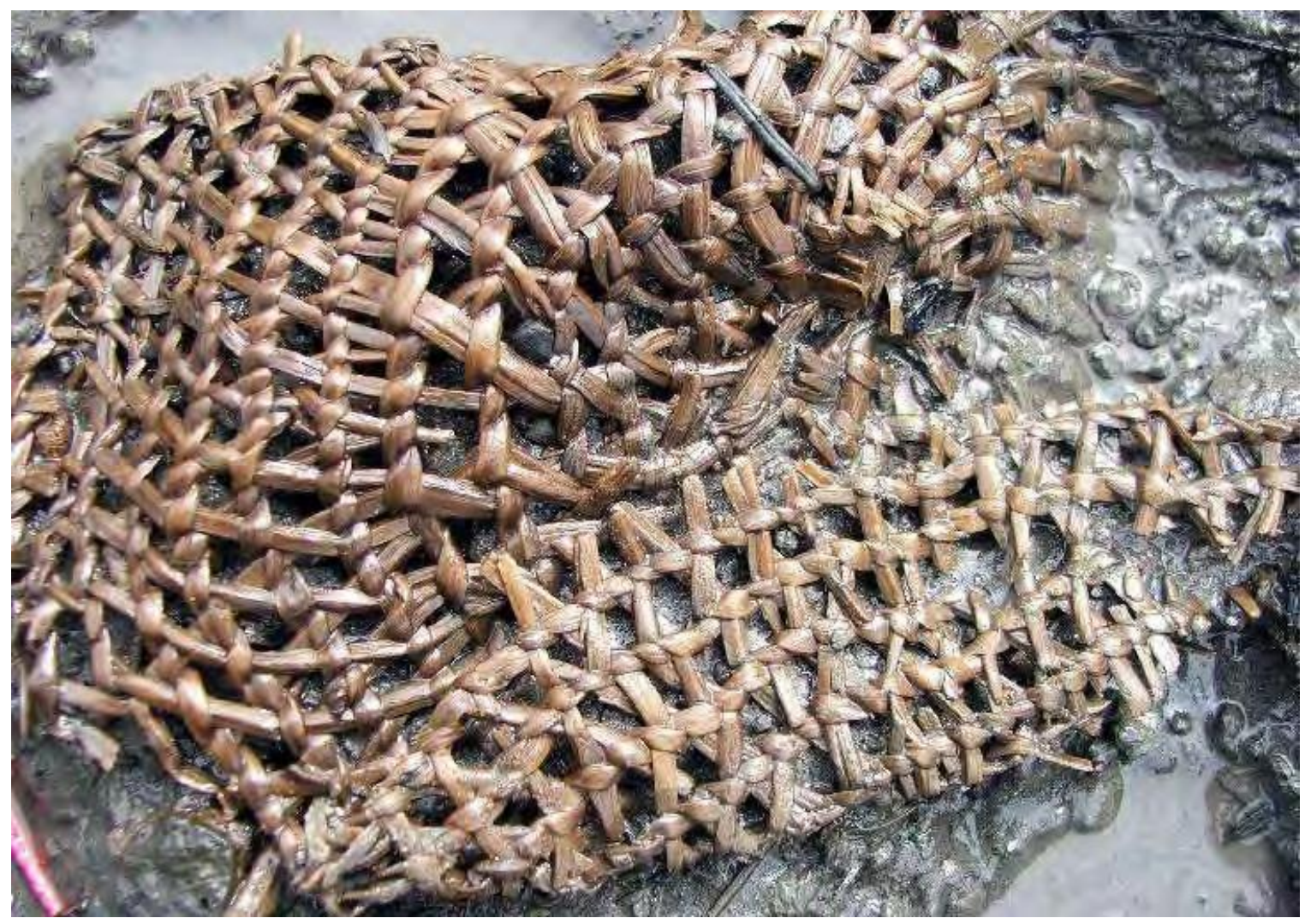

Figure 2.14. Intact basketry recovered at the Sunken Village (35MU4) wet site, photo from Croes et al. (2007).

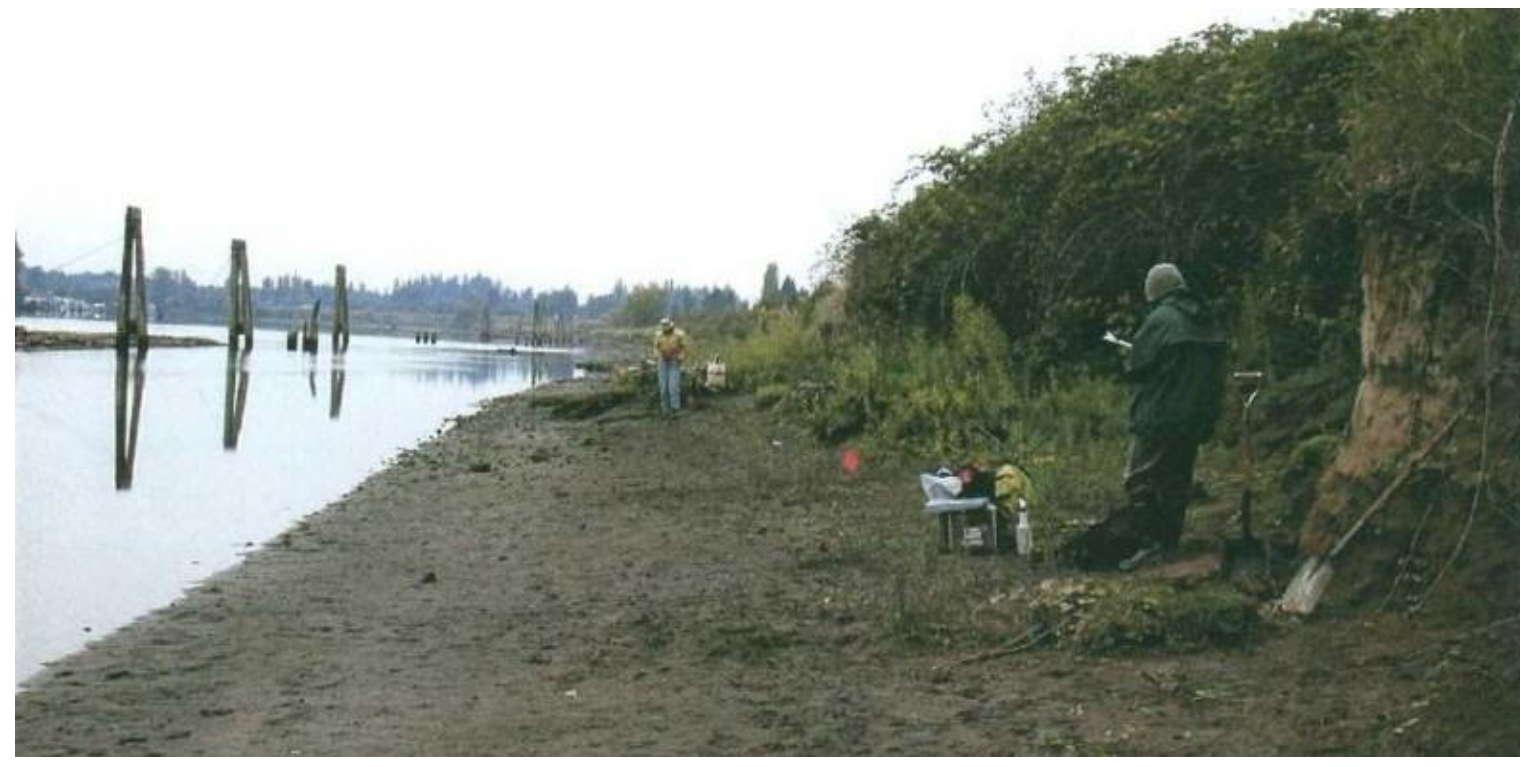

Figure 2.15. The Sunken Village site prior to late 2000's excavation and subsequent protective riprapping, note sheer, eroding bank face, photo from Fagan (2004). 
In total, eight previously recorded sites were revisited during my research (Table 2.3). These sites have varied recording backgrounds and recording timelines (Figure 2.16). The 35MU61 (Marked), 35MU62 (Howell), and 35MU63 sites are multicomponent, recorded as part of a 1987 Hibbs and Associates (now defunct; Darby et al. 1987; Reese 1987a; Reese et al. 1987a) survey for an incoming gas pipeline. Prior to my rerecording, these sites had not been reexamined or revisited since those initial surveys. The $35 \mathrm{CO} 75$ and $35 \mathrm{CO} 76$ sites were recorded in 2015 by Archaeological Investigations Northwest (AINW) as part of a survey ahead of soil disposal by the Oregon Department of Fish and Wildlife (Jenkins 2015a; 2015b). The 35CO66 historic lumber mill site has been the subject of multiple recordings and is, by area, the largest site in my study. It was surveyed by both Applied Archaeological Research (AAR, Roulette and Finley 2009a) and Historical Research Associates (HRA, Ponte 2015) ahead of repeated but abandoned attempts to remove the massive piling field to restore natural habitats. The 35MU242 site is an historic dam, intake, and piling site that, like 35CO66, is spread across a large area at the southern tip of Sauvie Island. It was surveyed by Willamette Cultural Resources Associates (WCRA) as part of a commercial mitigation project (Pfandler 2013). 35MU4 or the Sunken Village site, has been surveyed and excavated at numerous times over the course of 50 years, for reasons of significance detailed above. 
Table 2.3. Previously recorded archaeological sites along the western Sauvie Island shoreline that were re-visited in my project, with primary sources and project years.

\begin{tabular}{|c|c|c|c|c|}
\hline $\begin{array}{c}\text { Site } \\
\text { (Smithsonian } \\
\text { Number and } \\
\text { Name, if } \\
\text { Applicable) } \\
\end{array}$ & County & $\begin{array}{c}\text { Brief } \\
\text { Description }\end{array}$ & $\begin{array}{c}\text { Year(s) } \\
\text { Recorded }\end{array}$ & Primary Sources \\
\hline $\begin{array}{c}\text { 35MU4 - } \\
\text { Sunken Village } \\
\text { Site }\end{array}$ & Multnomah & $\begin{array}{l}\text { Precontact Wet- } \\
\text { Site w/ Leaching } \\
\text { Pit Features }\end{array}$ & $\begin{array}{l}1973 \\
1977 \\
1987 \\
2004 \\
2009\end{array}$ & $\begin{array}{c}\text { Pettigrew 1973; T. Newman and } \\
\text { McNassar 1977; Pettigrew and } \\
\text { Lebow 1987; Croes 1987; M. } \\
\text { Newman 1991; Fagan 2004; } \\
\text { Croes et al. 2007; 2008; 2009 }\end{array}$ \\
\hline $\begin{array}{l}\text { 35MU61 - } \\
\text { Marked Site }\end{array}$ & Multnomah & $\begin{array}{c}\text { Precontact FCR } \\
\text { Scatter and } \\
\text { Possible Weir } \\
\text { Feature } \\
\end{array}$ & 1987 & Reese et al. 1987 \\
\hline $\begin{array}{l}\text { 35MU62 - } \\
\text { Howell Site }\end{array}$ & Multnomah & $\begin{array}{l}\text { Precontact FCR } \\
\text { Scatter, Hearth, } \\
\text { and Historic-era } \\
\text { Trash Scatter }\end{array}$ & 1987 & Darby et al. 1987 \\
\hline 35MU63 & Multnomah & $\begin{array}{c}\text { Precontact FCR } \\
\text { and Historic-Era } \\
\text { Trash Scatter w/ } \\
\text { Midden/Dock } \\
\text { Feature } \\
\end{array}$ & 1987 & Reese 1987 \\
\hline 35MU242 & Multnomah & $\begin{array}{l}\text { Historic-Era } \\
\text { Dam/Intake }\end{array}$ & 2013 & Pfandler 2013 \\
\hline $35 \mathrm{CO} 66$ & Columbia & $\begin{array}{c}\text { Historic-Era } \\
\text { Timber Mill } \\
\text { Structures and } \\
\text { Scatter } \\
\end{array}$ & $\begin{array}{l}2009 \\
2014\end{array}$ & $\begin{array}{l}\text { Roulette and Finley 2009; Perrin } \\
\qquad 2014\end{array}$ \\
\hline $35 \mathrm{CO} 75$ & Columbia & $\begin{array}{l}\text { Precontact FCR } \\
\text { Scatter w/ } \\
\text { Hearth and } \\
\text { Historic-Era } \\
\text { Scatter } \\
\end{array}$ & 2015 & Jenkins 2015 \\
\hline $35 \mathrm{CO} 76$ & Columbia & $\begin{array}{c}\text { Precontact FCR } \\
\text { Scatter w/ } \\
\text { Hearth } \\
\end{array}$ & 2015 & Jenkins 2015 \\
\hline
\end{tabular}




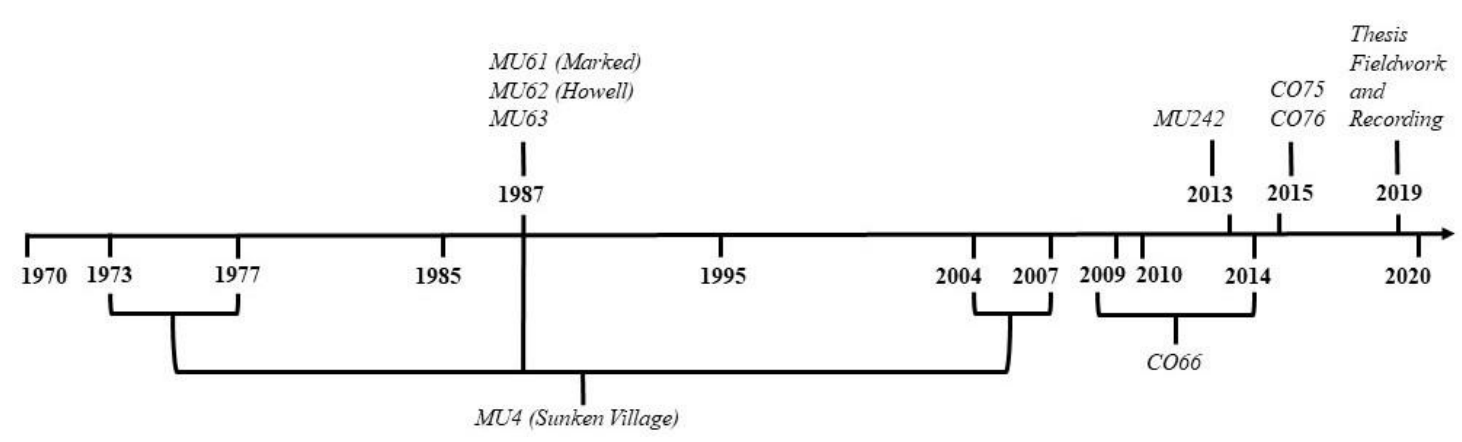

Figure 2.16. A timeline of field visits for previously known sites in the project area.

In addition to resources on the immediate western shoreline, the bank above holds several sites that are essential elements in the regional Portland Basin chronology developed by Pettigrew $(1977 ; 1981)$ and thus worth noting. Such sites in close proximity to my study area included 35MU1, 35MU6, and 35CO7 or the Cholick, Lyons, and Pumphouse sites respectively (Pettigrew 1973b; 1973c; 1973d). Unlike many surface scatters on the island, each has stratified deposits, with artifacts and features that included lithic debris, projectile points, netweights, faunal remains, groundstone, fire-cracked rock, and housepits. Together with other mainland assemblages, these sites form a regional chronology, the Multnomah 1 (35MU1, dates from 850-1720 BP) and Multnomah 2 (35MU6, dated $530 \mathrm{BP}$ and 35CO7, dated $260 \mathrm{BP}$ ) sub-phases (Pettigrew 1977; 1981). Changes include shifts in netweight hafting and a decreasing size in projectile points, although Pettigrew notes that overarching Portland Basin cultural patterns have maintained a great deal of continuity for over 2500 years, an observation echoed by later research (e.g., Minor 1983; Saleeby 1983). Although these sites and assemblages analyzed by Pettigrew are important parts of the local record and would represent significant loss if threatened by environmental factors, their location on and 
back from the bank above the Multnomah Channel puts them just beyond the boundary of my study area.

\section{Perspectives from Lower Columbia Indigenous Stakeholders}

The Lower Columbia cultural record is also immensely important to descendent communities, who classify cultural resources to reflect tribal values and priorities that extend beyond the physical archaeological record, such as the ability of the tribe to reconnect to the site, through visitation or as part of a teaching program. A number of distinct Indigenous stakeholder communities in the Lower Columbia area have interests in this study area, including both federally recognized and unrecognized tribal groups. These include the Confederated Tribes of Grande Ronde, the Confederated Tribes of Siletz Indians, Confederated Tribes of Warm Springs, the Cowlitz Indian Tribe, and the Chinook Indian Nation. The unique voices of these Indigenous stakeholders can help researchers to fully understand the value of cultural heritage along the Lower Columbia.

As will be discussed in Chapter 3, at the outset of my project, I contacted five regional tribes to determine their willingness and interest in collaborating on a project that would incorporate tribal views into a risk assessment process. The Confederated Tribes of the Grand Ronde responded favorably, so I proceeded to develop a project with them, as a case study. They provided a model that lays out ways to conceptualize values for cultural resources, which are divided into the tangible and the intangible (Figure 2.17). Tangible resources are physical in nature and can include archaeological sites and plant communities. Intangible resources relate to nonphysical aspect of tribal culture, such as language, stories, oral traditions, and ceremonies. The intersection of the tangible 
and intangible, such as where landscapes are associated with traditional stories, is critical to establishing value for the tribe (Edwards 2018).

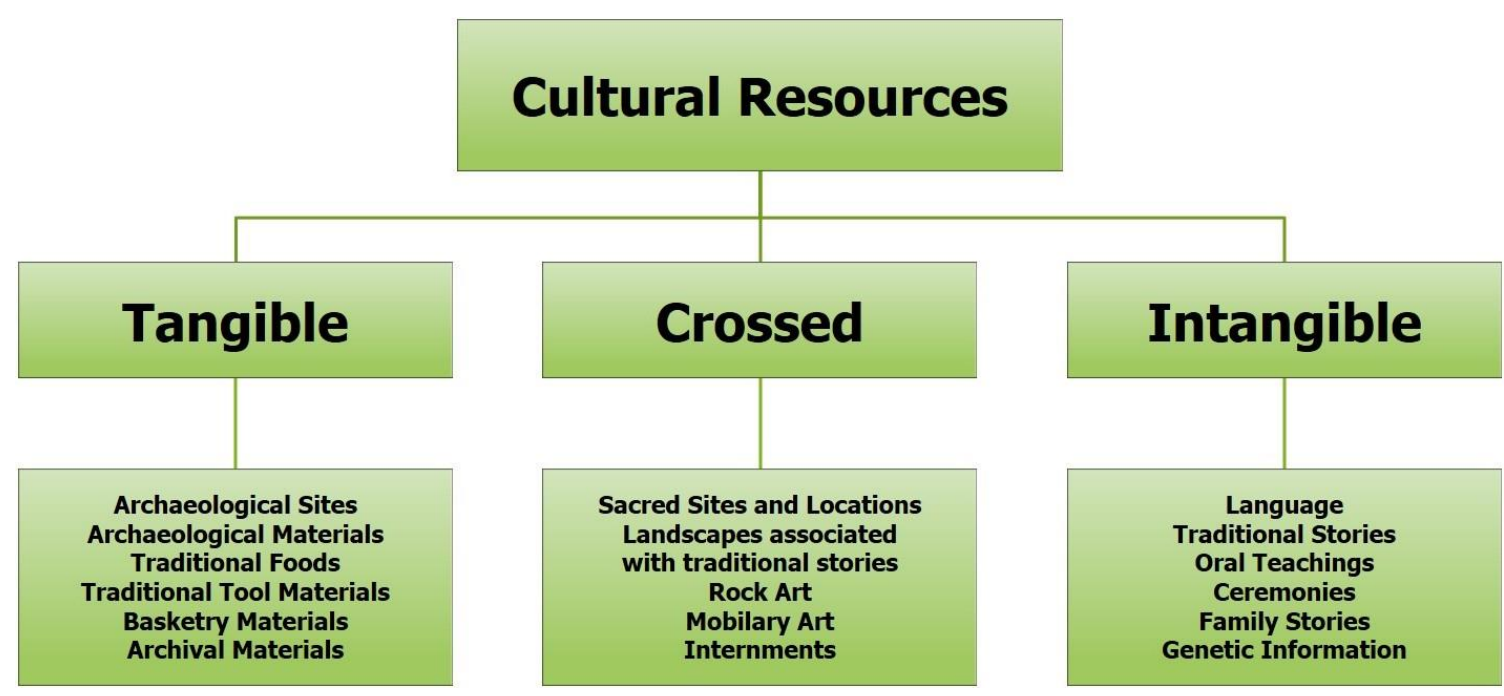

Figure 2.17. An Indigenous understanding of cultural resources, as illustrated by the Grand Ronde Historic Preservation Department (Edwards 2018).

This holistic understanding of what constitutes cultural heritage allows for the recognition of diverse community resources that demonstrate tribal persistence, connecting past lifeways with descendent communities on the river (T. Johnson 2017). Along the Lower Columbia, this record encompasses traditional subsistence, land management, rituals, the reclamation of languages, and tribal identity (Chinook Nation 2019; T. Johnson 2013; Zenk and T. Johnson 2013). Collaborative efforts that consider this record can build tribal capacity to manage, interpret, preserve, and advocate for their own cultural heritage (Gonzalez et al. 2018; The Confederated Tribes of Grand Ronde 2019). For Lower Columbia tribes, cultural resources are important as an argument for existence that stretches into time immemorial. Ongoing connections to the land are a demonstration of resilience in the face of Euro-American contact and colonialism, playing a major role in the fight for tribal sovereignty and land claims (Daehnke 2017; T. 
Johnson 2017; Salcedo et al. 2017). This nuanced and multifaceted Indigenous understanding of the value and meaning of cultural heritage adds much to the academic conception of resource value. 


\section{Chapter 3. Research Design and Methodology}

My thesis research sought to develop a prioritization assessment and recording procedure for cultural resources along the western shoreline of Sauvie Island, in a manner that incorporated tribal values and concerns. To address this goal, over the course of nearly three years (Figure 3.1), I contacted regional tribes to assess their interest in the project and seek input on the selection of a study area of both tribal and archaeological interest. I developed a survey and recording process for my fieldwork, to ensure that the information collected from the baseline assessment of condition for each cultural resource recorded would be adequate for the prioritization process. I then met with tribal partners to discuss field results and develop criteria to document tribal values not routinely included in site evaluations. In collaboration with tribal partners, I developed a prioritization assessment, designed to assign numerical scores for each site based on archaeological and tribal value, and the risk factors observed at each site.

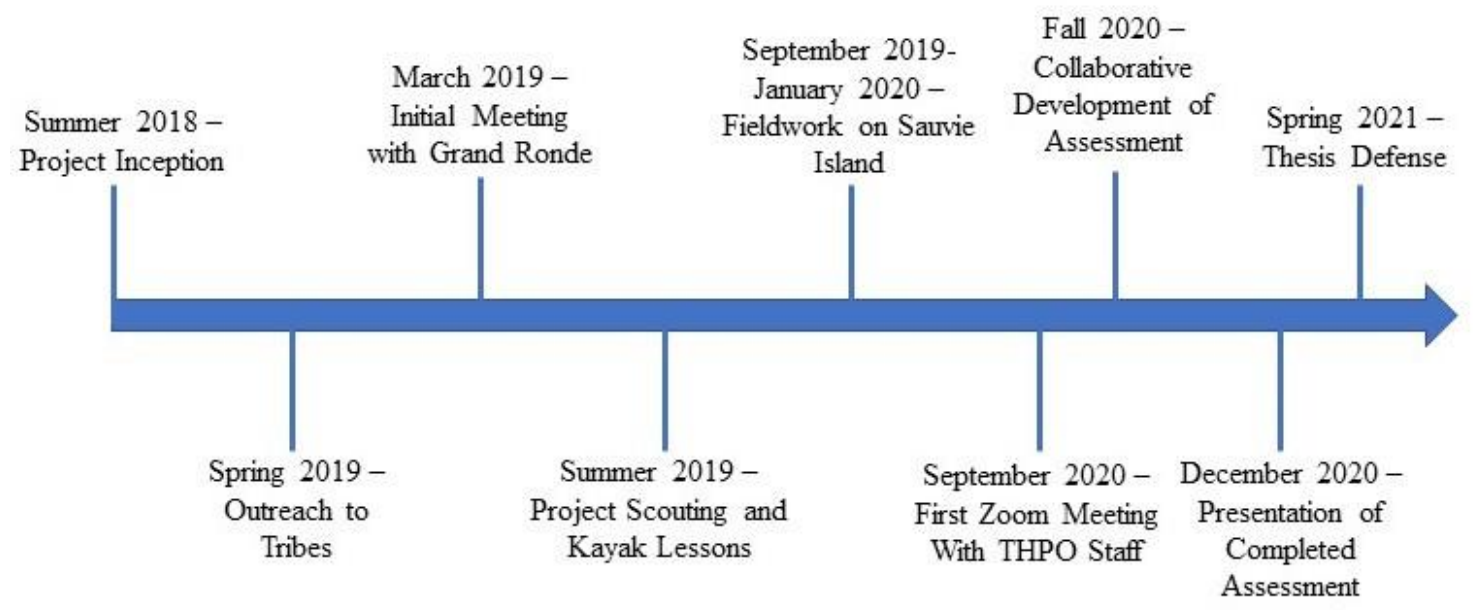

Figure 3.1. Project timeline from Summer 2018 to Spring 2021, highlighting major actions as they occurred during the thesis process. 


\section{Tribal Collaboration}

One goal of my thesis research was to incorporate tribal perspectives into a prioritization assessment that would reflect not only archaeological values, but tribal values as well, in a case study that would allow for broader application. In order to accomplish this, between January and March of 2019, I contacted five tribes with ties to the Lower Columbia, the Confederated Tribes of the Grand Ronde, the Chinook Nation, the Confederated Tribes of Warm Springs, the Confederated Tribes of Siletz Indians, and the Cowlitz Indian Tribe. For each tribal community, I contacted staff members in the Tribal Historic Preservation Office (THPO) and/or staff archaeologists, as well as, in the case of the Chinook Nation, the Tribal Chairman. Each tribal contact was emailed a short introduction to my project as well as a prospectus (Appendix A), with efforts made to establish in-person contact at regional conferences and summits, such as the annual Northwest Anthropological Conference (NWAC) and the Grand Ronde History and Culture Summit. After several attempts at outreach, one tribe, the Confederated Tribes of the Grand Ronde indicated their desire to collaborate in the creation of a prioritization assessment. In April 2019, we had our first meeting to discuss selection of a study area and share overlapping interests and concerns about how the project would unfold.

In April of 2019, Virginia Butler and I had our first in-person meeting at the

Grand Ronde cultural center. We discussed our shared mutual interests and goals for the project, we selected a project area, and we discussed ways that the tribe would provide input as the work proceeded. During this meeting, we decided to focus on Sauvie Island, particularly the $\sim 34 \mathrm{~km}$ western shoreline. As a cultural landscape, the island is of great 
importance to the tribe and had already been brought into a GIS bathtub model to estimate site inundation with varying scenarios of rising sea levels due to climate change. The island is also relatively close to Portland, making it relatively easy to access for fieldwork. During our meeting with the tribe, we also learned that to the extent possible, the tribe wished to know about culturally important plant resources, such as those used in basketmaking, that might be present within the study area. Finally, we also decided during this initial meeting that the input we received from the tribe would involve members of the THPO staff only. While some previous risk assessment projects incorporating Indigenous perspectives involved conducting interviews with elders, delivering surveys to tribal members, or conducting joint site visits, these types of engagement were beyond the scope of my project. Given the degree of effort involved in the planned archaeological fieldwork, focusing on tribal input from the THPO office would provide important perspectives in a manner scaled to this thesis project. Additionally, with the coronavirus pandemic of 2020-2021, incorporating perspectives beyond the THPO office, in a manner practiced in other risk assessments, would not only have been logistically challenging, but would have presented an unacceptable health risk for all involved.

As fieldwork was occurring between September 2019 and January 2020, I updated THPO partners regularly about the progress of the project via email. Beginning in March 2020, after the Covid-19 pandemic precluded our ability to meet face-to-face, my advisor, Virginia Butler, and I, met with THPO partners a total of seven times, with meetings lasting between one to three hours. The key goal of these virtual meetings was 
to discuss both the definition and potential scoring of tribal values. This was an iterative process and during these meetings, findings from my fieldwork were exchanged, discussed, and reviewed in-meeting and via Google Drive, with THPO staff reviewing each draft of the prioritization assessment process and providing input so that it could be further refined to reflect tribal values.

\section{Study Area Selection}

The study area for my project had to meet several criteria. Most importantly, it needed to be of relevance and interest to the Grand Ronde, either through location, through cultural properties to be surveyed, through potential knowledge gained, or all three. The study area selected also needed to provide an at-risk shoreline with an exposed beach that was surveyable, accessible via boat or on foot. The area also needed to have potential for newly identified archaeology as well as records from previously identified sites, to estimate the degree to which site condition had deteriorated. Finally, the area of study needed to be properly scaled for my thesis, as well as my logistical capabilities. This process led to the selection of the $34.6 \mathrm{~km}$ western shoreline of Sauvie Island, along the Multnomah Channel, as the project area.

Beyond the value that this area holds to the Grand Ronde, as discussed prior, there were other benefits to selecting the western shoreline of Sauvie Island for study. Outside of the extensive work at Sunken Village and a handful of small projects near the north end of the island, the northern half of the western shoreline of Sauvie Island was almost completely unsurveyed, while the southern half had been visited by professionals since the late 1980's. The lack of survey of the northern half of the shoreline represented a gap 
in knowledge of Sauvie Island archaeology, while preexisting records for the southern half of shoreline provided comparative information on site assemblages and conditions. Having this original documentation, a past perspective, allowed me to better estimate the impacts of modern cultural activities on site integrity.

\section{Fieldwork}

To conduct my fieldwork along the Sauvie Island shoreline, I developed a strategy for land access, guidelines for survey process, and a recording procedure for cultural resources when encountered. This included arranging for land access by contacting relevant landowners and securing appropriate permissions and permits. This also included the preparation of the necessary equipment for waterborne survey and consideration of the natural and artificial forces that would constrain survey times and access, as well as the identification of safety concerns and conditions that would dictate survey exclusions. Finally, to conduct my fieldwork, I developed methodology for how and what to record when a cultural resource was identified. I completed my fieldwork with the help of Madeline Robin, a volunteer research assistant who provided transportation to the project area and assisted with survey procedures, including documentation and photography. My fieldwork was conducted intermittently between late October 2019 and early January 2020. All site recording was completed by early November 2019, with limited clean-up survey in December 2019/January 2020. In total, fieldwork spanned over 31 days, with 8-10 hours spent in the field each day, along with additional data processing after returning from the field. 


\section{Survey}

Oregon state law stipulates that along navigable waterways, the general public has the right to access and use any shoreline extending up to the high-water mark (ODSL 2007; 2008). Recent research, including other risk assessments, highlighted the value of small, shallow draft boats, such as kayaks or canoes, to access such shorelines. A recent study by Reeder-Myers and Rick (2019) tested the concept in Chesapeake Bay, noting the value of low-tide access when assessing site condition and addressing larger regional archaeological questions of land use. In the Great Lakes region, Gendron (2018) utilized canoes to observe cultural resources along a segment of the Trent-Severn waterway, recording various aspects of cultural resources from the perspective of historical archaeology and tribal meaning. Given Sauvie Island's significant amount of exposed shoreline below the high-water mark, this was determined to be the ideal means to legally access a sizeable survey area without being required to secure land access permission from private landowners, who own the majority of the southern half of the island. This shoreline also presented a manageable and clearly defined survey area, given the largely consistent presence of a near vertical, heavily vegetated bank at the high-water mark, while the low-tide mark constrained pedestrian survey to a 10-20 m wide area. This corridor could be accessed via kayak within the project timeline, during fall, when water levels were lowest, which allowed for continuous survey throughout the low water season.

While Oregon law allows for public access to the Sauvie Island shoreline via the water, some landowner permissions were sought, as a matter of best practice, partnership, 
and due to need for more efficient overland routes in some cases. To gain this land access, I contacted state and local agencies, as well as private landowners. Extensive Oregon Department of Fish and Wildlife (ODFW) holdings on Sauvie Island (Figure 3.2) and assistance from ODFW staff, archaeologist Daniel Pettit and Sauvie Island Wildlife Area Manager Mark Nebeker, facilitated both kayak survey and overland pedestrian survey for the northern half of the study area, with some caveats explained later in this section. Supportive of my work on this thesis, they allowed largely unrestricted access within the boundaries of the refuge, including overland access to the shoreline. Documentation included a general parking pass for standard recreational periods as well as a special research permit to allow access to the refuge during hunting season. In addition to ODFW holdings, the Oregon Parks and Recreation Department (OPRD) also has a small land parcel along the western shoreline, the Wapato Access Greenway. The appropriate research permit was filed with the agency through communication with OPRD archaeologist Nancy Nelson, and permission from the local ranger. Finally, Oregon Metro, the agency that encompasses the three counties comprising the Portland metropolitan area, also owns a small parcel along the western shoreline, just to the north of the Sunken Village site. Special access permits were filed, allowing for parking on the Metro-owned portion of the levee, above the beach where survey was to take place. Three private landowners on the southern half of the island were also contacted, because their property offered a more efficient overland route to key shoreline segments and/or because their personal residences were on or near the waterline. Notably these properties included a cluster of previously recorded sites located during the oil and gas pipeline surveys 
conducted by Hibbs \& Associates in the late 1980's, the Fort William Bend area, and Sunken Village, owned by David Fazio, Joe Pastorino, and the descendants of the Douglas family, respectively. While the Douglas family members were responsive and allowed overland access to the Sunken Village site, all other private landowners were either resistant or unresponsive. These privately-owned shoreline areas represented the majority of shoreline that was excluded from the final survey. 


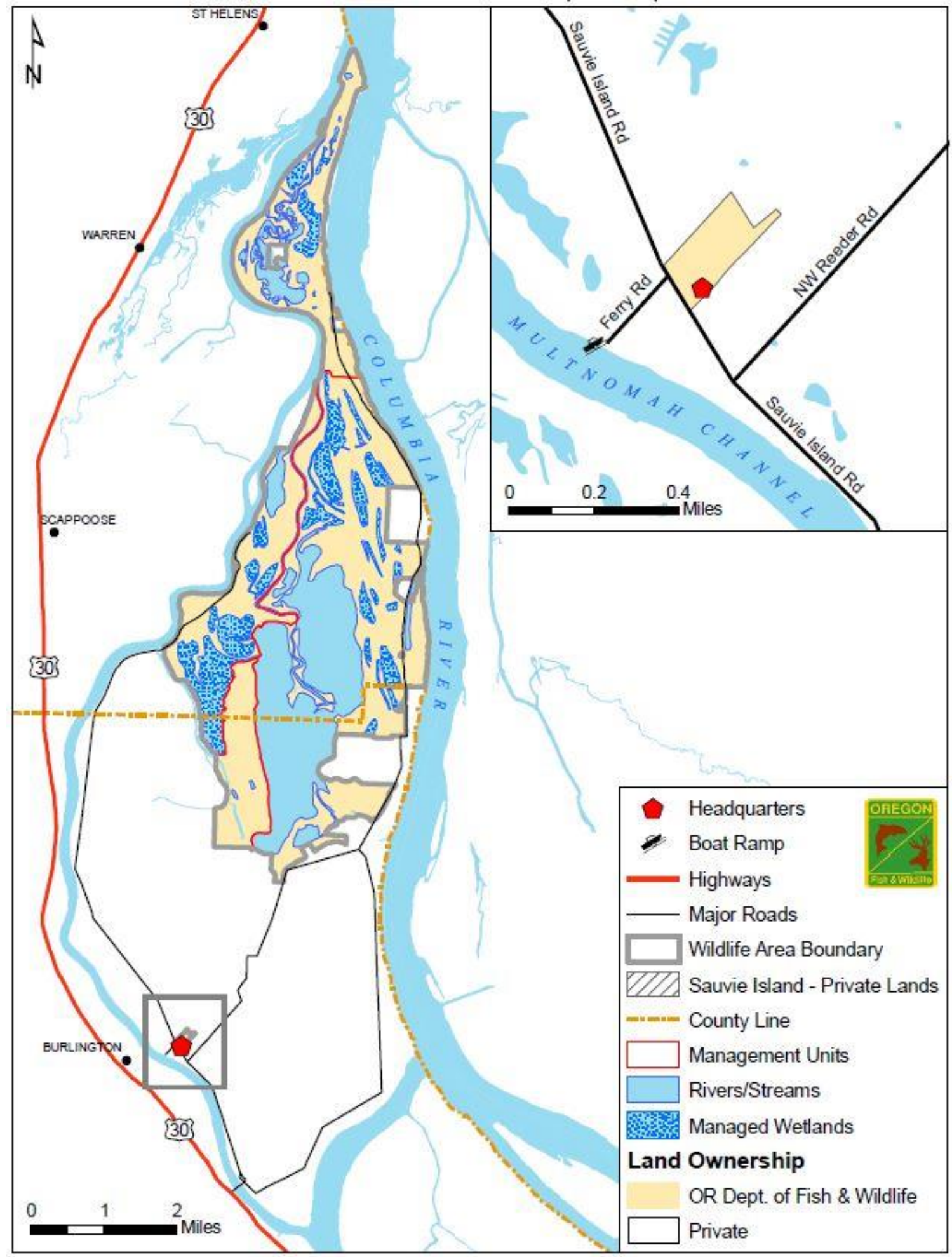

Figure 3.2. ODFW (2019) map of Sauvie Island land ownership, public and private, with additional major features, https://myodfw.com/sauvie-island-wildlife-area-visitors-guide. 
To access the shoreline from the water, my volunteer research assistant and I used recreational, single-seat sea kayaks. I rented these kayaks and accompanying equipment through the Portland State University Outdoor Program. My kayak-based field survey was preceded by a local Scappoose Bay kayaking class, which provided boating skills, safety guidelines, and information on navigating the Multnomah Channel. Additional time was taken prior to the survey to practice kayaking skills in a recreational setting. I conducted my preliminary scouting for the project in Summer/Fall 2019, via overland hiking routes. Dennis Torresdal, Sauvie Island resident and citizen archaeologist who I have come to know through Portland area archaeology gatherings, guided me on a shallow-draft jetboat tour of the shoreline, pointing out sites of interest and places I could access later via kayaks.

In addition to selecting a low-water portion of the year, a crucial part of my survey process was identifying daily low-tide periods and planning survey for these times. This was done using NOAA tidal data from the Rocky Point Station, near the midpoint of the Multnomah Channel. Also, I used NOAA yearly tables to plan my survey for relatively low-water points during the general time period when I had access to survey equipment (October 2019-January 2020), while also planning daily survey around low tide periods for each day during that time. Attempts to rerecord existing sites were targeted at low-tide periods, while attempts were made to return to newly identified sites if these resources were initially located as the low-tide window was ending. The optimal time period for low-tide survey was found to typically be around four hours long, distributed evenly on each side of the low-tide point. 
Beyond tidal forces, portions of the study area could not be surveyed for several reasons. Downed trees, or deadfall, were common along the shoreline and decreased ground and bank visibility dramatically, obstructed continuous survey efforts, and made overland surveys unsafe by blocking return routes as low-tide periods ended. As such, areas of this nature were observed from the water. Along some areas of the shoreline, the bank terminated directly into deep water, with no exposed beach even at low tide. These areas were only observed from the water. Areas with clear safety concerns, such as private landowner residences on the shoreline, underwater obstacles, hazardous waste, or dense commercial traffic were outright excluded. Some areas were excluded due to their extreme distance from the nearest boat ramp, inaccessible due to limits on daylight or physical abilities of myself and my volunteer assistant to traverse the distance.

Related to exclusions, safe practice was an important part of my fieldwork. The use of the kayaks, small craft less than $5 \mathrm{~m}$ long, necessitated good visibility while travelling along the channel, as well as relatively good weather, to allow for efficient travel and optimal safety conditions, as large boats, both recreational and commercial, often pass through the channel. Survey days were chosen accordingly, avoiding large storms, as well as dense fog, with sailing beginning only at full morning light and terminating at dusk hours. Efforts were made to avoid large recreational or commercial craft, beaching kayaks to avoid the boats themselves or severe wake when necessary. Additionally, the Multnomah Channel has seen well over a century of commercial activity, and many underwater hazards sit offshore, in the form of aging pilings and other debris that can snag and sink boats. In the case of these obstacles, if kayaks could not be 
landed and overland survey was not possible, these survey areas were excluded, as detailed in my results section. Another component of safe access involved the launch point for kayaks, which had to be within paddling range of survey areas. Four launch points, Fred's Marina and the Metro owned Sauvie Island Boat Ramp at the south end of the island, a Columbia Country boat ramp midway up the channel, and the ODFW owned Gilbert River Boat Ramp near the north end of the island, were chosen for this purpose, in order to maximize the range of the kayaks. Distance remained an issue however, and survey points beyond range of the kayaks were either excluded or accessed via overland routes. Finally, much of the southern half of the island is privately owned. Although the beach is public access, in the case of unresponsive landowners with residences along the beach, survey areas on their property were excluded, to avoid confrontations.

\section{Field Recording}

The goal of fieldwork was to relocate previously recorded sites using information from existing SHPO site forms, while also identifying new sites. In Oregon, a site is a group of associated artifacts greater than nine in number, over 75 years old, and part of the physical record of an Indigenous or other culture found in the state or waters of the state. Once sites were identified as per this definition, field recording procedures were followed according to standard Oregon SHPO guidelines (Appendix B). I used these guidelines to format my own field forms and GIS files so that recorded data were adequately suited to update existing site forms, add new site forms, and update SHPO GIS records. Additionally, I also recorded characteristics specific to my prioritization assessment work. This standardized documentation (Appendix C) during my survey 
facilitated easy addition to these existing records by mirroring existing SHPO form templates, aiding future application of my assessment by land managers, archaeologists, and tribal staff.

For my recording, I used a GPS-equipped Nikon 9300 camera for photographs and the GIS point, line, and polygon functions on a Trimble Juno 3B unit to provide locations that could be revisited during future research. This equipment was furnished by Shelby Anderson, from the PSU Anthropology Department. A Trimble data dictionary was created specifically for the project using the TerraSync software, with fields customized for Sauvie Island geomorphological features, cultural resources, and regional geography. GPS points and survey lines were backed up via a Garmin 62st handheld unit, to provide redundancy in case of equipment failure. During survey and recording, no subsurface testing occurred, no samples were collected from sites, and surface artifacts were only moved temporarily, for photography. For previously recorded sites, I explicitly considered previous descriptions of assemblages and compared those with new observations, but beyond that, the recording process was identical to newly identified sites.

When a site was identified, I established a site polygon boundary and datum point. All artifacts, features, or disturbances were marked using flags or flagging tape, to assist in the establishment of this boundary, which was set at least $30 \mathrm{~m}$ beyond the final extent of the assemblage. Points, lines, and polygons were recorded, as applicable, for any photographs taken, for diagnostic artifacts, for concentrations, for features, or for modern cultural disturbances. Additional GPS data included geotagged photography, for 
diagnostic artifacts, concentrations, features, and general overview. All photographs were logged in the field and converted to a digital photo log upon completion of fieldwork.

There were three aspects to my determination of site area. For each site, an exact GIS polygon was taken, with area measured within. However, in post-field analysis, the impacts of incoming tides (covering low-lying portions of the site prior to measurement) and the geographic layout of sites (non-linear eroding banks, other obstacles) were considered as limiters on the precision of Trimble measurements, particularly when collected areas for previously recorded sites were compared to initial data in SHPO records. To address this discrepancy, the GIS polygons were used as a template to measure the maximum length and width of the site, using tools in ArcGIS, measurements which were then multiplied to form adjusted rectangles, the areas of which were reported as the final areas of the sites. There were two exceptions to this, where polygon data was not collected due to equipment malfunctions, at sites PJD001 and PJD006. To estimate site area at these sites, a combination of collected points and measurement tools in ArcGIS were used to produce a rough approximation of site area. Additionally, for sites such as 35CO66 and 35MU242, where multiple distinct portions of the site exist, both within and beyond the study area, applicable portions that were surveyed were combined to form a total site area.

Diagnostic artifacts included temporally identifiable projectile points or other lithic tools, historic-era glass or ceramic with maker's marks, or any other historic item with identifiable logos or designs. These were recorded as GPS points, photographed with scale, and measured, with details such as material type noted in the field, while 
maker's marks were identified after leaving the field. Non-diagnostic artifacts (e.g., lithic debitage, fire-cracked rock, groundstone, or fragments of metal, glass, or ceramic lacking any property signifying age or cultural affiliation) were combined by category and not individually photographed or tagged via GPS.

The Oregon SHPO site form requires estimated counts of artifacts, which was done as per the following. Fire-cracked rock was always found in large numbers and as such, count was broadly estimated through a brief visual survey. Lithics, including debitage and formed objects, including groundstone, were generally rare and as such, each item was counted. Material, linear dimensions, and other observations, such as flake or netweight form (perforated, notched), were also recorded for these artifacts. Always found in large numbers, historic-era glass and ceramics were estimated by minimum vessel count, drawn from the number of unique pieces found at each site, such as bases, handles, or diagnostic markings. In the case of non-diagnostic glass, a scatter of a singular color of glass within roughly a meter diameter was assumed to originate from a single vessel, providing that distinctive vessel traits, such as base fragments, were not duplicated in the area. Scatters of ceramic fragments were estimated in the same manner, with attention paid to varying print designs on the fragments. For both glass and ceramic, color was noted, as were distinctive designs or patterns, as well as type of ceramic, such as earthenware or stoneware. Most metal items were fragmentary and corroded, often unidentifiable, with many pieces, and counts were estimated in a brief visual overview similar to that of fire-cracked rock, although when clearly identifiable items were found, such as nails, they were counted individually, due to their small numbers. 
Per the Oregon SHPO site form, I assigned artifacts to either precontact or historic components, with multicomponent sites having both present. However, I recognize that these terms are imperfect because they neither correctly indicate temporality or ethnicity in regard to cultural remains. Indigenous peoples used fire-cracked rock, lithic and ground stone tools, and more, long before and after Euro-American contact. Also, Indigenous peoples utilized items of Euro-American manufacture, such as ceramics, glass, and metal. As such, both temporality and ethnicity of cultural resources are not so easily decided.

The condition of a site was also carefully recorded, with special attention paid to key risk factors outlined prior to survey. As described in detail below, geomorphological aspects recorded included eroding bank overviews, both of exposed and undercut bank, as well as associated elements such as deadfall, angle, beach termination, runoff, and more. Precise GPS data were not typically taken for each of these aspects of the site, although I photographed and geotagged such conditions. Modern cultural disturbances, such as irrigation features, levees, looting piles, and cattle trampling were also recorded, with GPS data, measurements, and function often collected, due to the distinct nature of these disturbances. Other aspects relating to risk were also recorded, such as the presence of riprapping on the bank opposite of where I was surveying. I also spent time at each site documenting the plants present and the extent to which vegetation covered the areas, taking photographs and attempting to identify plants by using taxonomic guides. 
Developing a Prioritization Assessment

To guide future management and preservation, I developed an assessment process for each site surveyed and recorded in the study area (Appendix D). This process guided data collection in the field, where observations of site damage, assemblage type, modern disturbance, and more were recorded for use in the assessment. The process then directed how those observations would be quantified to produce a priority preservation score. To produce this score, my assessment used the sum of scores, determined for the archaeological and tribal values of cultural resources, as well as for the risk factors associated with those sites. I developed the assessment process for my project based on formats used in several case studies, including a vulnerability assessment developed by Shelby Anderson (Portland State University, Appendix E). Scores were summed for each category and then added together to form the final prioritization scores, which were divided into a 5-part prioritization scale ranging from "Very Low" to "Very High".

\section{$\underline{\text { Archaeological Value }}$}

This includes six values or variables based in large part on the objective presence or absence of observable characteristics noted during site recording. These variables included dateable features, diagnostic artifacts, rare characteristics, deposition, multicomponent site assemblage, and proximity to ethnographically documented Indigenous places (Table 3.1). In total, these variables summed to a maximum possible score of "9" with several variables weighted higher to reflect their greater contribution to the understanding of a site, such as whether it could be dated to a time period, or the degree to which the nature or extent of use at a site could be determined. 
Table 3.1. Scoring process for archaeological value.

\begin{tabular}{|c|c|}
\hline Archaeological Variable/Value & Scoring \\
\hline $\begin{array}{l}\text { Dateable Features and Materials } \\
\text { (Hearth/FCR/Charcoal): }\end{array}$ & $\ldots$ Yes $(2), \ldots$ No $(0)$ \\
\hline $\begin{array}{l}\text { Diagnostic Artifacts (Makers Marks/Projectile } \\
\text { Points): }\end{array}$ & $\ldots$ Yes $(2), \ldots$ No $(0)$ \\
\hline $\begin{array}{l}\text { Deposition (presence of in situ cultural deposits in } \\
\text { bank): }\end{array}$ & $\ldots$ Yes $(2), \ldots$ No $(0)$ \\
\hline $\begin{array}{l}\text { Rare Characteristics } \\
\text { (non-ubiquitous in archaeological record): }\end{array}$ & $\ldots$ Yes $(1), \ldots$ No $(0)$ \\
\hline $\begin{array}{l}\text { Multicomponent Site } \\
\text { (Multiple Cultural Phases): }\end{array}$ & $\ldots$ Yes $(1), \ldots$ No $(0)$ \\
\hline $\begin{array}{l}\text { Proximity to Ethnographically Documented } \\
\text { Indigenous Place(s): }\end{array}$ & $\ldots$ Yes $(1), \ldots$ No $(0)$ \\
\hline Total Archaeological Value: & \\
\hline
\end{tabular}

Dateable features included hearths or charcoal deposits observed in the bank, or on tidal flats, while diagnostic artifacts included historic glass with maker's marks or projectile points established in regional chronologies. In this system, aspects of the assemblage could be counted in more than one variable. For example, the presence of diagnostic artifacts would be scored " 2 " for diagnostic and if those artifacts were found in situ in the bank, the site would also be scored " 2 " for deposition, for a sum total of " 4 ". On the other hand, in situ features that included debitage or fire cracked rock (nondiagnostic), would receive a score of " 2 " for deposition, but a score of " 0 " for diagnostic artifacts. Rare characteristics were traits of site assemblages that were unique or uncommon in the Sauvie Island or broader regional archaeological record, contributing new understanding to cultural behavior. For the purposes of my study area, these 
included sites with hearth features, for example. For the multicomponent variable, if only artifacts linked to Indigenous occupation (e.g., FCR, lithics, etc.) or Euro-American manufacture (historic ceramics, glass, metal) were observed, the site was considered single component; if both lithics and Euro-American made materials were present, the site was considered multicomponent. As noted previously, because Indigenous peoples continued to utilize Sauvie Island through the $19^{\text {th }}$ century and relied on tools and materials of Euro-American manufacture, the presence of "historic" artifacts could represent either Indigenous or Euro-American occupation.

A final variable of archaeological value was the proximity of sites to ethnographically documented Indigenous places. This variable was included based on discussions with the Grand Ronde; ethnographic places were limited to a GIS database of villages provided by the THPO staff. This database had been drawn from ethnographic source material and run through an internal tribal process to define precise locations on a map, in the form of GIS polygons. I utilized thesis data, forming $1 \mathrm{~km}$ buffer zones around the datums for each of my sites, and then identifying which ethnographically recorded villages fell within that buffer zone. Sites with villages within their buffer zones received a " 1 " score, while sites with no villages inside their buffer zones received a "0". The use of a buffer was designed to reflect the multiple means of travel across the landscape, as well as the zone of use that exists around a site.

\section{$\underline{\text { Tribal Value }}$}

Over the course of seven intensive, multi-hour Zoom meetings, I presented each resource identified during my project to THPO staff members, with in-depth 
examinations of GIS data, photographs, site descriptions, artifact assemblages, features, physical characteristics, means of access, and any other pertinent observations for each site. THPO staff members were then asked to define how they valued cultural resources, what types of resources held greater value and what characteristics of said resources helped to establish their value. Then, using an iterative process, we reviewed each site in detail, initially establishing values based on a five site, randomly generated sample, which I then applied to all 18 sites. I returned to THPO staff members with these values for each site, at which point staff members reviewed my process, offered comment, and edited as needed, to ensure that tribal values were accurately defined and then applied to each site. This process produced 6 values or variables, which included proximity to tribally known location, survivability, reconnectivity, dateable features, rare characteristics, and deposition (Table 3.2). In total, these variables summed to a maximum possible score of "9". Although there was some overlap between archaeological and tribal variables, namely in regard to physical archaeology, weighting of key values shifted to variables unique to tribal interests. These variables reflected a tribal focus on the intangible characteristics of sites, and scaling was added to further clarify the degree to which these characteristics were present at a site. 
Table 3.2. Scoring process for tribal value.

\begin{tabular}{|c|c|}
\hline Tribal Variable/Value & Scoring \\
\hline $\begin{array}{l}\text { Proximity to Tribally Known Location }(>1.5 \mathrm{~km}= \\
0,<1.5 \mathrm{~km}=1,<0.75 \mathrm{~km}=2) \text { : }\end{array}$ & $\ldots$ Yes $(1,2), \ldots$ No $(0)$ \\
\hline Survivability (prevent or allow loss): & _ Yes $(1,2), \ldots$ No $(0)$ \\
\hline $\begin{array}{l}\text { Reconnectivity (tribe retains ability to engage with } \\
\text { site): }\end{array}$ & $\ldots$ Yes $(1,2), \ldots$ No $(0)$ \\
\hline $\begin{array}{l}\text { Dateable Features and Materials (potential for } \\
\text { Hearth/FCR/Charcoal): }\end{array}$ & $\ldots$ Yes $(1), \ldots$ No $(0)$ \\
\hline $\begin{array}{l}\text { Rare Characteristics } \\
\text { (non-ubiquitous in tribal record): }\end{array}$ & $\ldots$ Yes $(1), \ldots$ No $(0)$ \\
\hline $\begin{array}{l}\text { Deposition (potential for in situ cultural deposits } \\
\text { in bank): }\end{array}$ & $\ldots$ Yes $(1), \ldots$ No $(0)$ \\
\hline Total Tribal Value: ___ & \\
\hline
\end{tabular}

In similar fashion to the archaeological value score, the presence or absence of dateable features, rare characteristics, and in situ cultural deposition was factored into the overall tribal value, although these variables were weighted lower than the other three variables, proximity, survivability, and reconnectivity, all three of which were determined, through input from tribal staff, to better reflect tribal value than the simple presence or absence of physical archaeology alone. Additionally, the presence or absence of dateable features and cultural deposits was altered in tribal value scoring, to reflect not only objective observations of these site characteristics, as found in the archaeological values, but also the potential for these characteristics to exist at a site, to be identified in future investigations or exposed due to ongoing erosional processes. While archaeological value focuses on what is or is not present at the site during survey, the 
tribal value recognizes that a site's potential may be just as important as the physical archaeology observed during a single survey, particularly in consideration of sites which are in settings that are experiencing active erosion.

Geographic proximity to ethnographically recorded villages, also used in the archaeological value score, is present in tribal value as well, but has been modified and weighted to reflect the greater priority the tribes place on it. This variable used the same set of GIS data provided by the tribe, with several key expansions. Two buffer zones were established for each site, set at $750 \mathrm{~m}$ and $1.5 \mathrm{~km}$, with a corresponding higher score ("2", within $750 \mathrm{~m}$ ) and lower score ("1", between 750 and $1500 \mathrm{~m}$ ). A score of "0" was assigned for sites outside of the $1.5 \mathrm{~km}$ buffer. This served to refine the relationships between sites and villages along the channel, given how many villages are in the Sauvie Island area.

The two most important variables to the Grand Ronde cultural resource staff were survivability and reconnectivity. For these values, tribal input was particularly important, as the process is much more subjective. Survivability refers to an important part of how the Grand Ronde view site preservation, highlighting a distinction between resources lost to natural processes and those lost to purely anthropogenic processes. Put succinctly, the tribe does not wish to prevent the loss of all sites and in some cases, they view the loss of a site as part of the natural process. Survivability considers two interconnected aspects, namely, what is the nature of the impact(s) putting the site at risk and to what degree does that site exist in tribal memory. In regard to impacts, even anthropogenically exacerbated erosion only builds on a process that would occur naturally, while a site being actively 
disturbed by cattle trampling or recreational access would be at risk from forces that are entirely modern and anthropogenic in nature. The latter type of impact is an unnatural risk factor and one that could be mitigated to tangible effect at the site, whereas erosion could only be limited at best, and potentially at great sacrifice to the site from the very methods needed to stave off such erosion. In relation to the second aspect of survivability, if a site does not exist in tribal memory, the interest in halting its loss is lessened. An example of this might be the contrast between two historic sites. A large, early historic-era commercial site with a well-documented narrative could be connected to tribal members working in a post-contact world, while a small, isolated, late historicera private dock of unknown origin would be nearly impossible to connect to activities of tribal members in the historic-era. Put broadly, the greater the purely anthropogenic impact on the site, and the greater the degree to which the site could exist in tribal memory, the higher the survivability score.

Reconnectivity refers to the degree to which a site retains the ability of the tribe to engage through a site's broader connection to the cultural landscape, in the form of other archaeological or ethnographic places or direct affiliation with a cultural resource, story, or activity, through oral histories or assemblage characteristics. By retaining such characteristics, tribal members can actively reengage with a site and the broader landscape. Reconnectivity can be expressed in a variety of ways. These may include the physical space of the site, where a large site area or location on public lands might facilitate visitation by tribal members. Reconnectivity might also include the context of the site and its connection to other known cultural properties or events, as well as the 
value it might have for purposes of tribal education programs on cultural heritage. Sites do not have to be fully intact to retain reconnectivity, nor must they have a readily apparent Indigenous component to the cultural assemblage. In some cases, the destruction of a site's physical assemblage may increase its tribal value, if that destruction represents lessons learned, if it offers a point of reflection for tribal members. Reconnectivity helps to express the evolving, fluid nature of engagement with a site. Put broadly, the more accessible a site is to tribal members, the more applicable it is to tribal education, and the more clearly the site can be associated with an event or activity, the greater the reconnectivity value. As with survivability, the scalable nature of the weighted score is designed to address these nuances.

\section{$\underline{\text { Risk Factors }}$}

The 15 variables in this part of the prioritization scheme refer to characteristics that increase the risk of loss at the site and include estimated damage, bank angle, disturbance, vegetation cover, undercutting, sloughing, inside curve, rip rap, cultural materials, sheer beach, rodent activity, cattle activity, looting, deadfall, and runoff (Table 3.3). In total, these variables summed to a maximum possible score of " 20 ". The majority of the variables were not weighted, but simply scored by presence or absence, as observed during site recording. Two exceptions, estimated damage and bank angle, were made for variables that require a scaled gradient to accurately reflect the nuance of the variable. Estimated damage was given a "1-to-4" scale based on degree of damage, while bank angle was given a "0-to-4" scale, with the score increasing as the bank angle increased. Variables included a number of geomorphological observations, as well as the 
presence of ongoing anthropogenic disturbance from forces beyond water driven erosion, such as cattle activity, development, or other modern cultural activity.

Table 3.3. Scoring process for risk factors.

\begin{tabular}{|c|c|}
\hline Risk Factor & Scoring \\
\hline $\begin{array}{l}\text { Estimated \% Damage (Geomorphological) }(>20 \% \text {, } \\
>40 \%,>60 \%,>80 \%) \text { : }\end{array}$ & $\ldots$ Yes $(1,2,3,4), \ldots$ No $(0)$ \\
\hline Bank Angle $\left(>50^{\circ},>65^{\circ},>80^{\circ}\right)$ : & $\ldots$ Yes $(1,2,3), \ldots$ No $(0)$ \\
\hline Disturbance (Modern Cultural Damage): & $\ldots$ Yes $(1), \ldots$ No $(0)$ \\
\hline Lacks Vegetation Cover (on beach): & $\ldots$ Yes $(1), \ldots$ No $(0)$ \\
\hline Bank Undercutting: & $\ldots$ Yes $(1), \ldots$ No $(0)$ \\
\hline Sloughing/Slumping: & $\ldots$ Yes $(1), \ldots$ No $(0)$ \\
\hline Inside Curve (of Channel): & $\ldots$ Yes $(1), \ldots$ No $(0)$ \\
\hline Rip Rap on Opposite Shore: & $\ldots$ Yes $(1), \ldots$ No $(0)$ \\
\hline Exposed Cultural Materials (in bank): & $\ldots$ Yes $(1), \ldots$ No $(0)$ \\
\hline Sheer Beach Edge: & _ Yes $(1), \ldots$ No $(0)$ \\
\hline Rodent Activity: & $\ldots$ Yes $(1), \ldots$ No $(0)$ \\
\hline Cattle Activity: & _ Yes $(1), \ldots$ No $(0)$ \\
\hline Looting/Vandalism: & _ Yes $(1), \ldots$ No $(0)$ \\
\hline Deadfall/Downed Trees: & $\ldots$ Yes $(1), \ldots$ No $(0)$ \\
\hline Runoff Channeling: & Y Yes $(1), \ldots$ No $(0)$ \\
\hline Total Risk Factor Score: & \\
\hline
\end{tabular}

Disturbance refers to any direct damage or impact from cultural activity. This

excludes anthropogenically exacerbated impacts such as general streambank erosion and instead centers on damage from recreational use, human pedestrian traffic, and trash dumping. Estimated damage is a subjective estimate of the site condition, based on previous site records, and the existing condition of the assemblage and feature(s) if applicable, graded on a scale. All sites along the Multnomah Channel shore have 
sustained an estimated degree of damage above $20 \%$ and a scaled score reflects damage estimated between $20-40 \%$ (>20\%), 40-60\% (>40\%), 60-80\% (>60\%), and $80-100 \%$ (>80\%). The lack of vegetation cover refers only to the beach proper, and not the bank, with a score of " 1 " meaning vegetation is absent and therefore the beach is more subject to erosion. Undercutting is defined as the active creation of an overhang, where sediment below the top of the bank is being cut back by tidal forces or wave action. Undercutting often happens where trees are present, which helps stabilize the upper portion of the bank, but the lower bank is exposed without supporting vegetation. Slumping/Sloughing usually occurs on sheer banks with less tree cover, where wedges of soil slide down as bank integrity is compromised from top to bottom. These banks rarely have trees holding the topsoil together, hence the slumping/sloughing.

The presence of riprap on the shore opposite a site can accelerate erosion of the site by redirecting water across the channel with increased force and speed. Bank angle refers to the sheerness of the bank slope against the site. Excluding gradually sloping banks ( $<50$ degrees), bank slopes are scored on a scale, with vertical or near vertical banks having the highest risk factor, and while gradually sloped banks may have other risk factors present, the low angle can better preserve bank deposits and support plant communities. Cultural features/materials refer to the presence or absence of these in the bank wall, with exposure highlighting an active risk factor at the site. Cattle trampling, looting/vandalism, and rodent activity refer to the presence or absence of these activities, as indicated by cattle in the vicinity, open pasture, hoof marks, looter's piles, or visible burrows. Deadfall refers to trees that have eroded out of the bank above the site, pulling 
sediment with them and destabilizing the bank; the presence of deadfall indicates a particular kind of acceleration in the erosional process. Runoff channeling refers to grooves across either the beach or bank that indicate distinctive paths being carved by water running across the site.

\section{$\underline{\text { Summary of Assessment Process }}$}

Following site survey and recording, Butler and I shared results with the cultural resources staff of the Grand Ronde and considered various approaches to scoring site variables. I shared preliminary scoring with the tribe and then we met to consider, review, and rework the scoring results as needed. Scores for archaeological and tribal values, and risk factors were combined to create a prioritization score for each site surveyed. These finalized scores, developed through tribal input, were tallied, and summed into five priority divisions, ranging between "Very Low" and "Very High" (Table 3.4).

Table 3.4. Final outline of the preservation priority scoring.

\begin{tabular}{|c|c|}
\hline \multicolumn{2}{|c|}{ Preservation Priority Level } \\
\hline _ Very Low $(0-7)$ & Total Archaeological Value: \\
\hline _ Low (8-15) & Total Tribal Value: \\
\hline _ Medium (16-22) & Total Risk Factor Score: \\
\hline _ High (23-30) & Total Prioritization Score: \\
\hline _ Very High (31-38) & \\
\hline
\end{tabular}




\section{Chapter 4. Results}

My thesis research sought to produce a prioritization assessment of cultural resources along the western shoreline of Sauvie Island, which explicitly incorporated tribal perspectives in that assessment. As an initial effort toward including tribal views, my project worked with THPO staff from the Confederated Tribes of the Grand Ronde. This research process produced two classes of results, the observations of cultural resources and identified risk factors during fieldwork, and the results of the prioritization scoring process. Presented below is an overview of the results of the survey and the resources located, followed by data on the archaeological remains observed during recording, as well as on-the-ground examples of the risk factors identified prior to survey. Finally, the results of the prioritization assessment are presented in depth. Scoring results are subject to simple statistical analysis, contrasting and uniform scores are described, and site examples are noted. Implications from the results are discussed in Chapter 5.

\section{Summary of Survey Results}

A total of 18 sites were recorded during the project, including eight previously recorded sites and ten newly identified ones (Figure 4.1; Table 4.1). Some sites are linked exclusively with Indigenous occupation (lithic debitage, FCR scatters), however, material culture produced by Euro-Americans (imported nails, ceramics, etc.) may reflect Indigenous or Euro-American use, given that Indigenous peoples continued to engage with Euro-American material culture after contact. Included below are brief overviews of the sites identified and general characteristics of the assemblages and features therein (Overviews in Appendix F; Site Condition in Appendix H). 


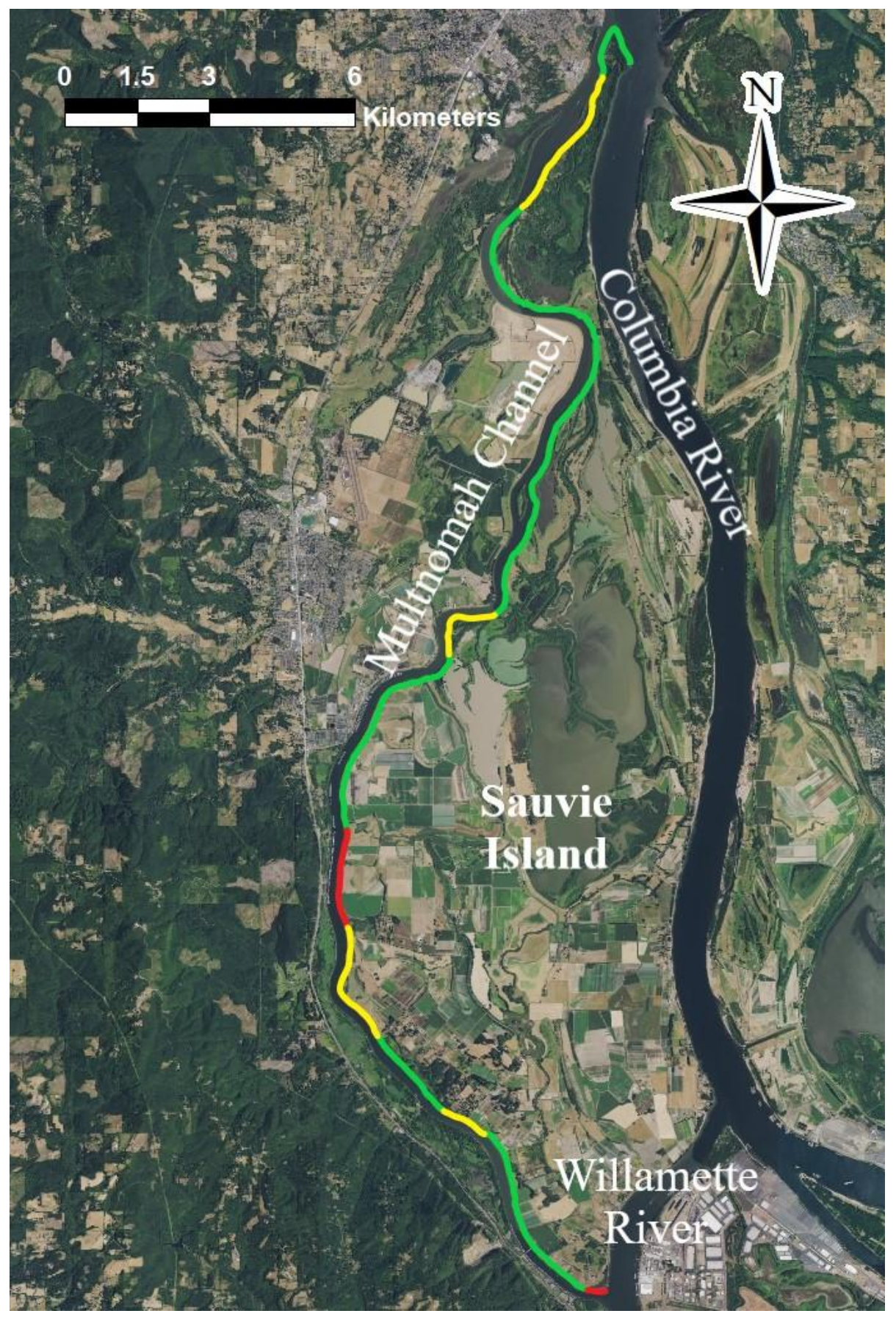

Figure 4.1. Map showing 18 sites visited and status of shoreline survey at the conclusion of fieldwork. Green represents shoreline fully surveyed; yellow is shoreline observed from water, red is excluded shoreline not surveyed. Previously identified sites indicated by Smithsonian trinomials, newly identified sites assigned temporary field numbers with the prefix "PJD". [NOTE: Site locations have been redacted at the request of our tribal partners and to prevent site disturbance. Please refer to the Oregon State Historic Preservation Office records for unredacted version.] 
I was able to fully access an estimated $20 \mathrm{~km}$ of the $34 \mathrm{~km}$ western shoreline, with this survey segment shown in green (Figure 4.1). This meant conducting pedestrian survey on the shoreline and observing the tidal flats and bank. I was able to examine an estimated $10 \mathrm{~km}$ of the $34 \mathrm{~km}$ western shoreline from the water only, a survey segment shown in yellow (Figure 4.1). In these areas, I was unable to conduct pedestrian survey on the shoreline, because the beach was absent owing to steep shoreline topography, or due to extensive deadfall, but I was able to inspect the bank from the water when vegetation was absent. An estimated $4 \mathrm{~km}$ of shoreline had to be entirely excluded, as shown in red (Figure 4.1), due to private landowners not offering permission to access the beach via their land.

For three sites, a full recording was not possible. At PJD002, recording was limited due to high water levels. Although all other sites recorded were visited close enough to the low-tide mark to be sufficiently documented, PJD002 has cultural deposits that are only visible during the yearly low-water mark, typically between August and October. This necessitates a future return and is discussed in my conclusions. A piling field exists at the southern portion of 35MU242, which was inaccessible due to numerous safety issues, including underwater obstacles and traffic from large commercial vessels. Thus, my records at 35MU242 focused on the northern portion of the site, a dam and riprap spoils pile. Similarly, 35CO66 had piling fields beyond the study area that were not surveyed. Based on previous records of the sites and observations during survey, it is unlikely that additional field survey of $35 \mathrm{MU} 242$ or $35 \mathrm{CO} 66$ would change the assessment, since they consist entirely of large commercial features that have seen 
relatively little degradation. Unrelated to tidal issues, two sites, PJD001 and PJD005, were not given proper GPS point and polygon boundaries due to technical issues with the Trimble device. Backup data were collected using the Garmin, but a site polygon had to be artificially created after the fact, and the total area of the sites had to be estimated during post-field processing. The recording of the assemblage or the taking of geotagged photography for these sites was not impacted by these issues, nor was the prioritization assessment impacted in any way. All other sites that I assessed were recorded in their entirety.

Overview of Cultural Resources

The archaeological record that I documented for the western shoreline was extensive and diverse, with significant expansions to the current knowledge of Sauvie Island cultural resources. In total, across 18 sites, nearly 2,000 artifacts were observed, ten features were identified across seven sites, in situ bank deposits were present at seven sites, seven sites included diagnostic artifacts, and dateable features were present at four sites (Table 4.1). Appendix F provides an overview of each site documented. Broadly, across the 18 sites, fire-cracked rock, assumed to be indicative of Indigenous use, was a common and defining part of the assemblage, appearing at 13 sites, with previous reports indicating its presence at an additional two sites, although this was not observed during survey. Items of Euro-American manufacturing origin were typically characterized by glass fragments, found at four sites, and dock/piling remains, in the form of surface features or in situ deposits, found at five sites, marked by milled lumber and iron nails, among other items. Of the 18 sites surveyed, the majority of previously recorded sites, 
five of the eight, were located along the southern half of the western shoreline while the majority of the newly identified sites, eight of ten, were located along the northern half of the western shoreline. The majority of newly identified sites were located within the ODFW Sauvie Island Wildlife Refuge, which had been largely unsurveyed before my project. 
Table 4.1. Overview of archaeological sites recorded in project area. Eight sites with Smithsonian trinomials were previously recorded, those with the PJD prefix were newly recorded during this project. Site areas with an asterisk represent the area of said site that fell within the project area and/or could be recorded due to survey limitations.

\begin{tabular}{|c|c|c|c|c|c|c|c|}
\hline Site Number & $\begin{array}{c}\begin{array}{c}\text { Site Area } \\
\left(\mathbf{m}^{2}\right)\end{array} \\
\end{array}$ & $\begin{array}{c}\text { Artifact Count } \\
\text { (est.) }\end{array}$ & $\begin{array}{c}\text { Diagnostic } \\
\text { Artifacts } \\
\end{array}$ & $\begin{array}{c}\text { FCR } \\
\text { Present } \\
\end{array}$ & $\begin{array}{c}\text { Euro- } \\
\text { American } \\
\text { Artifacts } \\
\end{array}$ & $\begin{array}{c}\text { In Situ Bank } \\
\text { Deposits } \\
\text { Present } \\
\end{array}$ & $\begin{array}{c}\text { Dateable } \\
\text { Features } \\
\text { Present } \\
\end{array}$ \\
\hline $35 \mathrm{CO} 66$ & $16808^{*}$ & 125 Artifacts & Yes & No & Yes & No & No \\
\hline $35 \mathrm{CO} 75$ & 1302 & 40 Artifacts & Yes & No & Yes & No & No \\
\hline $35 \mathrm{CO} 76$ & 162 & 125 Artifacts & No & Yes & No & Yes & Yes \\
\hline 35MU242 & $171^{*}$ & 0 Artifacts & No & No & Yes & No & No \\
\hline 35MU4 & 18432 & 10 Artifacts & No & No & Yes & Yes & Yes \\
\hline 35MU61 & 210 & 50 Artifacts & No & Yes & No & No & No \\
\hline 35MU62 & 12375 & 50 Artifacts & Yes & Yes & Yes & Yes & Yes \\
\hline 35MU63 & $\begin{array}{c}3180 \\
\sim 5500\end{array}$ & 125 Artifacts & Yes & Yes & Yes & Yes & No \\
\hline PJD001 & (est.) & 150 Artifacts & No & Yes & No & No & No \\
\hline PJD002 & 600 & 75 Artifacts & Yes & Yes & Yes & Yes & Yes \\
\hline PJD003 & 224 & 50 Artifacts & No & Yes & No & No & No \\
\hline PJD004 & 384 & 100 Artifacts & No & Yes & No & No & No \\
\hline PJD005 & 1395 & 150 Artifacts & No & Yes & No & No & No \\
\hline PJD006 & $\sim 200$ (est.) & 75 Artifacts & No & Yes & No & No & No \\
\hline PJD007 & 576 & 100 Artifacts & No & Yes & No & No & No \\
\hline PJD008 & 342 & 30 Artifacts & Yes & No & Yes & Yes & No \\
\hline PJD009 & 656 & 175 Artifacts & No & Yes & No & No & No \\
\hline PJD010 & 4130 & 275 Artifacts & Yes & Yes & Yes & Yes & No \\
\hline
\end{tabular}


Two newly recorded (PJD002, PJD010) and two previously recorded (35MU62, 35MU63) sites were multicomponent, with artifacts linked to Indigenous use and to Euro-American manufacturing (Table 4.1). The site forms for two previously recorded sites (35MU61, 35CO75) noted the presence of both lithics and historic-era remains, but in my site visits, in the case of 35MU61, the historic-era remains were not relocated while in the case of $35 \mathrm{CO} 75$, the lithic artifacts were not relocated. As my results in this regard draw on what was observed during my recording, 35MU61 and 35CO75 were not included in my count of multicomponent sites. Almost every site surveyed was either largely or entirely composed of a surface scatter. However, for eight sites, 35MU4, 35MU62, 35MU63, 35CO66, 35CO76, PJD002, PJD008, and PJD010, in addition to large scatters, sites also included features (in the bank or exposed on the beach) or remains of structures and pilings (Table 4.1). Only site 35MU242 lacked any artifact scatter, but did have a dam, riprap pile, and piling field, although all elements of the site were on or near the surface. During survey, minimal signs of artifact movement due to current or wave action were observed. Although wave action may cause artifacts along steeply terminating beaches to slip into deeper water, no signs of artifact movement along the channel, or redistribution, were observed, either in multiple site visits or in comparison to previous reports.

My project did not identify any of the culturally important plants, of interest to the Grand Ronde Tribe, either on the beach or on the immediately visible bank. The western shoreline of Sauvie Island is largely devoid of vegetation, with only sparse grass communities remaining in the survey corridor. Of the 18 sites surveyed, nine had no 
vegetation whatsoever on the beach proper, with the remaining nine sites having only sporadic, low-lying ground cover. Bank vegetation was also noted, largely a combination of the non-native blackberry (Rubus discolor), dogwood (Cornus sp.), and cottonwood (Populus trichocarpa). Unfortunately, none of the culturally important plants suggested by the Grand Ronde were observed, either on the beach or on the immediately visible bank. This was not only true during my October-November 2019 recording period, but also during my scouting period throughout the summer of 2019 and during the early spring of 2020, suggesting that even with seasonal changes, the western shoreline of Sauvie Island lacks culturally-important plants. As such, plant communities played no role in assessing values for sites, although their presence or absence played a role in the risk factor scoring.

Several sites surveyed showed excellent stratigraphy and may be useful for establishing a geologic chronology for the island and connecting its formation with broader regional events. At sites such as 35MU62, a reddish-brown layer was observed near the base of the exposed bank (Figure 4.2). As indicated by Bourdeau (2004), this layer may be connected to the Bonneville flood or caused by massive landslide events, upriver from Sauvie Island, at the Cascades on the Lower Columbia. Further investigation of this layer could help to anchor site assemblages temporally and dating of the hearth features identified during my project could clarify the history of human occupation on Sauvie Island in relation to these deposition events. The hearth feature at 35MU62 is above this reddish-brown layer, while the hearth feature at PJD002 may be 
below it, although future work is necessary to determine this, as discussed in my conclusions.

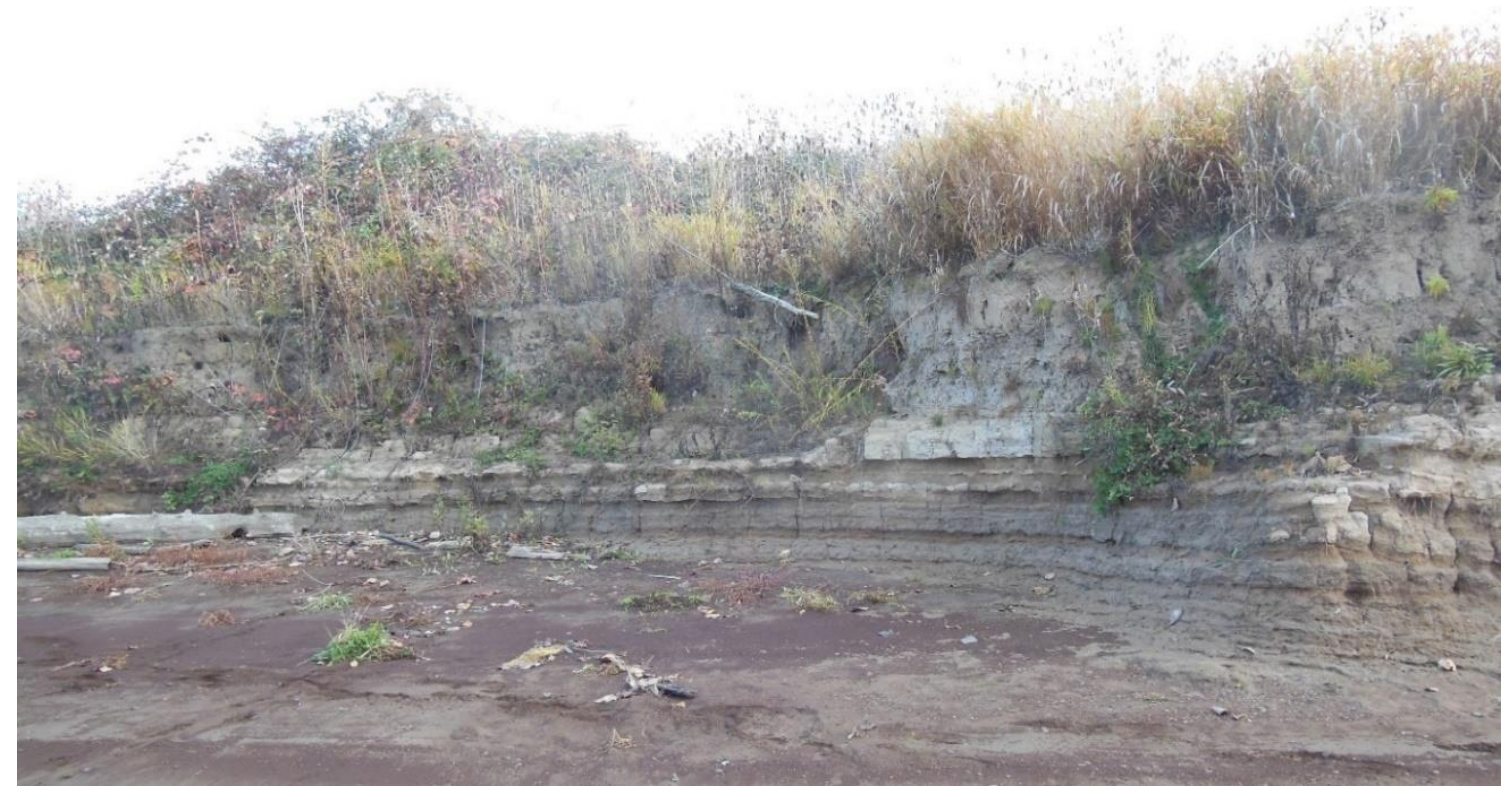

Figure 4.2. Exposed cut-bank at site 35MU62, where a reddish-brown layer at base of bank may indicate a geologically dateable flood deposit.

Several aspects of site assemblages recorded and rerecorded during this project contributed to the temporal sequencing of sites surveyed. It is recognized that there is not a distinct line between Indigenous activity on and Euro-American occupation of Sauvie Island. Not only did Indigenous activities like wapato gathering and processing likely occur into the post-contact period, but Indigenous peoples were employed by the HBC and other commercial enterprises and interacted with settlers in various ways, including through intermarriage. That being said, it is reasonable to assume that some artifacts represent Indigenous activity, such as fire-cracked rock or projectile points, or were part of activities taking place in the post-contact period, due to origins in Euro-American manufacturing. Some of these items can be useful temporal markers and include 
projectile points with established chronologies. The projectile point recorded at site PJD010 (Figure 4.3) has several characteristics (shape of barb and stem) which place it in Pettigrew's Type 9, within the Multnomah Phase, in the Sauvie Island sub-phase, dating to 1800 and $750 \mathrm{BP}$. Although only a single netweight example was found during the project (Figure 4.4), a preform that is not definitively diagnostic, its rough characteristics, including small, flaked notches, suggest chronological placement within the same phase.

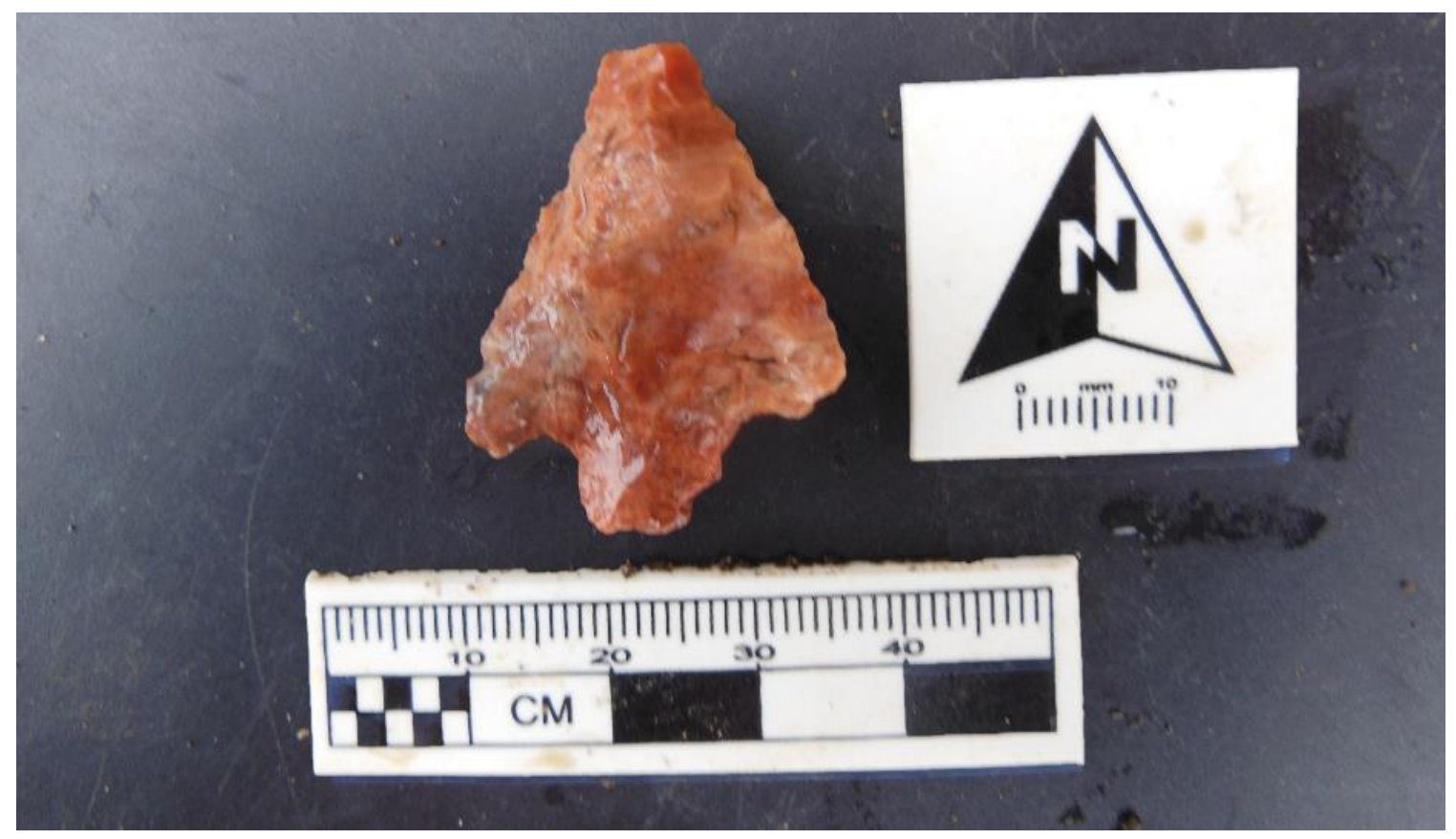

Figure 4.3. Red-white cryptocrystalline, corner notched (barbed shoulder), converging (non-divergent) stem with random flaking and tip missing, found at PJD010, likely dating to Pettigrew's Type 9, in the Multnomah Phase, between 1800 and 750 BP. 


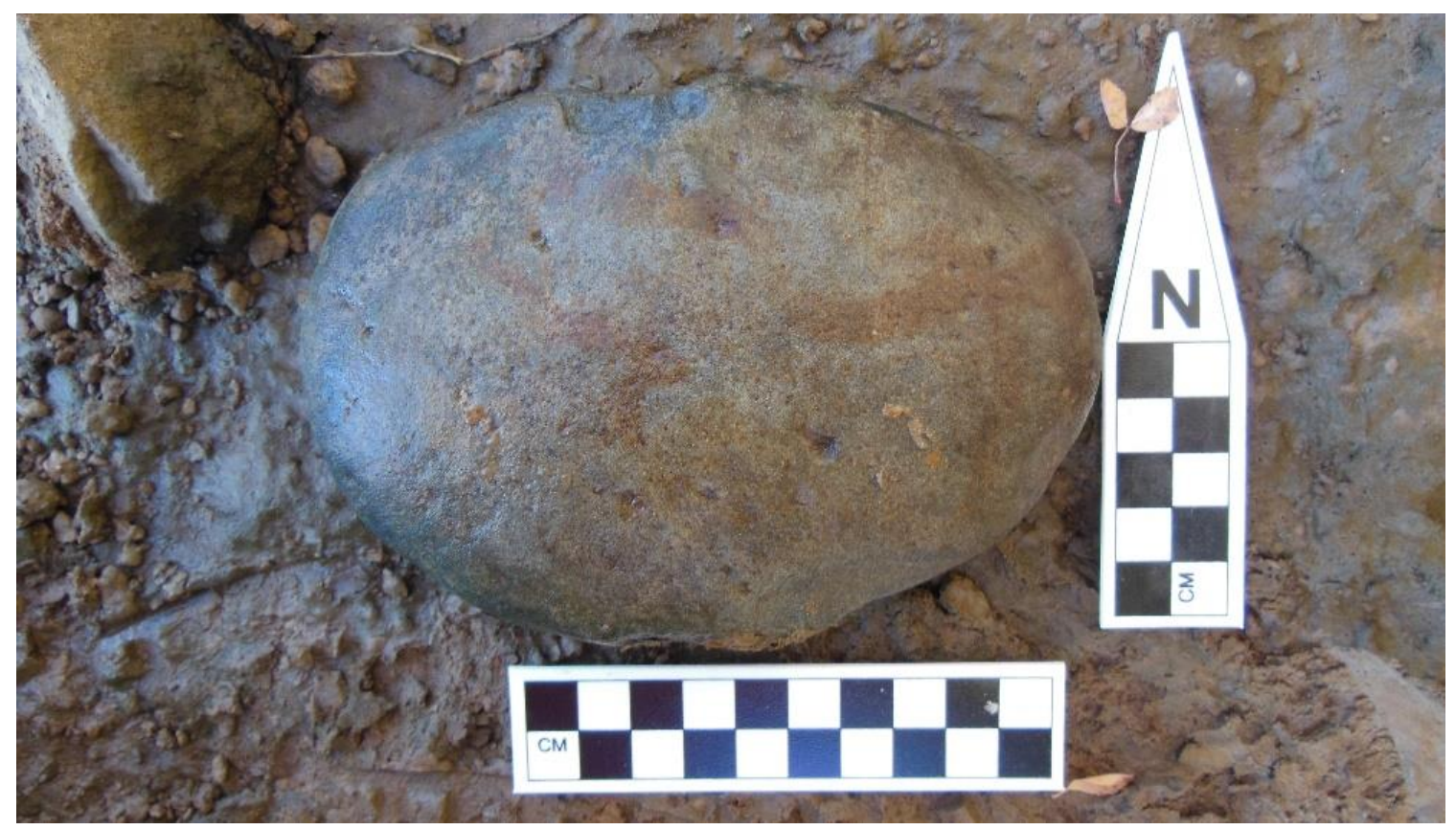

Figure 4.4. Single groundstone tool found at site PJD004, a rough, preform netweight.

Of Euro-American manufacture, the glass, ceramics, bricks, or cans with maker's marks, logos, or other identifiable design or label, such as those found at sites PJD002, 35MU62, and 35MU63, can also be useful temporal markers. At site PJD002, multiple examples of late- $19^{\text {th }}$ century ceramics were identified (Figure 4.5 and 4.6). Additionally, some features can be dated, either through radiocarbon dating of charcoal fragments, or through stratigraphic association with diagnostic artifacts, such as the features at 35MU63, which are part of a large trash midden deposit that includes diagnostic glass bottles with intact maker's marks. 


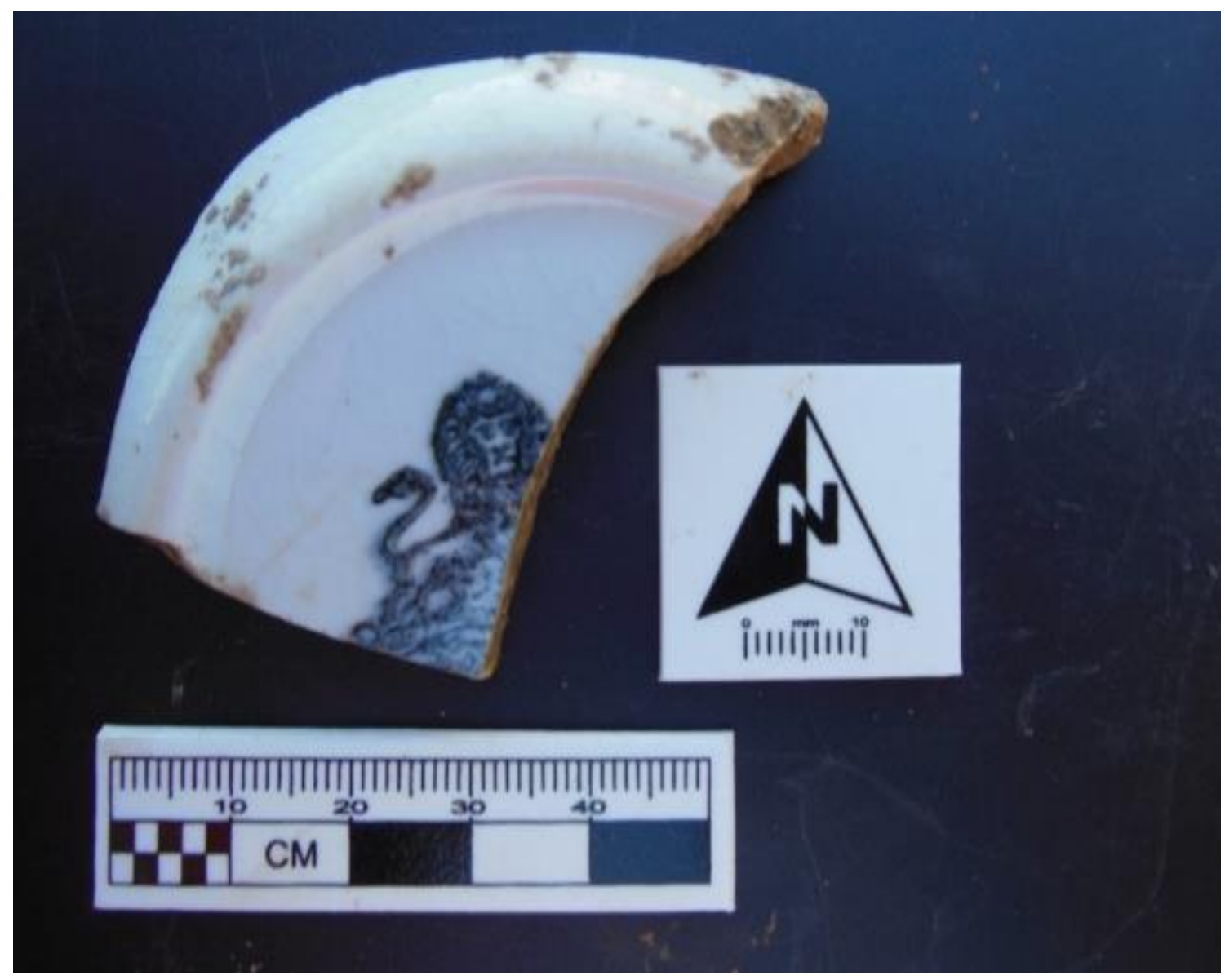

Figure 4.5. White ceramic transfer print fragment from PJD002, likely white graniteware. Use of British coat of arms and quality of print suggests an import, likely Henry Burgess, ca. 1864-1891 (Gibson 2011). 


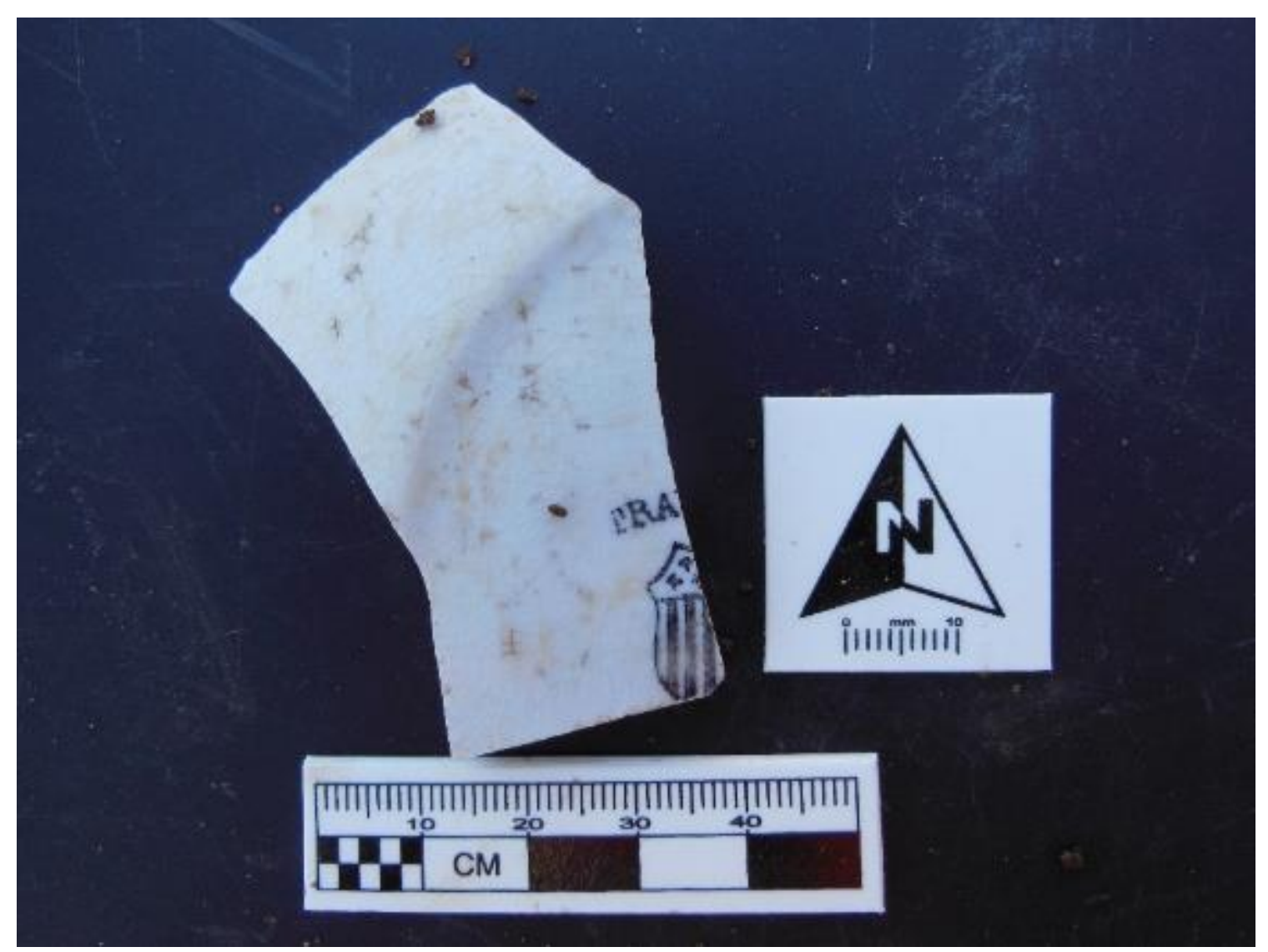

Figure 4.6. A white ceramic earthenware Spode transfer print base fragment found at PJD002, with a black shield maker's mark, likely Edward Clark \& Co. Burslem ceramic, ca. 1880-1887 (Gibson 2011).

Seven sites have in situ cultural deposits in the exposed bank (Table 4.1), four of these contained fire-cracked rock, charcoal concentrations, or both, suggesting they were once used as hearths linked to Indigenous occupation (e.g., Figure 4.7). All Indigenous features were composed of a combination of charcoal and fire-cracked rock; none were associated directly with additional artifacts, as had been reported in previous site recordings, where hearth features were reported to include items such as bone and lithic debitage. At three previously recorded sites, 35MU61, 35MU62, and 35CO75, Indigenous in situ bank deposits were not relocated, including one hearth at 35CO75, as 
well as potential hearth and/or organic features at 35MU61 and 35MU62, although in the case of the latter, one of the two previously noted features was relocated (Figure 4.7).

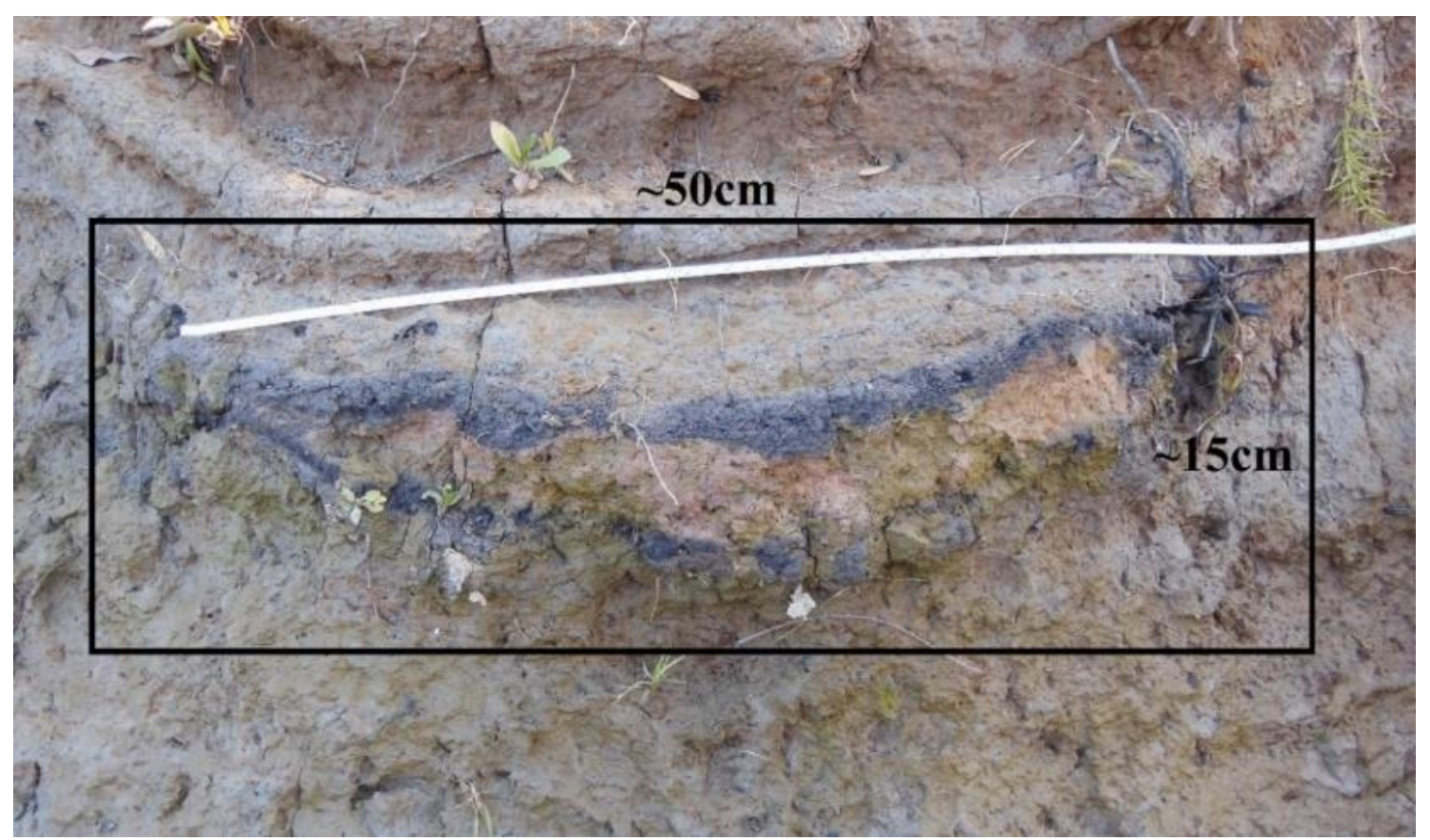

Figure 4.7. Exposed hearth feature eroding out of sheer bank at previously recorded $35 \mathrm{MU} 62$.

A total of six sites are notable for the Euro-American milled lumber constructions such as pilings, piers, and docks related to commercial and recreational boat traffic along the channel and included dock remains, arranged both as bank deposits and linear features across the beach, as well as a dam and a piling field with structural elements, and the remains of a lumber mill at the northern end of the island. Euro-American feature materials included wood, angular riprap, and some associated refuse, such as glass and nails. At the three previously recorded sites with such remains, little change was observed in comparison to descriptions from prior recording. 
Prioritization Scoring

Using data collected in the field and input provided by the Grand Ronde, I scored the 18 sites recorded as part of this project, producing an archaeological value, tribal value, and risk factor score for each, culminating in a prioritization preservation score. This provided an opportunity to assess a number of patterns that emerged during this process, including in the range and average of scores observed, in the characteristics of sites within each preservation priority category, through comparisons between values, and in the individual variables that played the biggest role in producing significant changes in scoring results. These findings are presented in the subsections below.

\section{Archaeological Value.}

Among the archaeological values (Table 4.2) for the 18 recorded sites, total scores fell into three primary groups, the extremely low $(0-1)$, the mid-range $(3-6)$, and the extremely high scores $(8-9)$. For all sites recorded, scores ranged between " 0 " and " 9 ", with an average score of “ 3 ”. For extremely low scoring sites $(0-1)$, nine in total, archaeological value, when present at all, was composed entirely of the most commonly present variable throughout all recorded sites, proximity to ethnographically documented villages (Figure 4.8). 13 of the 18 recorded sites, or $72 \%$, scored a " 1 " in this regard (Table 4.2). This reflects the dense concentration of villages in the Sauvie Island area, as described in previous sections, but also reflects that proximity did not correlate to the observed presence of key aspects of physical archaeology. In this regard, the lowest scoring sites for archaeological value, PJD006 and 35MU61, at "0", were defined by 
homogenous, non-diagnostic fire-cracked rock assemblages where no dateable features were present.

Among mid-range sites $(3-6)$, six in total, scores were bolstered by the next two most common variables, scored at "2" and "1" respectively, the presence of diagnostic artifacts, found at eight, or $44 \%$, of sites and the presence of in situ cultural deposits, found at seven, or 39\%, of sites (Table 4.2). This was due to the wide range of artifacts considered diagnostic, some of which are discussed above, and the combination of both Indigenous and historic-era structural features present along the Sauvie Island shoreline. Diagnostic artifacts tended to be durable, with examples observed during this project made of stone, glass, ceramic, or metal, while in situ cultural deposits included a wide variety of Indigenous features related to processing, as well as historic-era features related to Euro-American commercial, water management, or recreational activity. 
Table 4.2. Archaeological value scores for all surveyed sites

\begin{tabular}{|c|c|c|c|c|c|c|c|}
\hline & $\begin{array}{l}\text { Presence } \\
\quad \text { of } \\
\text { Dateable } \\
\text { Features }\end{array}$ & $\begin{array}{l}\text { Presence of } \\
\text { Diagnostic } \\
\text { Artifacts }\end{array}$ & $\begin{array}{c}\text { Proximity to } \\
\text { Ethnographically } \\
\text { Documented } \\
\text { Villages }\end{array}$ & $\begin{array}{c}\text { Rare } \\
\text { Characteristics }\end{array}$ & $\begin{array}{c}\text { Presence } \\
\text { of In Situ } \\
\text { Cultural } \\
\text { Deposits } \\
\text { in Bank }\end{array}$ & $\begin{array}{l}\text { Multicomponent } \\
\text { Site }\end{array}$ & $\begin{array}{l}\text { Arch } \\
\text { Value } \\
\text { Total } \\
\text { (max } \\
=9)\end{array}$ \\
\hline PJD001 & 0 & 0 & 1 & 0 & 0 & 0 & 1 \\
\hline PJD002 & 2 & 2 & 1 & 1 & 2 & 1 & 9 \\
\hline PJD003 & 0 & 0 & 1 & 0 & 0 & 0 & 1 \\
\hline PJD004 & 0 & 0 & 1 & 0 & 0 & 0 & 1 \\
\hline PJD005 & 0 & 0 & 1 & 0 & 0 & 0 & 1 \\
\hline PJD006 & 0 & 0 & 0 & 0 & 0 & 0 & 0 \\
\hline PJD007 & 0 & 0 & 1 & 0 & 0 & 0 & 1 \\
\hline PJD008 & 0 & 2 & 1 & 0 & 2 & 0 & 5 \\
\hline PJD009 & 0 & 0 & 1 & 0 & 0 & 0 & 1 \\
\hline PJD010 & 0 & 2 & 0 & 1 & 2 & 1 & 6 \\
\hline 35MU4 & 2 & 2 & 0 & 1 & 2 & 1 & 8 \\
\hline 35MU61 & 0 & 0 & 0 & 0 & 0 & 0 & 0 \\
\hline 35MU62 & 2 & 2 & 1 & 1 & 2 & 1 & 9 \\
\hline 35MU63 & 0 & 2 & 0 & 0 & 2 & 1 & 5 \\
\hline 35MU242 & 0 & 0 & 1 & 0 & 0 & 0 & 1 \\
\hline $35 \mathrm{CO} 66$ & 0 & 2 & 1 & 0 & 0 & 0 & 3 \\
\hline $35 \mathrm{CO} 75$ & 0 & 2 & 1 & 0 & 0 & 0 & 3 \\
\hline $35 \mathrm{CO} 76$ & 2 & 0 & 1 & 1 & 2 & 0 & 6 \\
\hline
\end{tabular}




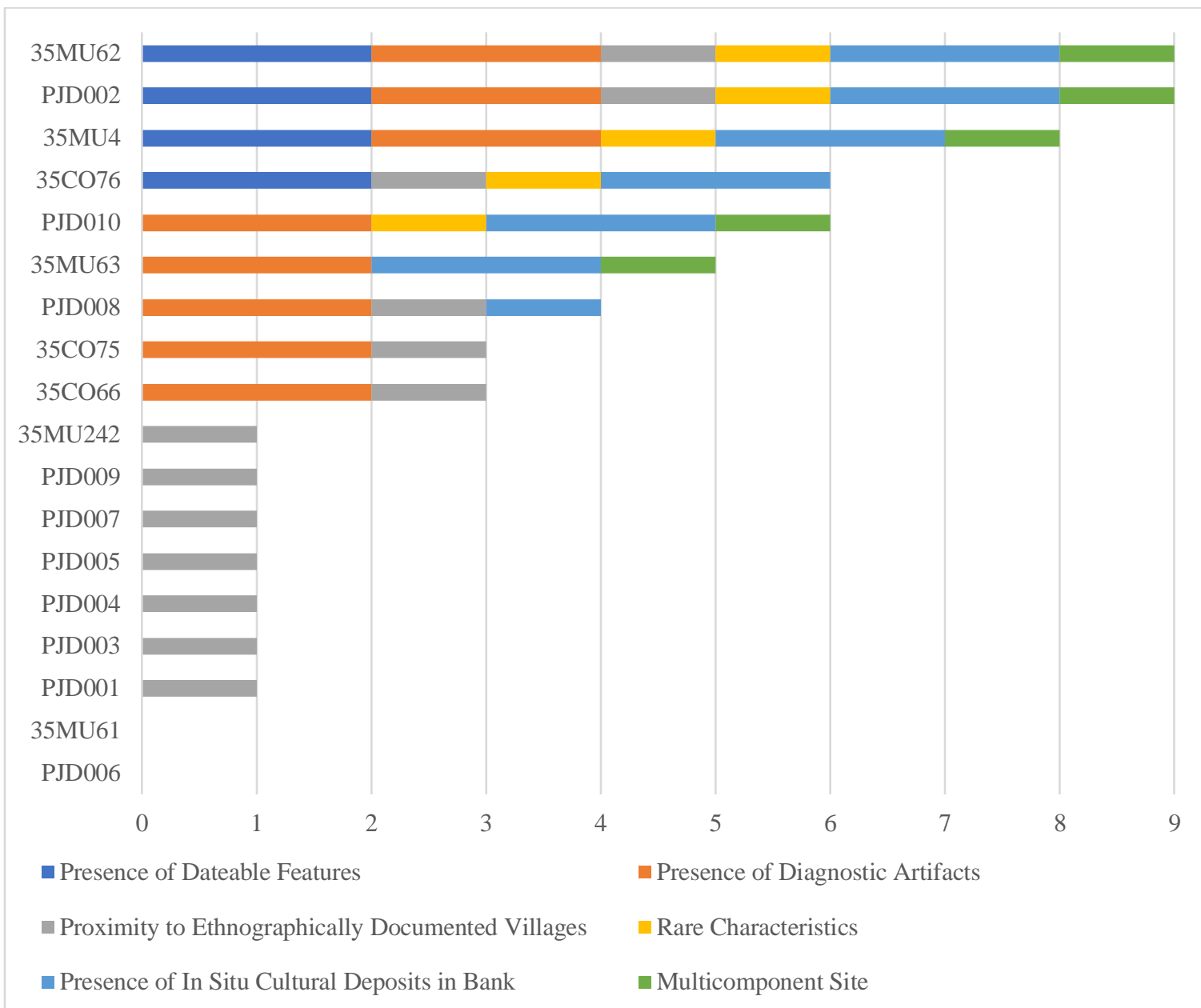

Figure 4.8. The distribution of archaeological value variables for each site, in ascending order of total archaeological value scores.

Among extremely high scoring sites $(8-9)$, numbering three in total, three variables, including dateable features, rare characteristics, and multicomponent assemblages, were present at all three sites, distinguishing these total scores from the low and mid-range groups (Figure 4.8). Of the elements of physical archaeology considered within archaeological value, scores for rare characteristics and multicomponent sites were the second least common value found at the sites recorded for this project. Of the 18 sites surveyed, only five, or $28 \%$, had what was deemed to be a rare characteristic(s) and/or multiple components (Table 4.2). At sites PJD002, PJD010, 35MU4, 35MU62, and 
35CO76, rare characteristics included dateable or unique features, with all but one of the sites also having an assemblage with both an Indigenous and Euro-American component. As intended, these categories recognized elements key to expanding archaeological knowledge of Sauvie Island. Scores for rare characteristics paralleled multicomponent scores, suggesting a link between rare features and sites with a more diverse assemblage. Also included in the high scoring group was the least commonly found variable, dateable features, present at only four of the 18 recorded sites, or 22\%, at PJD002, 35MU4, 35MU62, and 35CO76, with scarcity due to high vulnerability to erosion observed among cut-bank hearth features.

\section{Tribal Value}

For the 18 sites recorded during this project, tribal values (Table 4.3), while overlapping with archaeological values in some respects, largely centered on the intangible and potential characteristics of sites. Among the tribal values for all recorded sites, three scoring groups emerged, low $(1-3)$, mid-range $(4-7)$, and high $(8-9)$, although divisions between these groups were less distinct than with archaeological value. The low group, numbering five sites in total, was distinguished by heavily damaged sites with few values beyond proximity to ethnographic villages (Figure 4.9). As with archaeological value, the majority of sites recorded, 17 in total, or 94\%, scored for proximity and its common presence defines many of the sites with the lowest tribal value (Table 4.3). Notable among low scoring sites was limited reconnectivity scores and lack of survivability scores, paired with lack of potential, reflecting the degree of damage observed at the sites, three of which were previously recorded, providing comparative 
records from which to better assess damage. At sites such as 35CO75, catastrophic levels of damage stripped the site not only of physical archaeology, but of the intangible characteristics and potential defining higher tribal value scores. 
Table 4.3. Tribal value scores for all surveyed sites.

\begin{tabular}{|c|c|c|c|c|c|c|c|}
\hline & $\begin{array}{c}\text { Proximity to } \\
\text { Tribally } \\
\text { Known } \\
\text { Location } \\
\end{array}$ & $\begin{array}{l}\text { Potential } \\
\text { for } \\
\text { Dateable } \\
\text { Features } \\
\text { and } \\
\text { Materials }\end{array}$ & $\begin{array}{c}\text { Rare } \\
\text { Characteristics }\end{array}$ & $\begin{array}{l}\text { Potential for In } \\
\text { Situ Cultural } \\
\text { Deposits in } \\
\text { Bank } \\
\end{array}$ & Survivability & Reconnectivity & $\begin{array}{c}\text { Tribal } \\
\text { Value } \\
\text { Total } \\
\left(\begin{array}{c}\text { max }= \\
9)\end{array}\right.\end{array}$ \\
\hline PJD001 & 1 & 1 & 0 & 1 & 1 & 2 & 6 \\
\hline PJD002 & 1 & 1 & 1 & 1 & 2 & 2 & 8 \\
\hline PJD003 & 2 & 0 & 0 & 0 & 0 & 0 & 2 \\
\hline PJD004 & 2 & 1 & 0 & 1 & 1 & 2 & 7 \\
\hline PJD005 & 2 & 1 & 0 & 1 & 1 & 2 & 7 \\
\hline PJD006 & 1 & 1 & 0 & 1 & 1 & 2 & 6 \\
\hline PJD007 & 2 & 0 & 0 & 0 & 1 & 2 & 5 \\
\hline PJD008 & 2 & 0 & 0 & 1 & 0 & 0 & 3 \\
\hline PJD009 & 2 & 1 & 0 & 1 & 2 & 2 & 8 \\
\hline PJD010 & 1 & 1 & 1 & 1 & 2 & 2 & 8 \\
\hline 35MU4 & 1 & 1 & 1 & 1 & 2 & 2 & 8 \\
\hline 35MU61 & 0 & 0 & 0 & 0 & 0 & 1 & 1 \\
\hline 35MU62 & 2 & 1 & 1 & 1 & 2 & 2 & 9 \\
\hline 35MU63 & 1 & 1 & 0 & 1 & 2 & 1 & 6 \\
\hline 35MU242 & 2 & 0 & 0 & 0 & 0 & 1 & 3 \\
\hline $35 \mathrm{CO} 66$ & 1 & 0 & 0 & 0 & 2 & 1 & 4 \\
\hline $35 \mathrm{CO} 75$ & 2 & 0 & 0 & 0 & 0 & 0 & 2 \\
\hline $35 \mathrm{CO} 76$ & 2 & 1 & 1 & 1 & 1 & 2 & 8 \\
\hline
\end{tabular}




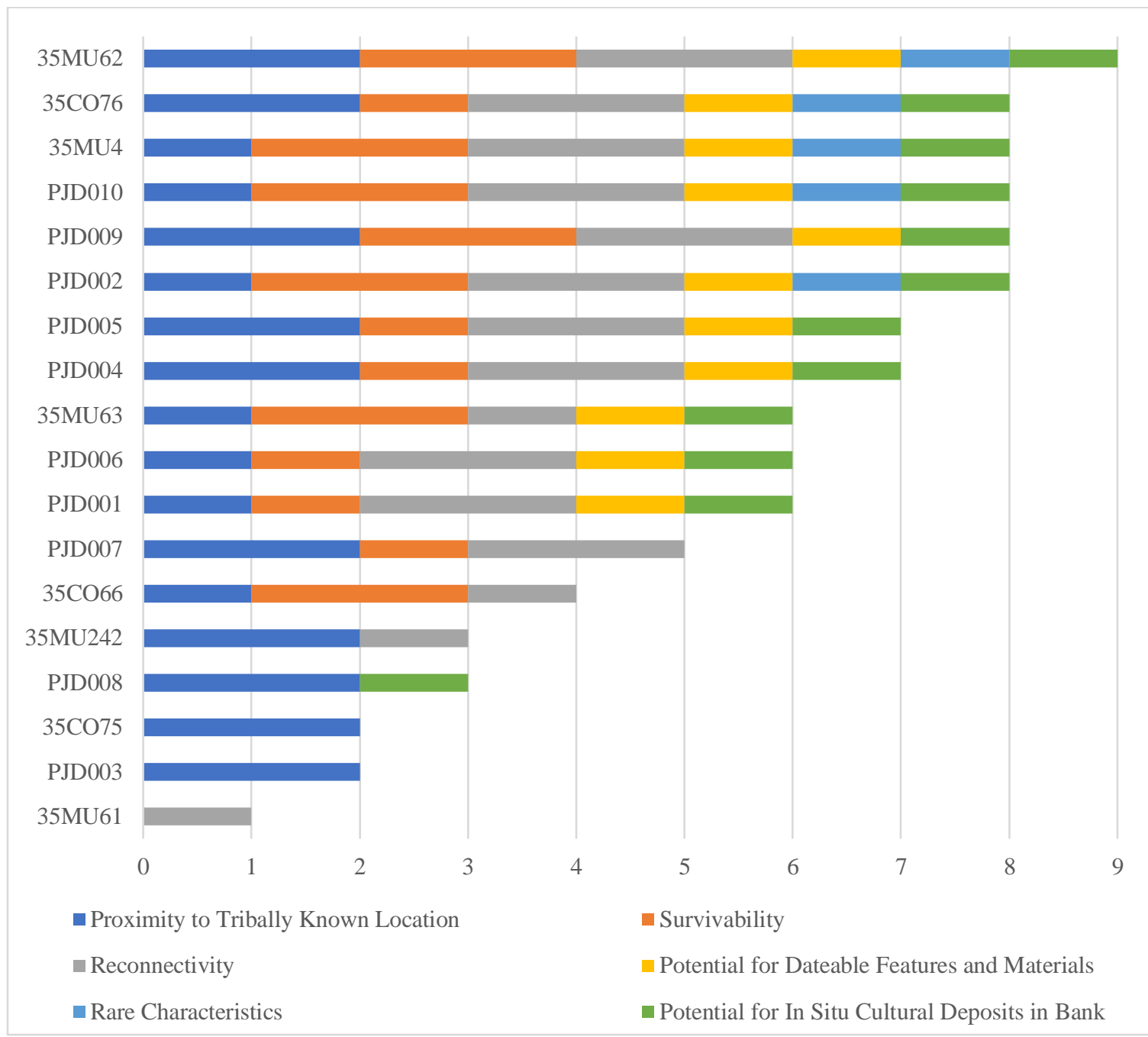

Figure 4.9. The distribution of tribal value variables for each site, in ascending order of total tribal value scores.

Among the seven sites in the mid-range group (4-7), intangible values of reconnectivity and survivability became consistent for each site in the group, and both variables regarding site potential were present at all but two of the sites within the group (Figure 4.9). While mid-range sites had diverse tribal values, up to five distinct variables at a single site, lower scores on weighted sliding scale variables distinguished these sites from those in the high group. At mid-range sites, many of which were fire-cracked rock scatters, survivability scored a "1" on the sliding scale for five of the seven sites (Table 
4.3). This reflected the nature of damage at these sites, all of which were more isolated from modern cultural impacts than sites in the high group, with primary impact factors centering around anthropogenically exacerbated erosion. Given the role of natural processes at sites such as PJD007, where an extremely small site area was being subjected to both bank and beach erosion, survivability was scored lower on the sliding scale than was the case in the high group.

Within the six sites of the high group $(8-9)$, the presence of scores for all six values was notable, with five of the sites given scores for all of the values being assessed (Figure 4.9). Sites within this group were distinguished by large, multicomponent assemblages, in situ deposits, and dateable features, rare in their own right and suggesting high potential for each site within the group. Such characteristics also lent themselves to high reconnectivity scores in particular (Table 4.3), providing ample potential for tribal members to interact with the site from a visitation or teaching perspective. High values on the heavier weighted, sliding scale variables were also important to the final scores for these sites. Each high group site scored a " 2 " on at least two of those weighted variables, and two high group sites scored the maximum possible for these three values, a " 6 " in total (Table 4.3). Also important was the presence of a rare characteristics scores for the six high group sites, all but one of which included either dateable features and/or a multicomponent assemblage. The intersection of all tribal value variables is apparent at 35MU62, where high potential, accessibility for visitation, close proximity, and other intangible aspects are paired with a multicomponent site with both a large area and a large assemblage, as well as a dateable feature. 
Among the unique tribal values, a number of sites highlighted how the most important intangible values were scored. Sites such as PJD003 and PJD002 are excellent examples of the application of the scaled survivability score. At site PJD003, one of five sites with a survivability score of " 0 " (Table 4.3), the assemblage consisted entirely of a small scatter of fire-cracked rock, within a small area, tucked against a rapidly eroding, abruptly terminating beach edge. Access to this site is challenging; it is often underwater, the area of exposed beach is minimal, and the site can only be reached by hiking along the beach or via kayak during a narrow window of time at low tide, during seasonal low water periods. As such, the primary impact is inevitable erosion; there is no appeal for recreationalists and few means of access, so future damage is expected at this site from purely anthropogenic modern cultural impacts.

Conversely, at site PJD002, with a survivability score of "2", while the site is impacted by the same erosional forces as sites such as PJD003, and has an abruptly terminating beach edge, the site is also subject to two modern cultural impacts, a wellmarked ODFW recreational dirt parking area just above the site and a cattle pasture with a shoreline watering hole to the south. These factors expose the site to recreationalists and cattle, and the activities of both likely contribute to the rapidly eroding and slumping bank. As such, even if the site is lost to erosion at a later date, mitigating the two entirely anthropogenic impacts could well slow that loss in a meaningful way, while also protecting the assemblage from looting or vandalism by recreationalists who currently have ready access to the site. 
The unique considerations involved in the scoring for reconnectivity are apparent at sites such as 35MU61, which scored a "1" (Table 4.3). At this site, significant loss to the assemblage has occurred, in similar fashion to $35 \mathrm{CO} 75$. Previously recorded as having a diverse assemblage with associated in situ deposits, upon rerecording, only a small scatter of fire-cracked rock was observed at 35MU61. However, the site sits in close proximity to a several other sites, 35MU62 and 35MU63, part of a chain of sites to the north and south of Sunken Village. In close proximity to this important regional site, 35MU61 sits along a beach that can be readily accessed via the water and then traversed with relative ease, due to its width during low tide and gentle slope. Furthermore, overland access is held by an amenable private landowner (Carolyn Reynolds, a Douglas Family descendent) and a responsive public agency (Metro). As such, despite the degree of loss and damage at 35MU61, it retains reconnectivity value to the Grand Ronde, expressed through the sliding scale scoring system.

For other sites, the greater weight of the full reconnectivity score expresses the unique tribal value of otherwise unassuming sites. Although similar to many of the homogenous fire-cracked rock scatters in the Refuge, PJD005, which scored a "2" in reconnectivity (Table 4.3), is one of only a few sites to be situated on a large, gradually sloping beach, with space to not only land a small sea kayak, but to land multiple boats, including large canoes used by the tribal community during paddling events. The large beach also increases the amount of time that the site can be visited, and some portions of the site may remain above water at high tide and even for the majority of the year. The site is located on public land and can be readily accessed via the water, from the state- 
owned Gilbert River Boat Ramp, which is a short paddle away to the north. The site is part of a string of fire-cracked rock scatters, in extremely close proximity to an ethnographically known village location and judged to be of high potential for future identification of important resources. It is located near the head of a slough known to lead to a productive wetland in the island's interior, the Crane Lake area. Viewed holistically, looking beyond physical archaeology, PJD005 is an example of the rich and complex nature of reconnectivity as a tribal value along the Sauvie Island shoreline.

\section{Comparing and Contrasting Archaeological and Tribal Value}

The differing methods of scoring for archaeological and tribal value produced sharp contrasts in both single variable and overall scores (Figure 4.10). These contrasts were most prominent in the newly identified fire-cracked rock scatters along the northern half of the shoreline, such as at site PJD009, which had a seven-point scoring difference between the archaeological value, of "1", and the tribal value, of "8". Importantly, archaeological value never scored more than one point higher than tribal value, as was the case at site PJD002, with an archaeological value score of "9" and a tribal value score of "8" (Figure 4.10). 


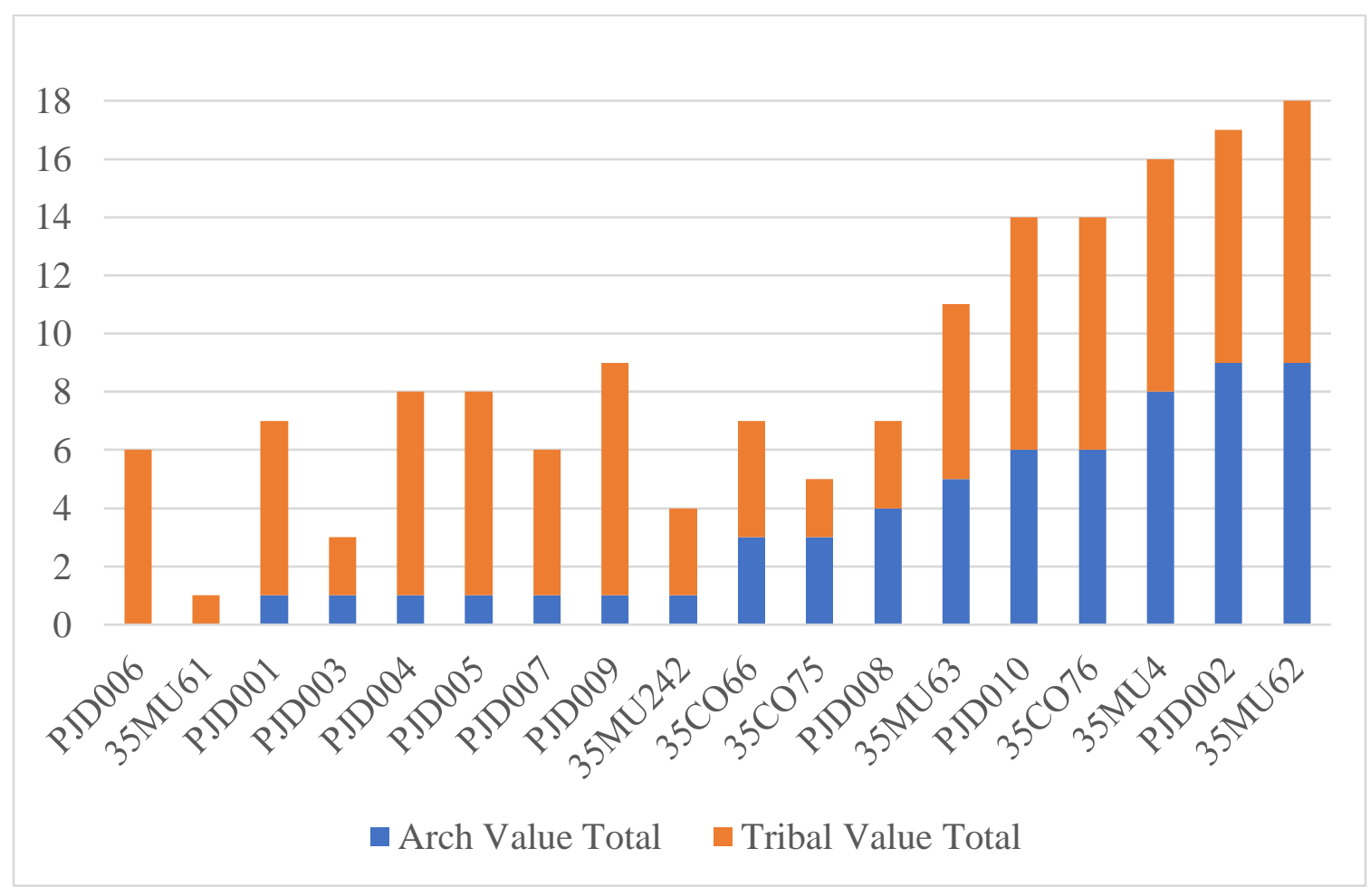

Figure 4.10. Comparing and contrasting archaeological (blue) and tribal (orange) values arranged in ascending order by archaeological value.

One reason for the differences in average scores between archaeological and tribal value (Table 4.4), with the average tribal value double that of archaeological value, is likely the scaled nature of the three highest scoring tribal values, while the comparably scored archaeological values were simple presence or absence. For archaeological value, as denoted by the lower average score, more sites had fewer variables present, and therefore scored lower. Indeed, for archaeological value, nine sites, or 50\%, had one or less variables observed on-site, while only three sites, or $17 \%$, had at least five variables represented in their scores. This number of lower value sites is much higher than in the case of tribal value, where only two sites, or $11 \%$, had one or fewer variables represented, while 11 sites, or $61 \%$, had at least five or more variables represented in their scores. The 
scaled nature of the tribal value variables allows for better expression of values that may be present to varying degrees at each site.

Table 4.4. Comparison of aggregate and average archaeological and tribal scores across the 18 recorded sites.

\begin{tabular}{|c|c|c|c|c|c|c|c|c|c|c|c|c|c|c|c|c|c|c|c|}
\hline & 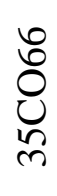 & 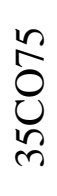 & 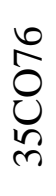 & 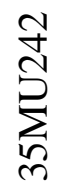 & $\underset{n}{\stackrel{Ð}{\ominus}}$ & $\underset{n}{\vec{\sigma}}$ & 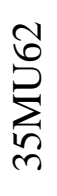 & 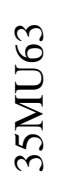 & $\begin{array}{l}\overline{8} \\
\overline{8} \\
\end{array}$ & $\begin{array}{l}\text { 용 } \\
\text { }\end{array}$ & 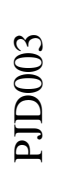 & $\begin{array}{l}\text { ¿ } \\
\stackrel{8}{8}\end{array}$ & 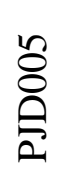 & $\begin{array}{l}8 \\
8 \\
8 \\
\text { ค }\end{array}$ & $\begin{array}{l}\hat{8} \\
\text { } \\
\text { 요 }\end{array}$ & $\begin{array}{l}\infty \\
\stackrel{8}{8} \\
\stackrel{8}{2}\end{array}$ & $\begin{array}{l}\stackrel{8}{8} \\
\stackrel{8}{2}\end{array}$ & $\begin{array}{l}\stackrel{0}{0} \\
\stackrel{2}{\circ} \\
\end{array}$ & $\frac{\sqrt[I]{0}}{\frac{\pi}{2}}$ \\
\hline $\begin{array}{l}\frac{0}{J} \\
\frac{\pi}{7} \\
\bar{J} \\
\dot{Z}\end{array}$ & 3 & 3 & 6 & 1 & 8 & 0 & 9 & 5 & 1 & 9 & 1 & 1 & 1 & 0 & 1 & 4 & 1 & 6 & 3 \\
\hline 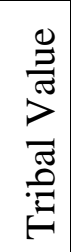 & 4 & 2 & 8 & 3 & 8 & 1 & 9 & 6 & 6 & 8 & 2 & 7 & 7 & 6 & 5 & 3 & 8 & 8 & 6 \\
\hline
\end{tabular}

Another important reason for the contrasting scores between archaeological and tribal value is the difference between cultural materials, rare, dateable, diagnostic, or in situ, that must be observed on-site in archaeological value, whereas it is the potential that is scored in tribal value. For archaeological value, observations during survey found such cultural materials, either individually or in combination, at only six recorded sites, or $33 \%$ (Figure 4.8), contributing to a low archaeological value for many sites, such as the fire-cracked rock scatters along the northern half of the shoreline. Conversely, for tribal value, the assemblages at these sites represented the opposite, with only six recorded sites, or $33 \%$ (Figure 4.7), receiving no score for potential in at least one of these categories. At fire-cracked rock scatters such as PJD005, with its long stretch of exposed 
bank, relatively large assemblage, and proximity to ethnographic village locations, this contrast between observed presence/absence and potential is evident, as the broader context of the site suggests high potential even when such resources were not immediately observed.

One key area of overlap between archaeological and tribal value is the proximity to ethnographic village locations. This variable is set up in a similar manner between archaeological and tribal values, although the tribal variable has a sliding scale varying by distance. Unique to this project, this variable utilizes a data set provided by the Grand Ronde THPO staff. Considering this, the archaeological value is simpler, to accommodate future work which may not initially have tribal contribution of records. Nevertheless, in only four cases, or $22 \%$, did sites lack a proximity score in archaeological value while having a proximity score in tribal value. While the tribal value was more refined, generally, it still paralleled that of archaeological value, reflecting the sheer density and extent of Indigenous habitation in the Sauvie Island area, as recorded in the ethnographic record.

Another area of overlap, one that was completely identical in scoring across all sites for both tribal and archaeological value, was the rare characteristics variable. Targeted at unique elements of a site, these scores were identical for all 18 sites surveyed, in part because they considered similar aspects of physical archaeology to be rare and in part because variables exclusive and important to tribal value tend to be present at many Sauvie Island sites and are not considered uncommon, at least during this study. For example, in the case of physical archaeology, dateable features, such as hearths, were 
considered rare occurrences for both archaeological and tribal value. But reconnectivity, while an especially important and unique tribal value, was found to some degree across most sites recorded and thus factored minimally into considerations of rare characteristics that would make a site unique to either archaeologists or tribal members.

\section{$\underline{\text { Risk Factors }}$}

Prior to fieldwork, I identified a number of risk factors that could affect the baseline condition of sites to be surveyed and were likely to be observed in the field. These forces can be broadly divided into two categories, risk factors related to anthropogenically exacerbated erosion and risk factors related exclusively to modern cultural activity. Across the 18 sites I recorded during my project (Table 4.5), 17 sites, or 94\%, had multiple risk factors, with the exception of 35MU242, which was composed entirely of large static wood and stone features that had seen little impact since prior recording and faced few risks due to the nature of the assemblage. All 18 of the sites surveyed were estimated as being over $20 \%$ damaged, with sites having greater than $60 \%$ estimated damage on average (score $=3$ or 4 , Table 4.5 ). Severe depletion of beach plant communities was observed in half of the sites surveyed, where beaches lacked surface vegetation entirely, while the other half of sites surveyed had only minimal low-lying groundcover on portions of the beach. Rodent activities, thought to potentially be a more common negative impact on bank integrity, due to their prevalence in other waterways in the Sauvie Island area, were observed at only four sites. 
Table 4.5. Risk factor scores for all surveyed sites.

\begin{tabular}{|c|c|c|c|c|c|c|c|c|c|c|c|c|c|c|c|c|}
\hline & 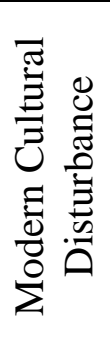 & 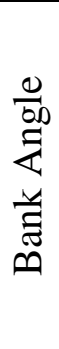 & 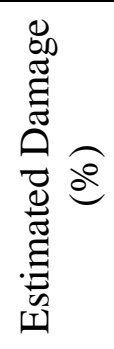 & 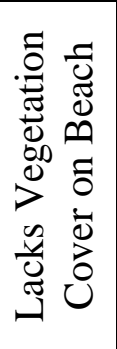 & 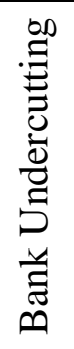 & 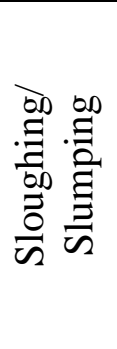 & 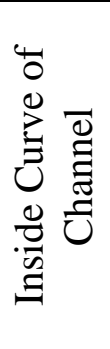 & 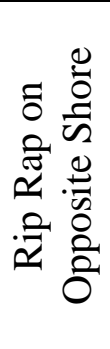 & 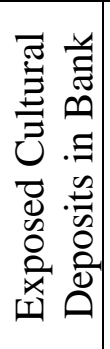 & 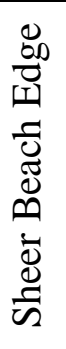 & 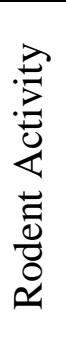 & 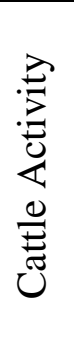 & 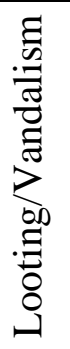 & 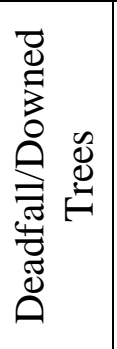 & 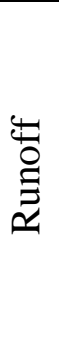 & 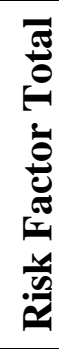 \\
\hline PJD001 & 0 & 2 & 3 & 0 & 1 & 1 & 0 & 0 & 0 & 0 & 0 & 0 & 0 & 1 & 1 & 9 \\
\hline PJD002 & 1 & 3 & 4 & 1 & 1 & 1 & 1 & 0 & 1 & 1 & 1 & 1 & 0 & 0 & 0 & 16 \\
\hline PJD003 & 0 & 2 & 3 & 1 & 1 & 1 & 0 & 0 & 0 & 1 & 1 & 0 & 0 & 1 & 0 & 11 \\
\hline PJD004 & 0 & 3 & 2 & 1 & 0 & 0 & 0 & 1 & 0 & 0 & 0 & 0 & 0 & 1 & 1 & 9 \\
\hline PJD005 & 1 & 2 & 2 & 0 & 0 & 1 & 1 & 1 & 0 & 0 & 0 & 0 & 0 & 1 & 0 & 9 \\
\hline PJD006 & 0 & 3 & 2 & 1 & 1 & 0 & 0 & 0 & 0 & 0 & 0 & 0 & 0 & 1 & 0 & 8 \\
\hline PJD007 & 0 & 1 & 4 & 0 & 0 & 0 & 1 & 1 & 0 & 1 & 0 & 0 & 0 & 0 & 0 & 8 \\
\hline PJD008 & 0 & 0 & 2 & 1 & 1 & 0 & 0 & 0 & 1 & 0 & 0 & 0 & 0 & 0 & 0 & 5 \\
\hline PJD009 & 0 & 3 & 4 & 1 & 1 & 1 & 1 & 1 & 0 & 1 & 0 & 0 & 0 & 1 & 0 & 14 \\
\hline PJD010 & 1 & 2 & 2 & 0 & 1 & 1 & 0 & 1 & 1 & 0 & 0 & 0 & 0 & 1 & 0 & 10 \\
\hline 35MU4 & 1 & 3 & 3 & 1 & 0 & 0 & 0 & 0 & 0 & 0 & 0 & 0 & 0 & 0 & 0 & 8 \\
\hline 35MU61 & 0 & 2 & 4 & 0 & 0 & 1 & 0 & 0 & 0 & 0 & 0 & 0 & 0 & 0 & 0 & 7 \\
\hline 35MU62 & 1 & 3 & 2 & 1 & 1 & 1 & 1 & 0 & 1 & 0 & 1 & 0 & 1 & 0 & 1 & 14 \\
\hline 35MU63 & 0 & 2 & 3 & 0 & 1 & 1 & 0 & 0 & 1 & 0 & 0 & 0 & 0 & 0 & 0 & 8 \\
\hline $35 \mathrm{MU} 242$ & 0 & 0 & 1 & 0 & 0 & 0 & 0 & 0 & 0 & 0 & 0 & 0 & 0 & 0 & 0 & 1 \\
\hline $35 \mathrm{CO} 66$ & 0 & 0 & 3 & 0 & 0 & 0 & 0 & 0 & 0 & 0 & 1 & 0 & 1 & 1 & 0 & 6 \\
\hline $35 \mathrm{CO} 75$ & 0 & 2 & 4 & 0 & 1 & 1 & 0 & 1 & 0 & 0 & 0 & 0 & 0 & 1 & 0 & 10 \\
\hline $35 \mathrm{CO} 76$ & 0 & 3 & 4 & 1 & 1 & 0 & 1 & 1 & 1 & 1 & 0 & 0 & 0 & 0 & 0 & 13 \\
\hline
\end{tabular}


Considering the 18 sites overall, the average risk factor score is " 9 " and on average, six distinct risk factors were observed at each site (Table 4.6). While most factors were not common across all sites, factors directly involving bank erosion were present at 16 sites, $(89 \%)$. Of these resources, 13 sites, $72 \%$, showed signs of sloughing/slumping (Figure 4.11) and/or bank undercutting, while 15 sites, 83\%, had greater than what was considered to be a gradual bank angle $\left(<50^{\circ}\right)$ (Figure 4.12$)$. While nine sites had some scattered low-lying vegetation cover on the beach, every site lacked the large, high density plant communities that help stabilize the bank or trap sediment deposited along the beach. Of the sites recorded, only two, 35CO66 and 35MU242, had no sloughing, slumping, bank undercutting, or greater than gradual bank angle $\left(>50^{\circ}\right)$. 
Table 4.6. Risk factor score, and number of risk factors present at each site.

\begin{tabular}{|c|c|c|}
\hline & Risk Factor Total (max $=\mathbf{2 0})$ & $\begin{array}{c}\text { \# of Risk Factors Present }(\mathbf{m a x}= \\
\mathbf{1 5}\end{array}$ \\
\hline PJD001 & 9 & 6 \\
\hline PJD002 & 16 & 8 \\
\hline PJD003 & 11 & 6 \\
\hline PJD004 & 9 & 7 \\
\hline PJD005 & 9 & 5 \\
\hline PJD006 & 8 & 5 \\
\hline PJD007 & 8 & 4 \\
\hline PJD008 & 5 & 9 \\
\hline PJD009 & 14 & 8 \\
\hline PJD010 & 10 & 4 \\
\hline 35MU4 & 8 & 3 \\
\hline 35MU61 & 7 & 11 \\
\hline 35MU62 & 14 & 5 \\
\hline 35MU63 & 8 & 1 \\
\hline 35MU242 & 1 & 4 \\
\hline 35CO66 & 6 & 6 \\
\hline 35CO75 & 10 & 8 \\
\hline 35CO76 & 13 & 6 \\
\hline Average & 9 & \\
\hline & & 6 \\
\hline
\end{tabular}




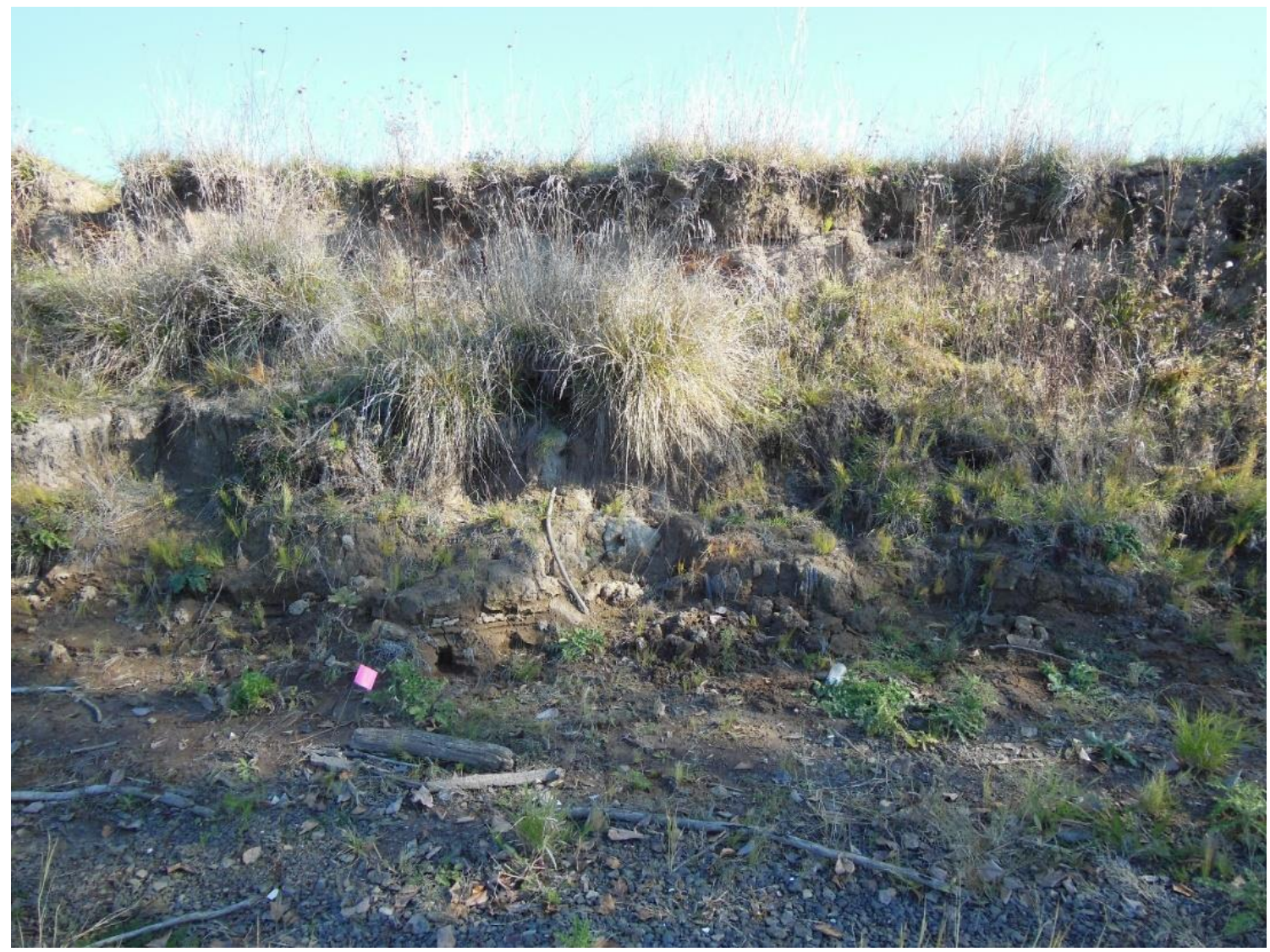

Figure 4.11. Example of severe bank slumping/sloughing at newly identified site PJD002. 


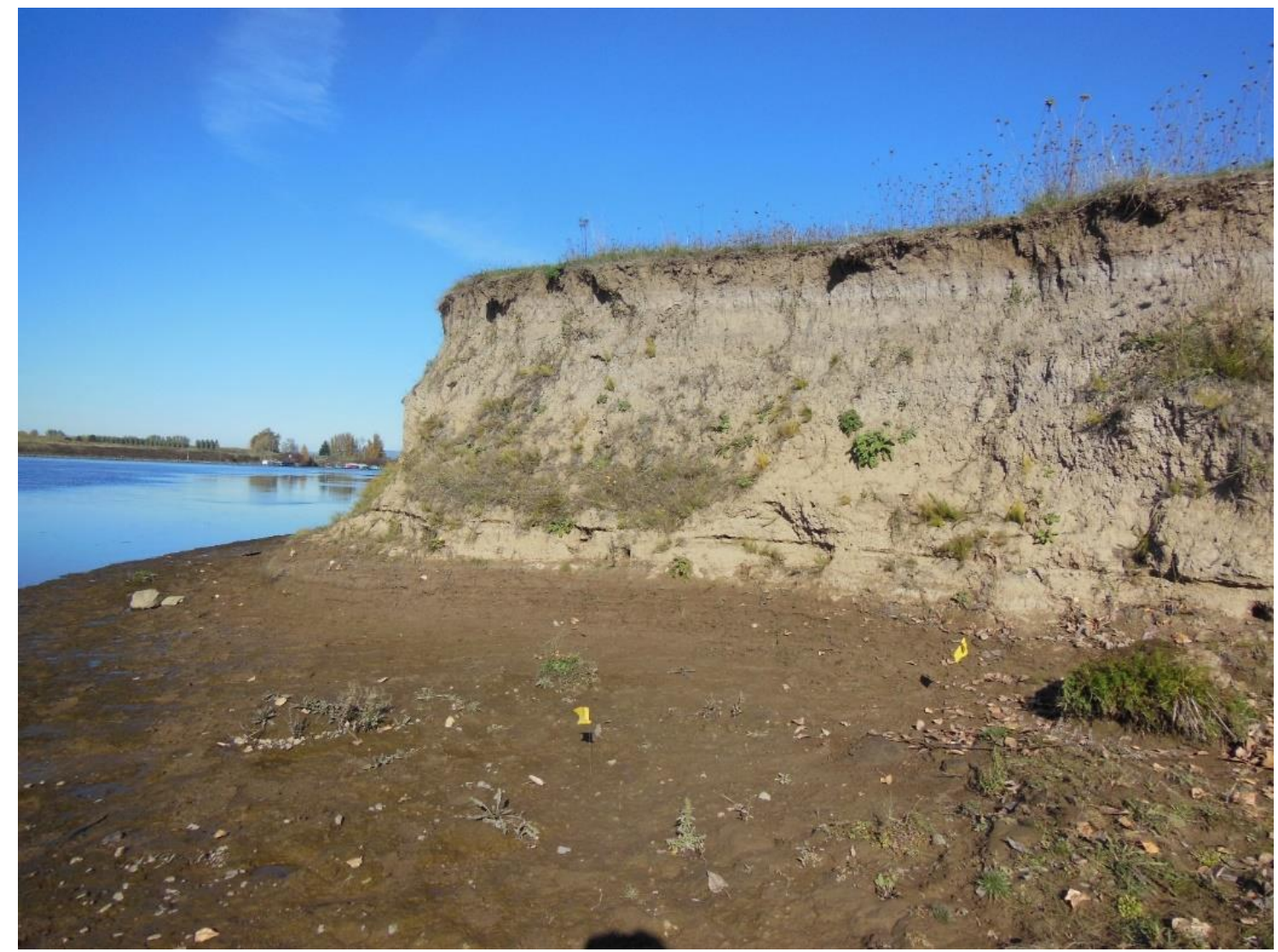

Figure 4.12. Example of sheer, exposed bank at near $90^{\circ}$ angle, at newly identified site PJD002.

Of the sites surveyed, deadfall was observed at nine sites, $50 \%$, resulting from erosion, and then further accelerating the process by undermining bank integrity. The position of each site on the inside or outside curve of the channel was an excellent predictor for steep beach terminations into the channel, caused when water is accelerated around a bend in the channel and impacts with disproportionately high strength on the shoreline on the inside curve. Only six of the 18 surveyed sites, $33 \%$, were on the inside curve (Table 4.5), but each of those six sites showed a steeply terminating beach where, in some cases, cultural resources were actively slipping off the beach and eroding into the deep water of the channel. Conversely, all other sites showed a gradual beach angle into 
the water, the result of slower currents depositing sediment on the outside bend of the channel, after stripping it off inside bends. Finally, runoff channeling, initially expected to be more common in the project area, was only observed at three sites surveyed, although evidence of this factor could change seasonally. The two most uncommon risk factors noted were direct evidence of cattle trampling or looting. PJD002 was the only site to show evidence of cattle impacts, a distinct change from the era of previous recordings, when cattle moved much more freely across the island and shoreline, as is still the case along other regional waterways. Similarly, 35MU62 and 35CO66 were the only sites to show direct evidence of looting or vandalism, another shift from early recordings on the island, when pothunter excavations and collecting were common, and the public had easy access to resources across the island.

In addition to anthropogenically exacerbated natural erosional forces, a number of purely anthropogenic cultural impacts were noted at the 18 recorded sites. Of the 18 sites surveyed, seven sites, 39\%, were located across from riprapped levees on the mainland side of the Multnomah Channel. These artificially hardened banks are thought to redirect water currents towards the opposite bank at greater force than would otherwise occur, outside of or in addition to the redirection that occurs naturally. Only two sites, 35CO66 and 35MU62 showed clear signs of looting and/or vandalism, in the form of a distinct looters pile of Euro-American bricks with maker's marks, and an illegally created trail leading from Sauvie Island Road to the shoreline (Figure 4.13). Although looting may well be responsible for the loss of diagnostic elements of the Indigenous assemblage at multiple previously recorded sites, no clear evidence of this was noted. The illegally 
constructed trail, made of steps supported by rebar and wood planks, may provide access for fishing (personal communication, Carolyn Reynolds, 2019). Finally, one site, PJD002, showed signs of cattle disturbance. The site is located just to the north of a watering hole that connects to and is supplied by the channel, and the bank above the site is an in-use free-range grazing pasture. It is possible that cattle may have accessed the site directly from the south, but the most concerning element of the impact may be the acceleration of erosion from cattle trampling on the bank above the site.

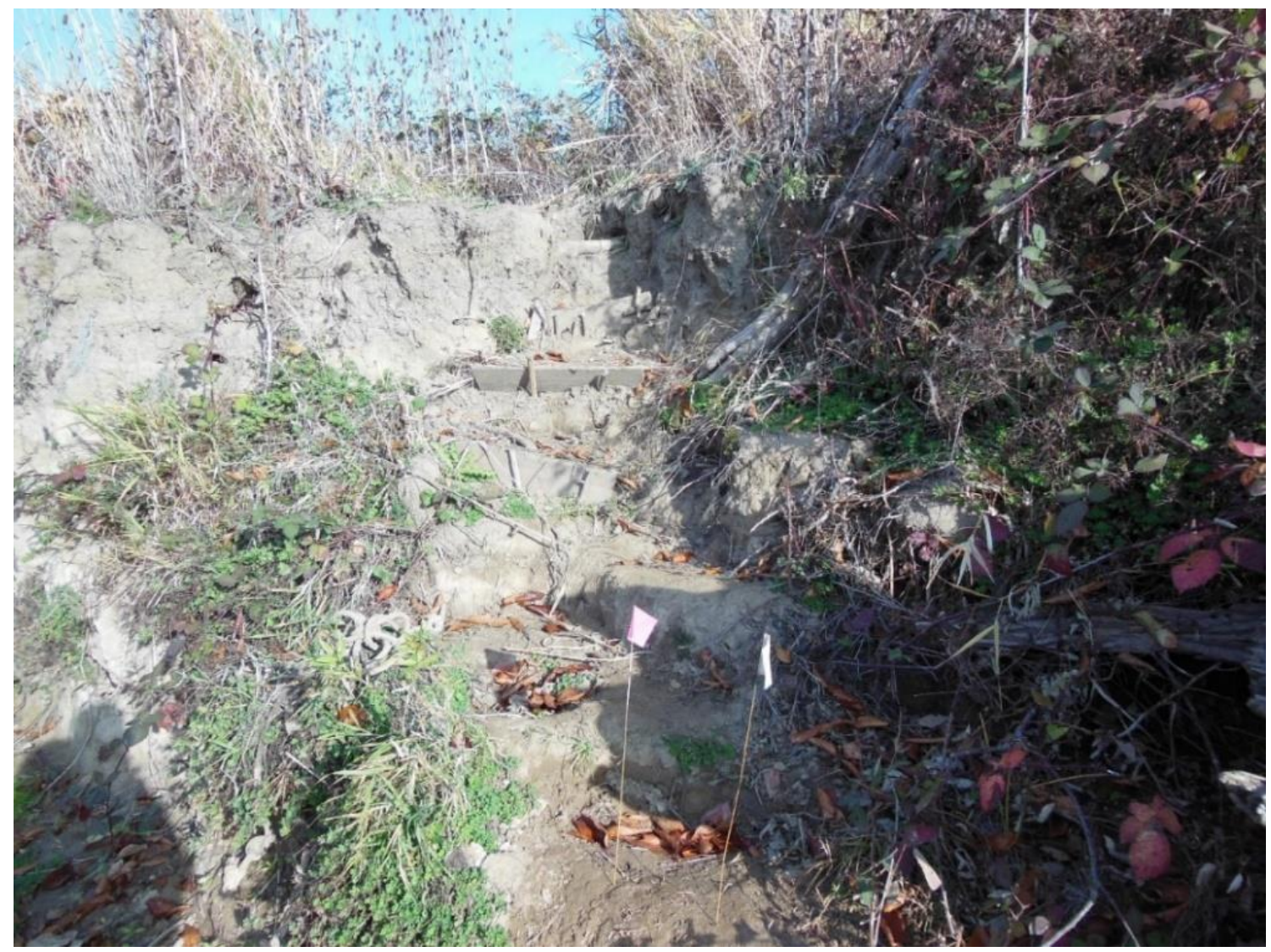

Figure 4.13. Illegally constructed trail with wood and rebar supports, leading from Sauvie Island Road to beach of site 35MU62. The trail offers easy access to multiple sites along the shoreline. 
The eight sites that were previously recorded and then revisited provided an opportunity for me gauge ways that site condition had changed since the previous recording. Previous records of these sites range widely in age and detail, as noted in previous chapters, but all included some description of negative impacts for comparative purposes (Table 4.7). For four previously recorded sites, pothunting and cattle trampling were the common key negative impacts noted previously but were not evident in my survey. Although common in decades past, increased community awareness, academic engagement, and legal enforcement may have contributed to reduced pothunting, particularly illegal excavation, which was much more common in the 1970's and 1980's and is noted by Pettigrew and others in many initial reports. In regard to cattle, due to the construction of the levee through the 1940's and a shift towards agricultural crops, at least for much of the southern half of the island, not only were cattle separated from the beach, but their numbers on the island decreased, particularly where most of these previously recorded sites are located. In comparison to previous records, erosion such as slumping, and bank exposure continues to be the most negative impact. These kinds of erosion are present at six of the eight previously recorded sites, with only 35MU4 and 35MU242 showing little signs of erosional damage. 
Table 4.7. Comparison of site conditions for previously recorded sites.

\begin{tabular}{|c|c|c|}
\hline $\begin{array}{c}\text { Site } \\
\text { Number }\end{array}$ & $\begin{array}{l}\text { Last Recorded Condition Prior } \\
\text { to Project } \\
\end{array}$ & $\begin{array}{c}\text { Condition Recorded During } 2019 \\
\text { Fieldwork } \\
\end{array}$ \\
\hline 35MU4 & $\begin{array}{l}\text { 2007: Site condition good, some } \\
\text { bioturbation, erosion, looting, } \\
\text { vandalism, and animal trampling }\end{array}$ & $\begin{array}{l}\text { Site condition good, riprap protecting } \\
\text { bank, basket features silted over }\end{array}$ \\
\hline 35MU61 & $\begin{array}{l}\text { 1987: Eroding shoreline, land } \\
\text { manager reported artifact } \\
\text { collectors, pipeline construction, } \\
\text { cattle grazing }\end{array}$ & $\begin{array}{l}\text { Eroding cut-bank, slumping, runoff } \\
\text { channeling, gradually sloping beach }\end{array}$ \\
\hline 35MU62 & $\begin{array}{l}\text { 1987: Undercut bank, cultural } \\
\text { materials eroding out of bank, } \\
\text { log rafts offshore, close } \\
\text { proximity to dike and roadside } \\
\text { dumping, recreational use, wave } \\
\text { action, pothunting }\end{array}$ & $\begin{array}{c}\text { Sheer exposed cut-bank, visible } \\
\text { slumping, erosion of existing feature, } \\
\text { illegal access trail in cut-bank, nearby } \\
\text { houseboat moorage }\end{array}$ \\
\hline 35MU63 & $\begin{array}{l}\text { 1987: Cattle grazing and } \\
\text { agriculture, recreation, features } \\
\text { eroding out of cut-bank, looting, } \\
\text { vandalism, dike construction }\end{array}$ & $\begin{array}{l}\text { Sheer to gradually exposed cut-bank, } \\
\text { slumping }\end{array}$ \\
\hline 35MU242 & $\begin{array}{l}\text { 2013: Site condition poor, } \\
\text { erosion, inundation, weathering }\end{array}$ & $\begin{array}{l}\text { Gradually sloping beach, unexposed } \\
\text { bank, weathering }\end{array}$ \\
\hline $35 \mathrm{CO} 66$ & $\begin{array}{l}\text { 2014: Erosion and decay by } \\
\text { inundation, weathering }\end{array}$ & $\begin{array}{c}\text { Gradually sloping cut-bank w/o } \\
\text { significant exposure, some sloughing, } \\
\text { looting }\end{array}$ \\
\hline $35 \mathrm{CO} 75$ & 2015: Erosion due to inundation & $\begin{array}{l}\text { Gradually sloping beach, varying } \\
\text { slope/exposure of bank, slumping, } \\
\text { secondary cut-bank forming, } \\
\text { undercutting, cattle grazing above site }\end{array}$ \\
\hline $35 \mathrm{CO} 76$ & 2015: Erosion due to inundation & $\begin{array}{l}\text { Abruptly terminating beach, } \\
\text { beach/bank features eroding, sheer } \\
\text { exposed bank }\end{array}$ \\
\hline
\end{tabular}

\section{Overall Prioritization}

Scores for archaeological and tribal value and risk factors were combined for the 18 sites to create an overall prioritization score, divided into five main categories (Tables 4.8). One site was assessed as Very Low priority, seven sites were assessed as Low priority, four sites were assessed as Medium priority, four sites were assessed as High 
priority, and two sites were assessed as Very High priority. Site 35MU242 received the lowest score of sites recorded, scoring a "5", while site PJD002 received the highest score of sites recorded, scoring a "33". The average archaeological value score assigned to a site was a " 3 ", the average tribal value score assigned to a site was " 6 " (Table 4.4), the average risk factor score assigned to a site was "9" (Table 4.6), and the average overall prioritization score assigned to a site was "18", or a Medium prioritization ranking. The mode, or most commonly appearing score assigned to a site was " 1 " for archaeological value, "8" for tribal value, "8" for risk factors, and " 14 " for overall prioritization score, although in the case of the latter, with a range of 28 , scores varied widely, with only three scores repeated among the sites (Table 4.8, Figure 4.14, 4.15). 
Table 4.8. Archaeological value, tribal value, risk factor, and overall priority preservation score, arranged by the five preservation categories.

\begin{tabular}{|c|c|c|c|c|c|}
\hline & $\begin{array}{c}\text { Arch Value } \\
\text { Total }\end{array}$ & $\begin{array}{c}\text { Tribal } \\
\text { Value Total }\end{array}$ & $\begin{array}{c}\text { Risk } \\
\text { Factor } \\
\text { Total } \\
\end{array}$ & $\begin{array}{c}\text { Priority } \\
\text { Preservation } \\
\text { Score }\end{array}$ & $\begin{array}{c}\text { Priority } \\
\text { Preservation } \\
\text { Level }\end{array}$ \\
\hline 35MU242 & 1 & 3 & 1 & 5 & Very Low \\
\hline 35MU61 & 0 & 1 & 7 & 8 & Low \\
\hline PJD008 & 4 & 3 & 5 & 12 & Low \\
\hline $35 \mathrm{CO} 66$ & 3 & 4 & 6 & 13 & Low \\
\hline PJD003 & 1 & 2 & 11 & 14 & Low \\
\hline PJD006 & 0 & 6 & 8 & 14 & Low \\
\hline PJD007 & 1 & 5 & 8 & 14 & Low \\
\hline $35 \mathrm{CO} 75$ & 3 & 2 & 10 & 15 & Low \\
\hline PJD001 & 1 & 6 & 9 & 16 & Medium \\
\hline PJD004 & 1 & 7 & 9 & 17 & Medium \\
\hline PJD005 & 1 & 7 & 9 & 17 & Medium \\
\hline 35MU63 & 5 & 6 & 8 & 19 & Medium \\
\hline PJD009 & 1 & 8 & 14 & 23 & High \\
\hline PJD010 & 6 & 8 & 10 & 24 & High \\
\hline 35MU4 & 8 & 8 & 8 & 24 & High \\
\hline $35 \mathrm{CO} 76$ & 6 & 8 & 13 & 27 & High \\
\hline 35MU62 & 9 & 9 & 14 & 32 & Very High \\
\hline PJD002 & 9 & 8 & 16 & 33 & Very High \\
\hline
\end{tabular}




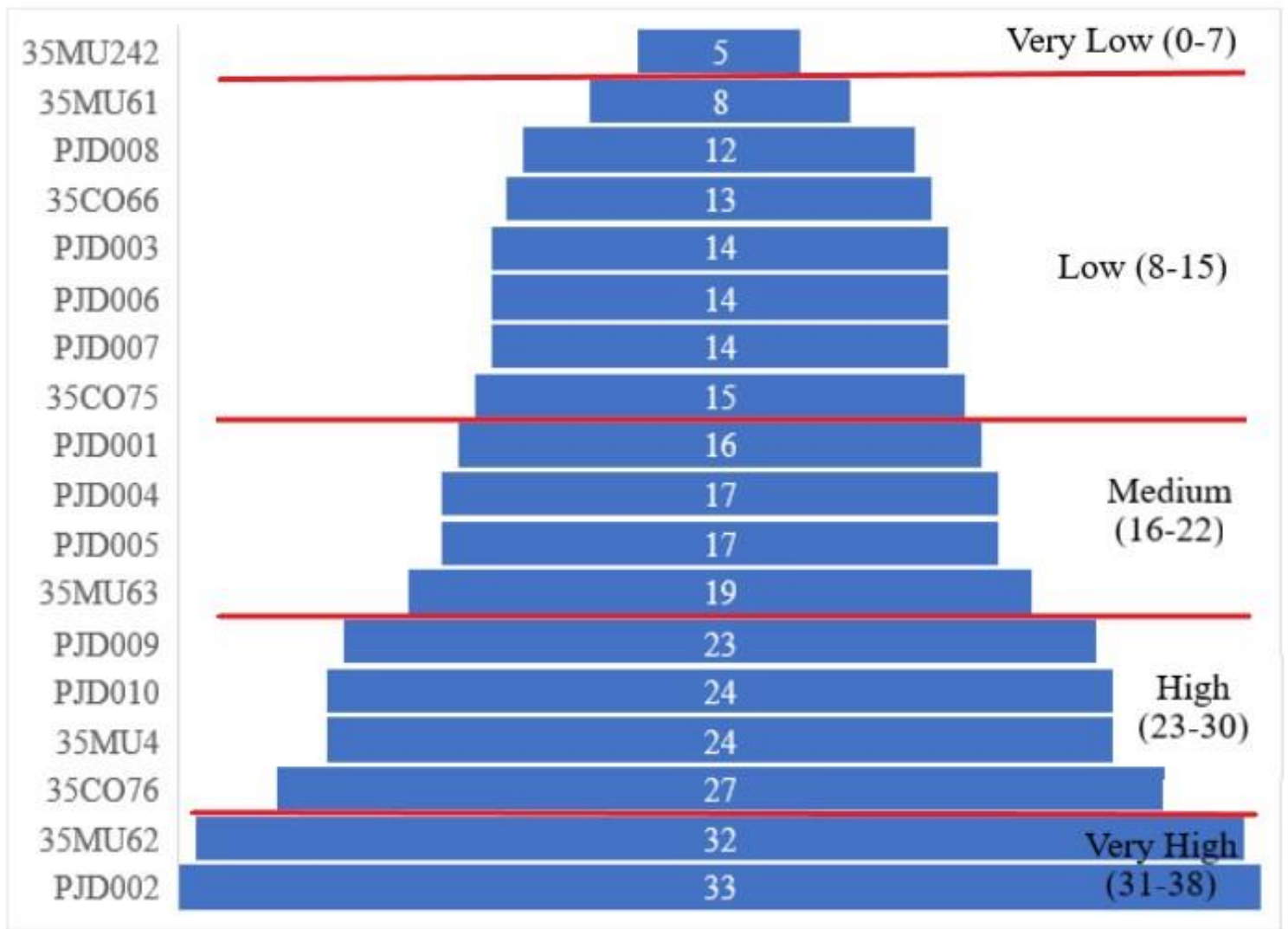

Figure 4.14. Chart showing the range and placement of prioritization scores across the 18 sites. 


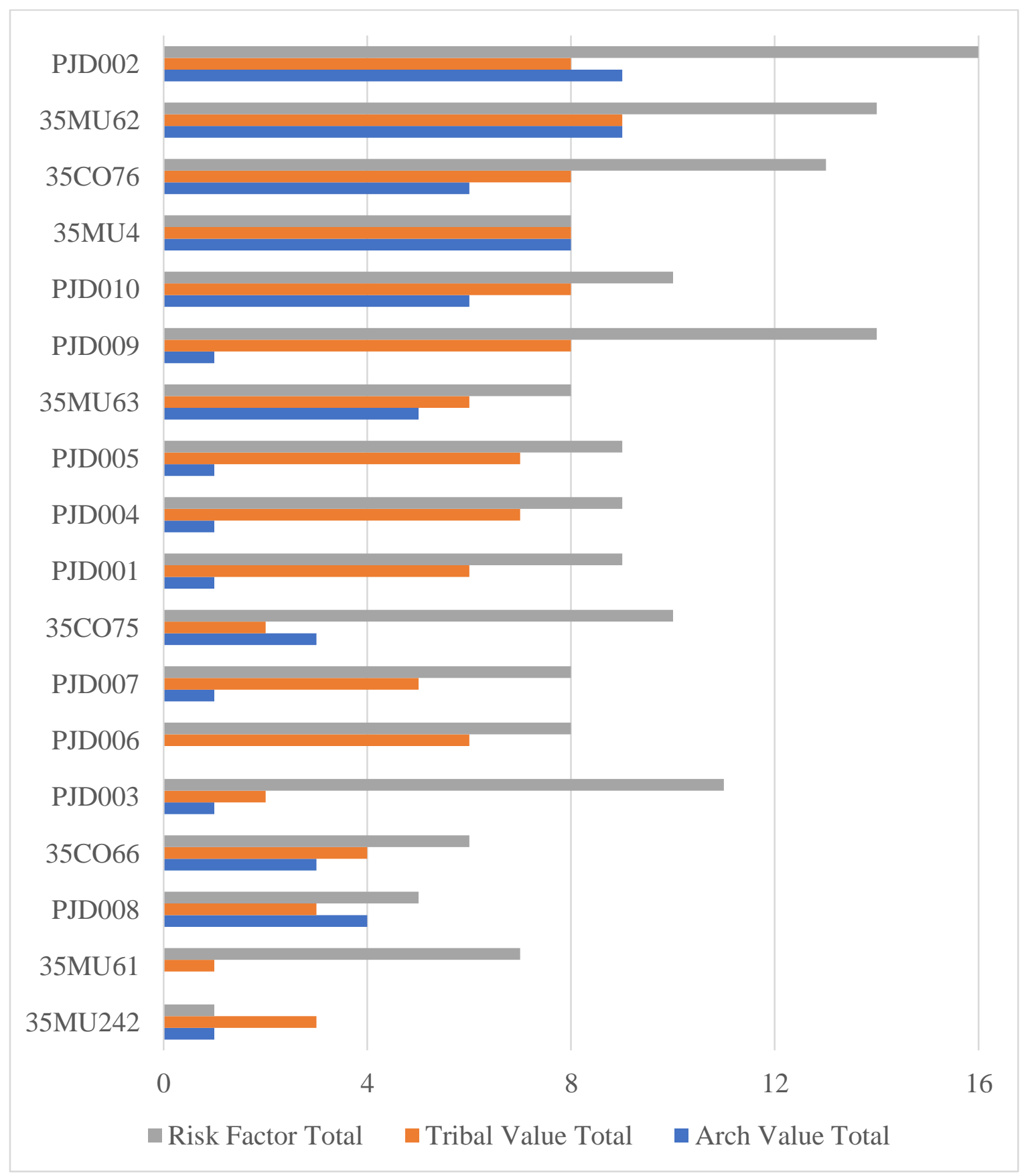

Figure 4.15. Range of scores across all 18 sites, arranged in ascending order of total prioritization score.

Ultimately, these final prioritization scores reflect sites where multiple risk factors are almost always present and where final scores are often decided through the combination or contrast between archaeological and tribal value. While the highest value 
sites have high scores across all three categories, many sites that fall in the middle have strong contrasts between these values, with tribal value often elevating sites that archaeological value would not otherwise prioritize.

\section{Summary}

Over the course of a month of fieldwork, I surveyed the majority of the western shoreline of Sauvie Island, revisiting eight previously recorded archaeological sites and identifying ten new sites. For each site, I documented the extent and nature of the archaeological assemblage, including artifacts and features. I also made extensive observations of factors relating to site condition. When my fieldwork was completed, I presented these findings to the THPO staff of the Confederated Tribes of the Grand Ronde. With their input, I developed a prioritization assessment, where the values and risk factors of each site were summed as per the goals of my research project. These results indicate that typically, sites received a higher tribal value than archaeological value, reflecting how tribal value expands the perception of what makes a site important. These results also confirm that the sites along the Sauvie Island shoreline face a plethora of distinct risks, many of which center around erosional forces. No site was without some degree of estimated damage and only a handful of sites did not appear to be suffering from one or more of the signs of extreme erosion. 


\section{Chapter 5. Discussion, Conclusions, and Future Research}

In this chapter, I discuss the results of my prioritization assessment from a procedural and practical perspective, while considering them in the context of broader risk assessment literature. I review the results of my assessment from the perspective of tribal collaboration and the impact of that collaboration on the assessment process and results. As explained previously, my project incorporated perspectives from one tribe, the Confederated Tribes of the Grand Ronde, and I recognize the limitations this imposes on the results. I discuss the impact of my work in the broader context of the Lower Columbia archaeological record, the developing sub-field of risk assessment archaeology, and the diverse needs of stakeholders when addressing the preservation of sites threatened by a multitude of negative forces. I also outline the potential future research projects prompted by my work on Sauvie Island. Finally, I consider the impact that such a collaborative project has had on my perspective as an archaeologist and how the changes that result suggest a more just and equitable direction for the future of the discipline.

Over the course of my research, the majority of the western shoreline of Sauvie Island was surveyed. A comparative examination of eight previously recorded sites was undertaken, while pedestrian survey added ten additional sites to the Sauvie Island archaeological record. The nature of these sites confirms many of the early EuroAmerican reports of Indigenous activity on the island. Prior to contact, the Sauvie Island shoreline was home to significant processing of resources, in a manner that ranges from the well-developed acorn processing of Sunken village to the large scatters of fire- 
cracked rock that line the shoreline. These assemblages confirm the island's place in Indigenous lifeways and my findings establish a new extent to these occupations, with the physical archaeological evidence confirming the knowledge that tribal communities have long held. Euro-American activity on the island follows a pattern that continues today, namely the accumulation of debris consistent with commercial activity, early homesteads, and recreational use of the island. Notable from my survey is the potential of select sites to offer a view into the blurred lines of first contact between Indigenous peoples and Euro-Americans. Indigenous use of Sauvie Island certainly continued into the historicera, but indigenous peoples also began to establish links to Euro-American industry, in addition to intermarriage with Euro-American fur traders (Watson 2010), suggesting a need to consider multiple descendent communities, as has been done elsewhere in the region (e.g.; Kretzler 2015; Wilson 2015).

New Knowledge of Sauvie Island Archaeology

The impact of this project has led to a greater understanding of the archaeological record of Sauvie Island, what condition that record is in, and what such a record suggests for our evolving knowledge of past human activities on Sauvie Island. This project has confirmed ethnohistorical accounts, significantly expanded the number of known sites along the western shoreline and identified key points of early Indigenous/Euro-American interaction. The project identified four in situ features that could be dated, to increase our understanding of the history of human occupation on the island. Additionally, this project has dramatically expanded the knowledge of the archaeology of the Sauvie Island Wildlife Refuge on the north half of the island, as managed by the Oregon Department of 
Fish and Wildlife. Prior to my project, only three sites, at Warrior Point (35CO66; Roulette and Finley 2009a; 2009b) and below Cunningham Lake (35CO75, 35CO76; Jenkins 2015a; 2015b) were known to exist along the western shoreline of the Refuge. With the completion of my project, there are now 11 recorded sites.

Much has also been learned about how previously known sites have changed along the Sauvie Island shoreline since their initial recording and the form that those changes have taken. At the start of this project, it was clear that erosional impacts would be a general negative force acting on sites surveyed, but the severity of that erosion, as well as the specific forms it would take along the shoreline were unknown. Over the course of my research, the impact of redirected currents, both naturally and due to riprap, was highlighted clearly with the observations of steeply terminating shorelines, particularly along the inside curve of the channel. The speed at which sheer, exposed banks are eroding is now better understood, based on observation of feature loss and exposure at previously recorded sites $35 \mathrm{CO} 75$ and 35CO76, respectively, sites which have degraded rapidly over the course of just four years. The changing nature of modern cultural impacts was also apparent during survey of previously recorded sites. While initial recording, particularly that in the 1970's and 1980's (e.g.; Darby et al. 1987; Pettigrew 1973a; 1973b; 1973c; 1973d; Reese 1987a; Reese et al. 1987a), highlighted the near constant presence of cattle and pothunters, these impacts are now rare along the western shoreline. Instead of large-scale looting and excavations, potentially negative impacts from modern cultural activity are often found in the context of illegal access 
attempts or legal recreational activities on the northern end of the island, as is the case with 35MU62 and PJD002, respectively.

My research has also shed much light on what has been lost from known assemblages, and what kind of loss should be expected for the future. My survey revealed an extensive loss of Indigenous components, particularly diagnostic artifacts from previously recorded assemblages. Features, particularly those with charcoal, are uniquely vulnerable to bank erosion that appears to be accelerating. At numerous sites, many defining aspects of previously recorded lithic assemblages were not relocated, nor were hearth features. This loss has taken place not only at sites that have not been visited in decades, but also at sites only just recently recorded. It is clear that wave action, redirected currents, and more are quickly degrading sites along the Multnomah Channel. My work has created the first shoreline-wide baseline for the current condition and assemblage characteristics of each site along the channel. This baseline assessment can be used to immediately address the loss I observed along the channel, with the continued partnership of the Grand Ronde, as well as that of applicable agencies, landowners, and other tribes.

Finally, my work along the shoreline has shed new light on the nature of Indigenous and Euro-American activity on Sauvie Island, through the precontact, postcontact, and late-historic periods. Ethnohistorically and ethnographically, it had been clear that Sauvie Island has been a source of Indigenous subsistence and gathering since the island's formation some 2,500 years ago. For the first time, a clear outline of sites, including site maps, photographs, and detailed descriptions, now exists for the majority 
of the western Sauvie Island shoreline. This exploration has revealed not only evidence of occupation and use, but has highlighted valuable aspects of the record, such as hearth features which will contribute to the chronology of human occupation on the island and help to date sites with greater specificity. Diverse, multicomponent assemblages may highlight the complex period of early post-contact interaction between Indigenous and Euro-American peoples. The presence of $19^{\text {th }}$ century ceramic remains, in conjunction with fire-cracked rock assumed to be Indigenous in origin, suggests an early post-contact landscape where Sauvie Island accommodated multiple populations and their cultural materials, likely intermingling. My research has identified new assemblages that may represent these diverse activities, be they trade, early agricultural efforts, or use of the island by Indigenous peoples following the epidemics of the 1830's.

\section{The Benefits of Collaboration and the Lessons Learned}

As has been demonstrated with other partnerships between descendant communities of the Lower Columbia and archaeologists (e.g.; Daehnke 2017; Wilson 2015), collaborating, in this case with the cultural resource staff of the Confederated Tribes of the Grand Ronde, was essential in selecting this study area, developing the prioritization assessment, and ultimately, completing this project. The nature and findings of said collaboration are, in and of themselves, an important part of the results and conclusions of this project. In addition to the preliminary collaboration with tribal partners, who assisted in the selection of the study area, collaboration during the development of the prioritization process expanded on the concept of cultural resource value, incorporating tribal values, which expand beyond the contribution of western 
science and knowledge, often used alone to assess significance according to NRHP guidelines. Thus, incorporating tribal knowledge and participation opened up new routes for preservation and mitigation, which must become increasingly adaptable as a rapidly increasing number of cultural resources are at risk of loss.

The most important part of my collaboration with the Grand Ronde THPO staff was the development and incorporation of intangible values, or intangible aspects of overlapping, already developed tangible values. For example, incorporating "reconnectivity" dramatically reframes the view of a site's importance. By traditional archaeological measures, the previously recorded 35MU61 site and newly identified PJD005 site rank low on the scale of importance. 35MU61 has seen significant loss of assemblage since the initial recording in the 1980's. The variety of tools and multicomponent nature of the site has been lost, as has the weir feature, and associated in situ bank deposit previously recorded. At PJD005, the assemblage is a homogenous scatter of fire-cracked rock with no apparent artifact diversity or observed cultural features. It has also been impacted by modern cultural disturbance in the form of recreational activity and discarded modern debris. From a traditional archaeological perspective, the value of these sites would be minimal, due to the damage and lack of obvious cultural materials. However, to the Grand Ronde, these sites garnered higher value scores due to reconnectivity, in these cases, the ability to and value of revisiting the site with tribal members, and the lessons to be taught and learned during that process.

To our tribal partners, these sites each represented two important aspects of reconnectivity. 35MU61 is part of a complex of fire-cracked rock sites, along with 
35MU62 and 35MU63, that runs along the southern shoreline to the north and south of the Sunken Village site. The Sunken Village site has long represented a teaching tool for the Grand Ronde, regardless of its current condition. Documentation of its assemblage is rich, landowners, public and private, are amenable to access, and the activities conducted at the site in the past are of great interest to the tribe. Most importantly in the context of 35MU61, the shoreline that connects the site to Sunken Village is flat and gradually sloping, with significant areas exposed consistently throughout the summer and late fall below the high-water mark. In simple terms, it is a brief and relatively easy walk from the Sunken Village site to the 35MU61 site. For the purposes of active teaching or revisitation sessions, the 35MU61 is part of a valuable and accessible complex. As such, even given its relatively poor condition, it retains a value to the Grand Ronde that cannot accurately be expressed purely in terms of the physical archaeology present at the site. PJD005 offers similarly accessible visitation opportunities and its location on exclusively public land would allow the Grand Ronde to spend as much time at the site as the tides allowed. Like 35MU61, it sits in the midst of numerous fire-cracked rock sites and within close proximity to multiple ethnographic village locations. These sites, with their intangible characteristics, do not represent the most extensive archaeological assemblages surveyed during my project, but they nevertheless represent some of the most distinct tribal values garnered during my assessment.

In addition, it was through collaboration with tribal staff that we developed a means of communicating proximity to ethnographic villages as a tribal and archaeological value. Although the general information on ethnographically recorded 
villages in the Sauvie Island area is publicly available, it was only through collaboration with the Grand Ronde that we gained access to a spatially anchored GIS dataset that would dramatically refine and accelerate the proximity determination process. Such datasets are a good example of the knowledge that tribal communities hold internally, knowledge that can be accessed through respectful inquiry and partnership.

Throughout my thesis research, the Confederated Tribes of the Grand Ronde were kept informed of the progress made, both in the form in-person meetings, as well as phone and email communication. Cultural resources staff from the tribe helped to select the study area on Sauvie Island and provided overview materials of the preliminary assessments of the island's cultural heritage from the perspective of the Grand Ronde. A map of that preliminary assessment indicated areas of ethnographic relevance to the Grand Ronde that went beyond existing site locations. Some areas, like Fort William Bend, are well known ethnohistorically as early settlements and gathering places on the island (Spencer 1950; Watson 2010) but others, such as areas in the island's north, are not clearly referenced in ethnographic records, other than as part of the general locations for the many villages proposed to be located on or around Sauvie Island (e.g.; Boyd 2011; Boyd and Hajda 1987; Deur 2012; Ellis et al. 2013; Zenk et al 2016). In discussions with Grand Ronde staff, it was indicated that these areas may correspond to knowledge from tribal ethnographies or reflect stories that were passed down from tribal members who may have once been involved with historic-era settlement on the island. Unsurprisingly, several new sites corresponded with these areas, particularly around the shoreline facing Coon Island on the Multnomah Channel. 
The Future and Broader Applications of Prioritization Assessments

Other scholars have demonstrated how the input of descendant communities can dramatically improve and expand the applicability, benefit, and equitability of the risk assessment process (e.g.; S. Anderson 2016; Carmichael et al. 2017a; 2017b; 2018; Newland et al. 2017). My research reinforced the importance of and the need to expand risk assessment to incorporate Indigenous values and I provide a model for such work. The collaborative approach I took yielded a wealth of information that can and should be accessed by future researchers and land managers as they seek to best address the need for preservation and mitigation in the coming years. The Western approach to cultural resource assessment and preservation has tended to focus on aspects traditionally associated with expansion of scientific knowledge, such as the presence, absence, and amount of physical material at an archaeological site, and sites are often held as distinct entities, with the status of their physical assemblage prioritized over the status of their intangibles. And while an increasing number of Western academics have acknowledged the need to deconstruct that trend (Hardesty and Little 2009; King 2013), case studies, such as those of Carmichael et al. (2017a; 2017b;), remain far too scarce. My collaboration with the Grand Ronde is an effort to redress this scarcity.

As demonstrated over the course of my project, a new path forward can be charted for risk assessment and cultural resource preservation. Although there is much overlap between how the Grand Ronde and the academic archaeological community prioritize cultural resources, my discussion with tribal partners over the course of this project highlighted the emphasis that the tribe places on potential, versus the limits of 
objective observation. The Grand Ronde view sites, even destroyed ones or those with seemingly "mundane" archaeological assemblages such as FCR scatters, as teaching opportunities, as places to revisit, and as evidence of their presence on the landscape. And although not all sites can be preserved and many are vulnerable even to purely natural forces, considering the intangible value of a site can guide the partnership between land managers and tribal members.

Recognizing the intangible values of cultural resources opens up new horizons for mitigation efforts (Carmichael et al. 2018). On the waterways of the Lower Columbia, shoreline cultural resources have the unique characteristic of being accessible via boat. Such an access strategy can expand and facilitate assessment and visitation efforts, as it has in the case in the work of Gendron (2018) and Reeder-Myers and Rick (2019), along the eastern seaboard of North America. Here on the Lower Columbia, in addition to those benefits, it can also allow tribes such as the Grand Ronde to visit in a traditional manner, via canoe paddling events, an important aspect of reconnectivity. Preservation too, can be viewed with a new perspective. What may be considered a simple fire-cracked rock scatter impacted by modern debris and trash offers an opportunity for tribal youth to engage in a visitation and clean-up effort. The value comes not simply in the physical characteristics of a site, but in the opportunity to interact with the place on the landscape, to understand its role in tribal history and tradition (Carmichael 2018). A string of Indigenous scatters in close proximity represents a pattern of activity, a group of sites that may well have been the task sites surrounding a village, or seasonally used processing locations, something that may be recognized in future work utilizing a landscape 
approach (Hardesty and Little 2009). And as such, one can also consider these areas high potential for future research purposes. In sum, their value is tenfold, it extends beyond immediately observed artifacts, and awareness of said value allows for preservation efforts to be efficiently and creatively tailored to the full value of a cultural resource.

My work allowed for these matters to be considered in a research methodology, site form, and series of informed questions that can serve as a template for land managers and archaeologists (Appendix G). Not only can such a template make mitigation efforts with tribal stakeholders more effective and efficient, but it can expand the options that land managers have at hand when considering the treatment of at-risk cultural resources. This is particularly true for the Sauvie Island area, where abundant shoreline resources and ongoing negative impacts from erosion should promote action by state and federal agencies. Using the outline that I have created here, first contact with tribal partners can be a much more efficient process, as land managers and academics work harder beforehand to identify what aspects of cultural resources would contribute to tribal value. Furthermore, my project has highlighted the role of creative mitigation strategies for sites where degradation and loss may be inevitable or far too expensive to prevent. In these situations, I have identified the value of mitigation strategies such as visitations or cleanup projects for modern trash cluttering a site area, as well as strategically targeted testing of features that may be of interest to both academic and tribal knowledge pursuits. These mitigation strategies are achievable on a landscape where cultural resources are under greater, more imminent risk than ever before. Ultimately, my prioritization assessment has provided a guideline for future cultural resource preservation and mitigation efforts 
by agencies and other stakeholders along the Sauvie Island shoreline, by providing extensive data on the characteristics of and risks facing each site along the western shoreline.

\section{Future Research and Engagement on Sauvie Island}

\section{Incorporating Views of Other Lower Columbia Tribes}

Other tribes, including those initially selected for outreach during this project, have deep interests and concerns regarding resources along the lower river. These tribes may well have different conceptualizations of value for cultural resources, different perspectives on the process, and different ideas of preservation and mitigation. Tribal values are alive, they grow and evolve, and can vary widely. As such, any future research using the framework I have developed here should seek to expand the circle of participation and gain a greater understanding of tribal values beyond those of the Grand Ronde. Over the course of our collaboration, a procedure has been developed as a case study, to help land managers and academics consider what values a tribe may hold in regard to a cultural resource, but the specifics of this undoubtedly will differ among tribes to an unknown degree. My work provides a template that allows for the exploration of these differences. Future research should devote resources and time to learning about how value varies across Lower Columbia tribal communities. In addition, Euro-American stakeholders, should be brought into discussion on establishing preservation priorities, given the complex nature of post-contact interaction, as noted in prior sections. In general, as demonstrated by Hambly (2017a; 2017b; 2018), there is great value in 
including broader community perception of cultural resources into both the assessment of those resources and the eventual preservation efforts that result.

\section{Visiting Sauvie Island with Tribal Staff and Members}

As has been the case elsewhere in the area, at sites such as Sunken Village (Croes 2007; 2009) and Fort Vancouver (Wilson 2015), a theme that asserted itself throughout my project and appears as a key aspect of reconnectivity in tribal value is the ability of tribal members to visit archaeological sites. While I have presented detailed accounts of the sites I recorded to the Grand Ronde, a next step could be for the Oregon Department of Fish and Wildlife to facilitate opportunities for THPO staff and tribal members at large to experience the sites that I identified during my work. As was reflected in my scores, the tribe places great value on the ability to use public land to access sites, either by water or by land, and the majority of the new sites that I located lie not just on public land, but within a short boat ride from ODFW managed public boat ramps. Moving forward, an important goal should be a touring of the sites located on the northern half of the western shoreline, conducted with myself, Dr. Butler, ODFW staff, and THPO staff members. These visits could not only allow THPO staff members to observe newly identified cultural resources, but these resources could well be incorporated into activities such as traditional canoe paddling events, teaching curriculum, or tribal youth programs. The relative accessibility of these sites can hopefully offer numerous reconnection opportunities to the Grand Ronde in the near future. 


\section{Expanding Prioritization Assessment to Greater Sauvie Island}

Sauvie Island's cultural resources, recorded and otherwise, extend far beyond the western shoreline. Several village sites are known in the interior (Pettigrew 1977; 1981), and tribal members are aware of isolates that suggest the presence of additional, as of yet unrecorded cultural resources. Some of these resources are on public land, others are on private land. Some have past records from the work of Pettigrew (e.g.; 1973d) and others, allowing for a baseline comparison of site condition. Moving forward, a future research goal should be the application of this prioritization assessment to the rest of the island's known archaeological sites, paired with a survey effort, in partnership with tribal staff and state agencies, as applicable, to identify new sites based on landowner reports, archaeological records, ethnographic information, and tribal knowledge. Additionally, expansion of survey and assessment into the island's interior could offer an opportunity to readdress tribal interest in culturally important plant resources that were not present along the shoreline but can likely be found in the interior.

\section{$\underline{\text { Seeking the Cunningham Weir Site }}$}

An attempt should be made to return to Cunningham Slough and conduct pedestrian and waterborne survey. Although access to the area can be challenging, due to distance from kayak launching points and dense overland vegetation, ethnographic records suggest that a village may have been located at the mouth of the slough and reports from local landowners suggest the potential for a partially intact weir. Additionally, survey by Jenkins and Fagan (2014) noted two inland sites, 35CO72 (Jenkins 2014a) and 35CO73 (Jenkins 2014b) along the slough and suggested the 
likelihood of additional exposure as erosion continues in that area. Survey and recording that were beyond the scope of my own project should be conducted as soon as possible. The slough is a prime access point for recreational hunters and sees significant seasonal boat traffic, which is likely impacting any cultural features that may remain in the area, through wake or due to pedestrian traffic from hunters heading inland. As is the case with all sites located on the northern half of the island, a partnership could easily be formed with the ODFW and tribal staff to facilitate visits to the area and subsequent survey and documentation. In this case, a visit via boat would be particularly important, not only for accessing the shoreline, but also for surveying shallow water in the slough where weir stakes might be embedded.

\section{Dating and Documentation at PJD002}

Perhaps most important in terms of physical archaeology assessed during my research, the PJD002 site is at a critical juncture. The site faces a variety of impacts, including inevitable and severe erosion, but also impacts from modern cultural activity that could be mitigated. The diverse assemblage at the site warrants further exploration, as does the potential for that assemblage to be tied to an early homestead, either further north or south along the shoreline, or towards the interior of the island. The most important archaeological element at the site is the reported hearth feature and dates acquired from surrounding sediments by USGS geologists (Evarts et al. 2016). A dating of the hearth itself could well indicate a site that represents the oldest human habitation on the island and could suggest a more precise age range for the island itself, which has only been generally dated. However, this hearth feature is under extreme threat due to 
erosion, staying at or below the waterline for the majority of the year. It is imperative that future research be conducted immediately, in partnership with the Grand Ronde and the ODFW, to acquire necessary SHPO permits and conduct a degree of strategic testing, while also visiting during extreme low water periods in July, to fully document the extent of the assemblage.

\section{$\underline{\text { Relocating Fort William }}$}

This represents one of the primary remaining gaps in archaeological knowledge of the island. Although significant ethnohistorical records have long documented some of the earliest Euro-American occupation in the area (Watson 2010), previously recorded Euro-American sites sit just inland, and Indigenous sites lie just to the south, no archaeological survey has been conducted in the area proper. Dedicated efforts should be made to contact and establish a relationship with the current owners, the Pastorino family. Overland access to the area would allow a pedestrian survey on and above the beach, which is critical to determining the location of the remains of Fort William, such as they are. The early post-contact nature of this site would offer insight into the transitionary period of early contact between Indigenous inhabitants and Euro-American settlers. The potential of connecting site PJD001 with both additional Indigenous sites along the shoreline, as well as post-contact cultural resources in the vicinity makes Fort William and the surrounding area an important location for future research.

\section{Accessing the Fazio Parcel}

In regard to previously recorded cultural resources, the shoreline cluster of sites that sit along the Fazio property represents the biggest gap, or exclusion, in my survey of 
the western shoreline. No less than six sites, 35MU64, 35MU65, 35MU66, 35MU67, 35MU68, and 35MU137 (Darby 1987; Newman and Reese 1987; Reese 1987b; Reese et al. 1987b; 1987c; Stenger and Newman 1987), sit on the shoreline of the Fazio property, but a moored houseboat in the area necessitates landowner permission to avoid any negative interaction with said landowner, despite technical public rights to access below the high-water mark. Although the landowner can be contacted via phone and email, an effort should be made to establish contact through annual events on Sauvie Island, such as the Sauvie Island Jubilee, which occurs every fall. That event could facilitate a more amicable, in-person contact with the landowner and/or connect future researchers with surrounding landowners who could also help facilitate communication. The recordings of sites on the Fazio property suggest relatively significant Euro-American scatters and structural debris, which could connect to early Euro-American agricultural efforts on the island. Better understanding the nature of these sites and comparing the condition of assemblages to that described in the 1980's would complete the understanding of existing sites along the western shoreline.

\section{$\underline{\text { Relocating the Pumphouse Site }}$}

Additionally, although it lies beyond the scope of this project, my background research suggested a need to update and rerecord the location for site $35 \mathrm{CO}$, the Pumphouse site, which is currently inaccurately depicted in SHPO records as being on private land. In fact, according to Pettigrew's (1973d) initial reports, the site likely sits on ODFW land, within a well-cleared field, allowing for easy seasonal access to conduct a surface survey and assessment. Relatively detailed description of the surface exists from 
the early 1970's, as well as reports from Pettigrew's $(1977 ; 1981)$ subsurface testing, allowing for a broad assessment of the nearly 50 years of impacts to the site. Pettigrew's research suggested a potential for an Indigenous village or semi-permanent habitation at the site and given its position away from the shoreline and its location on public land, the Pumphouse site may offer a unique opportunity for archaeologists, land managers, and tribal members to examine and protect a site which may be better preserved than shoreline sites. In the spirit of my research, if the site is relocated on public land, it would be of great importance to the Grand Ronde as a point of reconnection, because of the ease of access, for research, teaching, and general revisitation. Working with the ODFW, the site has a degree of survivability as well, given that the greatest impacts are likely from recreationalists and cattle, as opposed to anthropogenically exacerbated natural erosional impacts as seen on the shoreline.

\section{Bringing in Additional Professional and Academic Experts}

Questions regarding timing and nature of human use of the island, traditionally answered by western science, along with questions more specific to tribal goals, point to the value of targeted research by other specialists, integrated into an interdisciplinary approach, used successfully in other work related to risk assessment (e.g.; Feagin et al. 2005; C. Johnson and Germano 2020; Perdikaris et al. 2017). For example, geomorphological and hydrological questions could be addressed through interdisciplinary collaboration. Geologists have already conducted some work in the area (e.g.; Bourdeau 2004; Cannon 2015; Evarts et al. 2016) and have expressed interest in questions that could establish a more precise and accurate chronology of human use of 
the island. Such work could inform on both small- and large-scale flooding events that have shaped that use (e.g.; Evarts et al. 2016; Helaire et al. 2014; 2019). Light Detection and Ranging (LiDAR) may also offer tools for use in monitoring and assessment (e.g.; Rowland et al. 2014) and was just recently applied in the region as part of an interdisciplinary site identification project (e.g.; Cody 2019; Cody and S. Anderson 2021). Additionally, while modelling of the long-term impacts of climate change on the Lower Columbia in regard to cultural resources was beyond the scope of my work, the threat of climate change still looms over cultural resources (e.g.; C. Johnson and Germano 2020; Yu et al. In Press).

Future interdisciplinary collaboration, particularly with geologists and environmental engineers, could shed light on an issue that is already of concern to the Grand Ronde, as evidenced by the previously discussed bathtub model for Sauvie Island (Edwards 2018). Several avenues of existing research could contribute to a model specifically addressing impacts on cultural resources across the Lower Columbia. This could include work that explores the complex interaction between rising sea levels and seismic uplift along the Oregon coast (e.g.; Burgette et al. 2009; Talke et al. 2018), or work that addresses the impacts of rising sea levels on water management in urban areas (e.g.; Rostaminia and Wolff 2018). It could also include research that identifies how sea level rise impacts tidal variation (e.g.; Devlin et al. 2017; Jay et al. 2011; 2015) or discusses how changes in seasonal precipitation could impact runoff (e.g.; Chang and Jung 2010). While such efforts have largely been related to environmental conservation, water management, and infrastructure concerns, interdisciplinary work could allow for 
the application of these and other emerging modelling to better understand how the longterm impacts of climate change, notably sea level rise, will affect cultural resources in the Portland Basin area. Climate change was ultimately not the focus of my work, but its impacts cannot be underestimated.

Finally, while the scope of my work and limitations imposed by the pandemic necessitated a focus on working with the Grand Ronde THPO staff alone, future work could explore additional perspectives within the broader tribal community, both with the Grand Ronde as well as with other tribal communities. Examples of this are found in assessments such as conducted by Carmichael et al. (2017a; 2017b), where expansive ethnographic work, in the form of interviews, focus groups, and surveys, established a broad sample and recording of views on cultural resources throughout a region, for an Indigenous population. Such research could only serve to further refine the values identified during my project, and the aforementioned evolving nature of tribal values could be better explored.

\section{A New Perspective}

Over the course of the two years during which I have partnered with the Grand Ronde, I have grown immensely as an archaeologist and my understanding of how I want to conduct archaeology in the future has grown in turn, in a manner that is in its own way another result of this project. While I continue to acknowledge the answers that come from the Western scientific perspective, I have learned how and why to seek out the answers that lie beyond it, answers which are found in the incorporation of an Indigenous perspective. The process of finding those answers and that perspective is iterative, it 
requires a commitment to going beyond a single consultation, a genuine desire to return again and again to tribal partners, to establish a relationship of trust and friendship. Collaboration is not a one-way, single-take interaction, it is not extractive, nor can it result where there is no relationship. To best address the preservation of cultural resources, archaeologists must seek to establish a holistic understanding of the value of those cultural resources, an understanding that cannot be had without making a goodfaith commitment to investing time and resources into a genuine collaborative effort moving forward. To strive for decolonization, for democratization, and for inclusivity means directly communicating with our tribal partners, continuing that communication until the project at hand is completed, and then building on that successful communication to create better outcomes in the future. Methodology will evolve, tribal values will evolve, and research priorities will evolve. Without communication and collaboration, our process and our understanding will once again grow static and our actions reactive rather than proactive. Too often we commit to the preservation of culture without asking whose culture we are preserving. To preserve it is and must be a collective effort. It is both our mandate and our privilege as archaeologists to strive for that effort. These are but a few of the lessons I have taken from this project, and it is my hope that they can be learned across a new generation of archaeologists and a new era of archaeology.

\section{Summary}

In conclusion, my work on Sauvie Island has led to the creation of a blended prioritization assessment, a case study which demonstrates how the input of tribal 
partners can have a dramatic impact on an assessment, as well as its value to all stakeholders, not just agencies or academics. Through my collaborative efforts with the Grand Ronde THPO, I have laid out a process by which a non-tribal land manager can guide their background research, identify goals for assessment, develop an informed draft to deliver to tribal members, and dramatically expand the possibilities for mitigation, even for sites where complete loss is inevitable. This research outlines a process by which land managers and academics do not simply ask questions of tribal communities but ask questions with tribal communities, to develop a sense of value and strategies for preservation together, rather than apart. In addition to developing this process, I have dramatically expanded the archaeological knowledge of the western shoreline of Sauvie Island. Ten new sites have been located, many of which provide intriguing opportunities for future research that may help identify the earliest human occupation on the island, while also shedding light on the early post-contact period, when Indigenous inhabitant and Euro-American occupiers first began to interact on the landscape. Elements of ethnohistorical accounts have been confirmed or expanded upon, and combined with ethnographically recorded village locations, it may be possible to predict the location of future sites and better understand the activities of the Indigenous inhabitants of Sauvie Island prior to contact. In summary, Sauvie Island remains an integral part of Lower Columbia and Portland Basin archaeology and addressing the preservation of its cultural resources, while a daunting task, can be undertaken, and in partnership with the communities that have inhabited the land since time immemorial. 


\section{References Cited}

Ames, Kenneth M. 1992. Archaeological Context Statement Portland Basin. Portland: Department of Anthropology, Portland State University.

Ames, Kenneth M. 1994. "The Northwest Coast: Complex Hunter-Gatherers, Ecology, and Social Evolution." Annual Review of Anthropology 23: 209-229.

Ames, Kenneth M., and Elizabeth A. Sobel. 2009. "Finding and Dating Cathlapotle." Archaeology in Washington 15: pp. 5-32.

Ames, Kenneth M., and Emily E. Shepard. 2019. "Building Wooden Houses: The Political Economy of Plankhouse Construction on the Southern Northwest Coast of North America." Journal of Anthropological Archaeology 53: 202-221.

Ames, Kenneth M., Cameron M. Smith, William L. Cornett, Elizabeth A. Sobel, Stephen C. Hamilton, John Wolf, and Doria Raetz. 1999. Archaeological Investigations at 45CL1 Cathlapotle (1991-1996): Ridgefield National Wildlife Refuge, Clark County, Washington, A Preliminary Report. U.S. Fish and Wildlife Service, U.S. Department of the Interior, Portland: U.S. Fish and Wildlife Service, 1-106.

Ames, Kenneth M., Katie Henry, Kristen Ann Fuld, Sara J. Davis, Stephen Coursalt Hamilton, and Cameron McPherson Smith. 2017b. Lithic Technology, Projectile Points, Osseous Artifacts, and Artifact Classification of the Cathlapotle and Meier Archaeological Sites, Lower Columbia River. Cultural Resource Series Number 19, U.S. Department of the Interior, U.S. Fish \& Wildlife Service, Portland: Portland State University.

Ames, Kenneth M., Katie Henry, Stephanie Butler, William Gardner-O'Kearney, and Emily Shepard. 2017a. Architecture, Fire, and Storage: Cathlapotle and Meier Features. Cultural Resource Series Number 17, U.S. Department of the Interior, U.S. Fish \& Wildlife Service, Portland: Portland State University.

Ames, Kenneth M., Katie Henry, Virginia L. Butler, Gay Frederick, R. Lee Lyman, Tim Riley, Antonia Rodrigues, Shoshana J. Rosenberg, Camilla F. Speller, and Dongya Yang. 2017c. The Zooarchaeology of the Cathlapotle and Meier Archaeological Sites, Lower Columbia River. Anthropology Faculty Publications and Presentations. 171, Portland: U.S. Department of the Interior; U.S. Fish \& Wildlife Services, Region 1; and Portland State University, Department of Anthropology.

Anderson, David G., Thaddeus G. Bissett, Stephen J. Yerka, Joshua J. Wells, Eric C. Kansa, Sarah W. Kansa, Kelsey Noack Myers, R. Carl DeMuth, and Devin A. White. 2017. "Sea-Level Rise and Archaeological Site Destruction: An Example 
From the Southeastern United States using DINAA (Digital Index of North American Archaeology)." PLoS ONE 12 (11): p.e0188142.

doi:10.1371/journal.pone.0188142.

Anderson, Shelby. 2016. Northern Alaska National Historic Landmark Condition and Vulnerability Assessment Project. Risk Assessment, Portland: Portland State University, Department of Anthropology.

Anderson, Shelby, and Tia Cody. 2019. Final Report: The Western Arctic Parklands Cultural Resource Coastal Vulnerability Study. Risk Assessment Report, Portland: Portland State University, Department of Anthropology.

Atalay, Sonya. 2012. Community-Based Archaeology: Research With, By, and for Indigenous and Local Communities. 1st. Berkeley, California: University of California Press.

Atalay, Sonya. 2006. "Indigenous Archaeology as Decolonizing Practice." American Indian Quarterly 30 (3/4): 280-310.

Atalay, Sonya. 2008. "Multivocality and Indigenous Archaeologies." Chap. 3 in Evaluating Multiple Narratives: Beyond Nationalist, Colonialist, Imperialist Archaeologies, edited by Junko Habu, Clare Fawcett and John M. Matsunaga, 2944. New York, New York: Springer Science+Business, LLC.

Babcock, Sarah J. 1989. Side Slope Sedimentation Following New Work Dredging on the Lower Columbia River, Oregon and Washington. San Jose, California: Unpublished M.S. Thesis.

Barcalow, Kate Monti, and Jeremy Spoon. 2018. "Traditional Cultural Properties or Places, Consultation, and the Restoration of Native American Relationships with Aboriginal Lands in the Western United States." Human Organization 77 (4): 291-301.

Benito, Gerardo, and Jim O'Connor. 2003. "Number and Size of Last-Glacial Missoula Floods in the Columbia River Valley Between the Pasco Basin, Washington, and Portland, Oregon." GSA Bulletin 115 (5): 624-638.

Bickler, Simon, Rod Clough, and Sarah Macready. 2004. "The Impact of Climate Change on the Archaeology of New Zealand's Coastline: A Case Study from the Whangarei District." Science for Conservation, 1-54.

Boas, Franz. 1894. Chinook Texts. 1st. Washington D.C.: Smithsonian Institution, Bureau of Ethnology.

—. 1901. Kathlamet Texts. 1st. Vol. Bulletin 26. Washington D.C.: Smithsonian Institution, Bureau of American Ethnology. 
Boit, John. 1921. A New Log of the Columbia by John Boit on the Discovery of the Columbia River and Grays Harbor. 1st. Edited by Edmond S. Meany. Seattle, Washington: University of Washington Press.

Bonsall, James, and Sam Moore. 2017. "The MASC Project (Monitoring the Archaeology of Silgo's Coastline): Engaging Local Stakeholder Groups to Monitor Vulnerable Coastal Archaeology in Ireland." Chap. 7 in Public Archaeology \& Climate Change, edited by Tom Dawson, Courtney Nimura, Elías López-Romero and Marie-Yvane Daire, 62-71. Oxford: Oxbow Books.

Bourdeau, Alex. 2004. "Geologically Complex": The Flood Plain of the Lower Columbia River. Geological Report, U.S. Fish and Wildlife Service, Sherwood: U.S. Fish and Wildlife Service.

Boyd, Robert. 2011. Appendix 1B-II: Ethnohistorical Accounts of Indian Settlements and Land Use in the Vicinity of the Interstate 5 Bridge Over the Columbia River. CRC Archaeology Technical Report, Heritage Research Associates, Inc.

-. 2011. Cathlapotle and its Inhabitants, 1792-1860: A Report Prepared for U.S. Fish and Wildlife Service, Region 1. 1st. Vol. Cultural Resources Series \#15. Portland: U.S. Fish and Wildlife Service.

Boyd, Robert T. 2013. "Lower Chinookan Disease and Demography." Chap. 11 in Chinookan Peoples of the Lower Columbia, edited by Robert T. Boyd, Kenneth M. Ames and Tony A. Johnson, pp. 229-249. Seattle, Washington: University of Washington Press.

Boyd, Robert T., and Yvonne P. Hajda. 1987. "Seasonal Population Movement along the Lower Columbia River: The Social and Ecological Context." American Ethnologist 14 (2): 309-326. doi:10.1525/ae.1987.14.2.02a00080.

Bright, William. 2004. "A Glossary of Native American Toponyms and Ethnonyms from the Lewis and Clark Journals." Names 52 (3): 163-237. doi:10.1179/nam.2004.52.3.163.

Burgette, Reed J., Ray J. Weldon II, and David A. Schmidt. 2009. "Interseismic Uplift Rates for Western Oregon and Along-Strike Variation in Locking on the Cascadia Subduction Zone." Journal of Geophysical Research 114 (B01408): 1-24. doi:10.1029/2008JB005679.

Butler, Virginia L. 2007. "Relic Hunting, Archaeology, and Loss of Native American Heritage at The Dalles." Oregon Historical Quarterly 108 (4): 624-643.

Butler, Virginia L., and Michael A. Martin. 2013. "Aboriginal Fisheries of the Lower Columbia River." In Chinookan Peoples of the Lower Columbia, edited by Robert 
T. Boyd, Kenneth M. Ames and Tony A. Johnson, pp. 80-105. Seattle: University of Washington Press.

Caldwell, Warren Wendell. 1956. The Archaeology of Wakemap: A Stratified Site Near The Dalles of the Columbia. University of Washington, Seattle: Unpublished Phd Dissertation.

Canniff, KiKi. 2014. Sauvie Island: A Step Back in Time. 2nd. Keizer, Oregon: One More Press.

Cannon, Charles Matthew. 2015. "Landforms Along the Lower Columbia River and the Influence of Humans." Portland: Unpublished Masters Thesis, Department of Geology, Portland State University.

Canuti, Paolo, Nicola Casagli, Filippo Catani, and Riccardo Fanti. 2000. "Hydrological Hazard and Risk in Archaeological Sites: Some Case Studies in Italy." Journal of Cultural Heritage 1 (2): 117-125. doi:10.1016/S1296-2074(00)00158-8.

Carmichael, Bethune. 2015. "Supporting Indigenous Rangers' Management of ClimateChange Impacts on Heritage Sites: Developing an Effective Planning Tool and Assessing its Value." The Rangeland Journal 37: 597-607. doi:10.1071/RJ15048.

Carmichael, Bethune, Greg Wilson, Ivan Namarnyilk, Sean Nadji, Jacqueline Cahill, and Deanne Bird. 2017a. "Testing the Scoping Phase of a Bottom-Up Planning Guide Designed to Support Australian Indigenous Rangers Manage the Impacts of Climate Change on Cultural Heritage Sites." Local Environment (22) 10: 11971216. doi:10.1080/13549839.2017.1332018.

Carmichael, Bethune, Greg Wilson, Ivan Namarnyilk, Sean Nadji, Jacqueline Cahill, Sally Brockwell, and Deanne Bird. 2017b. "Australian Indigenous Rangers Managing the Impacts of Climate Change on Cultural Heritage Sites." Chap. 17 in Public Archaeology and Climate Change, edited by Tom Dawson, Courtney Nimura, Elías López-Romero and Maria-Yvane Daire, 162-174. Oxford: Oxbow Books.

Carmichael, Bethune, Greg Wilson, Ivan Namarnyilk, Sean Nadji, Sally Brockwell, Bob Webb, Fred Hunter, and Deanne Bird. 2018. "Local and Indigenous Management of Climate Change Risks to Archaeological Sites." Mitigation and Adaptation Strategies for Global Change 23: 231-255. doi:10.1007/s11027-016-9734-8.

Chang, Heejun, and Il-Won Jung. 2010. "Spatial and Temporal Changes in Runoff Caused by Climate Change in a Complex Large River Basin in Oregon." Journal of Hydrology 388: 186-207. doi:10.1016/j.jhydrol.2010.04.040.

Chinook Nation. 2019. Culture Committee.

http://www.chinooknation.org/committees/culture.html. 
Cody, Tia R., and Shelby L. Anderson. 2021. "LiDAR Predictive Modeling of Pacific Northwest Mound Sites: A Study of Willamette Valley Kalapuya Mounds, Oregon (USA)." Journal of Archaeological Science: Reports 38 (2021): 1-11.

Cody, Tia Rachelle. 2019. "LiDAR Predictive Modeling of Kalapuya Mound Sites in the Calapooia Watershed, Oregon." Portland: Unpublished M.S. Thesis, Portland State University.

Connolly, Thomas J., and R. Scott Byram. 1997. "Oregon Wet Site Basketry: A Review of Structural Types." In Contributions to the Archaeology of Oregon, 1995-1997, edited by Albert C. Oetting, pgs. 185-204. Eugene, Oregon: Association of Oregon Archaeologists.

Cox, Ross. 1832. Adventures on the Columbia River Including the Narrative of a Residence of Six Years on the Western Side of the Rocky Mountains. 1st. New York, New York: J. \& J. Harper.

Croes, Dale R. 1988. Sunken Village Site (35MU4): Archaeological Potential as a Northwest Coast Wet Site. Phase I Cultural Resource Management Report, Pullman: Washington State University and Pacific Northwest Archaeological Society.

Croes, Dale R., John L. Fagan, and Maureen Newman Zehendner. 2007. A U.S. National Historic Landmark Wet Site, The Sunken Village Site (35MU4), Portland, Oregon - The First Explorations. 2007 Report to the Oregon State Historic Preservation Office, Olympia, Portland U.S.A., Nara, Japan: Department of Anthropology, South Puget Sound Community College, Archaeological Investigations Northwest, Inc., Nara National Cultural Properties, National Institutes for Cultural Heritage.

Croes, Dale R., John L. Fagan, and Maureen Newman Zehendner. 2009. "Sunken Village, Sauvie Island, Oregon, USA: A Report on the 2006-2007 Investigations of National Historic Landmark Wet Site 35MU4." Journal of Wetland Archaeology 9: 1-216.

Cutright, Paul Russell. 2003. Lewis and Clark: Pioneering Naturalists. 1st. Lincoln, Nebraska: University of Nebraska Press.

Daehnke, Jon D. 2013. "“We Honor the House": Lived Heritage, Memory, and Ambiguity at the Cathlapotle Plankhouse." Wicazo Sa Review 28 (1): 38-64.

Daehnke, Jon D. 2007. "A 'Strange Multiplicity' of Voices." Journal of Social Archaeology 7 (2): 250-275. doi:10.1177/1469605307077484.

—. 2005. Cathlapotle...Catching Time's Secrets. 1st. Sherwood, Oregon: U.S. Fish \& Wildlife Service. 
-. 2017. Chinook Resilence: Heritage and Cultural Revitalization on the Lower Columbia River. 1st. Seattle, Washington: University of Washington Press.

Daly, Cathy. 2014. "A Framework for Assessing the Vulnerability of Archaeological Sites to Climate Change: Theory, Development and Application." Conservation and Management of Sites 16 (2): 268-282. doi:10.1179/1350503315Z.00000000086.

Darby, M. 1987. 35MU68 SHPO Site Form. Oregon SHPO Site Recording Form, Salem: Charles Hibbs \& Associates.

Darby, M., J. Johnston, and M. Shortridge. 1987. 35MU62 SHPO Site Form. Oregon SHPO Site Recording Form, Charles Hibbs \& Associates.

Darby, Melissa Cole. 1996. Wapato for the People: A Ecological Approach to Understanding the Native American Use of Sagittaria Latifolia on the Lower Columbia River. Portland, Oregon: Portland State University.

Darby, Melissa. 2002. "The Intensification of Wapato (Sagittaria latifolia) by the Chinookan People of the Lower Columbia River." Chap. 7 in Keeping It Living: Traditions of Plant Use and Cultivation on the Northwest Coast of North America, edited by Douglas Deur and Nancy J. Turner, 194-217. Seattle, Washington: University of Washington Press.

Dawson, Tom. 2013. "Erosion and Coastal Archaeology: Evaluating the Threat and Prioritising Action." Ancient Maritime Communities and the Relationship between People and Environment along the European Atlantic Coasts (2570): 77-83.

Dawson, Tom. 2015. "Taking the Middle Path to the Coast: How Community Collaboration can Help Save Threatened Sites." Chap. 15 in The Future of Heritage as Climate Change: Loss, Adaptation and Creativity, edited by David C. Harvey and Jim Perry, 248-267. New York, New York: Routledge.

Dawson, Tom, Joanna Hambly, and Ellie Graham. 2017. "A Central Role for Communities: Climate Change and Coastal Heritage Management in Scotland." Chap. 3, edited by Tom Dawson, Courtney Nimura, Elías López-Romero and Marie-Yvane Daire, 23-33. Oxford: Oxbow Books.

Delesalle, Veronique A., and Stephanie Blum. 1994. "Variation in Germination and Survival Among Families of Sagittaria Latifolia in Response to Salinity and Temperature." International Journal of Plant Science 155 (2): 187-195. doi:10.1086/297158.

Deur, Douglas. 2012. An Ethnohistorical Overview of Groups with Ties to Fort Vancouver National Historic Site. CRM Report, Pacific Northwest Cooperative Ecosystem Studies Unit, Pacific West Region, Seattle: National Park Service. 
Deur, Douglas. 2016. "The Making of Seaside's "Indian Place"." Oregon Historical Quarterly 117 (4): 536-573. doi:10.5403/oregonhistq.117.4.0536.

Devlin, Adam Thomas, David A. Jay, Edward Zaron, Stefan A. Talke, and Jiayi Pan. 2017. "Tidal Variability Related to Sea Level Variability in the Pacific Ocean." Journal of Geophysical Research: Oceans 122: 8445-8463. doi:10.1002/2017JC013165.

Dudley, Mabel Howell. 2019. The Flood of "48". 1st. Edited by Lee Greer, Rebecca McLain and Eric T. Jones. Unknown.

Dupont, Lien, and Veerle Van Eetvelde. 2013. "Assessing the Potential Impacts of Climate Change on Traditional Landscapes and their Heritage Values on the Local Level: Case Studies in the Dender Basin in Flanders, Belgium." Land Use Policy 35: 179-191. doi:10.1016/j.landusepol.2013.05.010.

Edwards, Briece R. 2018. "Potential Impacts of Sea-Level Rise to Traditional Cultural Landscapes, Properties, and Resources." Archaeology and Research Program, Historic Preservation Department, Confederated Tribes of the Grand Ronde.

Ellis, David V. 2013. "Cultural Geography of the Lower Columbia." In Chinookan Peoples of the Lower Columbia, edited by Robert T. Boyd, Kenneth M. Ames and Tony A. Johnson, pp. 42-62. Seattle: University of Washington Press.

Ellis, David V., Henry Zenk, and Robert Boyd. 2013. "Supplemental Materials for: Chapter 2: Cultural Geography of the Lower Columbia." Chap. 2: Supplemental in Chinookan Peoples of the Lower Columbia River, edited by Robert T. Boyd, Kenneth M. Ames and Tony Johnson, 1-27. Seattle, Washington: University of Washington Press.

Erlandson, Jon M. 2008. "Racing a Rising Tide: Global Warming, Rising Seas, and the Erosion of Human History ." The Journal of Island and Coastal Archaeology 3 (2): 167-169. doi:10.1080/15564890802436766.

Erlandson, Jon McVey. 2012. "As The World Warms: Rising Seas, Coastal Archaeology, and the Erosion of Maritime History." Journal of Coastal Conservation 16 (2): 137-142. doi:10.1007/s11852-010-0104-5.

Evarts, Russell C., Jim E. O'Connor, and Charles M. Cannon. 2016. Geologic Map of the Sauvie Island Quadrangle, Multnomah and Columbia Counties, Oregon, and Clark County, Washington: U.S. Geological Survey Scientific Investigations Map 3349, Scale 1:24,000, Pamphlet 34 p. Geologic Report, U.S. Geological Survey, U.S. Department of the Interior, U.S. Geological Survey. 
Evarts, Russell C., Jim E. O'Connor, and Ray E. Wells. 2009. "The Portland Basin: A (Big) River Runs Through It." GSA Today 19 (9): 4-10. doi:10.1130/GSATG58A.1.

Fagan, John L. 2004. Archaeological Exploration at 35MU4: The Sunken Village Site, A National Historic Landmark in Multnomah County, Oregon. Cultural Resource Management Report, Portland: Archaeological Investigations Northwest, Inc.

Feagin, Rusty A., Douglas J. Sherman, and William E. Grant. 2005. "Coastal Erosion, Global Sea-Level Rise, and the Loss of Sand Dune Plant Habitats." Frontiers in Ecology and the Environment 3 (7): 359-364. doi:10.1890/15409295(2005)003[0359:CEGSRA]2.0.CO.

Finegan, Chance. 2021. "How Can Urban Parks Support Urban Indigenous Peoples? Exploratory Cases from Saskatoon and Portland." Aboriginal Policy Studies 9 (2): 25-48.

Fisher, Andrew, and Melinda Marie Jetté. 2017. "Now You See Them, Now You Don't: Chinook Tribal Affairs and the Struggle for Federal Recognition." Chap. 14 in Chinookan Peoples of the Lower Columbia, edited by Robert T. Boyd, Kenneth M. Ames and Tony A. Johnson, pp. 288-306. Seattle, Washington: University of Washington Press.

FitzGerald, Duncan M., Michael S. Fenster, Britt A. Argow, and Ilya V. Buynevich. 2008. "Coastal Impacts Due to Sea-Level Rise." Annual Review of Earth and Planetary Sciences 36: 601-647. doi:10.1146/annurev.earth.35.031306.140139.

Foreman, Cam, and Dave Foreman. 1977. Herzog 45-CL-11. Portland: The Oregon Archaeological Society.

Franchere, Gabriel. 1854. Narrative of a Voyage to the Northwest Coast of America, In the Years 1811, 1812, 1813, and 1814 or the First American Settlement on the Pacific. 2nd. Edited by J.V. Huntington. New York: Redfield.

French, David. 1958. "Cultural Matrices of Chinookan Non-Casual Language." International Journal of American Linguistics 24 (4): 258-263.

Gahr, D. Ann Trieu. 2013. "Ethnobiology: Nonfishing Subsistence and Production." Chap. 3 in Chinookan Peoples of the Lower Columbia, edited by Robert T. Boyd, Kenneth M. Ames and Tony A. Johnson, 63-79. Seattle, Washington: University of Washington Press.

Gatschet, Albert S. 1877. "Indian Languages of the Pacific States and Territories." The Magazine of American History 1 (3): 145-171. 
Gendron, Danielle. 2018. "Paddling as Methodology." Northwest Anthropological Conference. Boise.

Gibson, Erica S. 2011. Ceramic Makers' Marks. 1st. New York, New York: Routledge.

Glick, Patty, Jonathan Clough, and Brad Nunley. 2007. Sea-Level Rise and Coastal Habitats in the Pacific Northwest: An Analysis for Puget Sound, Southwestern Washington, and Northwestern Oregon. Ecological Impact Report, National Wildlife Federation.

Gonzalez, Sara L., and Briece Edwards. 2020. "The Intersection of Indigenous Thought and Archaeological Practice: The Field Methods in Indigenous Archaeology Field School." Journal of Community Archaeology \& Heritage 7 (4): 239-254.

Gonzalez, Sara L., Ian Kretzler, and Briece Edwards. 2018. "Imagining Indigenous and Archaeological Futures: Building Capacity with the Confederated Tribes of the Grand Ronde." Archaeologies: Journal of the World Archaeological Congress 14 (1): 85-114.

Gonzalez, Sara, and Ian Kretzler. 2017. "Field School Update." 2018 Grand Ronde History and Culture Summit. Grand Ronde: The Confederated Tribes of Grand Ronde. https://www.grandronde.org/hcsummit/sara-gonzalez/.

Greenhow, Robert. 1844. The History of Oregon and California and the Other Territories of the North-West Coast of North America Accompanied by a Geographical View and Map of those Countires and a Number of Documents as Proofs and Illustrations of the History. 1st. Boston, Massachusetts: Charles C. Little and James Brown.

Hajda, Yvonne P. 1984. "Regional Social Organization in the Greater Lower Columbia, 1792-1830." Seattle: Unpublished Ph.D. Dissertation, University of Washington.

Hambly, Joanna. 2017a. Scotland's Coastal Heritage at Risk, A Review of Heritage at Risk from Coastal Processes in Scotland, Results from the Scotland's Coastal Heritage at Risk Project, 2012-2016. Risk Assessment and Community Engagement Report, St. Katharine's Lodge: The SCAPE Trust.

Hambly, Joanna. 2017b. Scotland's Coastal Heritage at Risk, Final Evaluation Report, August 2017. Risk Assessment and Community Engagement Report, St. Katharine's Lodge: The SCAPE Trust.

Hambly, Joanna. 2018. "Scotland's Coastal Heritage at Risk: Model of Volunteer Involvement in the Research and Management of a Threatened National Resource." The SAA Archaeological Record 18 (1): 16-20. 
Hardesty, Donald L., and Barbara J. Little. 2009. Assessing Site Significance: A Guide for Archaeologists and Historians. 2nd. Lanham, Maryland: Altamira Press.

Harvey, David C., and Jim Perry. 2015. "Heritage and Climate Change: The Future is not the Past." Chap. 1 in The Future of Heritage as Climates Change: Loss, Adaptation, and Creativity, edited by David C. Harvey and Jim Perry, 3-21. London: Routledge.

Helaire, Lumas T., Stefan A. Talke, David A. Jay, and Drew Mahedy. 2019. "Historical Changes in Lower Columbia River and Estuary Floods: A Numerical Study." Journal of Geophysical Research: Oceans 124: 7926-7946. doi:https://doi.org/10.1029/2019JC015055.

Helaire, Lumas, Andrew Mahedy, Stefan Talke, and David Jay. 2014. "Modeling Historic Columbia River Flood Impacts." Portland: Civil and Enviromental Engineering Faculty, Portland State University.

Hibbs, Charles H., and Judy Starkey. 1974. Archaeological Survey of Lady Island, Clark County, Washington. Portland: Oregon Archaeological Society.

Hollesen, Jørgen, Martin Callanan, Tom Dawson, Rasmus Fenger-Nielsen, T. Max Friesen, Anne M. Jensen, Adam Markham, Vibeke V. Martens, Vladimir V. Pitulko, and Marcy Rockman. 2018. "Climate Change and the Deteriorating Archaeological and Environmental Archives of the Arctic." Antiquity 92 (363): 573-586.

Intergovernmental Panel on Climate Change. 2015. Climate Change 2014: Synthesis Report. Contribution of Working Groups I, II and III to the Fifth Assessment Report of the. Edited by Core Writing Team, Rajendra K. Pachauri and Leo Meyer. Geneva: Intergovernmental Panel on Climate Change.

Ives, Timothy H., Kevin A. McBride, and Joseph N. Waller. 2018. "Surveying Coastal Archaeological Sites Damaged by Hurricane Sandy in Rhode Island, USA." The Journal of Island and Coastal Archaeology 13 (1): 66-89. doi:10.1080/15564894.2017.1284961.

Jacobs, Melville. 1945. Kalapuya Texts. 1st. Seattle: University of Washington.

Jameson Jr., John H. 2004. "Public Archaeology in the United States." In Public Archaeology, edited by Nick Merriman, 22-58. London: Routledge.

Jay, David A., Keith Leffler, and Sebastian Degens. 2011. "Long-Term Evolution of Columbia River Tides." Journal of Waterway, Port, Coastal, and Ocean Engineering 137 (4): 182-191. 
Jay, David A., Keith Leffler, Heida L. Diefenderfer, and Amy B. Borde. 2015. "TidalFluvial and Estuarine Processes in the Lower Columbia River: I. Along-Channel Water Level Variations, Pacific Ocean to Bonneville Dam." Estuaries and Coasts 38: 415-433. doi:10.1007/s12237-014-9819-0.

Jenkins, Sarah L. 2014a. 35CO72 SHPO Site Form. Oregon SHPO Site Recording Form, Archaeological Investigations Northwest, Inc., Salem: Oregon State Historic Preservation Office.

Jenkins, Sarah L. 2014b. 35CO73 SHPO Site Form. Oregon SHPO Site Recording Form, Archaeological Investigations Northwest, Inc., Salem: Oregon State Historical Preservation Office.

Jenkins, Sarah L. 2015a. 35CO75 SHPO Site Form. Oregon SHPO Site Recording Form, Archaeological Investigations Northwest, Salem: Oregon State Historic Preservation Office.

Jenkins, Sarah L. 2015b. 35CO76 SHPO Site Form. Oregon SHPO Site Recording Form, Archaeological Investigations Northwest, Salem: Oregon State Historic Preservation Office.

Jenkins, Sarah L., and John L. Fagan. 2014. Cultural Resources Survey of the North Unit Sauvie Island Habitat Restoration Phase 2 Project, Columbia County, Oregon. Cultural Resources Survey, Portland: Archaeological Investigations Northwest, Inc.

Johnson, Adam, Lisa Marrack, and Sara Dolan. 2015. "Threats to Coastal Archaeological Sites and the Effects of Future Climate Change: Impacts of the 2011 Tsunami and an Assessment of Future Sea-Level Rise at Hōnaunau, Hawai'i." The Journal of Island and Coastal Archaeology 10 (2): 232-252. doi:10.1080/15564894.2014.980472.

Johnson, Christopher F., and Vida Germano. 2020. "Evaluating the Adaptive Capacity of Cultural Landscapes to Climate Change: Incorporating Site-Specific Knowledge in National Park Service Vulnerability Assessments." Parks Stewardship Forum 36 (1): 49-56.

Johnson, Tony A. 2017. "Forward." In Chinook Resilience: Heritage and Cultural Revitalization on the Lower Columbia River, by Jon D. Daehnke, xi-xii. Seattle, Washington: University of Washington Press.

Johnson, Tony A. 2013. "The Chinook People Today." In Chinookan Peoples of the Lower Columbia, edited by Robert T. Boyd, Kenneth M. Ames and Tony A. Johnson, 4-20. Seattle: University of Washington Press. 
Jones, Roger N., and Benjamin L. Preston. 2011. "Adaptation and Risk Management." WIREs Climate Change 2: 296-308. doi:10.1002/wcc.97.

Jones, Roy F. 1972. Wappato Indians of the Lower Columbia River Valley. 1st. Vancouver: Privately Printed.

Kane, Paul. 1971. The Columbia Wanderer: Sketches, Paintings, and Comment, 18461847. 1st. Edited by Thomas Vaughn. Portland, Oregon: Oregon Historical Society.

Kenoyer, Louis. 2017. My Life. 1st. Corvallis, Oregon: Oregon State University Press.

King, Thomas F. 2013. Cultural Resource Laws and Practice. 4th. Lanham, Maryland: Altamira Press.

Kretzler, Ian. 2015. "Repatriation of "Culturally Unidentifiable" Human Remains: The View from Fort Vancouver." SAA Archaeological Record 15 (1).

Long, Season. 2007. Shoreline Erosion on Sauvie Island, Oregon: Perceptions and Management Practices. Unpublished Non-Thesis Masters Thesis, Corvallis: Marine Resource Management Program, College of Oceanic and Atmospheric Science, Oregon State University.

Lower Columbia Estuary Partnership. 2015. 2015 State of the Estuary. Environmental Impact Report, Portland: Lower Columbia Estuary Partnership.

Markham, Adam. 2017. "The Growing Vulnerability of World Heritage to Rapid Climate Change and the Challenge of Managing for an Uncertain Future." Chap. 2 in Public Archaeology \& Climate Change, edited by Tom Dawson, Courtney Nimura, Elías López-Romero and Marie-Yvane Daire, 10-22. Oxford: Oxbow Books.

Martin, Michael A. 2006. The Fisheries of the Lower Columbia River, 1792 to 1850, Based on EuroAmerican Explorer and Fur Company Accounts. Unpublished Masters Thesis, Portland: Portland State University Department of Anthropology.

McArthur, Lewis Ankeny, and Lewis L. McArthur. 2003. Oregon Geographic Names. 7th. Seattle, Washington: Oregon Historical Press.

Melnick, Robert Z. 2015. "Climate Change Challenges and Cultural Landscape Viability." Chap. 18 in Conserving Cultural Landscapes: Challenges and New Directions, edited by Ken Taylor, Archer St Clair and Nora J. Mitchell, 295-308. New York, New York: Routledge.

Melnick, Robert Z., and Nadja G. Quiroz. 2017. Study of Climate Change Impacts on Cultural Landscapes in the Pacific West Region, National Park Service, Phase II: Preliminary Vulnerabilty Assessments. Phase II Vulnerability Assessment, 
Eugene: Cultural Landscape Research Group, Department of Landscape Architecture, University of Oregon.

Melnick, Robert Z., Veronica Malinay, Noah P. Kerr, and Alison Lewis. 2016. Study of Climate Change Impacts on Cultural Landscapes in the Pacific West Region. Historic Preservation Report, Eugene: Cultural Landscape Research Group, Department of Landscape Architecture, University of Oregon.

Minor, Rick. 1983. "Aboriginal Settlement and Subsistence at the Mouth of the Columbia River." Eugene: Unpublished PhD Dissertation, Department of Anthropology, University of Oregon.

Minor, Rick, and Laurie E. Burgess. 2009. "Chinookan Survival and Persistence on the Lower Columbia: The View from the Kathlamet." Historical Archaeology 43 (4): 97-114.

Momber, Garry, Lauren Tidbury, Julie Satchell, and Brandon Mason. 2017. "Improving Management Responses to Coastal Change: Utilising Sources from Archaeology, Maps, Charts, Photographs and Art." Chap. 4 in Public Archaeology \& Climate Change, edited by Tom Dawson, Courtney Nimura, Elías López-Romero and Marie-Yvane Daire, 34-43. Oxford: Oxbow Books.

Mote, Philip, Amy K. Snover, Susan Capalbo, Sanford D. Eigenbrode, Patty Glick, Jeremy Littell, Richard Raymondi, and Spencer Reeder. 2014. "Ch. 21: Northwest." Chap. 21 in Climate Change Impacts in the United States: The Third National Climate Assessment, edited by J. M. Melillo, Terese (T.C.) Richmond and G. W. Yohe, 487-513. U.S. Global Change Research Program.

Mote, Philip, Doug Canning, David Fluharty, Robert Francis, Jerry Franklin, Alan Hamlet, Marc Hershman, and Molly Holmberg. 1999. Impacts of Climate Variability and Change in the Pacific Northwest. Impact Assessment Report, The JISAO Climate Impacts Group, University of Washington.

Mote, Philip, Eric Salathé, and Cynthia Peacock. 2005. Scenarios of Future Climate for the Pacific Northwest. Land Management Report, University of Washington, Seattle: Climate Impacts Group.

Moulton, Gary E. 1983a. Atlas of the Lewis \& Clark Expedition. Lincoln, Nebraska: University of Nebraska Press.

-. 1983b. The Journals of the Lewis and Clark Expedition. Lincoln, Nebraska: University of Nebraska Press.

Naik, Pradeep K., and David A. Jay. 2005. "Estimation of Columbia River Virgin Flow: 1879 to 1928." Hydrological Processes 19: 1807-1824. 
National Park Service. 2020. List of NHLs by State.

https://www.nps.gov/subjects/nationalhistoriclandmarks/list-of-nhls-bystate.htm\#onthisPage-37.

National Research Council. 2004. Managing the Columbia River: Instream Flows, Water Withdrawals, and Salmon Survival. Environmental Report, National Research Council of the National Academies, Washington D.C.: The National Academies Press.

National Research Council. 2012. Sea-Level Rise for the Coasts of California, Oregon, and Washington. Environmental Report, National Research Council of the National Academies, Washington, D.C.: The National Academies Press.

Neumann, Thomas W., and Robert M. Sanford. 2010. Practicing Archaeology: An Introduction to Cultural Resources Archaeology. 2nd. Lanham, Maryland: Altamira Press.

Neumann, Thomas W., Robert M. Sanford, and Karen G. Harry. 2010. Cultural Resources Archaeology: An Introduction. 2nd. Lanham, Maryland: Altamira Press.

Newland, Michael, Sandra Pentney, Reno Franklin, Nick Tipon, Suntayea Steinruck, Jeannine Pedersen-Guzman, and Jere H. Lipps. 2017. "Racing Against Time: Preparing for the Impacts of Climate Change on California's Archaeological Resources." Chap. 13 in Public Archaeology and Climate Change, edited by Tom Dawson, Courtney Nimura, Elías López-Romero and Marie-Yvane Daire, 115125. Oxford: Oxbow Books.

Newman, Maureen McNassar. 1991. Description and Management Plan for 35MU4, The Sunken Village Archaeological Site at Sauvie Island, Multnomah County, Oregon. Portland, Oregon: Unpublished M.A. Thesis.

Newman, Maureen, and Jo Reese. 1987. 35MU66 SHPO Site Form. Oregon SHPO Site Recording Form, Salem: Charles Hibbs \& Associates.

Newman, Thomas M., and Maureen McNassar. 1977. Preliminary Report on "Sunken Village" Site, at Sauvies Island, 35-MU-4. Cultural Resource Management, Portland: Department of Anthropology, Portland State University.

Nimura, Courtney, Tom Dawson, Elías López-Romero, and Marie-Yvane Daire. 2017. "Public Archaeology and Climate Change: Reflections and Considerations." Chap. 1 in Public Archaeology and Climate Change, edited by Tom Dawson, Courtney Nimura, Elías López-Romero and Marie-Yvane Daire, 1-9. Oxford: Oxbow Books. 
O'Connor, Jim E. 2004. "The Evolving Landscape of the Columbia River Gorge: Lewis and Clark and Cataclysms of the Columbia." Oregon Historical Quarterly 105 (3): 390-421.

Oregon Department of Fish and Wildlife. 1958. "Aerial." Document on file at the Oregon Department of Fish and Wildlife, Department of Engineering.

—. 2019. "Sauvie Island Features and Ownership Map." Sauvie Island Wildlife Area Visitors' Guide. Salem, Oregon: Oregon Department of Fish and Wildlife, March. Accessed July 9, 2019. https://myodfw.com/sauvie-island-wildlife-area-visitorsguide.

Oregon Department of State Lands. 2007. "Public Use of Oregon's Rivers and Lakes." Oregon: Oregon Department of State Lands.

—. 2008. "Public Use of Oregon's Rivers and Lakes: Your Rights to Use the Surface, Bed and Banks of Oregon's Rivers and Lakes." Oregon: Oregon Department of State Lands.

Oregon State Historic Preservation Office. 2018. "Archaeological Services." Salem, Oregon: Oregon Parks \& Recreation Department.

Orr, Elizabeth L., and William N. Orr. 2000. Geology of Oregon. 5th. Dubuque, Iowa: Kendall/Hunt Publishing Company.

Payne, Jeffrey T., Andrew W. Wood, Alan F. Hamlet, Richard N. Palmer, and Dennis P. Lettenmaier. 2004. "Mitigating the Effects of Climate Change on the Water Resources of the Columbia River Basin." Climatic Change 62: 233-256. doi:10.1023/B:CLIM.0000013694.18154.d6.

Perdikaris, Sophia, Allison Bain, Rebecca Boger, Sandrine Grouard, Anne-Marie Faucher, Vincent Rousseau, Reaksha Persaud, Stéphane Noël, Matthew Brown, and July Medina-Triana. 2017. "Cultural Heritage Under Threat: The Effects of Climate Change on the Small Island of Barbuda, Lesser Antilles." Chap. 15 in Public Archaeology \& Climate Change, edited by Tom Dawson, Courtney Nimura, Elías López-Romero and Marie-Yvane Daire. Oxford: Oxbow Books.

Perrin, N. 2014. 35CO66 SHPO Site Form, Site Update. Oregon State Historic Preservation Office Site Record, Update, Salem: Oregon State Historic Preservation Office.

Peterson, Curt D., Rick Minor, Gary L. Peterson, and Edward B. Gates. 2011. "Pre-and Post-Missoula Flood Geomorphology of the Pre-Holocene Ancestral Columbia River Valley in the Portland Forearc Basin, Oregon and Washington, USA." Geomorphology 129 (3-4): 276-293. doi:10.1016/j.geomorph.2011.02.022. 
Pettigrew, Richard M. 1973d. 35CO7 SHPO Site Form. Oregon Archaeological Survey, Site Form, University of Oregon, Museum of Natural History, Salem: Oregon State Historic Preservation Office.

Pettigrew, Richard M. 1973b. 35MU1 SHPO Site Form. Oregon Archaeological Survey, Site Form, University of Oregon, Museum of Natural History, Salem: Oregon State Historic Preservation Office.

Pettigrew, Richard M. 1973a. 35MU4 SHPO Site Form. Oregon Archaeological Survey, Site Form, University of Oregon, Museum of Natural History, Salem: Oregon State Historic Preservation Office.

Pettigrew, Richard M. 1973c. 35MU6 SHPO Site Form. Oregon Archaeological Survey, Site Form, University of Oregon, Museum of Natural History, Salem: Oregon State Historic Preservation Office.

Pettigrew, Richard M. 1981. A Prehistoric Culture Sequence in the Portland Basin of the Lower Columbia Valley. University of Oregon Anthropological Papers No. 22, Eugene, Oregon: University of Oregon.

Pettigrew, Richard M. 1990. Prehistory of the Lower Columbia and Willamette Valley. Vol. 7, in Handbook of North American Indians: Northwest Coast, edited by Wayne Suttles and William C. Sturtevant, 518-529. Washington, District of Columbia: Smithsonian Institution.

Pettigrew, Richard M., and Clayton G. Lebow. 1987. Archaeological Investigations at the Sunken Village Site (35MU4), Multnomah County, Oregon. Oregon Division of State Lands Report, Infotec Research Incorporated.

Pettigrew, Richard Munro. 1977. A Prehistoric Culture Sequence in the Portland Basin of the Lower Columbia Valley. Unpublished PhD Thesis, Eugene: University of Oregon Department of Anthropology, 1-483.

Pezeshki, S.R., R.D. DeLaune, and W.H. Patrick, Jr. 1987. "Effects of Flooding and Salinity on Photosynthesis of Sagittaria lancifolia." Marine Ecology 41: 87-91.

Pfandler, Andy. 2013. 35MU242 State of Oregon Archaeological Site Record. State of Oregon Archaeological Site Record, Willamette Cultural Resources Associates, Salem: Unpublished.

Pilkey, Orrin H., and J. Andrew G. Cooper. 2004. "Society and Sea Level Rise." Science 303 (5665): 1781-1782. doi:10.1126/science.1093515.

Ponte, L. 2014. 35CO66 State of Oregon Archaeological Site Record. State of Oregon Archaeological Site Record, Historical Research Associates, Salem: Unpublished. 
Quilliam, Lincoln, Ron Cox, Petra Campbell, and Michael Wright. 2014. "Coastal Climate Change Impacts for Easter Island in 2100." Rapa Nui Journal 28 (1): 6067.

Rahmstorf, Stefan. 2007. "A Semi-Empirical Approach to Projecting Future Sea-Level Rise." Science 315: 368-370.

Ray, Verne F. 1938. "Lower Chinook Ethnographic Notes." University of Washington Publications in Anthropology (The University of Washington) 7 (2): 29-165.

Reeder, Leslie A., Torben C. Rick, and Jon M. Erlandson. 2012. "Our Disappearing Past: A GIS Analysis of the Vulnerability of Coastal Archaeological Resources in California's Santa Barbara Channel Region." Journal of Coastal Conservation 16 (2): 187-197. doi:10.1007/s11852-010-0131-2.

Reeder-Myers, Leslie A. 2015. "Cultural Heritage at Risk in the Twenty-First Century: A Vulnerability Assessment of Coastal Archaeological Sites in the United States." Journal of Island \& Coastal Archaeology 10 (3): 436-445. doi:10.1080/15564894.2015.1008074.

Reeder-Myers, Leslie A., and Torben C. Rick. 2019. "Kayak Surveys in Estuarine Environments: Addressing Sea-Level Rise and Climate Change." Antiquity 93 (370): 1040-1051. doi:10.15184/aqy.2019.91.

Reese, J., M. Newman, and A. Stenger. 1987a. 35MU61 SHPO Site Form. Oregon SHPO Site Recording Form, Charles Hibbs \& Associates.

Reese, Jo. 1987a. 35MU63 SHPO Site Form. Oregon SHPO Site Recording Form, Charles Hibbs \& Associates.

Reese, Jo. 1987b. 35MU67 SHPO Site Form. Oregon SHPO Site Recording Form, Salem: Charles Hibbs \& Associates.

Reese, Jo, Maureen Newman, Alison Stenger, and Steve Hollender. 1987c. 35MU65 SHPO Site Form. Oregon SHPO Site Recording Form, Salem: Charles Hibbs \& Associates.

Reese, Jo, Steve Hollender, and Maureen Newman. 1987b. 35MU64 SHPO Site Form. Oregon SHPO Site Recording Form, Salem: Charles Hibbs \& Associates.

Ripple, William J., Christopher Wolf, Thomas M. Newsome, Mauro Galetti, Mohammed Alamgir, Eileen Crist, Mahmoud I. Mahmoud, William F. Laurance, and 15,364 Scientists Signatories from 184 Countries. 2017. "World Scientists' Warning to Humanity: A Second Notice." BioScience 67 (12): 1026-1028. doi:10.1093/biosci/bix125. 
Rockman, Marcy, Marissa Morgan, Sonya Ziaja, George Hambrecht, and Alison Meadow. 2016. Cultural Resources Climate Change Strategy. CRM Report, Cultural Resources, Partnership, and Science and Climage Change Response Program, Washington D.C.: National Park Service.

Rostaminia, Mojy, and Gary Wolff. 2018. Sea Level Rise: Implications for Water Level Management. Conference Presentation, Portland: Otak, Inc.

Roulette, Bill R., and Aimee A. Finley. 2009b. 35CO66 SHPO Site Form. Oregon State Historic Preservation Office Site Form, Salem: Oregon State Historic Preservation Office.

Roulette, Bill R., and Aimee A. Finley. 2009a. Historical and Cultural Resources Study of Three Pile Fields Along the Lower Columbia River, Columbia County, Oregon, and Wahkiakum County, Washington. Report No. 865, Portland: Applied Archaeological Research, Inc.

Rowland, Michael J., Sean Ulm, and Meredith Roe. 2014. "Approaches to Monitoring and Managing Indigenous Australian Coastal Cultural Heritage Places." Queensland Archaeological 17: 37-48.

2017. Promised Land. Documentary. Directed by Vasant Salcedo, Sarah Salcedo and Claire Salcedo. Produced by Tall Firs Cinema. Tall Firs Cinema. https://www.promisedlanddoc.com/about/.

Saleeby, Becky Margaret. 1983. Prehistoric Settlement Patterns in the Portland Basin of the Lower Columbia River: Ethnohistoric, Archaeological, and Biogeographic Perspectives. Unpublished PhD Thesis, Eugene: University of Oregon Department of Anthropology.

Saleeby, Becky, and Richard M. Pettigrew. 1983. "Seasonality of Occupation of Ethnohistorically-Documented Villages on the Lower Columbia River." In Prehistoric Places on the Southern Northwest Coast, edited by Robert Greengo, 169-193. Seattle, Washington: Thomas Burke Memorial Washington State Museum.

Sapir, Edward. 1907. "Preliminary Report on the Language and Mythology of the Upper Chinook." American Anthropologist 9 (3): 533-544.

—. 1909. Wishram Texts and Ethnography. 1st. Leyden: Late E. J. Brill.

Seaman, N.G. 1967. Indian Relics of the Pacific Northwest. 1st. Portland: Binfords \& Mort, Publishers. 
Shepard, Emily Evelyn. 2014. "Building and Maintaining Plankhouses at Two Villages on the Southern Northwest Coast of North America." Unpublished Master's Thesis, Department of Anthropology, Portland State University, Portland.

Shi, Benheng, Jean-Noël Proust, Marie-Yvane Daire, Elias Lopez-Romero, Hervé Regnauld, and Soazig Pian. 2012. "Coastal Changes and Cultural Heritage (2): An Experiment in the Vilaine Estuary (Brittany, France)." The Journal of Island and Coastal Archaeology 7 (2): 183-199. doi:10.1080/15564894.2012.686083.

Silverstein, Michael. 1990. Chinookans of the Lower Columbia. Vol. 7, in Handbook of North American Indians: Northwest Coast, edited by Wayne Suttles and William C. Sturtevant, 533-546. Washington, District of Columbia: Smithsonian Institution.

Slocum, Robert G., and Kenneth H. Matsen. 1972. "Duck Lake Archaeological Site Report, 45-CL-6A." Oregon Archaeological Society, Publication No. 6: 1-46.

Smith, Cameron McPherson. 2006. "Formation Processes of a Lower Columbia River Plankhouse Site." Chap. 11 in Household Archaeology on the Northwest Coast, edited by Elizabeth A. Sobel, D. Ann Trieu Gahr and Kenneth M. Ames, pgs. 233-269. Ann Arbor, Michigan: International Monographs in Prehistory.

- 2008. The Organization of Production Among Sedentary Foragers of the Southern Pacific Northwest Coast. 1st. Oxford: Archaeopress.

Smith, George S., Pei-Lin Yu, and Chen Shen. 2018. "Balancing the Past With the Needs and Concerns of Contemporary Society." Chap. 1 in Relevance and Application of Heritage in Contemporary Society, edited by Pei-Lin Yu, Chen Shen and George S. Smith, pp. 1-10. New York, New York: Routledge.

Snover, Amy K., Alan F. Hamlet, and Dennis P. Lettenmaier. 2003. "Climate-Change Scenarios for Water Planning Studies: Pilot Applications in the Pacific Northwest." Bulletin of the American Metrological Society 84 (11): 1513-1518.

Sobel, Elizabeth A. 2006. "Household Prestige and Exchange in Northwest Coast Societies: A Case Study from the Lower Columbia River Valley." Chap. 9 in Household Archaeology on the Northwest Coast, edited by Elizabeth A. Sobel, D. Ann Trieu Gahr and Kenneth M. Ames, pgs. 159-199. Ann Arbor, Michigan: International Monographs in Prehistory.

—. 2004. "Social Complexity and Corporate Households on the Southern Northwest Coast of North America, A.D. 1450-1855." Ann Arbor: Unpublished PhD Dissertation, Department of Anthropology, University of Michigan.

Sobel, Elizabeth A., Kenneth M. Ames, and Robert J. Losey. 2013. "Environment and Archaeology of the Lower Columbia." In Chinookan Peoples of the Lower 
Columbia, edited by Robert T. Boyd, Kenneth M. Ames and Tony A. Johnson, pp. 23-41. Seattle: University of Washington Press.

Spencer, Omar C. 1950. The Story of Sauvies Island. 1st. Portland, Oregon: Binfords \& Mort.

Stenger, A., and M. Newman. 1987. 35MU137 SHPO Site Form. Oregon SHPO Site Recording Form, Salem: Charles Hibbs \& Associates.

Stenger, Alison. 1987. 35MU136 SHPO Site Form. Oregon SHPO Site Recording Form, Salem: Charles Hibbs \& Associates.

Strong, Emory. 1967. Stone Age on the Columbia River. Portland: Binfords \& Mort.

Strong, William Duncan, W. Egbert Schenck, and Julian H. Steward. 1930. Archaeology of the Dalles-Deschutes Region. University of California Publications in American Archaeology and Ethnology 29, Berkeley, California: University of California Press.

Suttles, Wayne. 1990. Introduction. Vol. 7, in Handbook of North American Indians: Northwest Coast, edited by William C. Sturtevant and Wayne Suttles, pp. 1-15. Washington: Smithsonian Institution.

Suttles, Wayne, and William L. Lang. 2013. "Chinookan Writings: Anthropological Research and Historiography." Chap. 16 in Chinookan Peoples of the Lower Columbia, edited by Robert T. Boyd, Kenneth M. Ames and Tony A. Johnson, 326-345. Seattle, Washington: University of Washington Press.

Swan, James G. 1857. The Northwest Coast; or, Three Years' Residence in Washington Territory. 1st ed. New York: Harper \& Brothers Publishers.

Talke, Stefan, David Jay, and L. Helaire. 2018. Sea-Level Rise in the Columbia River Estuary, Past, Present, and Future. Conference Presentation, Portland: Portland State University.

Templeton, William J., and David A. Jay. 2013. "Lower Columbia River Sand Supply and Removal: Estimates of Two Sand Budget Components." Journal of Waterway, Port, Coastal, and Ocean Engineering 139 (5): 383-392. doi:10.1061/(ASCE)WW.1943-5460.0000188.

The Confederated Tribes of Grand Ronde. 2019. Cultural Resources. https://www.grandronde.org/departments/cultural-resources/.

Thompson, David. 1916. David Thompson's Narrative of his Explorations in Western America, 1784-1812. 1st. Edited by J.B. Tyrrell. Toronto, Montreal: The Champlain Society. 
Thompson, David. 1914. "Journal of David Thompson." Edited by T.C. Elliott. The Quarterly of the Oregon Historical Society 15 (2): 104-125.

U.S. Army Corps of Engineers. 2012. Columbia River Basin Dams. U.S. Army Corps of Engineers. May 4. Accessed June 8, 2020. https://www.nwd.usace.army.mil/Media/Fact-Sheets/Fact-Sheet-ArticleView/Article/475820/columbia-river-basindams/\#: :text=The\%20US\%20Army\%20Corps\%20of,on\%20the\%20Pend\%20Or eille\%20River.

U.S. Army Corps of Engineers. 1986. Investigation of Bank Erosion at Sauvie Island, OR, Planning Division Technical Report. Planning Division Technical Report, Portland District, US Army Corps of Engineers, Portland: US Army Corps of Engineers.

U.S. Army Corps of Engineers. 1983. Lower Columbia River Bank Protection. Sauvie Island Drainage District Design Memorandum Supplement No. 2, US Army Corps of Engineers, Portland: US Army Corps of Engineers.

U.S. Global Change Research Program. 2018. Impacts, Risks, and Adaptation in the United States: Fourth National Climate Change Assessment. 1st. Edited by D.R. Reidmiller, C.W. Avery, D.R. Easterling, K.E. Kunkel, K.L.M. Lewis, T.K. Maycock and B.C. Stewart. Vols. II: Report-in-Brief. Washington D.C. USA: U.S. Global Change Research Program.

United Nations Educational, Scientific, and Cultural Organization. 2007. Climate and World Heritage: Report on Predicting and Managing the Impacts of Climate Change on World Heritage and Strategy to Assist States Parties to Implement Appropriate Management Responses. Paris: United Nations Educational, Scientific, and Cultural Organization World Heritage Center.

Vancouver, George. 1798. A Voyage of Discovery to the Pacific Ocean and Round the World. 1st. Vol. 2. 6 vols. London: G.G. and J. Robinson.

Wallick, Jennifer Rose, Gordon E. Grant, Stephen T. Lancaster, John P. Bolte, and Roger P. Denlinger. 2007. "Patterns and Controls on Historical Channel Change in the Willamette River, Oregon, USA." Chap. 23 in Large Rivers: Geomorphology and Management, edited by Avijit Gupta, pp. 491-516. West Sussex: John Wiley \& Sons, Ltd.

Watson, Bruce McIntyre. 2010. Lives Lived West of the Divide: A Biographical Dictionary of Fur Traders Working West of the Rockies, 1793-1858. 1st. Kelowna, British Columbia: The Centre for Social, Spatial and Economic Justice. 
Wilkes, Charles. 2009. Charles Wilkes and the Exploration of Inland Washington Waters: Journals from the Expedition of 1841. 1st. Edited by Richard W. Blumenthal. Jefferson, North Carolina: McFarland \& Company, Inc.

-. 1958. Columbia River to the Sacramento. 1st. Oakland, California: Biobooks.

- 1849. Narrative of the United States Exploring Expedition, During the Years 1838, 1839, 1840, 1841, 1842. 1st. Vol. 5. 5 vols. Philadelphia, Pennsylvania.

-. 1849. Narrative of the United States Exploring Expedition, During the Years 1838, 1839, 1840, 1841, 1842. Vol. 4. 5 vols. Philadelphia, Pennsylvania.

Willingham, William F. 2018. U.S. Army Corps of Engineers. Oregon Historical Society. March 17. Accessed June 7, 2020.

https://oregonencyclopedia.org/articles/u_s__army_corps_of_engineers/\#.Xtzb7k VKhPZ.

Wilson, Douglas C. 2015. "A Mongrel Crowd of Canadians, Kanakas and Indians: The United States National Park Service Public Archaeology Programme and Fort Vancouver's Village." Journal of Community Archaeology \& Heritage 2 (3): 221237.

Wragg, Eliott, Nathalie Cohen, Gustav Milne, Stephanie Ostrich, and Courtney Nimura. 2017. "Community Recording and Monitoring of Vulnerable Sites in England." Chap. 5 in Public Archaeology and Climate Change, edited by Tom Dawson, Courtney Nimura, Elías López-Romero and Marie-Yvane Daire, 44-51. Oxford: Oxbow Books.

Wulf, Laurie. 2016. Metro Parks and Nature Field Guide: Howell Territorial Park. Field Guide, Portland: Metro.

https://www.oregonmetro.gov/sites/default/files/2016/02/19/Howell\%20Field\%20 Guide_0.pdf.

Yu, P.L., M. Rockman, and C. Neal. In Press. The State of Climate Change Vulnerability Assessments for National Park Services Cultural Resources: An Integrated Analysis. Fort Collins, Colorado: National Park Service.

Zenk, Henry B. 1990. Kalapuyans. Vol. 7, in Handbook of North American Indians: Northwest Coast, edited by Wayne Suttles and William C. Sturtevant, 547-553. Washington, District of Columbia: Smithsonian Institution.

Zenk, Henry B., and Tony A. Johnson. 2013. "Chinuk Wawa and its Roots in Chinookan." Chap. 13 in Chinook Peoples of the Lower Columbia, edited by Robert T. Boyd, Kenneth M. Ames and Tony A. Johnson, 272-287. Seattle, Washington: University of Washington Press. 
Zenk, Henry. 1994. "Tualatin Kalapuyan Villages: The Ethnographic Record." Contributions to the Archaeology of Oregon, 1989-1994, Occasional Papers No. 5: 147-166.

Zenk, Henry, Yvonne Hajda, and Robert Boyd. 2016. "Chinookan Villages of the Lower Columbia." Oregon Historical Quarterly 117 (1): 6-37. doi:10.5403/oregonhistq.117.1.0006.

Zhang, Keqi, Bruce C. Douglas, and Stephen P. Leatherman. 2004. "Global Warming and Coastal Erosion." Climatic Change 64 (1): 41-58. doi:10.1023/B:CLIM.0000024690.32682.48. 


\section{Appendices}

\section{Appendix A: Project Prospectus Delivered in 2019}

\section{A Community-Based Approach to Archaeological Site Preservation in a Changing Climate: A Lower Columbia Case Study}

The scientific community has indicated with increasing urgency that global climate change is the most pressing environmental concern facing humanity (Ripple et al. 2017). The adverse impacts of this anthropogenic induced crisis on human habitation, development, and infrastructure are well established (IPCC 2014; USGCRP 2018). Under these conditions, cultural resources are increasingly vulnerable (Erlandson 2008; 2012; Rockman et al. 2016) in the face of rising sea levels, increased storm frequency, and erosion (FitzGerald et al. 2008; NRC 2012; Pilkey and Cooper 2004; USGCRP 2018; Zhang et al. 2004).

A common approach to mitigating cultural resource loss due to climate change is to develop a risk assessment (e.g., S. Anderson et al. 2007; Hambly 2017a; A. Johnson et al. 2015; Reeder et al. 2012; Reeder-Myers 2015). Typically, these assessments take into account physical archaeological data, ethnohistorical accounts, and physiography to guide management and preservation of at-risk cultural resources. Assessments use interagency database overlay (D. Anderson et al. 2017), geographic information systems (Canuti et al. 2000; Dupont and Eetvelde 2013), and regional modelling of the impacts of climate change (A. Johnson et al. 2015; Westley et al. 2011) to achieve this. 
While these approaches are useful, they generally do not include communitybased participation or Indigenous stakeholder knowledge. Instead, independent archaeological records are typically used to specify places of concern, limiting the scope of preservation and the value such work has for Indigenous communities. Recent research in Australia is an important exception (Carmichael 2015; Carmichael et al. 2017a; 2017b; 2018). This project began with Indigenous stakeholders (called rangers), who brought concerns about climate change impacts to regional archeologists and land managers. Archaeologists helped to select a methodology, to collect ethnographic data from the Indigenous community, and to model the impacts of climate change. The rangers then used stakeholder knowledge along with other records to assess cultural resources in the study area and prioritize sites for preservation. The rangers prioritized sites not only by physical archaeology, ethnohistorical accounts, and physiography but also by significance to their community.

Building on this approach, my thesis project will provide a risk assessment model/process for cultural resources on the Lower Columbia (Oregon/Washington State) that not only considers commonly used variables (i.e., physical archaeology, ethnohistorical accounts, and the impacts of climate change) but also incorporates Indigenous stakeholder perspectives. The specific area along the river is yet to be determined. My work addresses two main gaps. First, the Lower Columbia lacks a risk assessment model for cultural resources threatened by climate change. Although cultural resources along the river are increasingly at risk, land managers have not yet devoted resources to developing a mitigation plan. Second, my project will incorporate 
Indigenous stakeholders' views in risk assessment, following efforts such as those carried out by Carmichael et al. (2017a; 2017b; 2018). My research will result in two deliverables - 1) A risk assessment model of the impacts of climate change on culturally important locations, useful for planning and deciding outcomes on the Lower Columbia and 2) A risk assessment process, originating in Indigenous community knowledge, that can be applied throughout the Lower Columbia, the Pacific Northwest, and beyond. 


\section{Appendix B: Example SHPO Site Form}

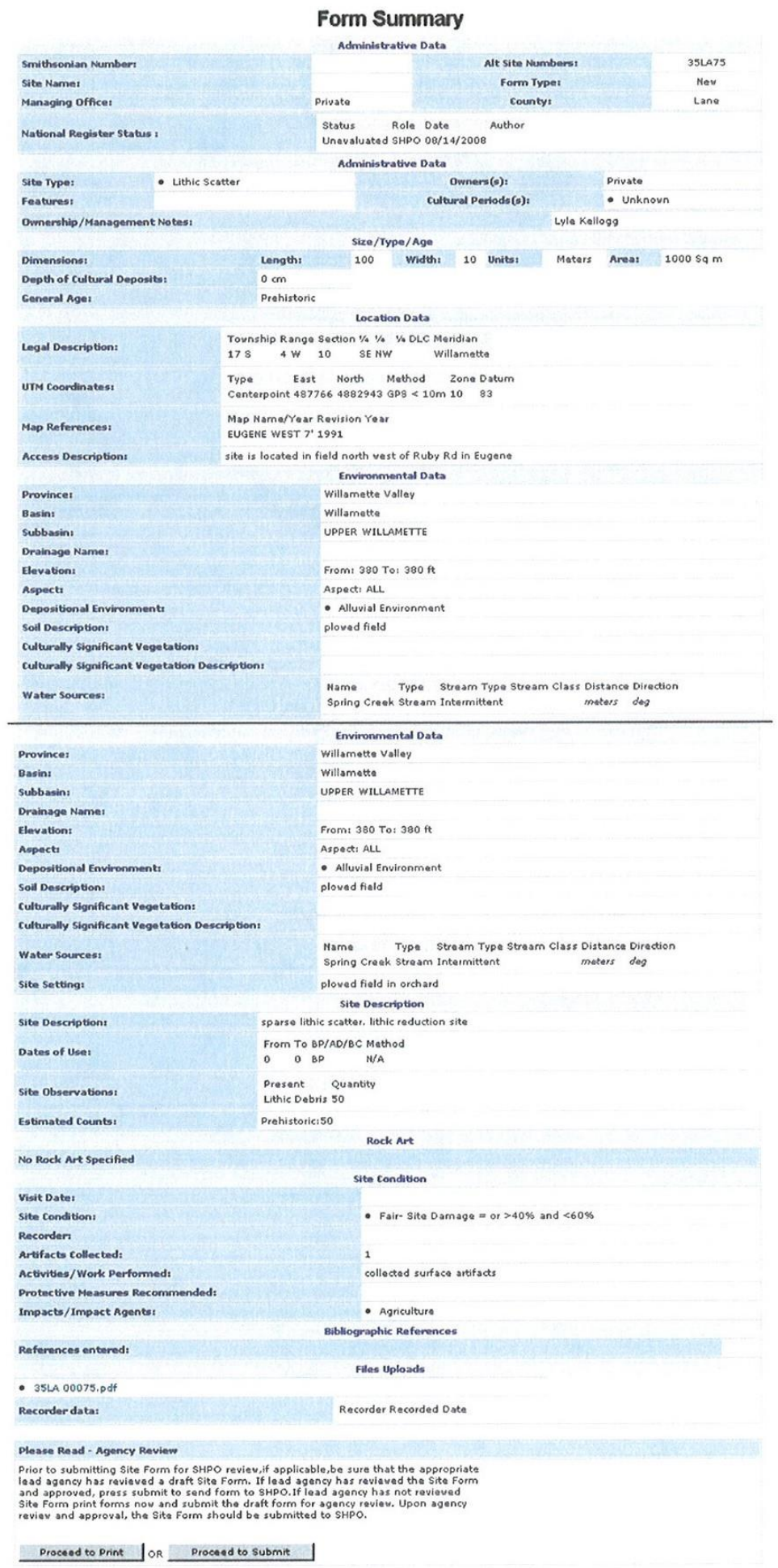


Appendix C: Baseline Site Form

\section{CULTURAL RESOURCE SITE RECORD}

\section{1) Administrative Data:}

Smithsonian Trinomial: Temporary Name/Number:

County: Historic Name:

Date(s) of Previous Recording(s):

Previous Recorder(s):

Date(s) of Current Recording:

Current Recorders(s):

Nature of Current Recording:

Recording Type: _ Re-Record, _ Record Able to Assess:

Yes, _ No

National Register Status:

Mean(s) of Access: _ Kayak (water), _ Overland (hike), _ Overland (road)

Trimble File(s):

Garmin File(s):

Camera(s):

1

Photo \#'s: 
Ownership of Resource: __ Private, __Public (Local), _ Public (State), _ Public (Federal)

Ownership/Management Notes:

Associated Address:

Associated Archaeologists, Agencies, and/or Cultural Resource Management Firms:

Previously Used Bibliographic References: 


\section{2) Site Identification:}

Site Type:

Features:

Cultural (Temporal) Period(s):

Depth of Cultural Deposit:

Site Dimensions (Last Previous Recording ):

Site Area: meters $^{2}$

Site Length: Site Width: Units Used:

Site Dimensions (Current Recording ):

Site Area: meters $^{2}$

Site Length: Site Width: Units Used: 


\section{3) Location Data}

Current Location/Coordinates (given here) are: __ Re-Recording (Update), __ New Recording

Township/Range/Section: 1 Meridian: Map References:

Site Datum Coordinates (Lat/Long - North/East): I

Site Datum Coordinates (UTM - East/North): 1

GPS Method/Accuracy Utilized - _ Trimble $(<4 \mathrm{~m}), \ldots$ Garmin $(<4 \mathrm{~m}), \ldots$ Camera $(<\ldots)$ Point of Access:

Point of Access Coordinates (Lat/Long): 1

Point of Access Coordinates (UTM - East/North): I

Location/Access Description (general to specific): 


\section{4) Environmental Data}

Date of Previous Assessment:

Date(s) of Current Assessment:

Province:

Basin:

Subbasin:_ Drainage

Name:

Elevation:___ Slope:___ Aspect:___ Depositional Environment:

Water Sources (type, distance, permanence):

Soil Description:

Historic Vegetation:

Setting At Previous Recording

Vegetation At Previous Recording

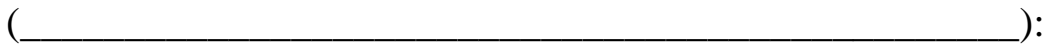


Setting At Current Recording

(_

Vegetation At Current Recording

( 


\section{5) Site Description}

Site Description (Date of Previous Recording

Site Features:

Count:

Type:

Site Artifacts:

Count: Type:

Site Description (Date of Current

Recording ) :

Site Features:

Estimated Count:___ Type:

Site Artifacts:

Estimated Count:__ Type:

Ground Visibility: _ Low ( $>75 \%$ GC), _ Medium (25-50\% GC), _ High (<25\% GC) Estimated Percentage of Site Exposed (on beach): $\%$

Beach Termination: __ Abrupt, __ Gradual, Site Extends into Water: __ Yes, __ No 
Time of Boundary Record/Daily Low Tide(s):

Low Tide Height Below/Above Mean Sea Level: feet/ meters

Max Tide Height at Recording: feet/ meters

Proximity to Low Tide ( _ Before, _ After): _ $>2 \mathrm{hrs}, \ldots>1 \mathrm{hr}, \ldots>30 \mathrm{~min}, \ldots>15 \mathrm{~min}$, $\sim$ LT

Comparative Observations: 


\section{6) Site Condition:}

Site Condition Overview (Previous Last Recording ):

Artifacts Collected: __ Yes, __ No

Nature of Work:

Impacts/Impact Agents Noted:

Protective Measures Recommended/Present/Expected:

Site Condition Overview (Current Recording ) :

Artifacts Collected: __ Yes, __ No Nature of Work:

Impacts/Impact Agents Noted: 
Site Condition (Current Recording): _ Very Poor (>80\% disturbed), _ Poor $(>60 \%$ disturbed), Very Good ( $>0 \%$ disturbed)

Fair ( $40 \%$ disturbed) _ Good (>20\% disturbed), _

Protective Measures Recommended/Present/Expected: 


\section{7) Site Artifact Details (From Current Recording):}

Date(s) of Current Assessment:

Artifact Tally (estimate): __ , Artifact Density (estimate): _ $\quad / \mathrm{m}^{2}$

Artifact Class: _ Precontact, _ Historic

Artifact Type(s): _ Ceramic, _ Glass, _ Metal, _ Wood, _ Bone, _ Lithic, Groundstone, __ FCR, _ Basketry, _ Other:

Artifact Type Tally/Description (add additional pages as needed):

Type: Tally: Description:

Type:

Tally:

, Description:

Type:

, Tally:

, Description:

Type:

, Tally:

, Description:

Type:

Tally:

, Description:

Tally:

, Description:

Type:

, Tally:

, Description:

Type:

, Tally:

, Description:

Type:

, Tally:

, Description: 
Type: __ Tally:___ Description:

Type: __, Tally:__, Description:

Type: __, Tally:__, Description:

Type: ___ Tally:___ Description: 


\section{8) Site Artifacts (Diagnostic)/Features (Current Recording):}

Date(s) of Current Assessment:

Diagnostic Artifact Tally:

Description of Site Presence:

SA001 Type:

Class:

, Material:

Dimensions (as applicable): cm (Length), cm (Width), $\mathrm{cm}$

(Thickness), $\mathrm{cm}$ (Diameter), cm (Other:

Diagnostic Artifact Description: )

)

\section{er:}

Class: __, Material:

$\overline{\text { Dimensions (as applicable): }}$

(Thickness), $\mathrm{cm}$ (Diameter), cm (Length), $\mathrm{cm}$ (Width), $\mathrm{cm}$

Diagnostic Artifact Description:

cm (Other:

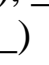

\section{$\mathrm{cm}$ (Other:}

\section{Diagnostic Artifact Description:}

SA003 Type:

Class: , Material:

Dimensions (as applicable): (Thickness), _ $\mathrm{cm}$ (Diameter), $\mathrm{cm}$ (Length), __ $\mathrm{cm}$ (Width), $\mathrm{cm}$

Diagnostic Artifact Description:

)
cm (Other:

Site Feature Tally:

Description of Site Presence:

SF001 Type:__C _ Class:__ Material(s):

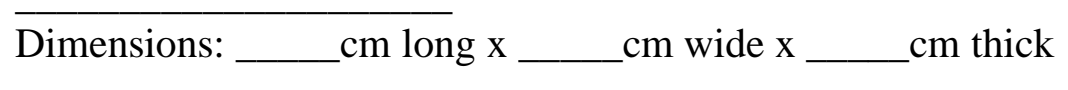


Feature Description:

SF002 Type:

Class:

, Material(s):

Dimensions: $\mathrm{cm}$ long $\mathrm{x}$ $\mathrm{cm}$ wide $\mathrm{x}$ cm thick Feature Description:

SF003 Type: Class: , Material(s):

Dimensions: $\mathrm{cm}$ long $\mathrm{x}$ cm wide $\mathrm{x}$ cm thick

Feature Description: 
9) Summary of Baseline Assessment: 


\section{Appendix D: Prioritization Assessment Form and Guide}

\section{Risk Assessment}

1) Archaeological Value

Dateable Features and Materials

(Hearth/FCR/Charcoal):

_ Yes (2), _ _ No (0)

Diagnostic Artifacts

(Makers Marks/Projectile Points):

_ Yes (2), __ No (0)

In Situ Deposits (presence of cultural

deposits in bank):

_ Yes (2), __ No (0)

Proximity to Ethnographically

Documented Indigenous Place(s):

_ Yes (1), __ No (0)

Rare Characteristics

(non-ubiquitous in archaeological

record):

_ Yes (1), __ No (0)

Multicomponent Site

(Multiple Cultural Phases):

Yes (1), __ No (0)

Total Archaeological Value: 
2) Tribal Value:

Proximity to Tribally Known Location

$(>1.5 \mathrm{~km}=0,<1.5 \mathrm{~km}=1,<0.75 \mathrm{~km}=2)$ :

Yes $(1,2), \ldots$ No $(0)$
Yes $(1,2), \ldots$ No $(0)$
Yes $(1,2), \ldots$ No $(0)$

engage with site):

— Yes $(1,2), \ldots$

Dateable Features and Materials

(potential for Hearth/FCR/Charcoal):

_ Yes (1), __ No (0)

Rare Characteristics

(non-ubiquitous in tribal record):

_ Yes (1), __ No (0)

In Situ Deposits (potential for cultural

deposits in bank):

_ Yes (1), __ No (0)

Total Tribal Value: 19 


\section{3) Risk Factor Score}

Disturbance (Modern Cultural Damage):

Estimated \% Damage

(Geomorphological) (>20\%, >40\%,

$>60 \%,>80 \%)$ :

Bank Angle $\left(>50^{\circ},>65^{\circ},>80^{\circ}\right)$ :

Lacks Vegetation Cover (on beach):

Bank Undercutting:

Sloughing/Slumping:

Inside Curve (of Channel):

Rip Rap on Opposite Shore:

Exposed Cultural Materials (in bank):

Sheer Beach Edge:

Rodent Activity:

Cattle Activity:

Looting/Vandalism:

Deadfall/Downed Trees:

Runoff Channeling:

Total Risk Factor Score:

120
_ Yes (1), __ No (0)

Yes $(1,2,3,4), \ldots$ No $(0)$
Yes $(1,2,3), \ldots$ No $(0)$
Yes $(1), \ldots$ No $(0)$
Yes $(1), \ldots$ No $(0)$
Yes $(1), \ldots$ No $(0)$
Yes $(1), \ldots$ No $(0)$
Yes $(1), \ldots$ No $(0)$
Yes $(1), \ldots$ No $(0)$
Yes $(1), \ldots$ No $(0)$
Yes $(1), \ldots$ No $(0)$
Yes $(1), \ldots$ No $(0)$
Yes $(1), \ldots$ No $(0)$
Yes $(1), \ldots$ No $(0)$
Yes $(1), \ldots$ No $(0)$

Preservation Priority Level:

_ Very Low (0-7)

Low (8-15)

Medium (16-22)

_ High (23-30)

Very High (31-38)
Total Archaeological Value: _ _ $\quad$ /9

Total Tribal Value: 19

Total Risk Factor Score: 120

Total Prioritization Score: 138 


\section{Appendix E: Anderson Template Assessment Form}

Site \#:

\section{Archaeological Site Condition and Climate Change \\ Vulnerability Assessment Form}

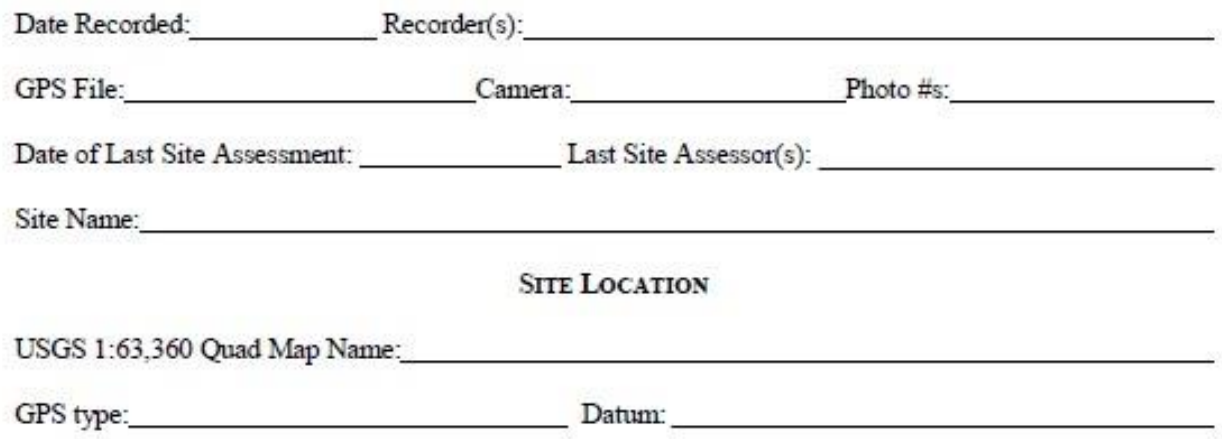

National Historic Landmark (NHI) Boundaries (UTM):

\begin{tabular}{|l|l|l|l|} 
Zone Northing & \multicolumn{1}{l}{ Easting } & \multicolumn{1}{l}{ Description } \\
\hline & & & \\
\hline & & & \\
\hline & & & \\
\hline & & & \\
\hline & & & \\
\hline & & & \\
\hline & & & \\
\hline
\end{tabular}

Property Owner(s):

Location Description (general to specific): 
Site \#.

Archaeology

\section{Site VULNERABHITY}

Site Type(s):

Approximate Site Age (circle all that apply): pre-contact / contact / post-contact

Environment

General Setting:

Landforms (local)

Landforms (regional):

Site Slope:

Site Aspect:

Site Elevation:

Local soil/sediment type:

Water Resources (type, distance, permanence):

Local Vegetation :

Estimate $\%$ vegetation ground cover on site:

Permafrost Zone:

Notes on site vulnerability in relationship to environmental setting and type of archaeology?

Overall Site Vulnerability:_Unknown / Low / Moderate / Severe 
Site \#:

\section{HAZARD AND CONDITION ASSESSMENT}

$\begin{array}{lllll}\text { Assessment Type (circle one): Baseline } & 1 \text { YR } & 5 \mathrm{YR} & 10 \mathrm{YR} & 15+\mathrm{YR}\end{array}$

Potential/Current Hazard Type:

Time Frame: Area of Site Disturbed ( $\mathrm{m}^{2 / \%} \%$ :

Potential/Current Hazard Type:

Time Frame: Area of Site Disturbed $\left(\mathrm{m}^{2} / \%\right)$ :

Potential/Current Hazard Type:

Time Frame: Area of Site Disturbed $\left(\mathrm{m}^{2 / \%} \%\right.$ :

Potential/Current Hazard Type:

Time Frame: Area of Site Disturbed $\left(\mathrm{m}^{2 / \%} \%\right)$

Potential/Current Hazard Type:

Time Frame: Area of Site Disturbed ( $\left.\mathrm{m}^{2} / \%\right)$ :

Potential/Current Hazard Type:

Time Frame: Area of Site Disturbed $\left(\mathrm{m}^{2} / \%\right)$ :

Total area of site disturbed $\left(\mathrm{m}^{2} / \%\right)$ :

Site Condition (circle one): Good / Fair / Poor / Destroyed / Inundated / Uncertain

Depositional Integrity (circle one):

Exceptional / Well Preserved / Substantial / Moderate / Poor / Lacking / Unevaluated Site Disturbance Severity Level: Unknown / Low / Moderate / Severe / Not Applicable Notes on hazards and site condition:

\begin{tabular}{l}
\hline \\
\hline \\
\hline \\
\hline \\
\hline
\end{tabular}


Site \#:

\section{RISK ASSESSMENT AND RECOMMENDATIONS}

Site Risk: Unknown / Low / Moderate / Severe

Overall Assessment of Site Risk to Climate Change and Other Hazards (consider vulnerability, potential/current hazards, and site significance:

Mitigation Recommendations

\section{NRHP ELIGIBIIITY EVALUATION}

Prior Eligibility Determination for the NRHP:

Date:

Current Recommendation (Eligible/Not Eligible/Unevaluated):

Justification for Current Recommendation:

Comments on Eligibility for NHL Listing: 


\section{Appendix F. Site Overviews and Photos}

\section{$\underline{\text { PJD001 }}$}

This site is a surface scatter of fire-cracked rock (FCR) on the western Sauvie Island shoreline, along the Multnomah Channel. The site has an estimated area of $5500 \mathrm{~m}^{2}$ and sits along an exposed eroding bank, with a partially vegetated beach that gradually slopes below the waterline. The assemblage is estimated at less than 150 artifacts of relatively uniform size and material, with no distinct concentrations or features. No cultural deposits were observed in situ in the exposed bank and the assemblage does not include diagnostic artifacts or dateable features. The site is completely inundated at high-tide and can only be accessed via boat at low-tide during the summer and fall months.

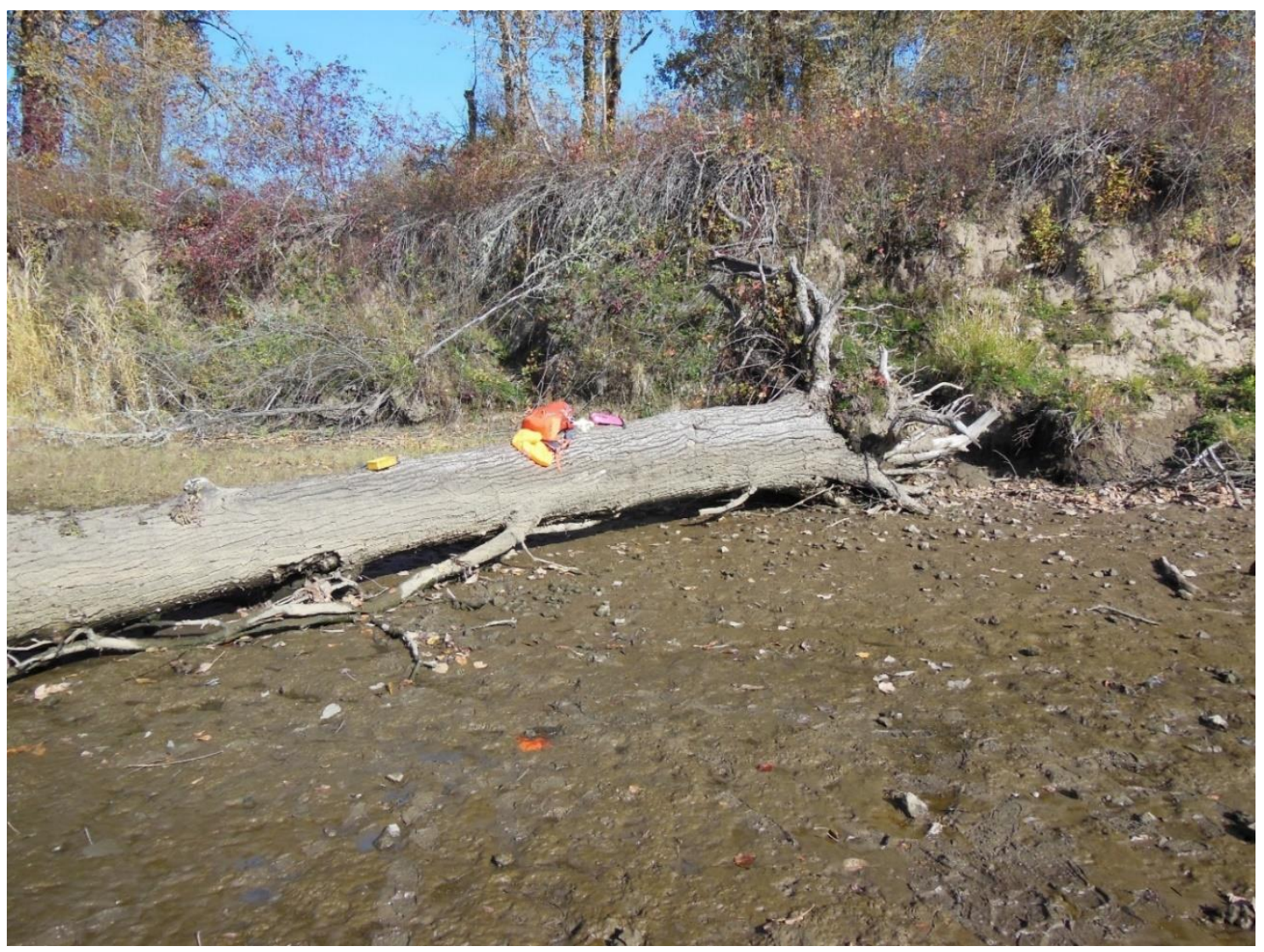

Fire-cracked rock scattered across gradually sloping beach at site PJD001. 


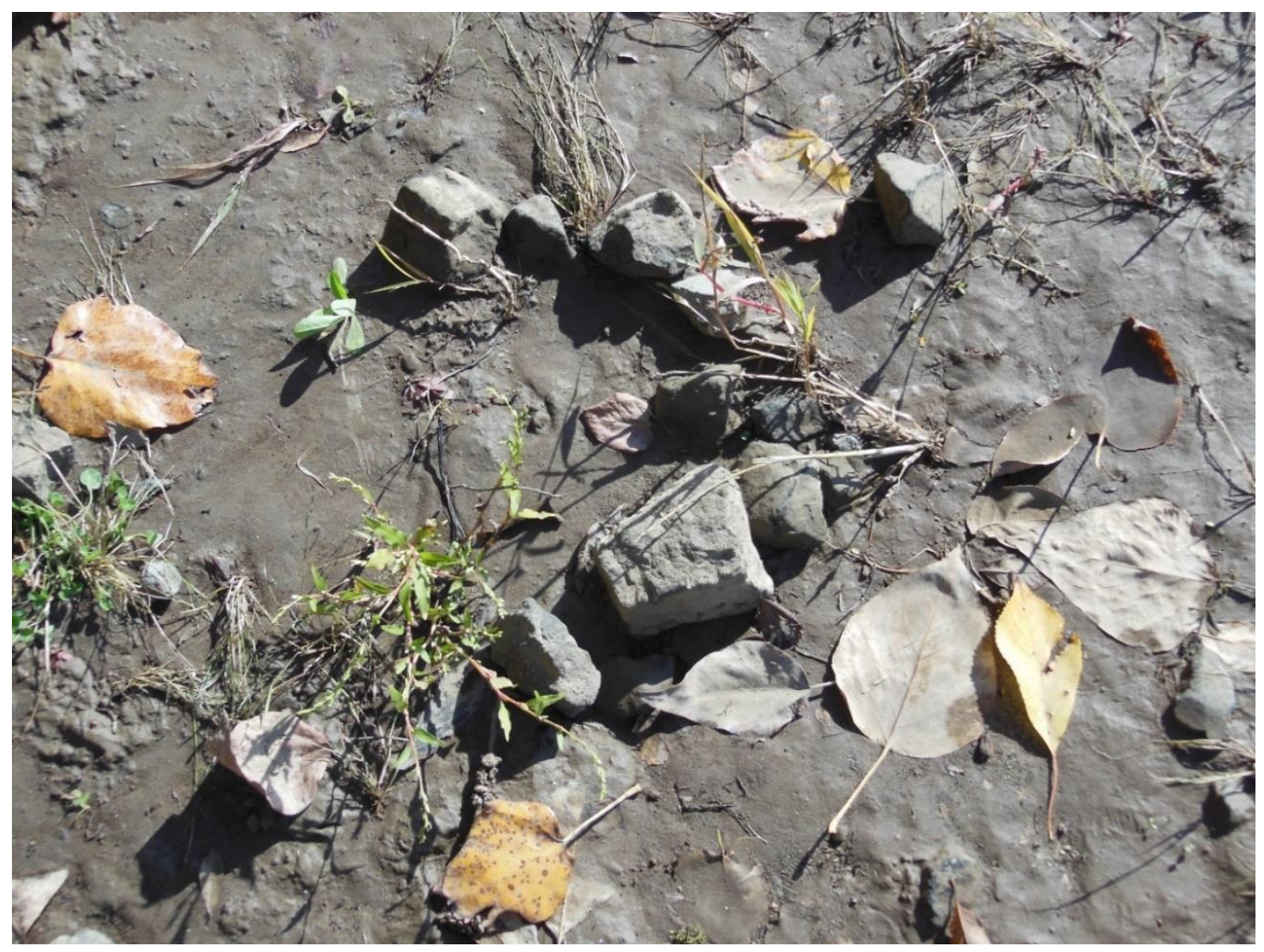

Close-up view of fire-cracked rock scatter at site PJD001. 


\section{$\underline{\text { PJD002 }}$}

This site is a multicomponent surface scatter of Indigenous fire-cracked rock and EuroAmerican refuse on western Sauvie Island shoreline, along the Multnomah Channel. The site has an area of $600 \mathrm{~m}^{2}$ and sits along a highly exposed eroding bank, with an unvegetated beach and an abrupt termination below the waterline. The assemblage is estimated at less than 75 artifacts, but is highly diverse, including a range of temporally diagnostic Euro-American ceramic artifacts, as well as glass, nails, and other bits of refuse. The extent of the site's FCR scatter is unknown but is estimated at around 35 fragments, with further investigation likely to expand this number. The site has in situ cultural deposits, including at least one hearth feature eroding out of the exposed, sheer bank, which terminates abruptly into the deeper waters of the channel. PJD002 is notable for an assemblage that may bridge the gap between Indigenous and Euro-American habitation, and the presence of a hearth feature at such a great depth suggests one of the oldest dated occupations on the island. The site can be accessed via the water or overland routes through the Sauvie Island Wildlife Refuge but is below water for the majority of the year, with the Indigenous component only visible during narrow window of yearly low-water periods and the Euro-American component only visible during low tide in the Fall months.

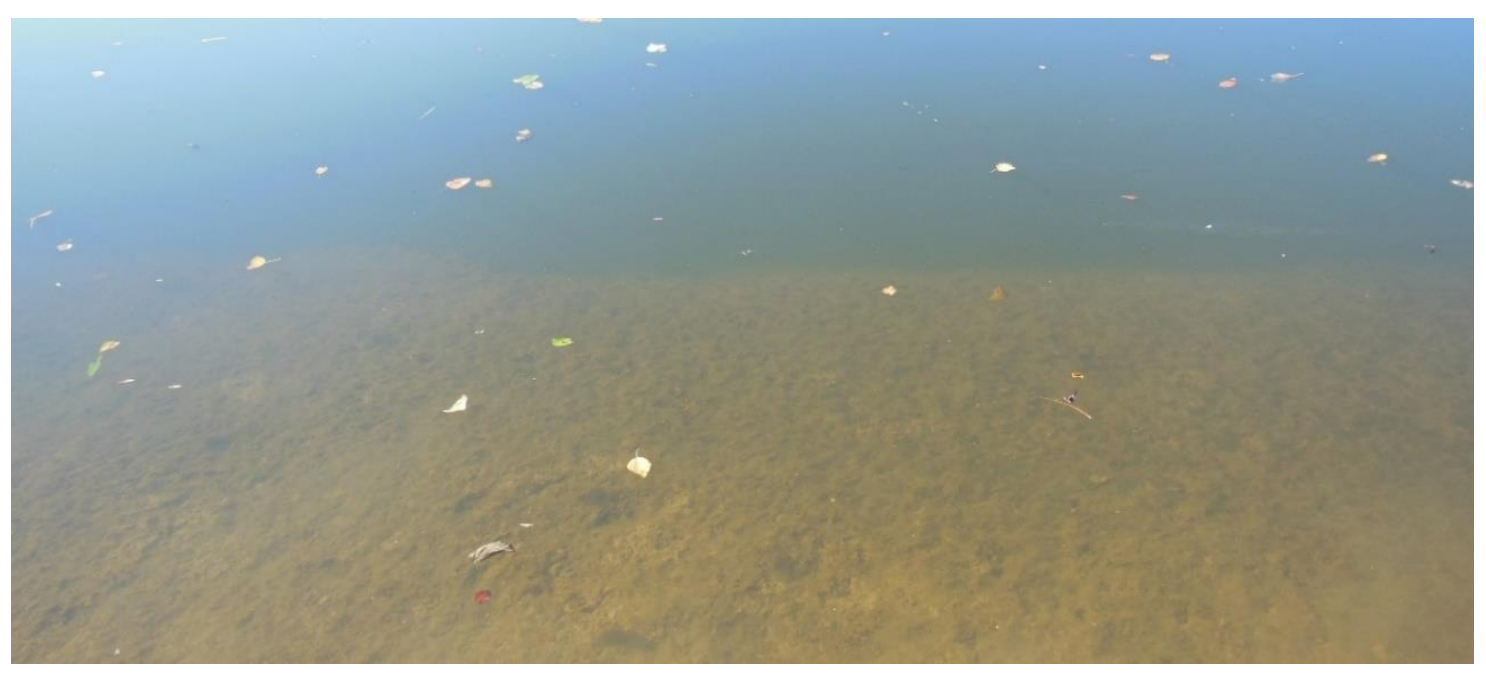

Steeply terminating beach immediately below the waterline at site PJD002. 


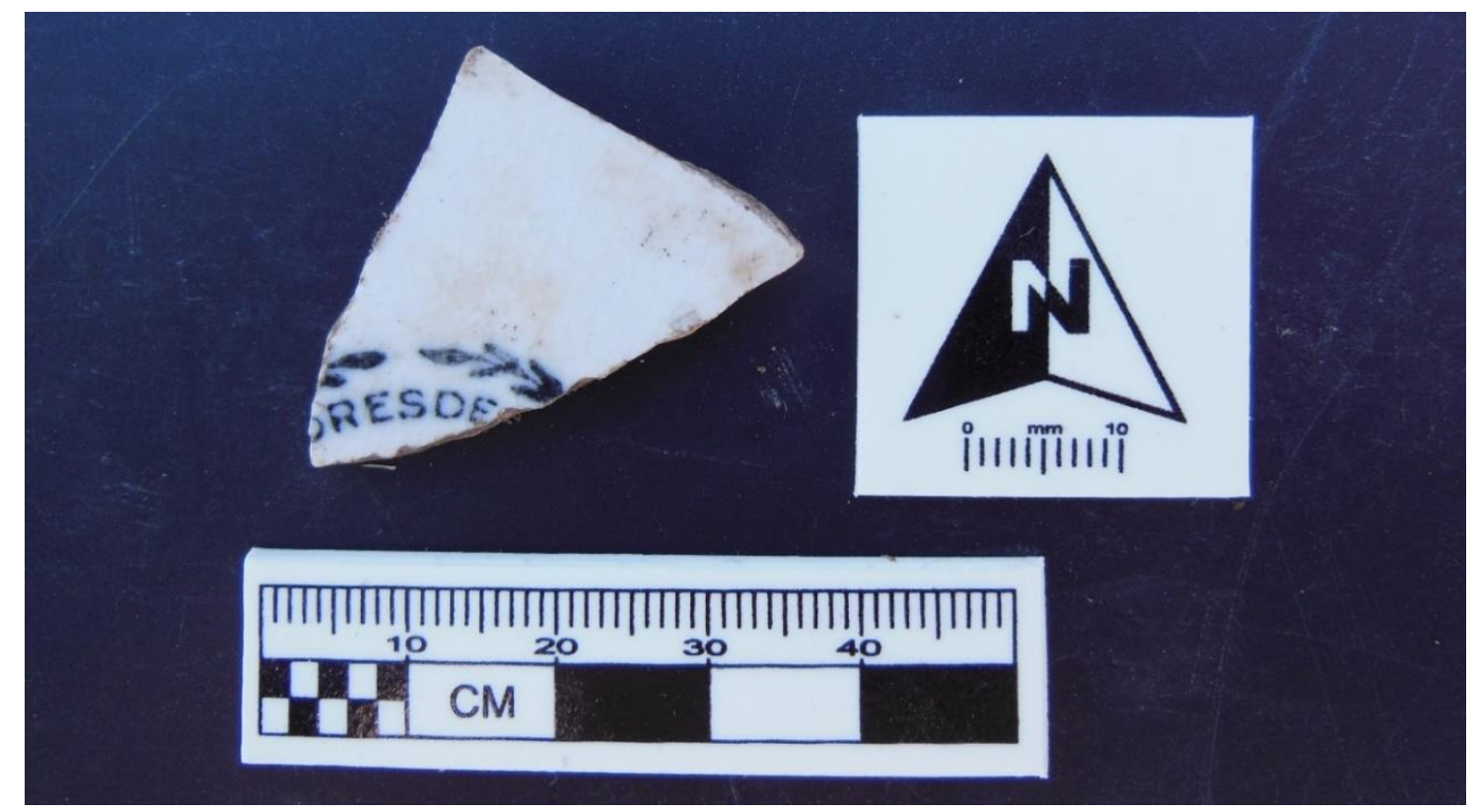

Partial maker's mark on a ceramic fragment at site PJD002, likely Dresden Floral Porcelain Co., ca. 1945-1956. 


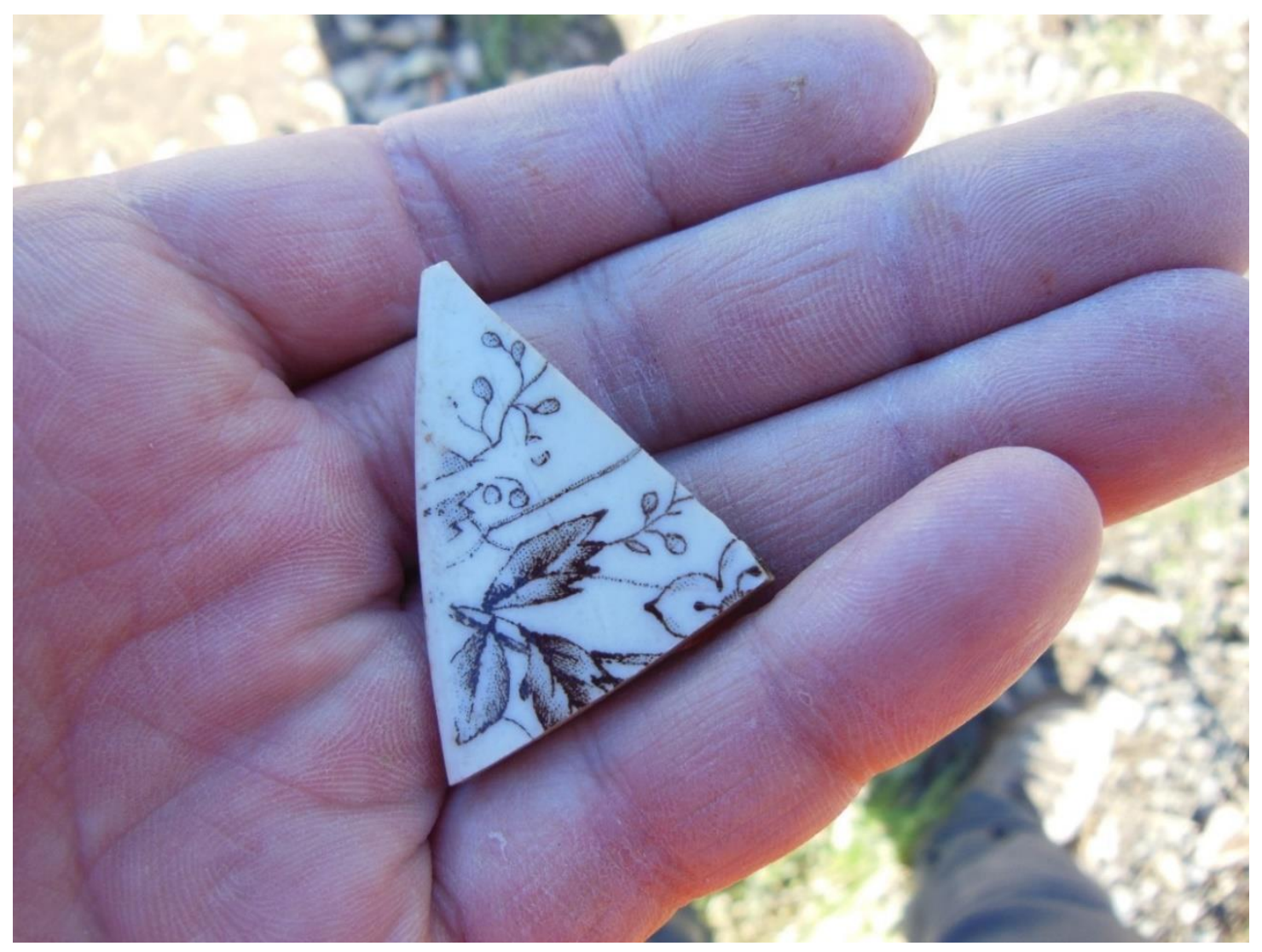

Ceramic fragment at site PJD002 of unknown origin, with floral print. 


\section{$\underline{\text { PJD003 }}$}

This site is a surface scatter of fire-cracked rock (FCR) on western Sauvie Island shoreline, along the Multnomah Channel. The site has an estimated area of $224 \mathrm{~m}^{2}$ and sits along an exposed eroding bank, on an unvegetated beach with an abrupt termination below the waterline. The assemblage is estimated at less than 50 artifacts of relatively uniform size and material, with no distinct concentrations or features. No cultural deposits were observed in situ in the exposed bank and the assemblage does not include diagnostic artifacts or dateable features. The site is completely inundated at high-tide and can be accessed via boat or on foot along the beach at low-tide during the summer and fall months.

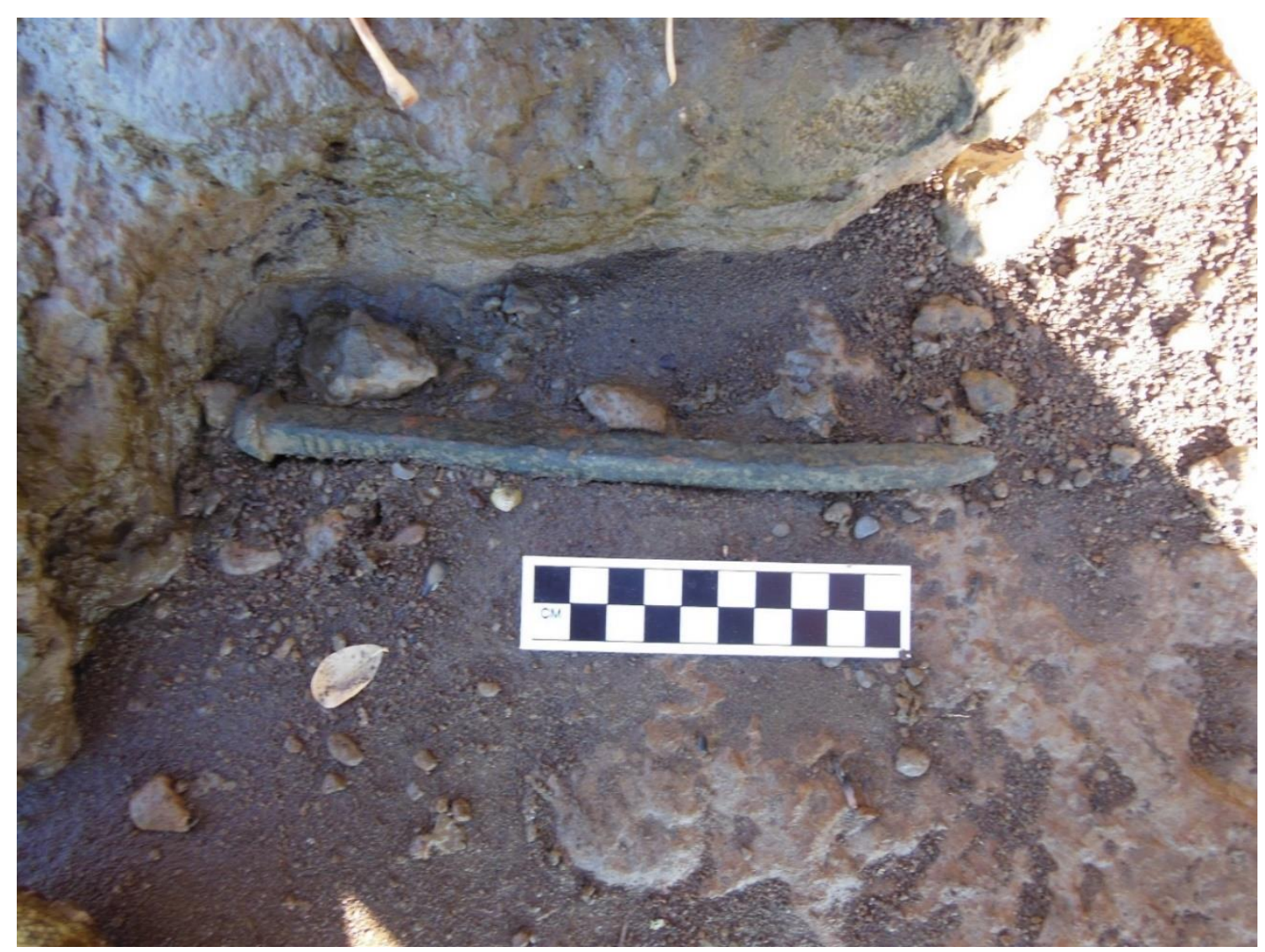

Nail of unknown origin at site PJD003. 


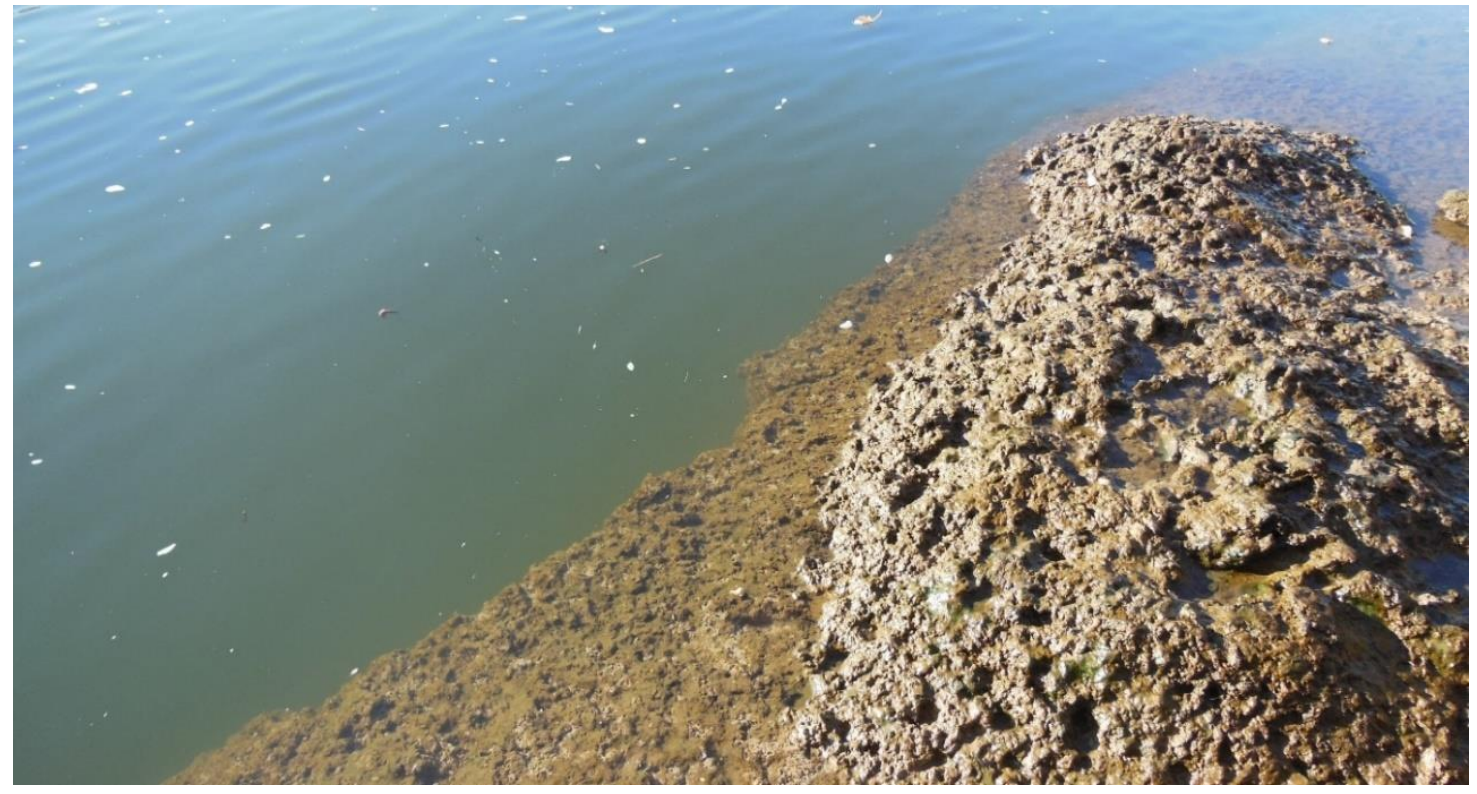

Steeply terminating beach edge at site PJD003. 


\section{$\underline{\text { PJD004 }}$}

This site is a surface scatter of fire-cracked rock (FCR) on the western Sauvie Island shoreline, along the Multnomah Channel. The site has an estimated area of $384 \mathrm{~m}^{2}$ and sits along an exposed eroding bank, with an unvegetated beach sloping gradually below the waterline. The assemblage is estimated at less than 75 artifacts of relatively uniform size and material, with no distinct concentrations or features, although at least one tool was found at the site, a side-notched netweight preform, with other FCR cobbles potentially representing recycled groundstone tools. No cultural deposits were observed in situ in the exposed bank and the assemblage does not include diagnostic artifacts or dateable features. The site is completely inundated at high-tide and only accessible via boat at or near low tide during the summer and fall months.

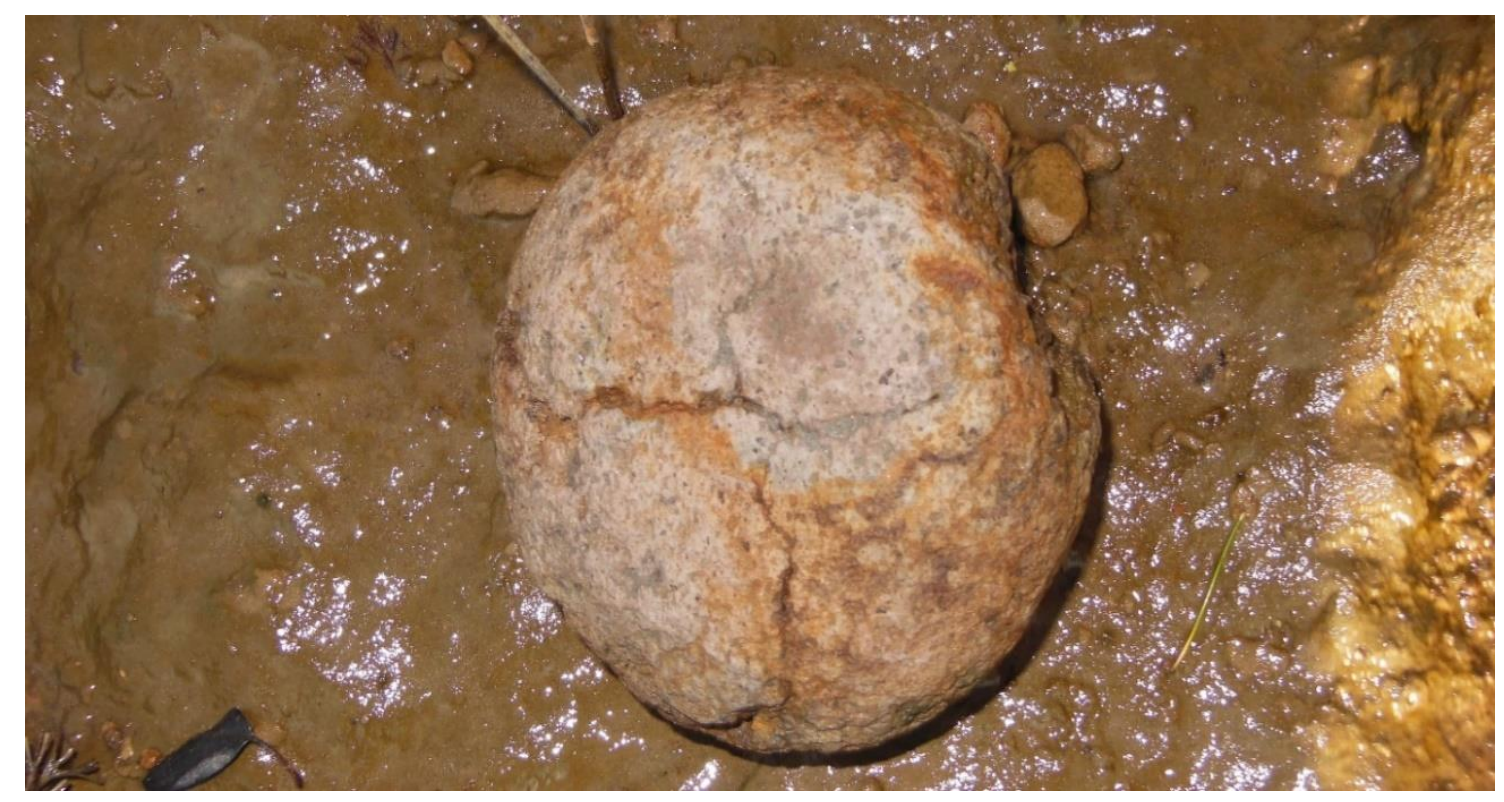

Fire-cracked and stained cobble at site PJD004, potential discarded/recycled hammerstone. 


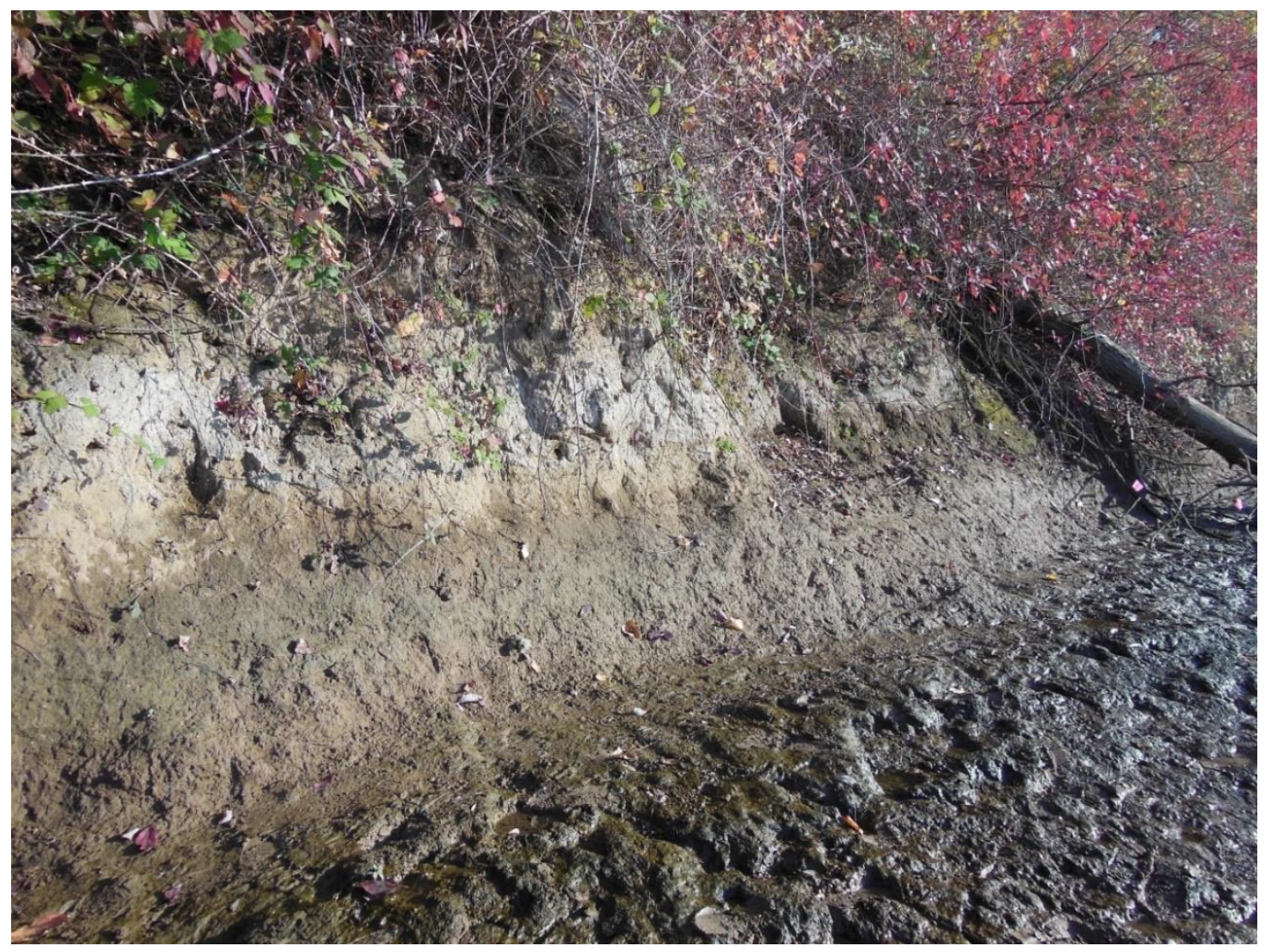

Exposed and high-angled bank at site PJD004. 


\section{$\underline{\text { PJD005 }}$}

This site is a surface scatter of fire-cracked rock on the western Sauvie Island shoreline, along the Multnomah Channel. The site has an estimated area of $1395 \mathrm{~m}^{2}$ and sits along an exposed eroding bank of varying angles, with a partially vegetated beach that slopes gradually below the waterline. Extensive deadfall is present across the site, as well as modern refuse related to recreational activities. The assemblage is estimated at less than 150 artifacts of relatively uniform size and material, with no distinct concentrations or features. No cultural deposits were observed in situ in the exposed bank and the assemblage does not include diagnostic artifacts or dateable features. Site area is accessible via boat at low tide throughout the summer and fall months, and some areas of the site may stay above water for majority of the year.

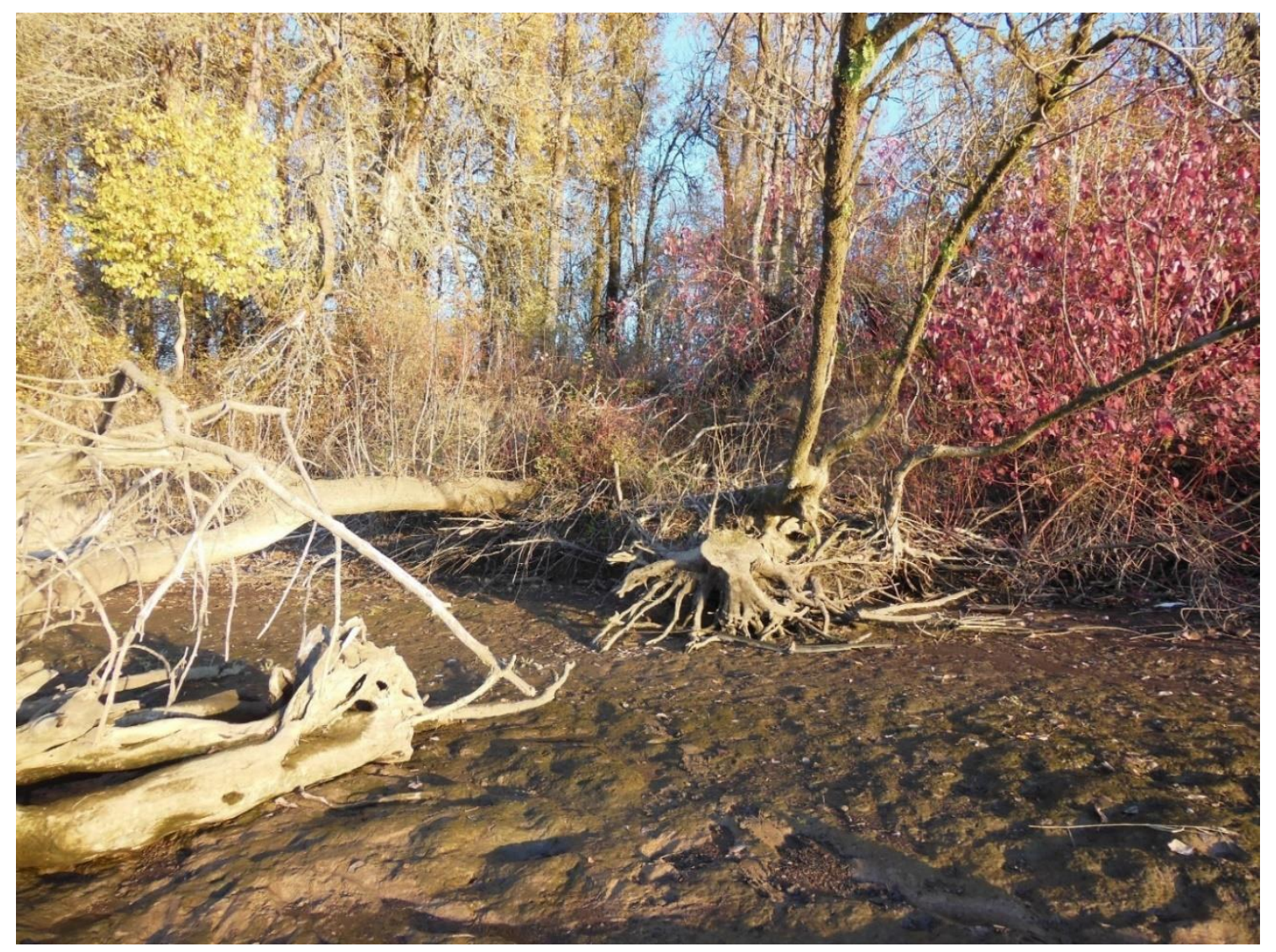

Large beach, fire-cracked rock scatter, and extensive deadfall at site PJD005. 


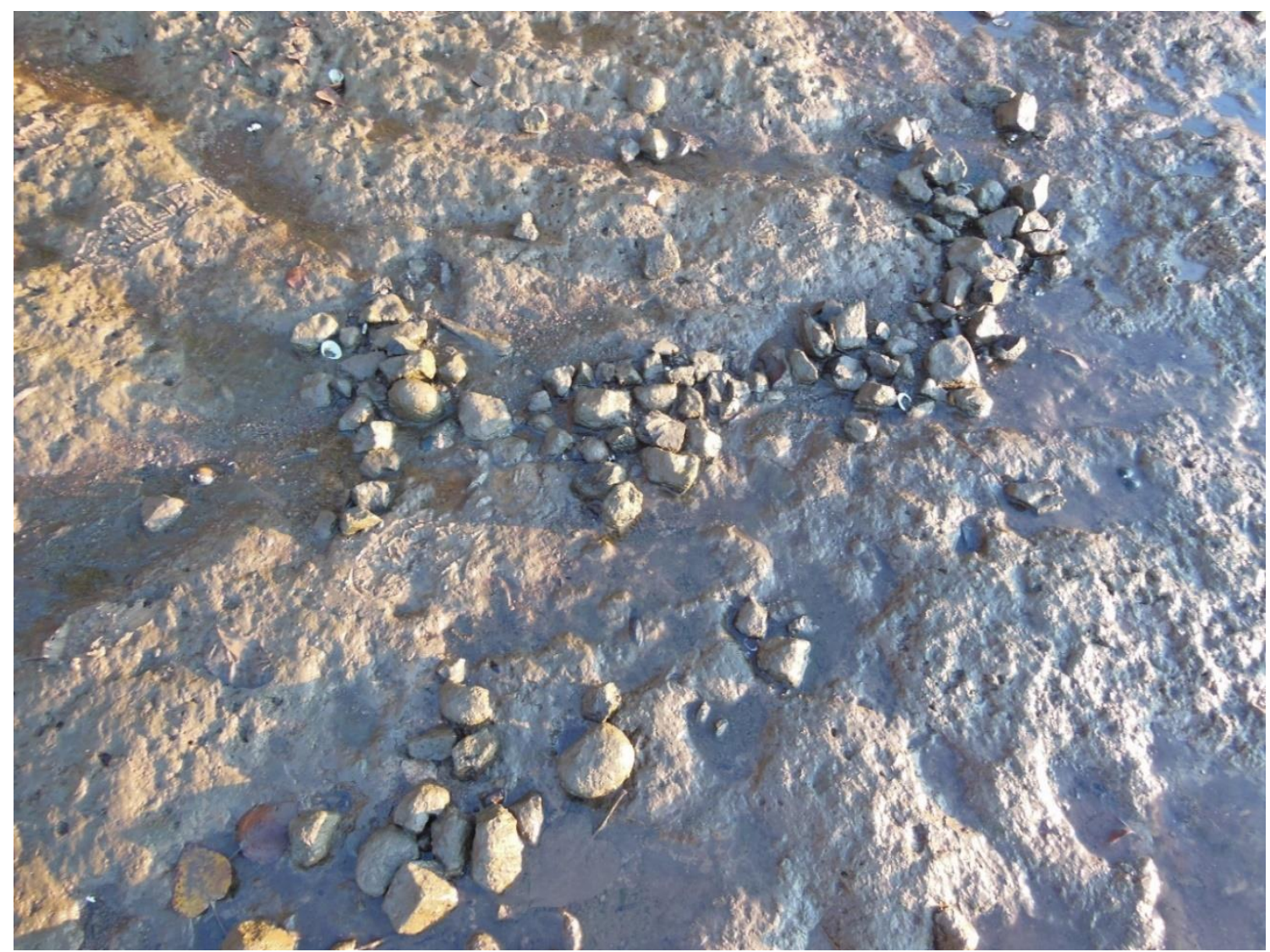

Close-up view of the large fire-cracked rock scatter at site PJD005. 


\section{$\underline{\text { PJD006 }}$}

This site is a surface scatter of fire-cracked rock (FCR) on the Sauvie Island shoreline, along the Multnomah Channel. The site has an estimated area of $200 \mathrm{~m}^{2}$ and sits along a steeply angled exposed eroding bank, with an unvegetated beach and a gradual slope below the waterline. The assemblage is estimated at less than 75 artifacts of relatively uniform size and material, with no distinct concentrations or features. No cultural deposits were observed in situ in the exposed bank and the assemblage does not include diagnostic artifacts or dateable features. The site is completely inundated at high-tide and only accessible via boat at or near low tide during the summer and fall months.

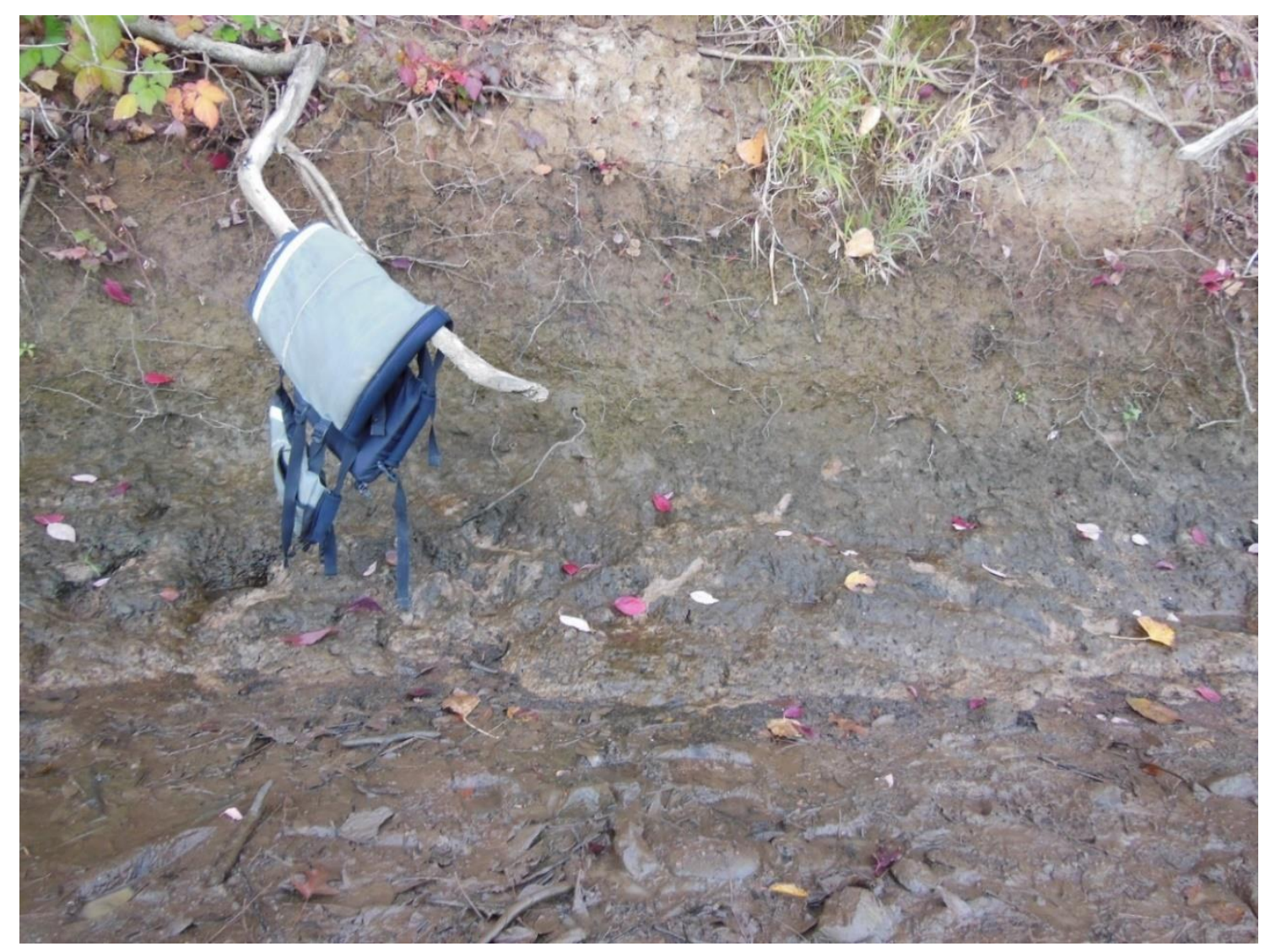

Exposed steeply angled cut-bank at site PJD006. 


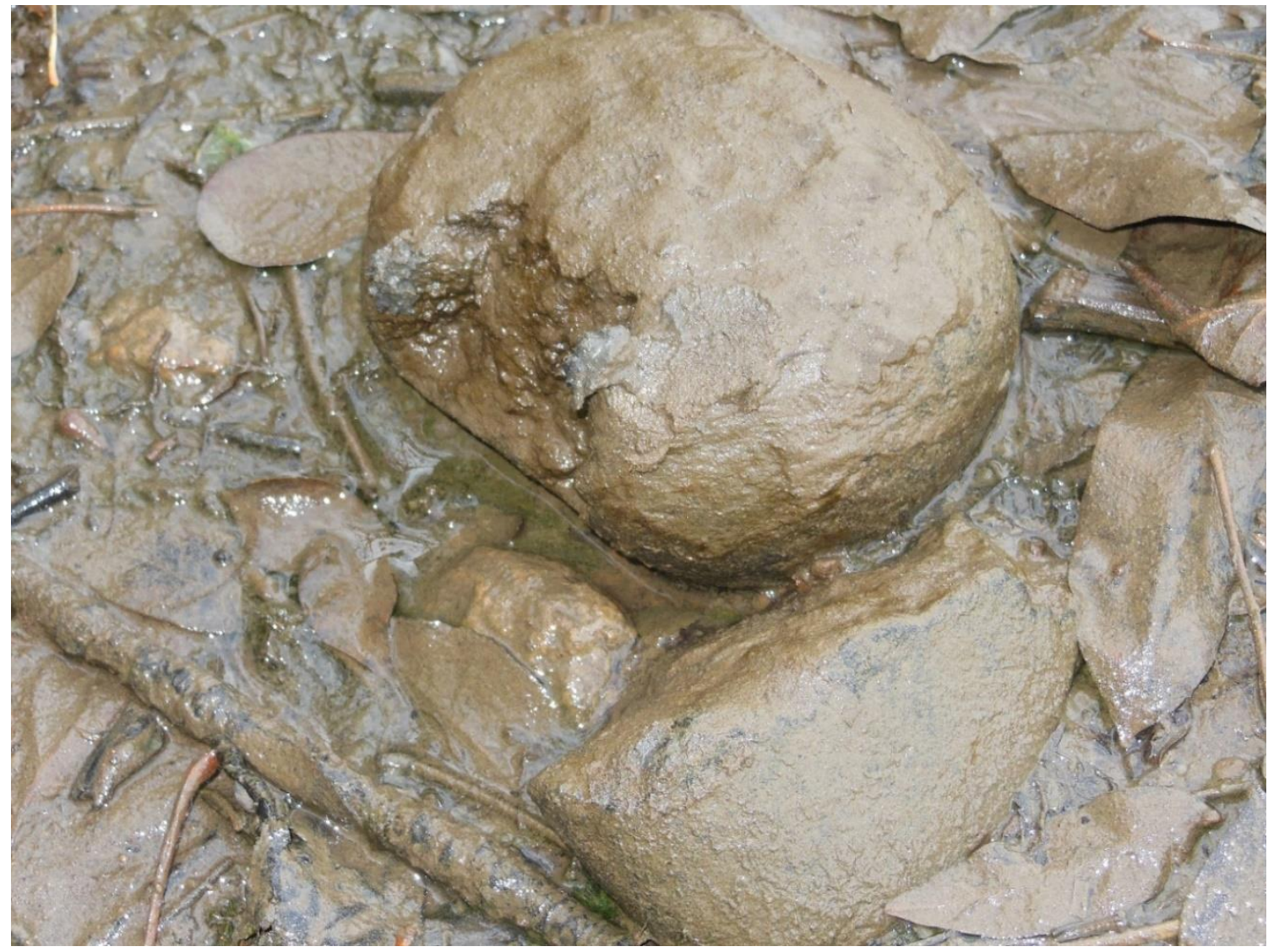

Close-up view of fire-cracked rock at site PJD006. 


\section{$\underline{\text { PJD007 }}$}

This site is a surface scatter of fire-cracked rock (FCR) on the Sauvie Island shoreline, along the Multnomah Channel. The site has an estimated area of $576 \mathrm{~m}^{2}$ and sits along an exposed eroding bank, with a partially vegetated beach with an abrupt termination below the waterline. The assemblage is estimated at less than 100 artifacts of relatively uniform size and material, with no distinct concentrations or features, although one tool was identified at the site. No cultural deposits were observed in situ in the exposed bank and the assemblage does not include diagnostic artifacts or dateable features. The site is completely inundated at high-tide and only accessible via boat at or near low tide during the summer and fall months.

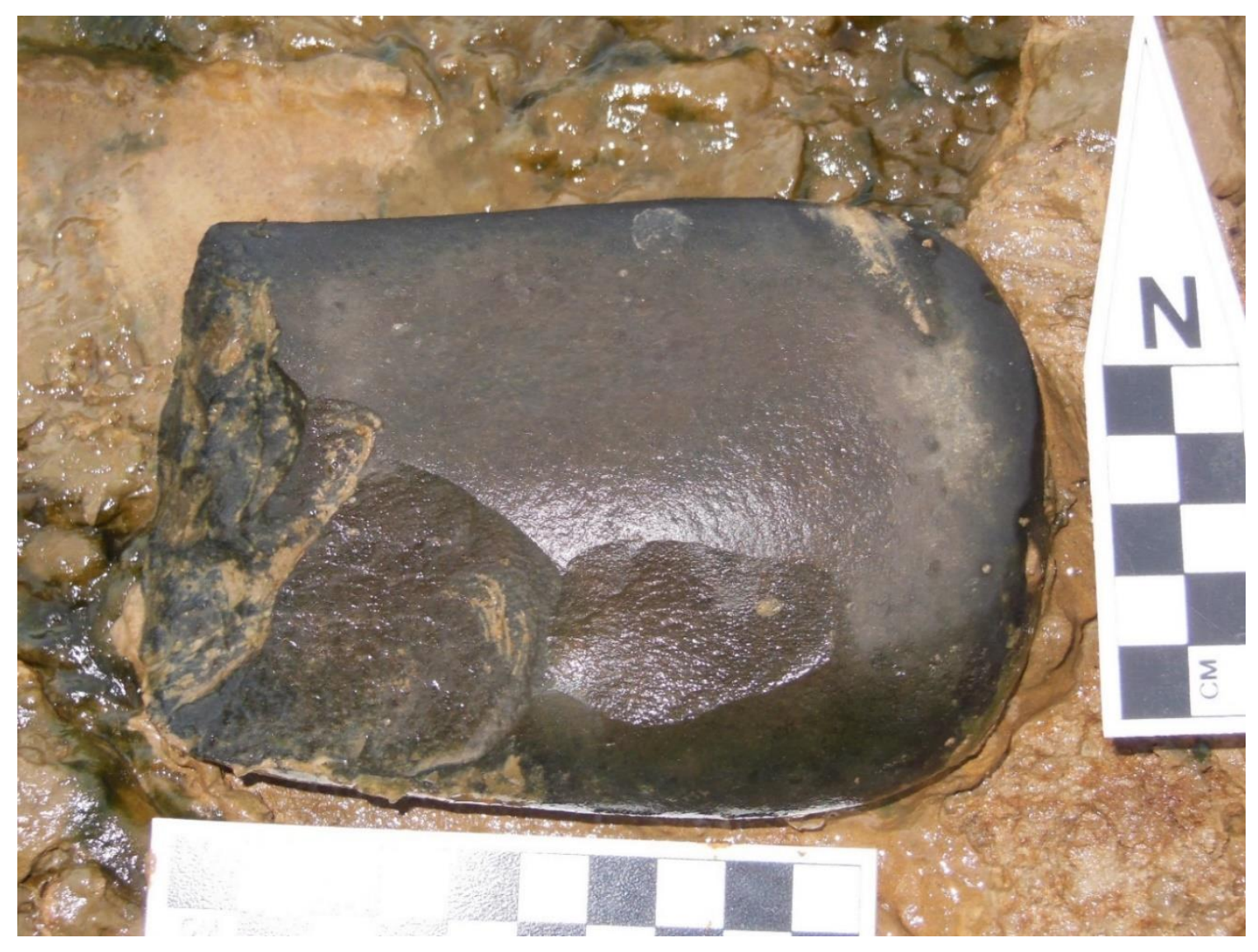

Basalt unifacial cobble chopper at site PJD007. 


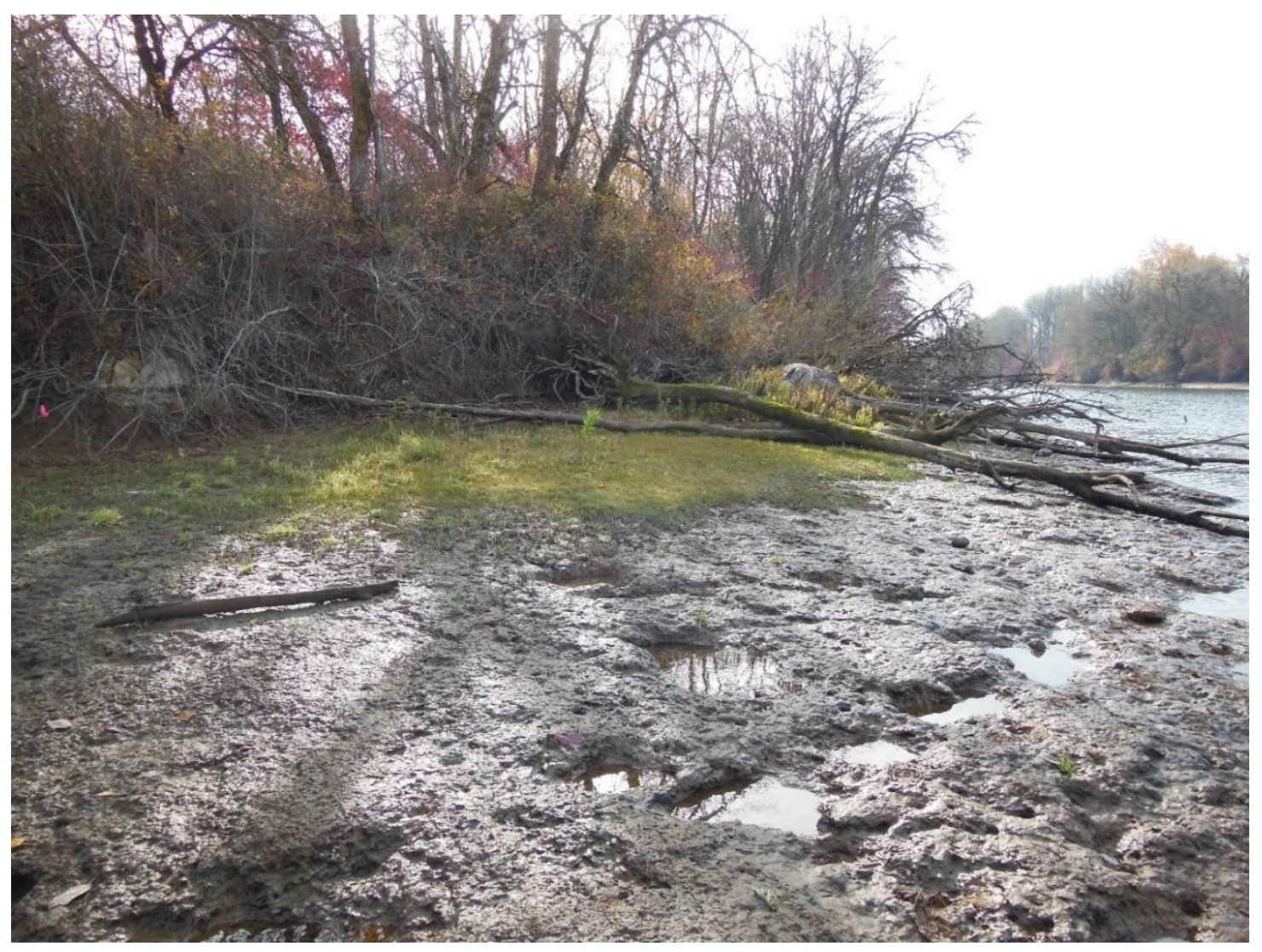

Gradually sloping, partially vegetated beach at site PJD007. 


\section{$\underline{\text { PJD008 }}$}

This site is a late-historic debris scatter and dock feature on the Sauvie Island shoreline, along the Multnomah Channel. The site has an area of $342 \mathrm{~m}^{2}$ and sits along a gently sloped, thickly vegetated eroding bank, with an unvegetated beach with a gradual slope below the waterline. The assemblage is estimated at less than 30 late-historic refuse fragments, scattered around the dock feature, with some diagnostic markings. Cultural deposits were observed in situ in the eroding bank and included the remains of a rotting wood structure, likely related to the dock feature. The site surface is completely inundated at high-tide, but the dock feature is visible above the waterline from summer through late fall, with the site being accessible by boat or via agriculturally developed private land on the bank above.

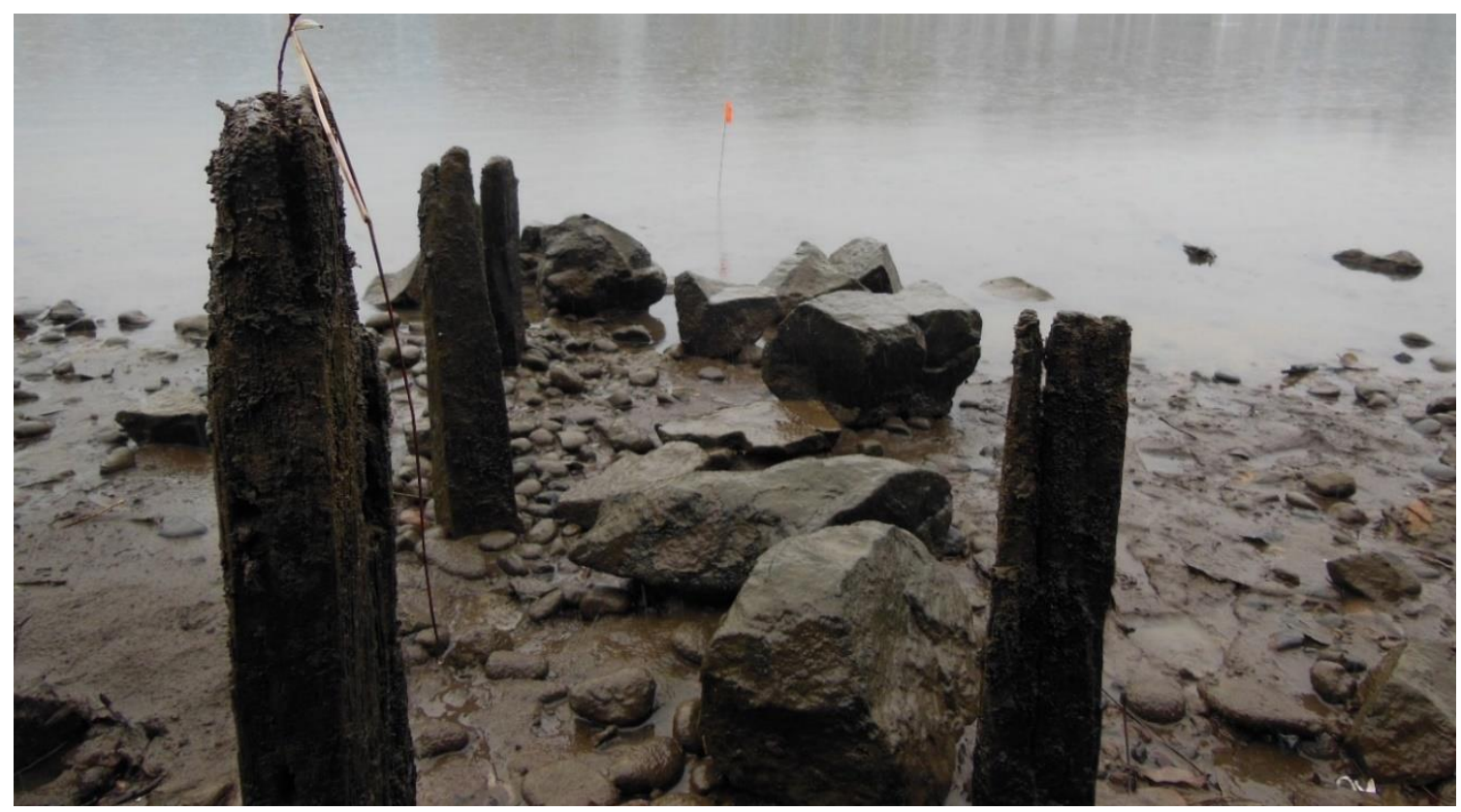

Wood and riprap remains of dock at site PJD008. 


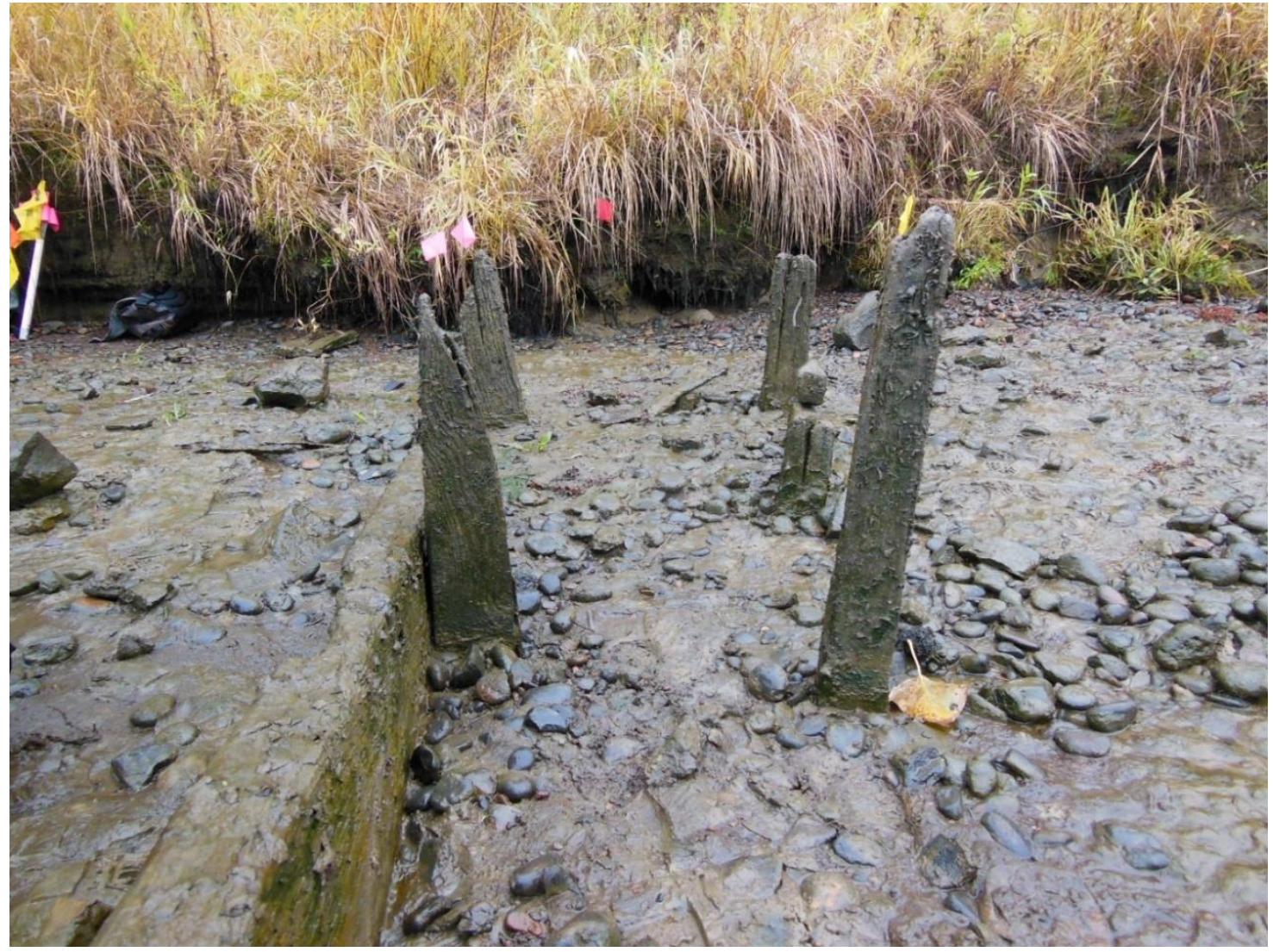

Wood remains of dock at site PJD008. 


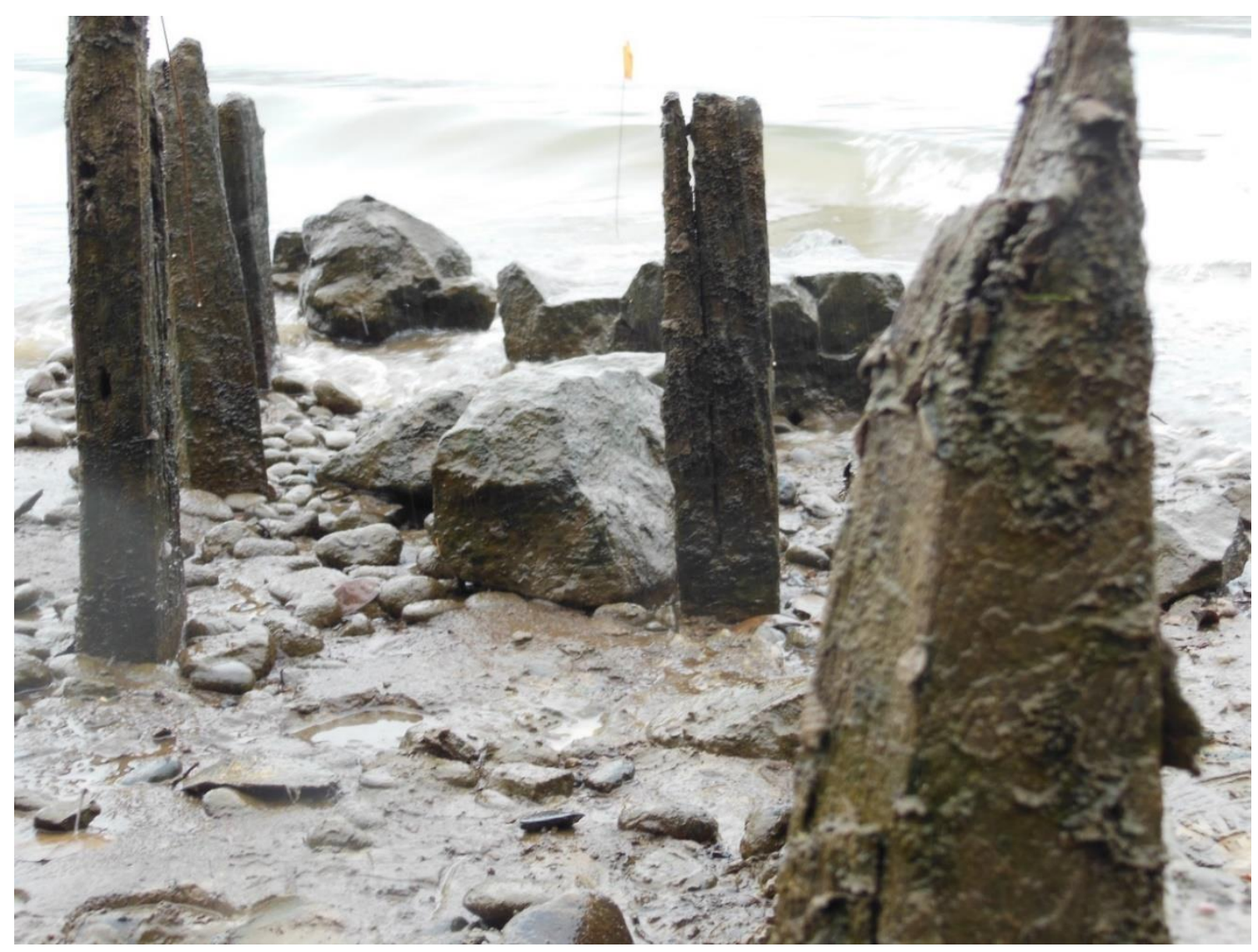

Close-up of wood and riprap dock remains at site PJD008. 


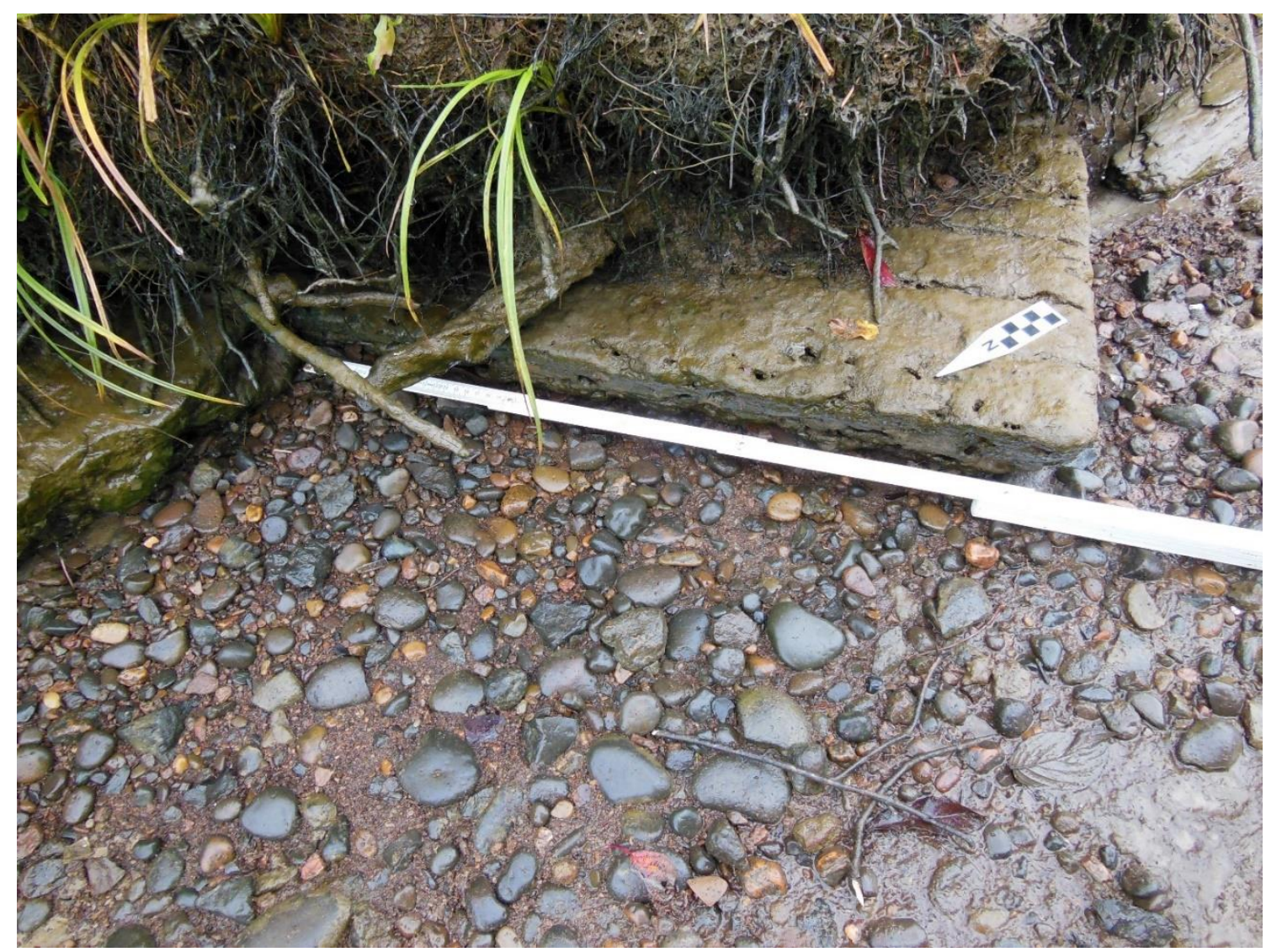

Machine cut wood plank in bank feature at site PJD008. 


\section{PJD009}

This site is a surface scatter of fire-cracked rock (FCR) on the Sauvie Island shoreline, along the Multnomah Channel. The site has an estimated area of $656 \mathrm{~m}^{2}$ and sits along an exposed eroding bank, with an unvegetated beach with an abrupt termination below the waterline. The assemblage is estimated at less than 175 artifacts of relatively uniform size and material, with several concentrations. No cultural deposits were observed in situ in the exposed bank and the assemblage does not include diagnostic artifacts or dateable features. The site is completely inundated at high-tide and only accessible via boat at or near low tide during the summer and fall months.

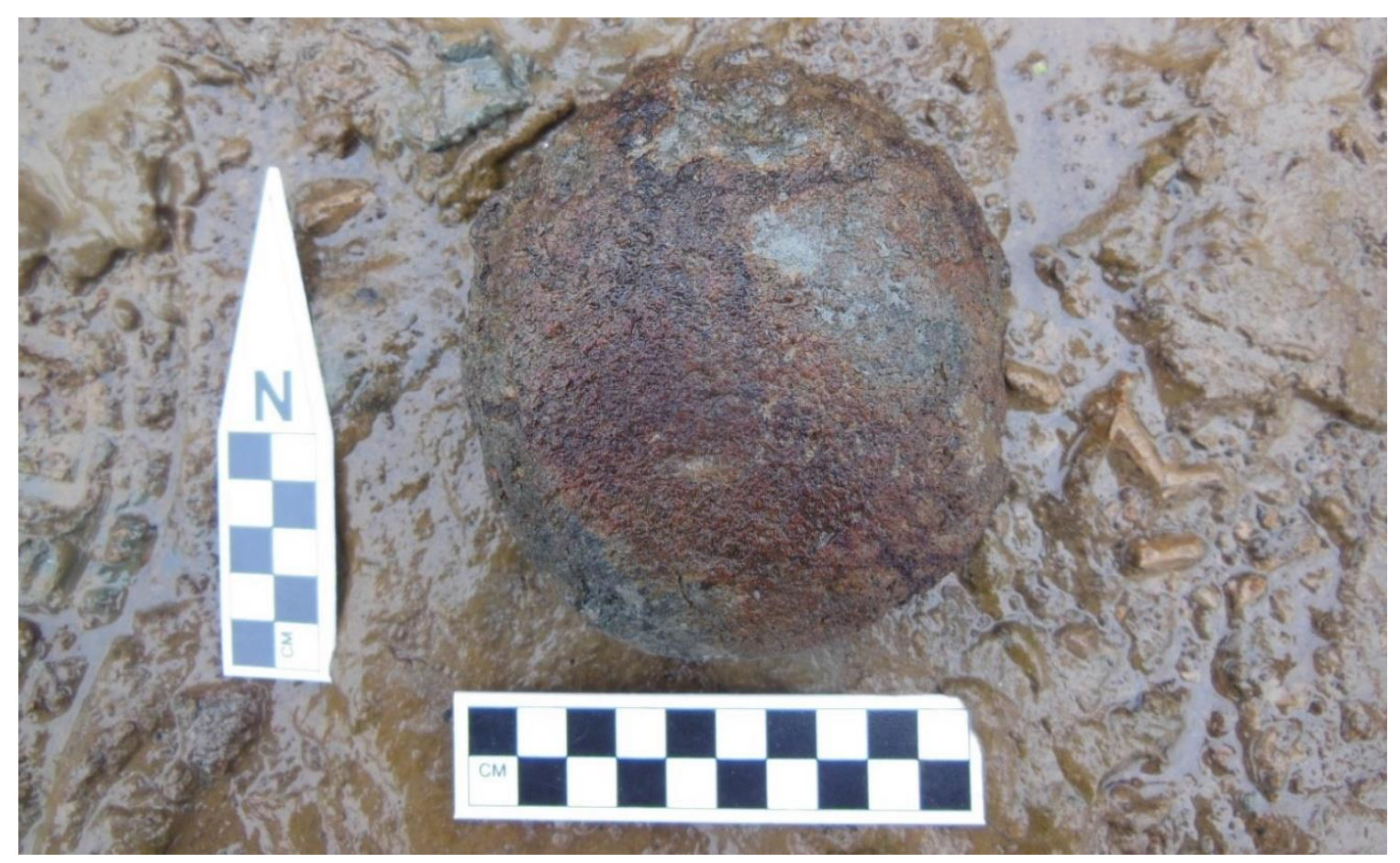

Fire-cracked cobble and possible hammerstone at site PJD009. 


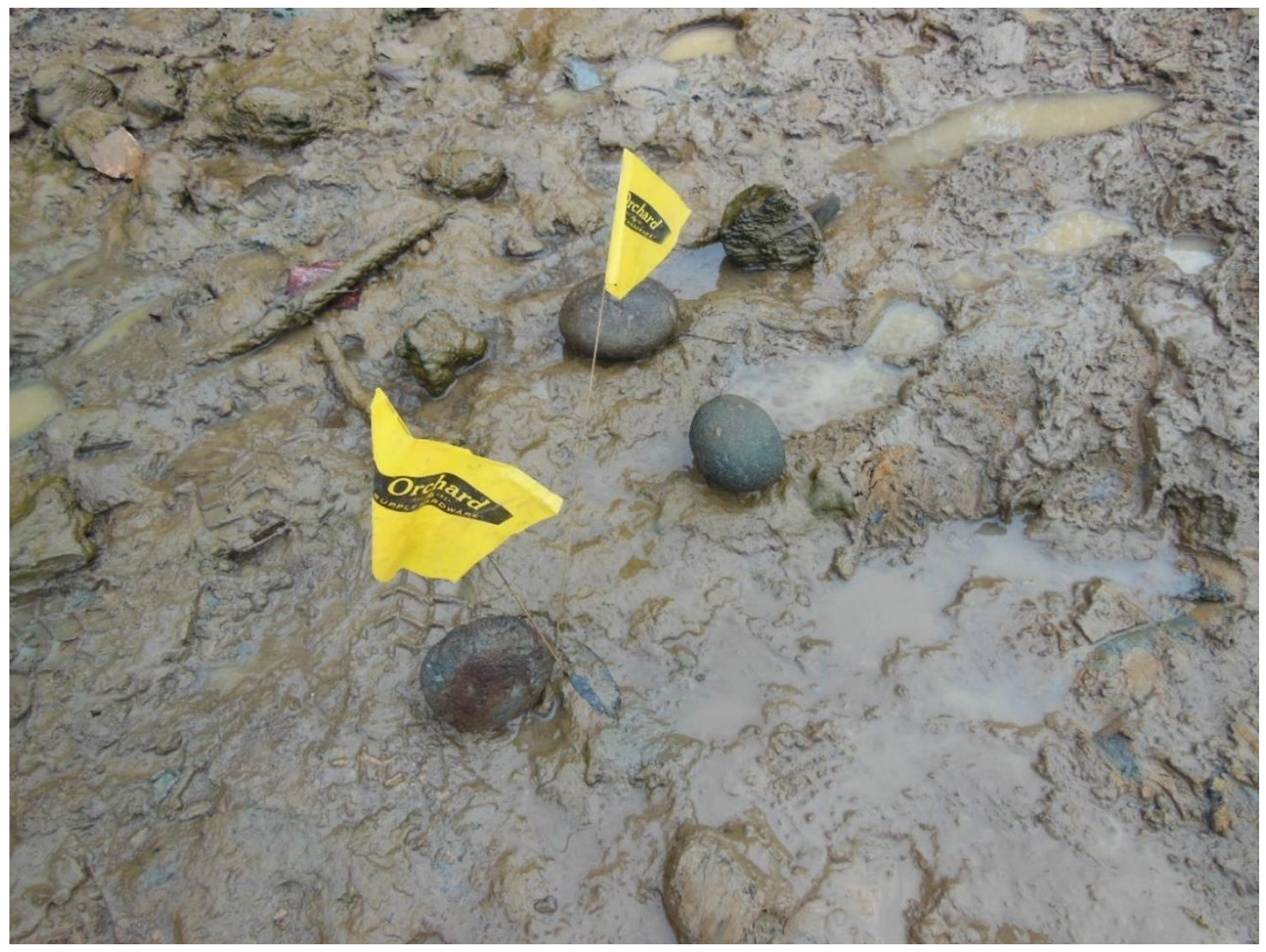

Fire-cracked cobbles on surface at site PJD009. 


\section{$\underline{\text { PJD010 }}$}

This site is a multicomponent surface scatter of Indigenous fire-cracked rock and EuroAmerican refuse on the Sauvie Island shoreline, along the Multnomah Channel. The site has an area of $4130 \mathrm{~m}^{2}$ and sits along a partially exposed eroding bank, with a partially vegetated beach with a gradual into the waterline. The assemblage is estimated at less than 275 artifacts and is highly diverse, including a range of temporally diagnostic EuroAmerican ceramic artifacts (Figure 4.5), nails, metal fragments, and other refuse, as well as a Euro-American dock feature. The Indigenous component includes a small lithic scatter and a diagnostic projectile point (Figure 4.6), along with extensive FCR scatter estimated to be less than 215 fragments. In situ cultural deposits were present in the form of FCR eroding out of beach overhang, although no dateable features were observed. PJD010 is notable for its large surface area and highly diverse artifact assemblage, all located on the surface of the shoreline. It is an excellent example of the many elements recorded during my fieldwork.

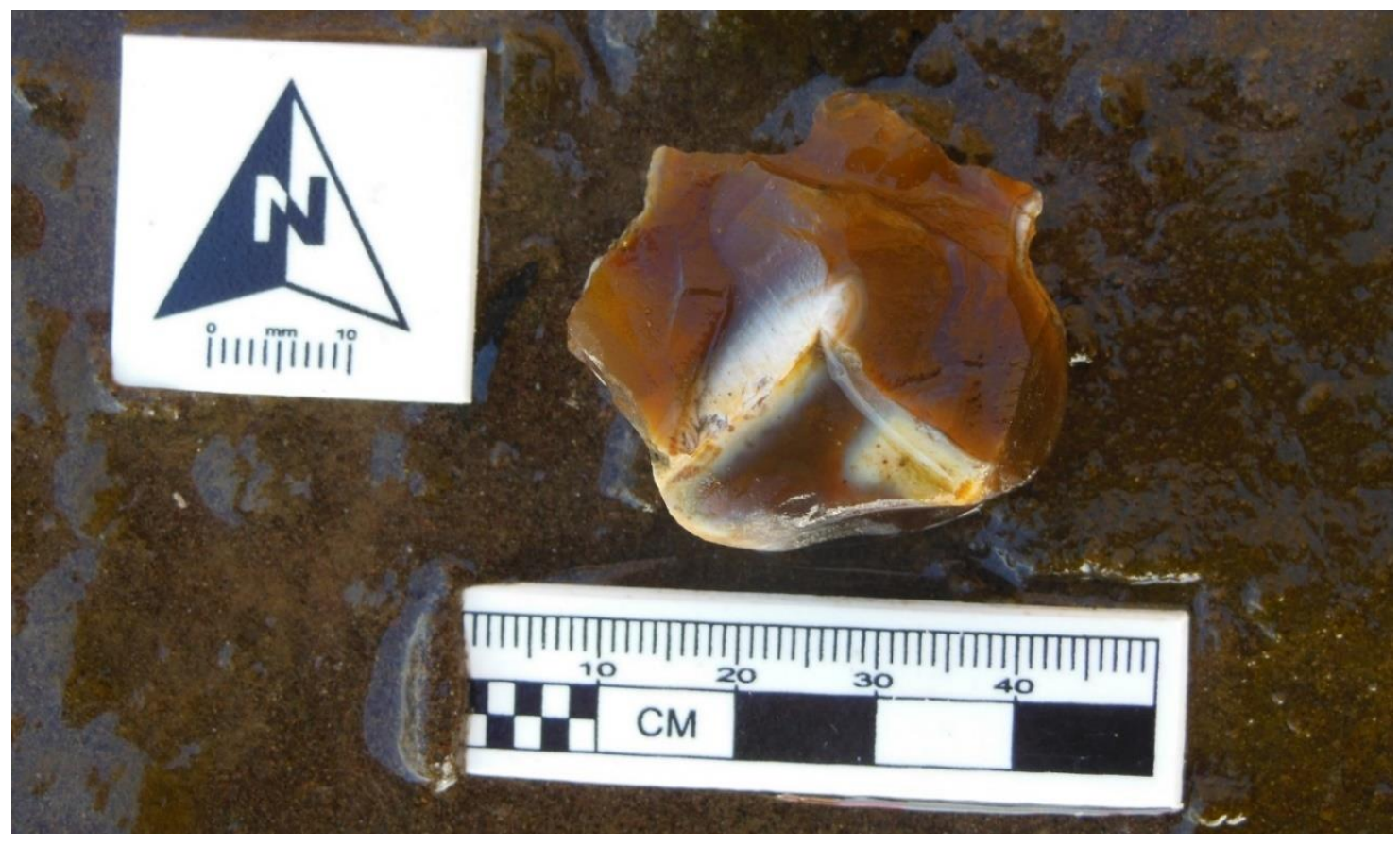

Cryptocrystalline core at site PJD010. 


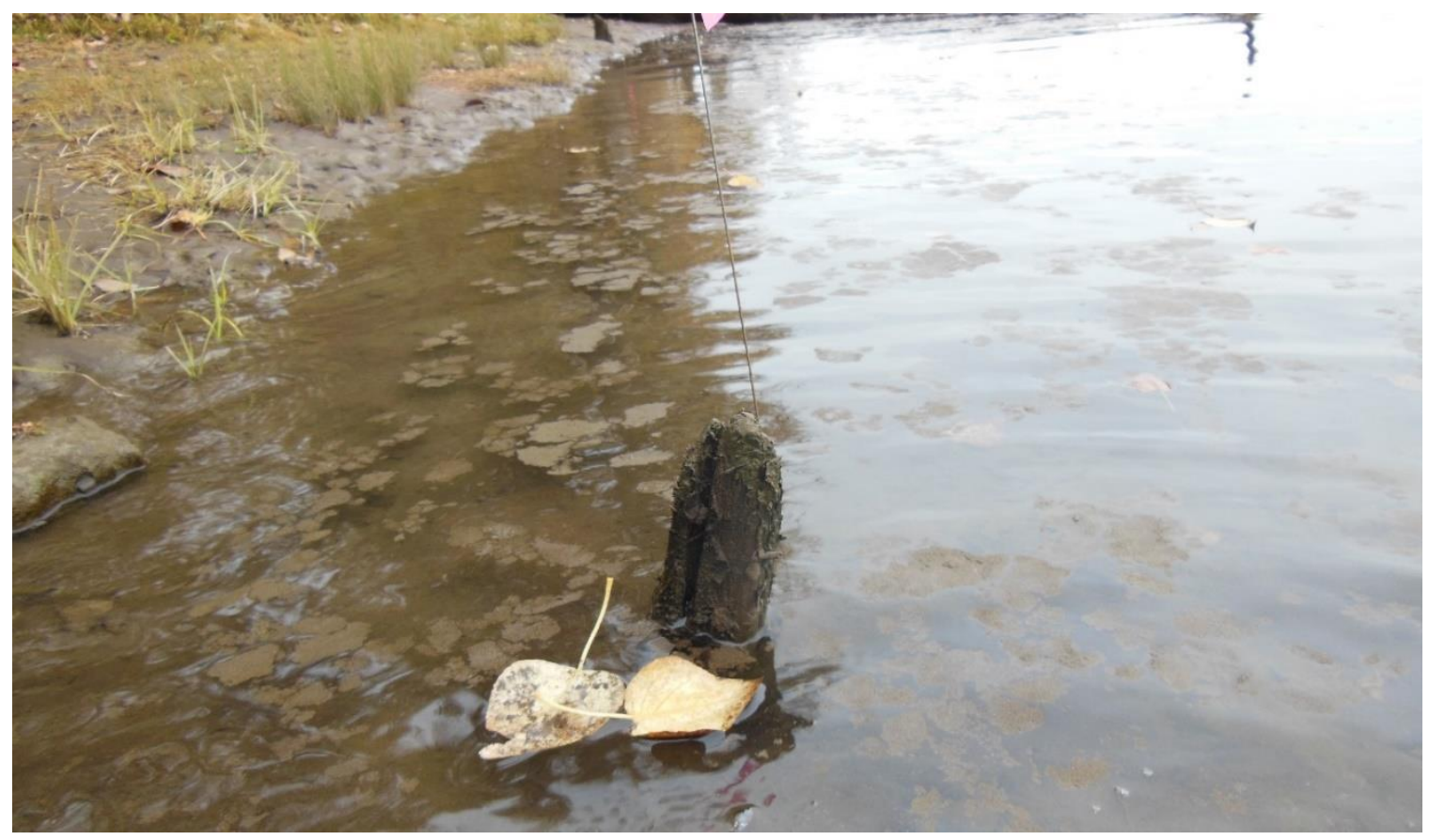

Wood post feature at site PJD010, possible dock. 


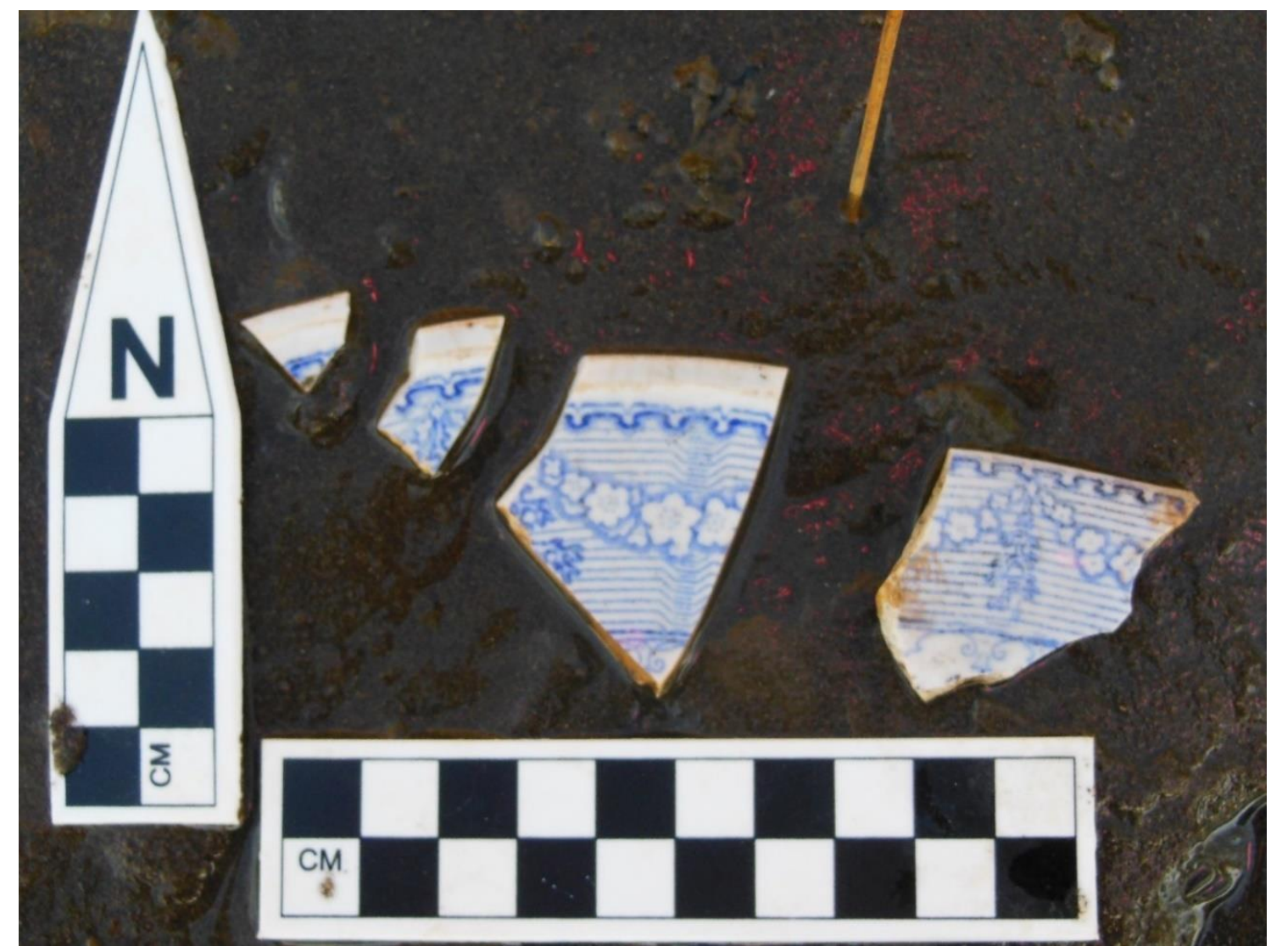

Porcelain dish fragments with blue floral transfer print at site PJD010. 


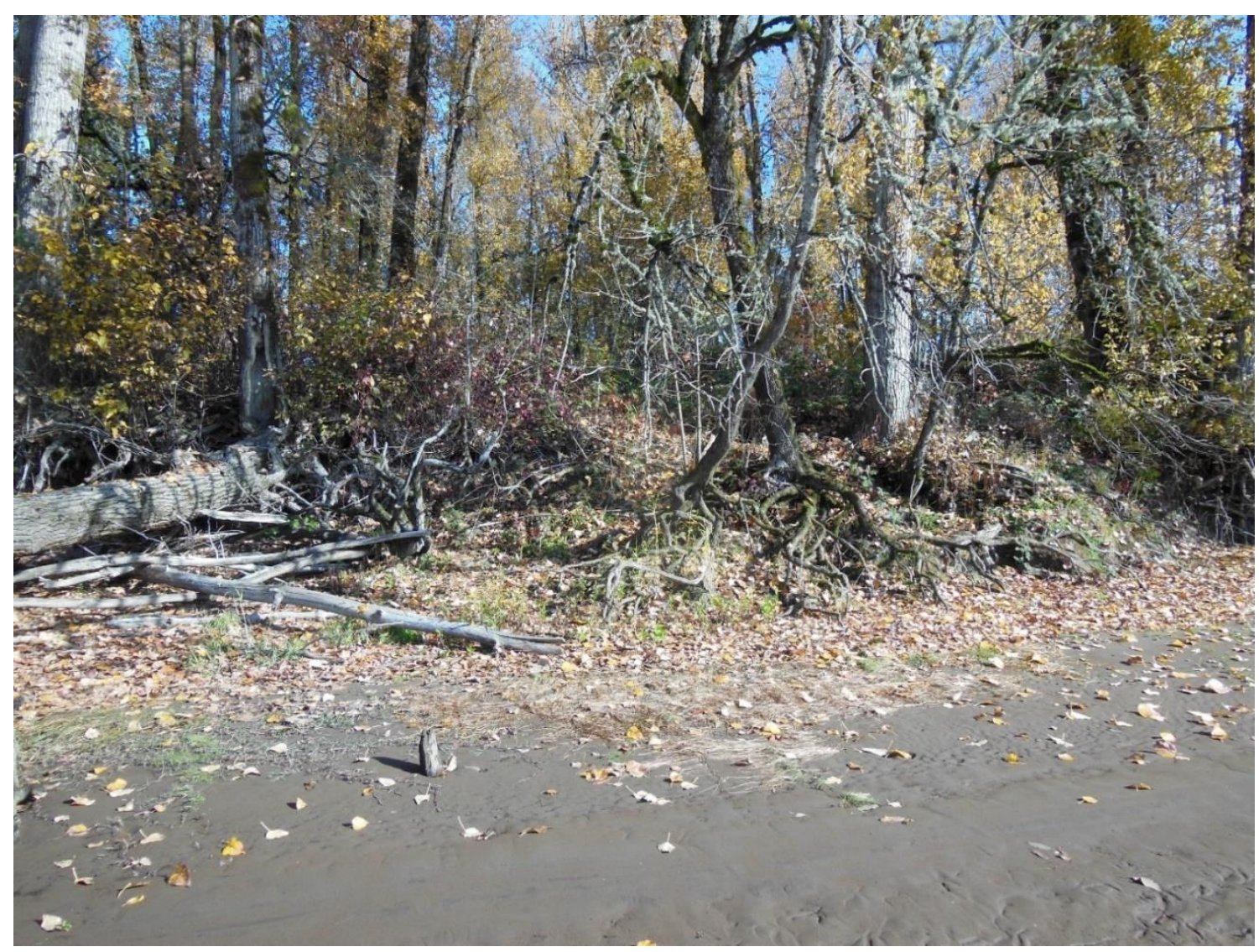

Varied bank angles at site PJD010. 


\section{$\underline{35 \mathrm{MU} 4}$}

The Sunken Village site is a previously recorded large-scale multicomponent acorn processing site with an extensive array of artifacts and basketry features embedded into the beach and bank. The site is located on the Sauvie Island shoreline, along the Multnomah Channel. The site's characteristics, as observed during this study, include an area of $18,432 \mathrm{~m}^{2}$, sitting against a riprapped levee, with no exposed bank. The beach is unvegetated, with a gradual slope below the waterline. As observed during this study, artifacts visible at the site during recording were estimated at less than 10 artifacts, limited to potential groundstone.

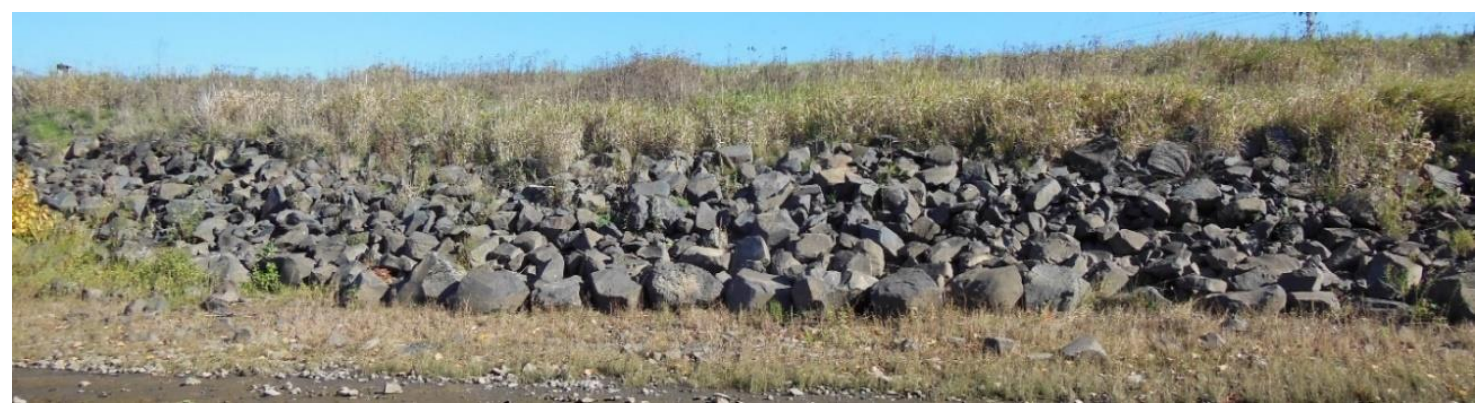

Riprapped bank edge at site 35MU4. 


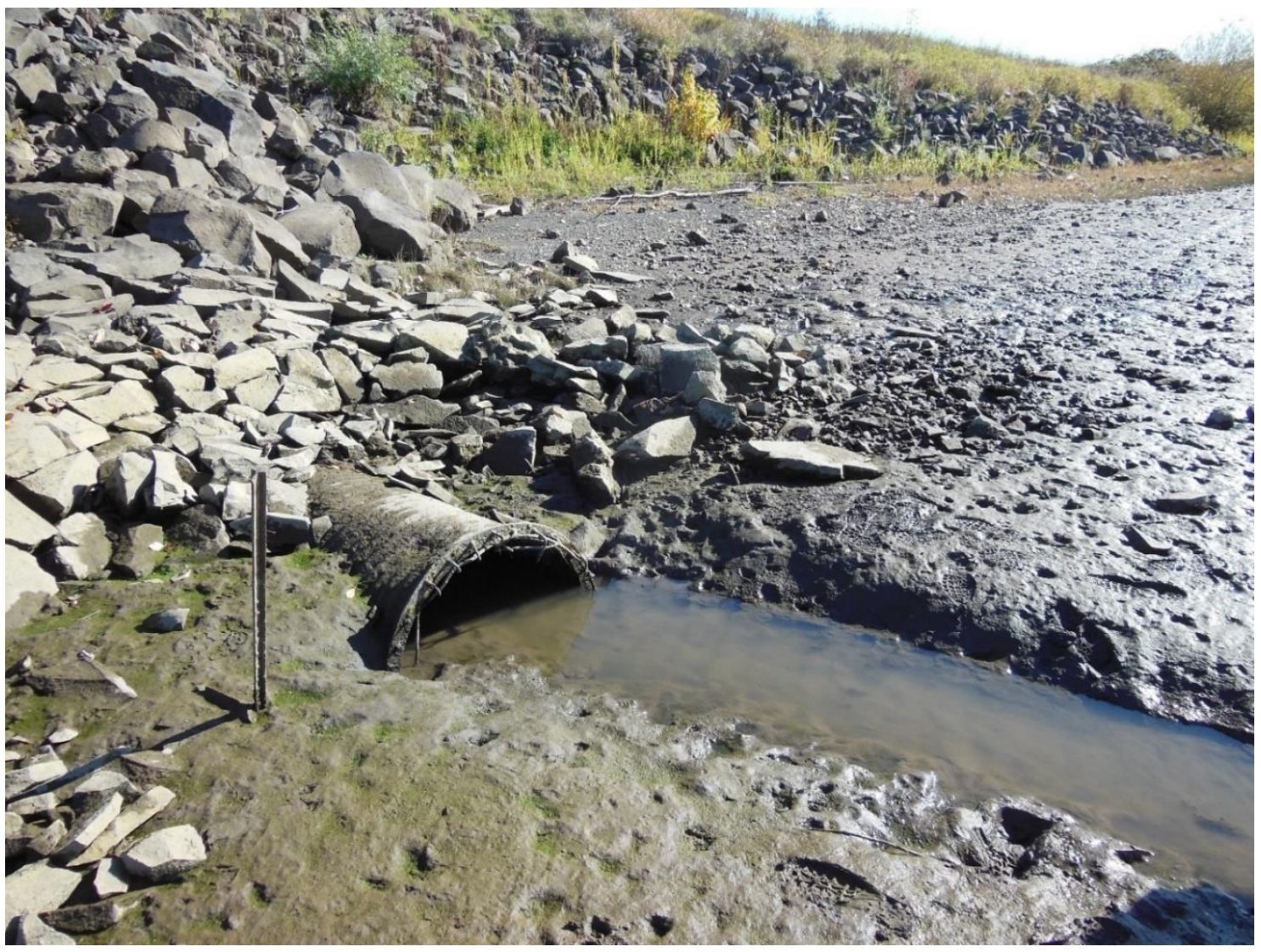

Modern irrigation drainage pipe at site 35MU4. 


\section{$\underline{35 \mathrm{MU} 61}$}

Previously recorded over 30 years ago, the Marked Site is a surface scatter of firecracked rock on the Sauvie Island shoreline, along the Multnomah Channel, north of the Sauvie Island Bridge, and just to the south of the Sunken Village site. The site has an area $210 \mathrm{~m}^{2}$ and sits along moderately sloped, partially exposed bank, with an unvegetated beach and a gradual slope below the waterline. The assemblage is estimated at less than 50 artifacts, exclusively made up of fire-cracked rock of relatively uniform size and material, with no distinct concentrations or features on the beach surface. Previously recorded cultural deposits were not relocated and are assumed destroyed. No diagnostic artifacts or dateable features were identified at the site. The site is inundated at high-tide but can be accessed during summer and fall months via boat or on foot along the beach at low-tide.

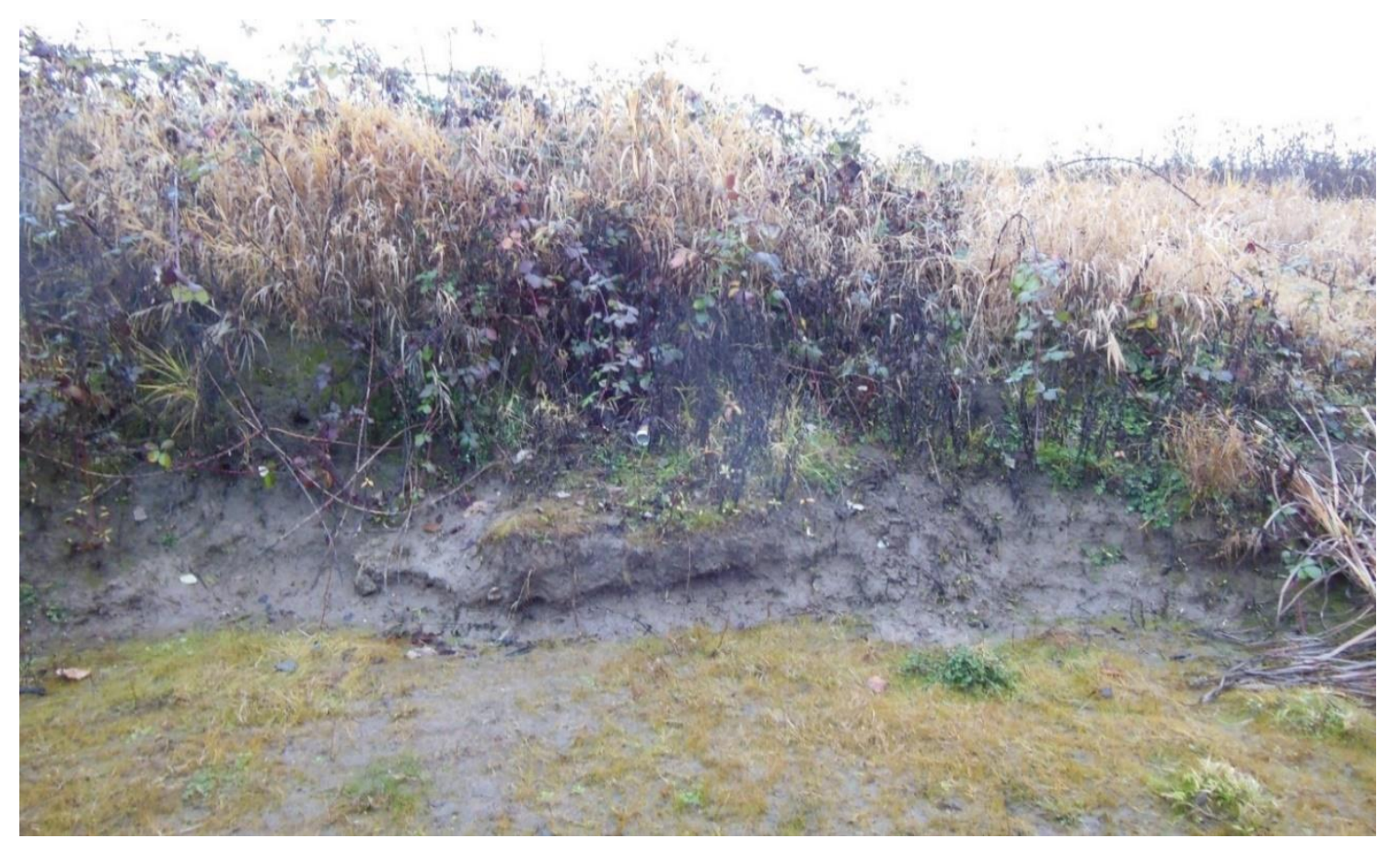

Gradually sloping cut-bank at site 35MU61. 


\section{$\underline{35 \mathrm{MU} 62}$}

Previously recorded over 30 years ago, the Howell Site is a multicomponent surface scatter of Indigenous fire-cracked rock and Euro-American refuse on the western Sauvie Island shoreline, along the Multnomah Channel. As rerecorded during survey, the site has an area of $12,375 \mathrm{~m}^{2}$ and sits along an exposed eroding bank, with an unvegetated beach and a gradual slope below the waterline, a similar profile to initial recording. In 1987, during first identification of the site, a small but diverse Indigenous component was recorded, with an array of exposed cultural materials in the bank, including bone, lithic debitage, diagnostic lithic tools, and fire-cracked rock. Recording at the time also noted Euro-American ceramics and structural debris. During rerecording for my project, significant changes were observed in the assemblage, which was estimated at less than 50 artifacts, including fire-cracked rock of relatively uniform size and material, with no distinct concentrations or features on the beach surface. The rerecorded assemblage also included late historic-era glass and cans, but no signs of ceramics or structural debris were found. Although a hearth feature was relocated in situ, all bank deposits noted prior appear to have been lost entirely to the extensive erosion at the site, evidenced from sheer, exposed bank walls, stepped beach, and complete lack of ground vegetation. Also, unique among the sites surveyed, in addition to legal land access from a Metro-owned parcel to the south, as well as access from the channel, 35MU62 can also be accessed via an illegally constructed fishing trail that connects the site with Sauvie Island Road above. 


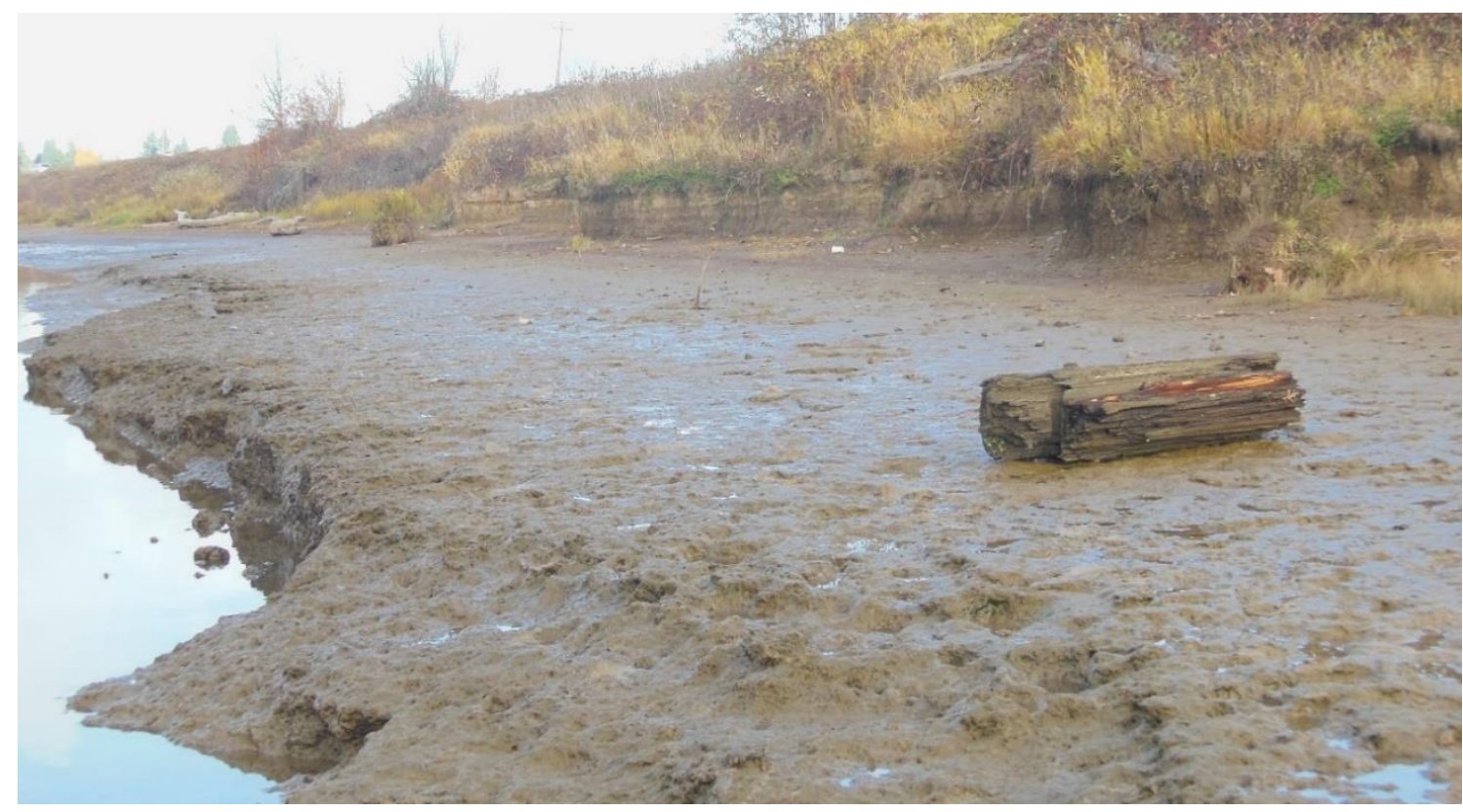

Multiple steeply angled cut-banks along beach at site 35MU62.

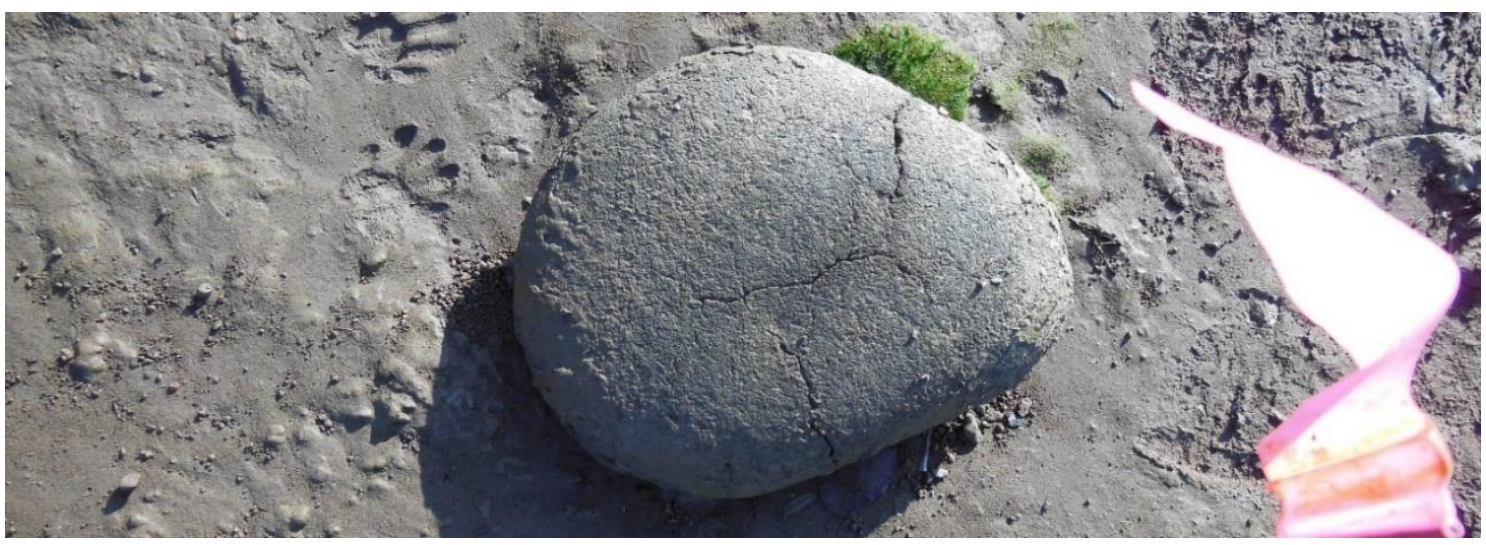

Fire-cracked cobble at site 35MU62. 


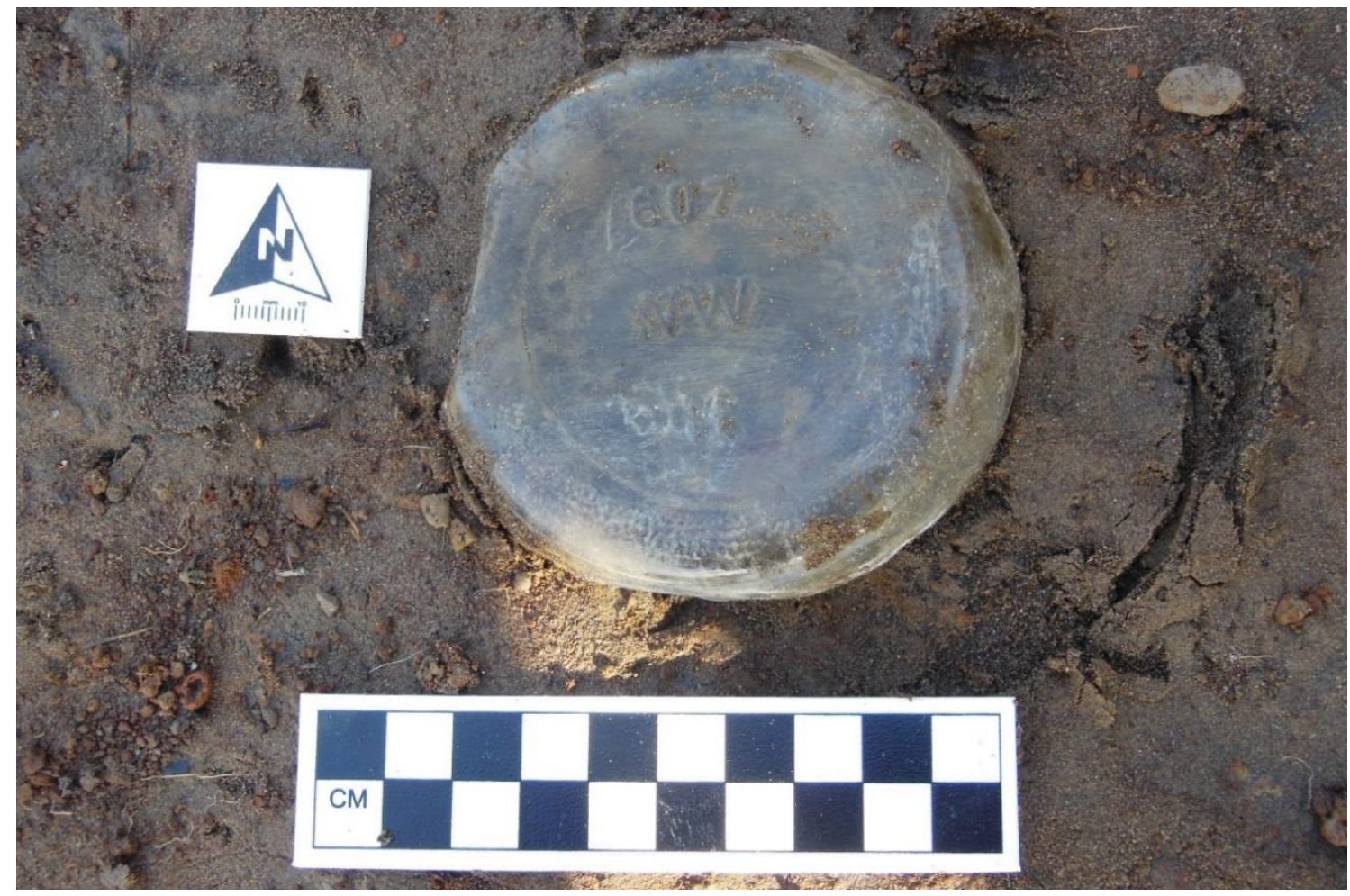

Colorless glass bottle base with Northwestern Glass Co. maker's mark, ca. 1931-1987, found at site $35 \mathrm{MU} 62$. 


\section{$\underline{35 \mathrm{MU} 63}$}

This site is a previously recorded multicomponent surface scatter of fire-cracked rock and historic refuse on the Sauvie Island shoreline, along the Multnomah Channel. The site has an area of $3180 \mathrm{~m}^{2}$ and sits along an exposed eroding bank with variable slopes, with a partially vegetated beach with a gradual slope below the waterline. The assemblage is estimated at less than 125 artifacts, including fire-cracked rock of relatively uniform size and material, with several distinct concentrations on the beach surface. The assemblage also included diagnostic historic-era glass and ceramics, along with additional refuse. Cultural deposits were observed in situ at the site in the form of extensive dock remains and refuse eroding out of the bank, including a variety of materials and diagnostic artifacts. The site is largely inundated at high-tide but can be accessed during summer and fall months via boat, on foot along the beach at low-tide, and directly from Sauvie Island Road above. 


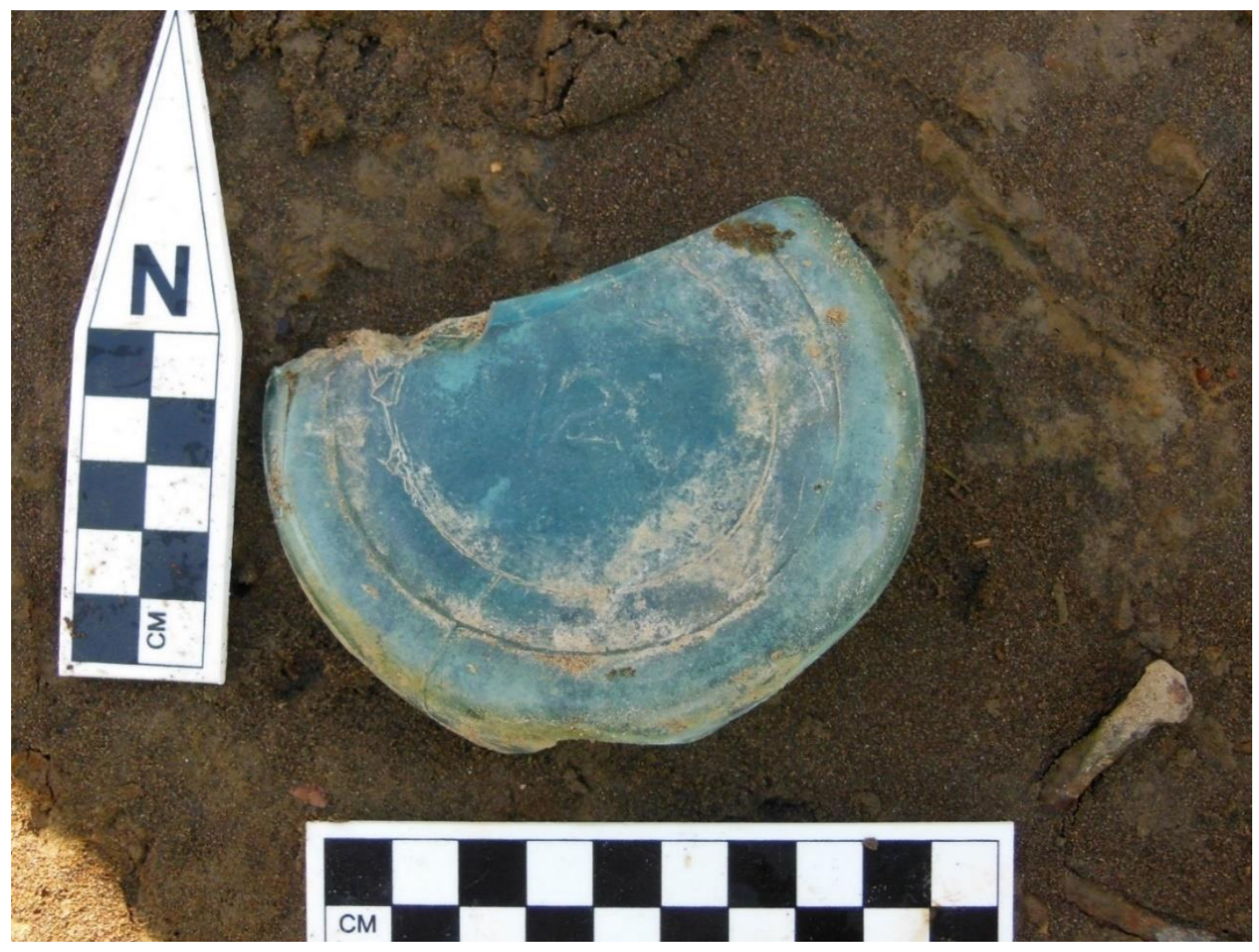

Aqua glass bottle base fragment at site 35MU63, suction marks suggest early/mid-20th century. 


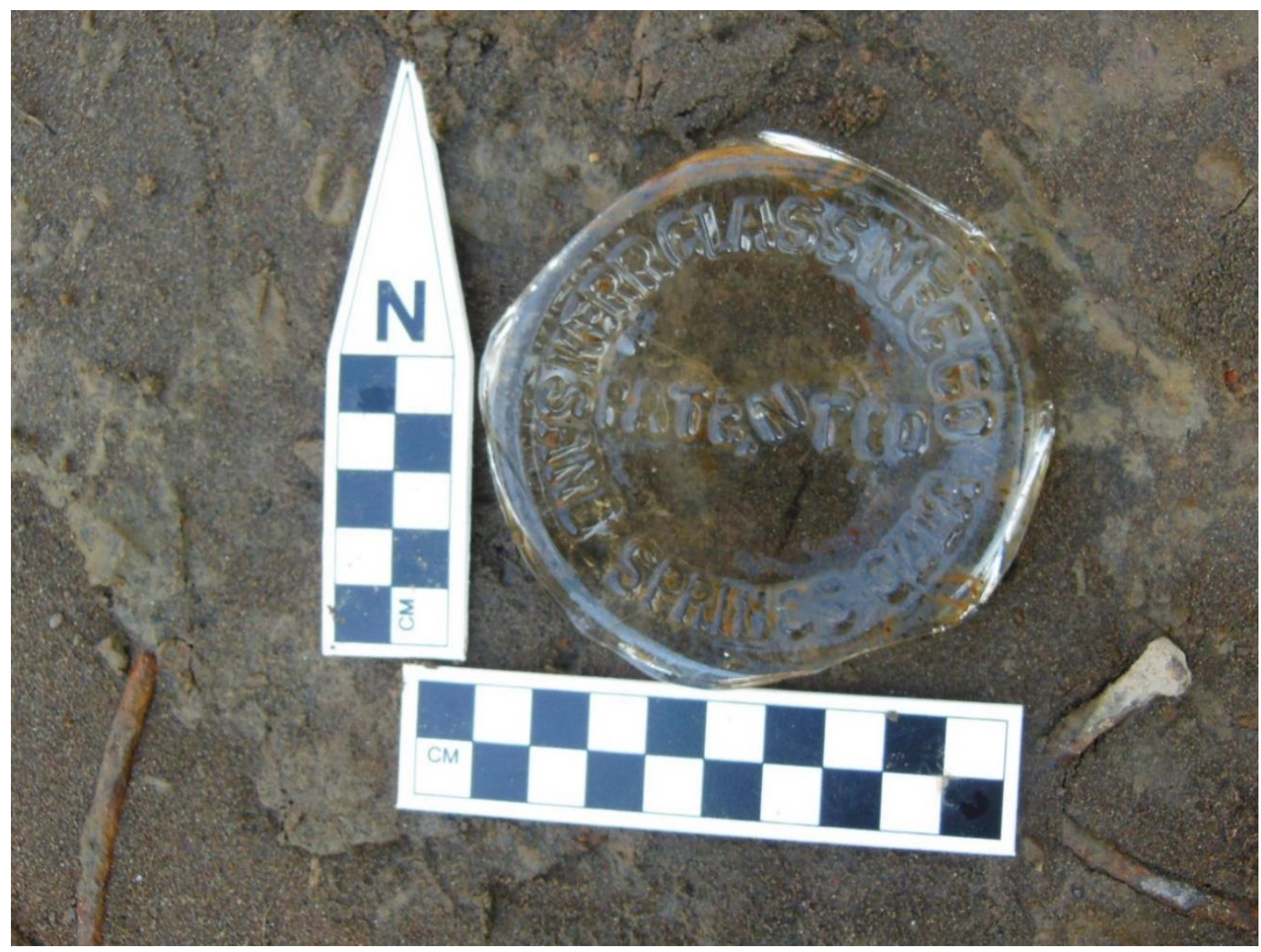

Historic colorless Kerr glass jar base from 35MU63 with "Sand Springs Oklahoma" in text, ca. 1915-1992, historic due to lack of stippling. 


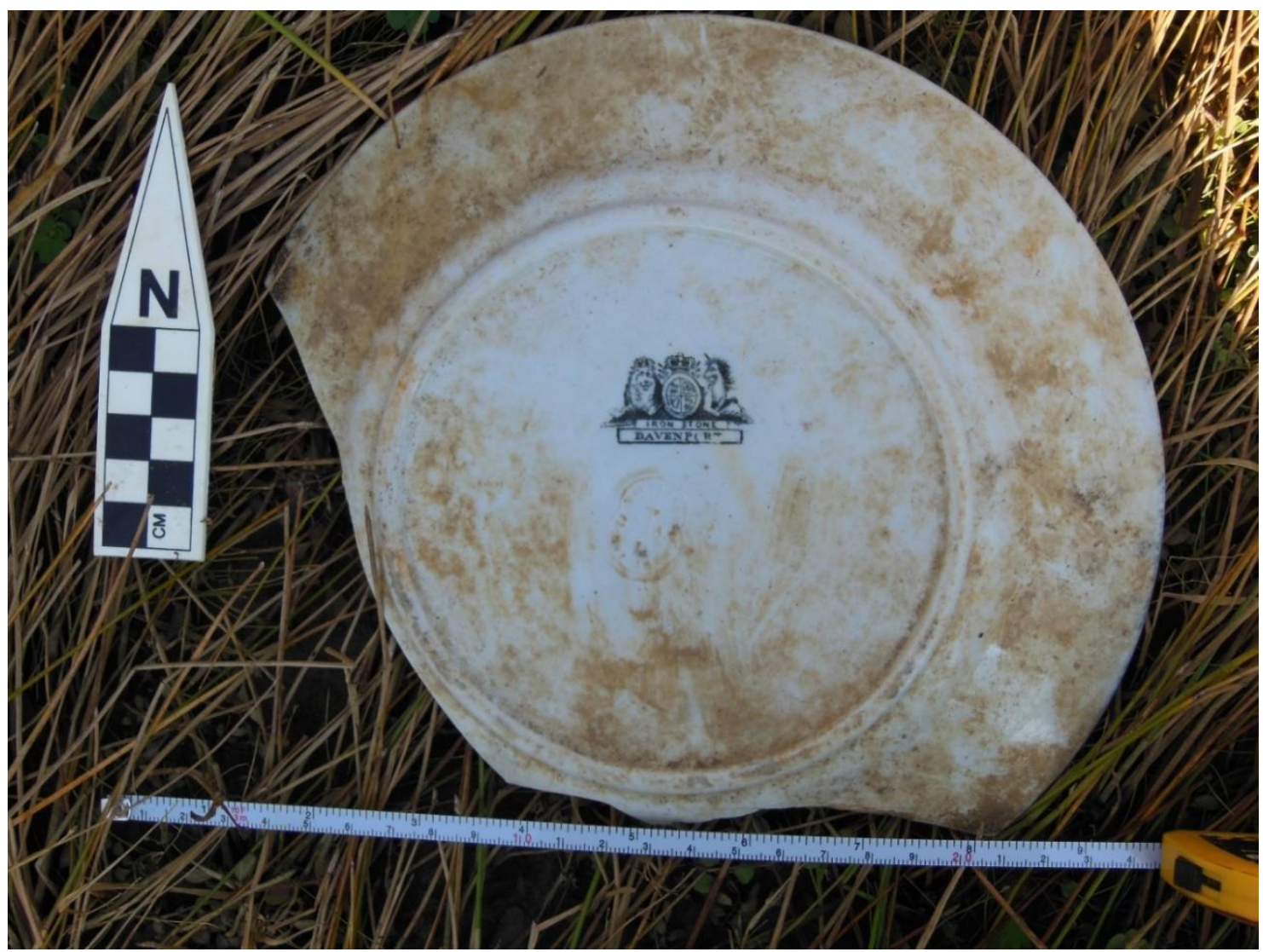

Historic white-cream Davenport porcelain plate found at site 35MU63, view of base with maker's mark, ca. 1794-1887. 


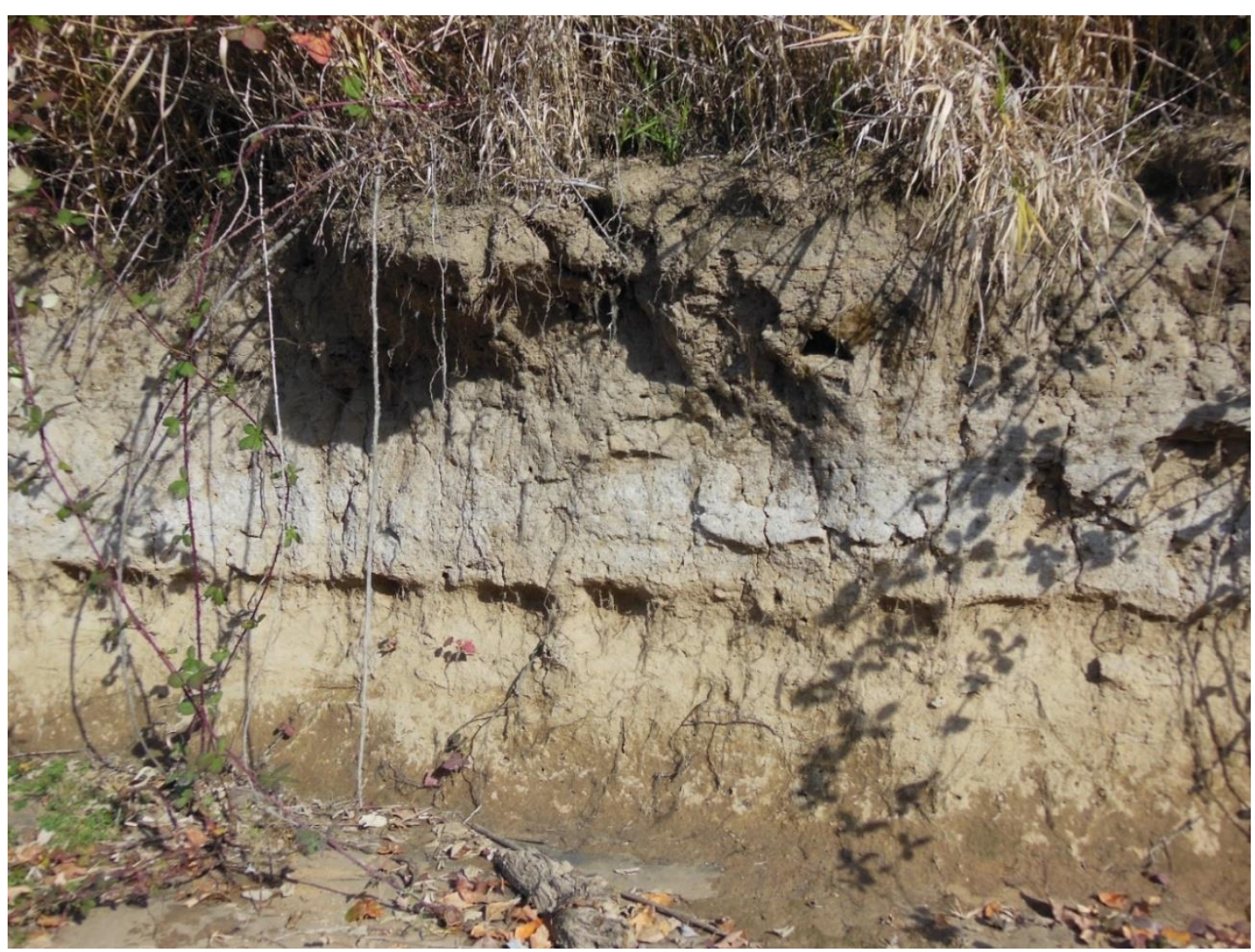

Sheer exposed cut-bank at site 35MU63. 


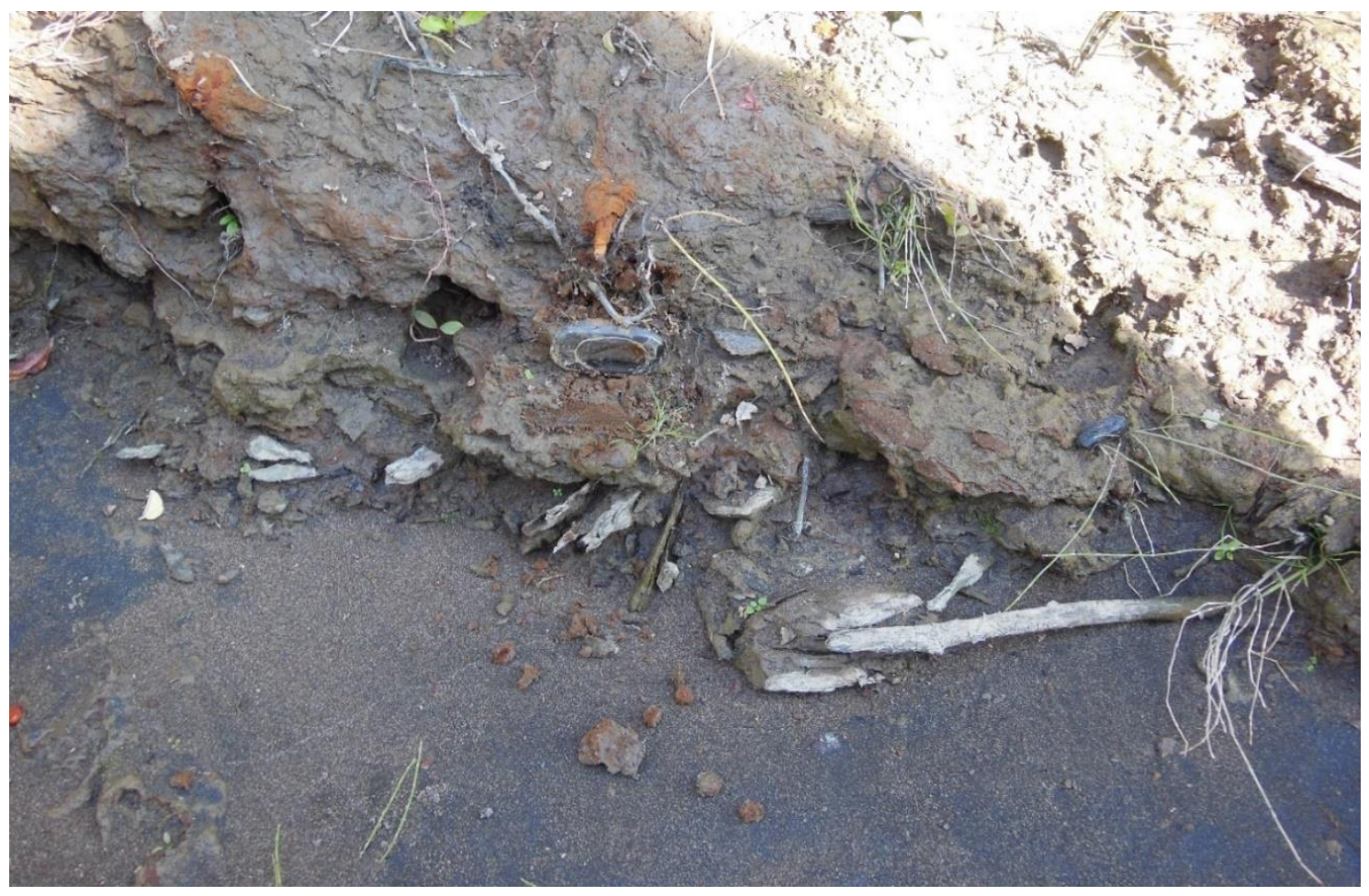

Historic refuse associated with dock feature at site 35MU63.

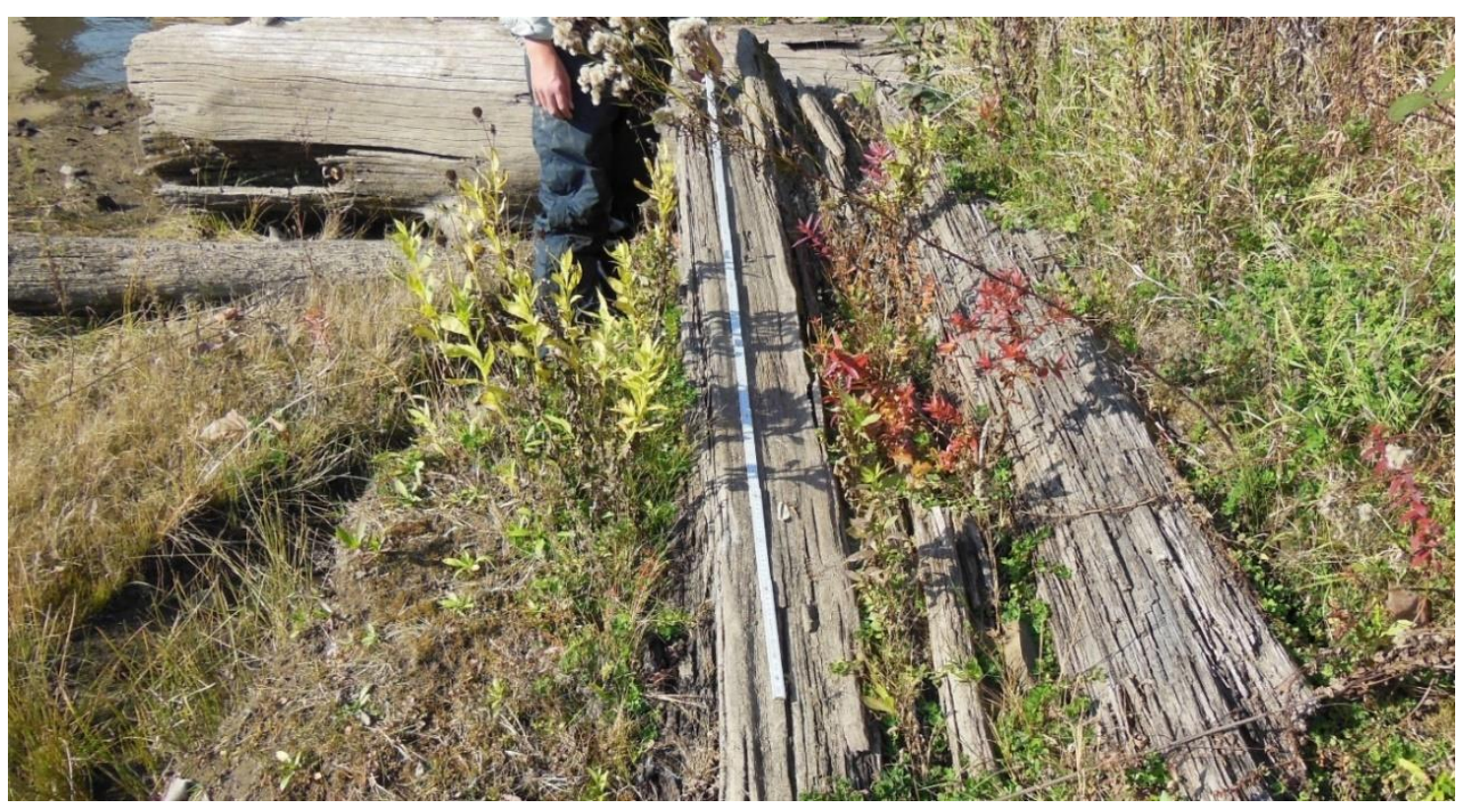

Historic dock feature at site 35MU63. 


\section{MU242}

This site is a previously recorded historic-era dam, intake, and piling field on the western Sauvie Island shoreline, along the Multnomah Channel. During survey, only the northernmost portion of the site, a stone and wood dam and associated riprap pile, could be assessed, due to significant commercial boat traffic, hazardous commercial waste, and underwater obstacles preventing kayak navigation. The area of the site assessed was $171 \mathrm{~m}^{2}$ and sits along a gradually sloping bank heavily vegetated with grasses, with an unvegetated beach with a gradual slope below the waterline. The site has no artifact assemblage and is limited to several features, including part of a dam, constructed with dock posts and riprap, as well as a riprap discard pile along the shoreline. No cultural deposits were visible in the bank, which had little exposed surface. Due to the height of the features, parts of the site remain above water throughout the year and are clearly visible in most satellite imagery of the area. Although the lack of dense bank vegetation could allow overland access, the land above the beach is privately held by commercial entities, who actively operate large machinery and have not maintained roads into the area. As such, the site can only be accessed by boat. Hazardous underwater obstacles necessitate careful navigation during low tide and extreme caution should be used when visiting site.

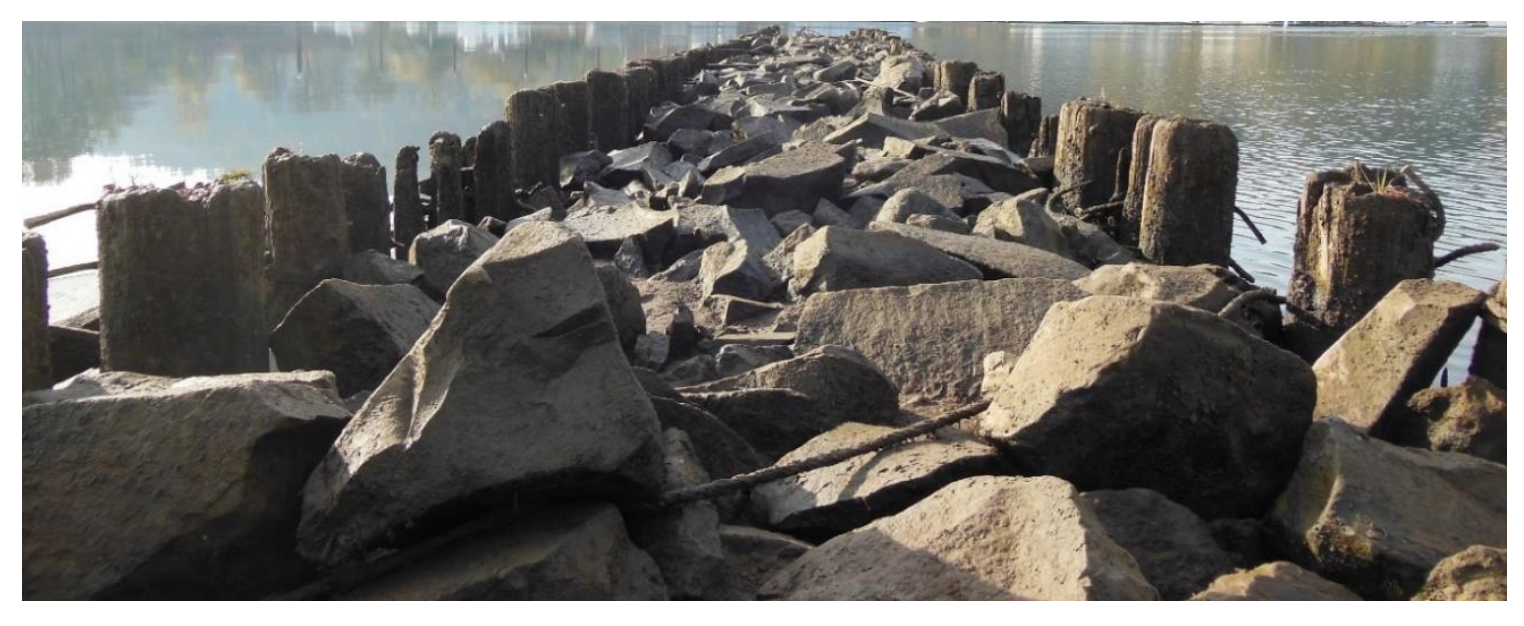

Historic dam at site 35MU242. 


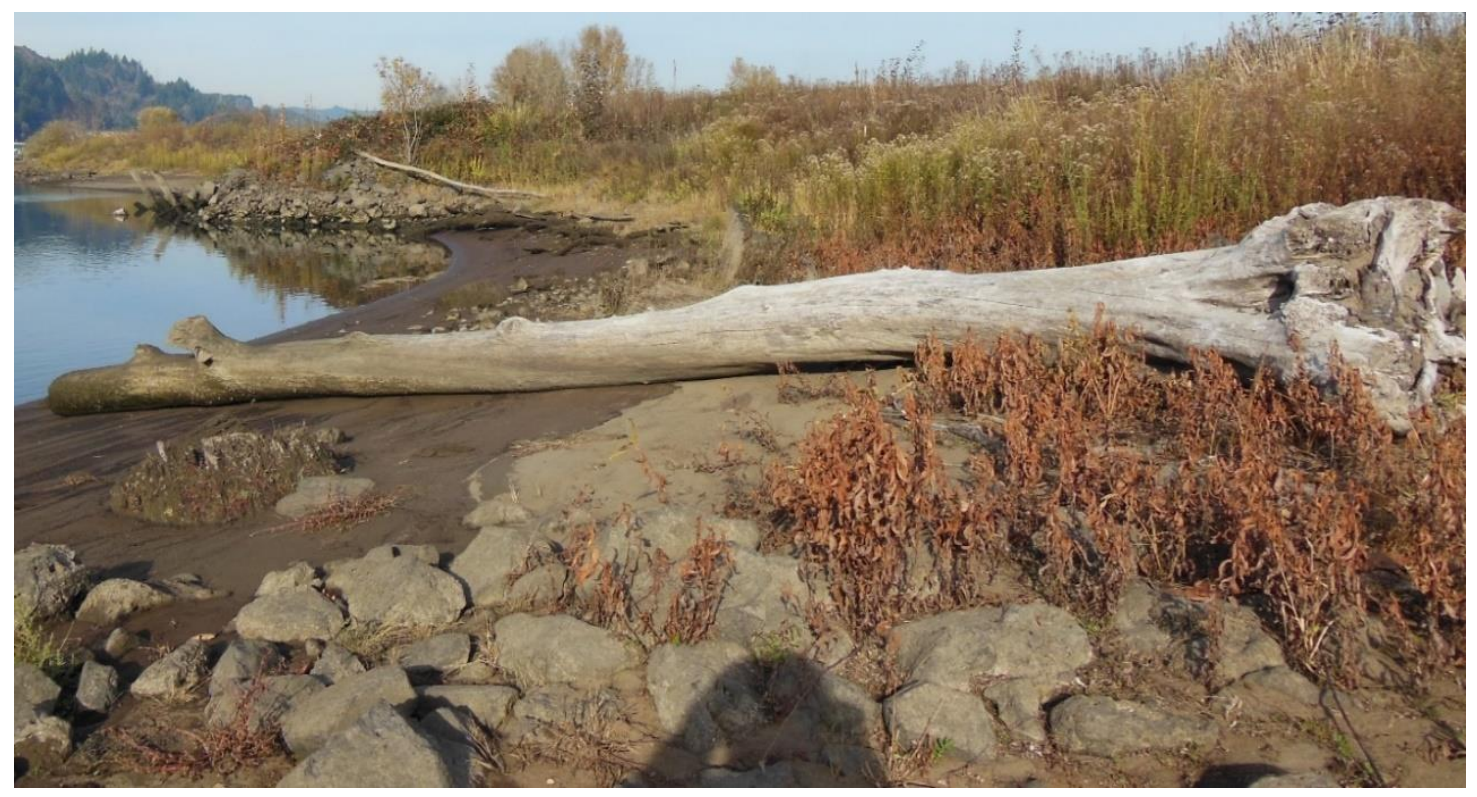

View of riprap piling at site 35MU242. 


\section{$\underline{35 \mathrm{CO} 66}$}

This site is a previously recorded historic-era lumber mill site with multiple piling fields, extensive artifact scatters, and large structural remains, previously recorded twice, on the western Sauvie Island shoreline, along the Multnomah Channel. During survey, only the portion of the site along the Sauvie Island shoreline was surveyed, with areas of site beyond the survey area, across the channel, excluded. The area surveyed was $16,808 \mathrm{~m}^{2}$ and sits along a broad, gradually sloping beach with a gradually sloping, minimally exposed, partially vegetated cut-bank. No dateable features or in situ cultural deposits were observed. Diagnostic artifacts included numerous bricks and fragments with maker's marks. Previously recorded ceramics and glass were not relocated. The site can be reached via boat or on foot, and portions of the site remain above water throughout the year.

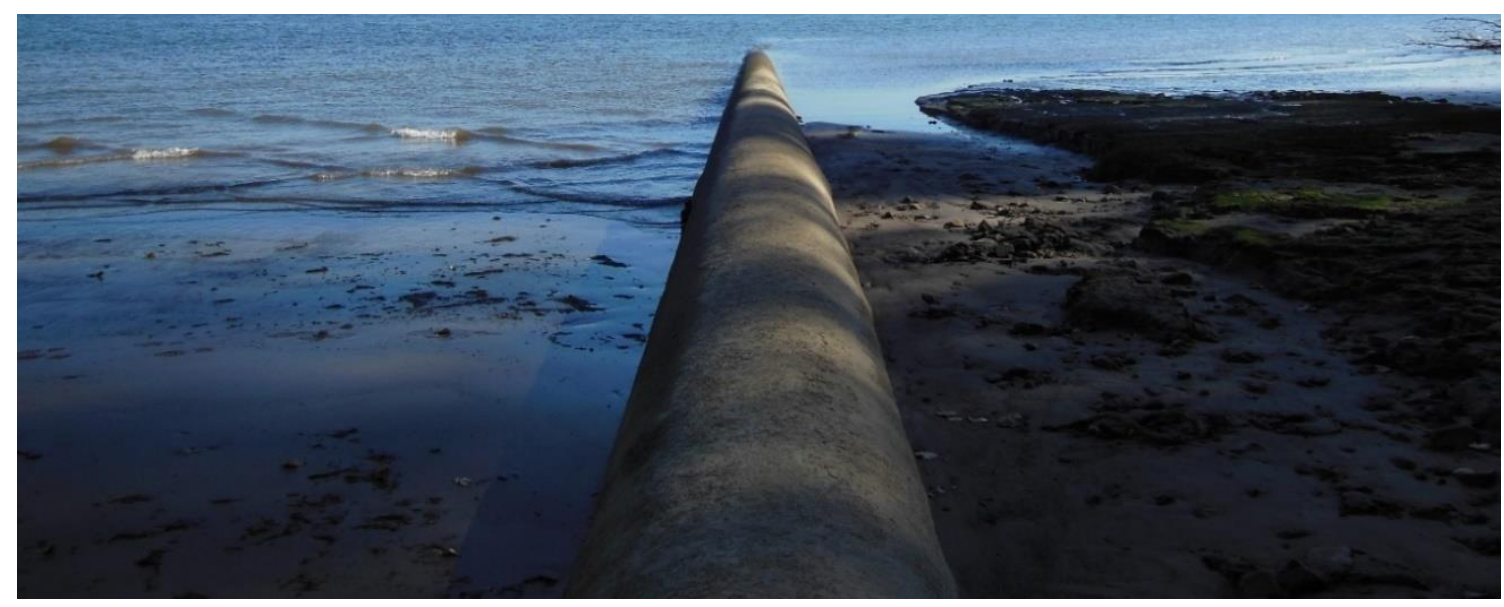

Concrete commercial pipe extending into the Columbia River 


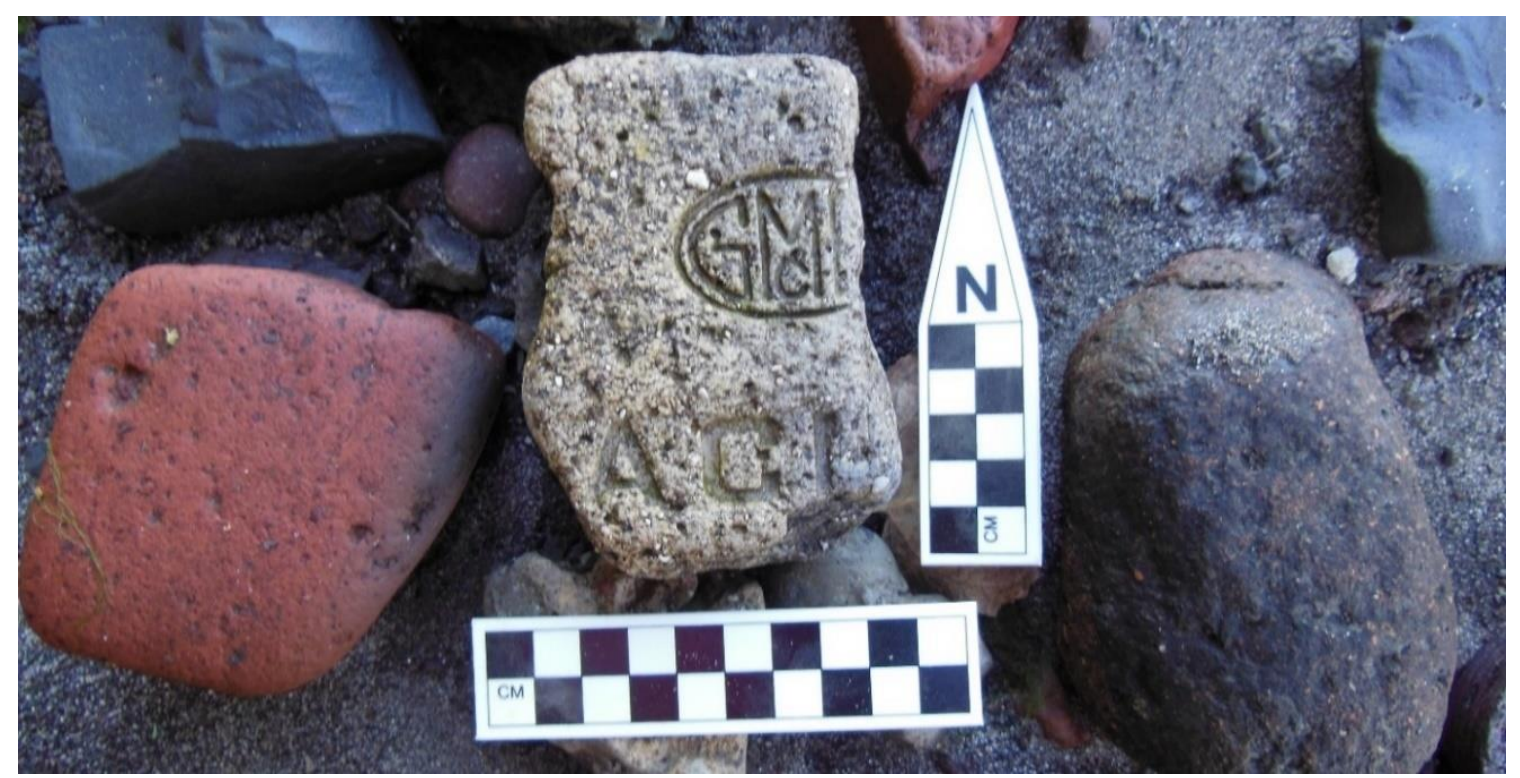

Gladding, McBean \& Company yellow-white brick fragment (ca. 1920-1950) from site $35 \mathrm{CO} 66$.

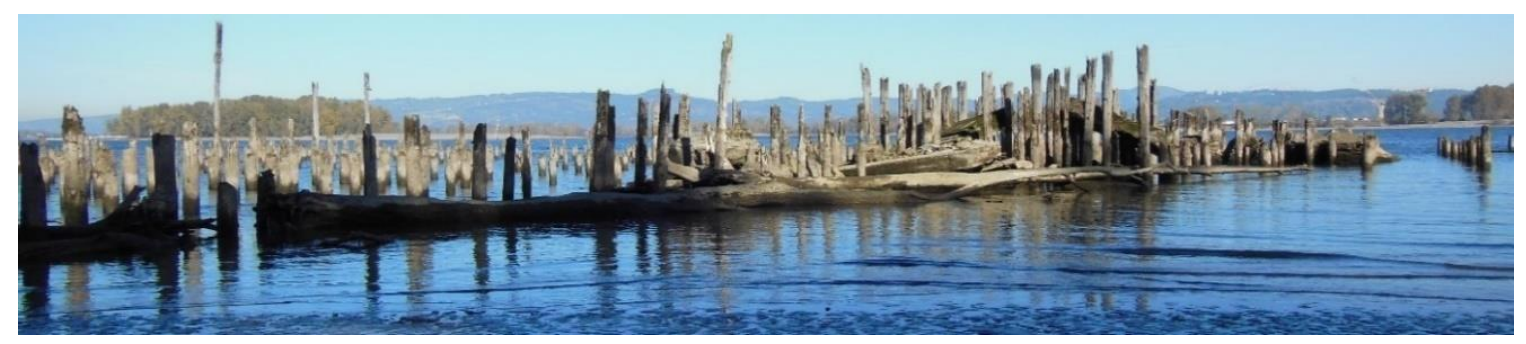

Piling field and structural elements at site 35CO66.

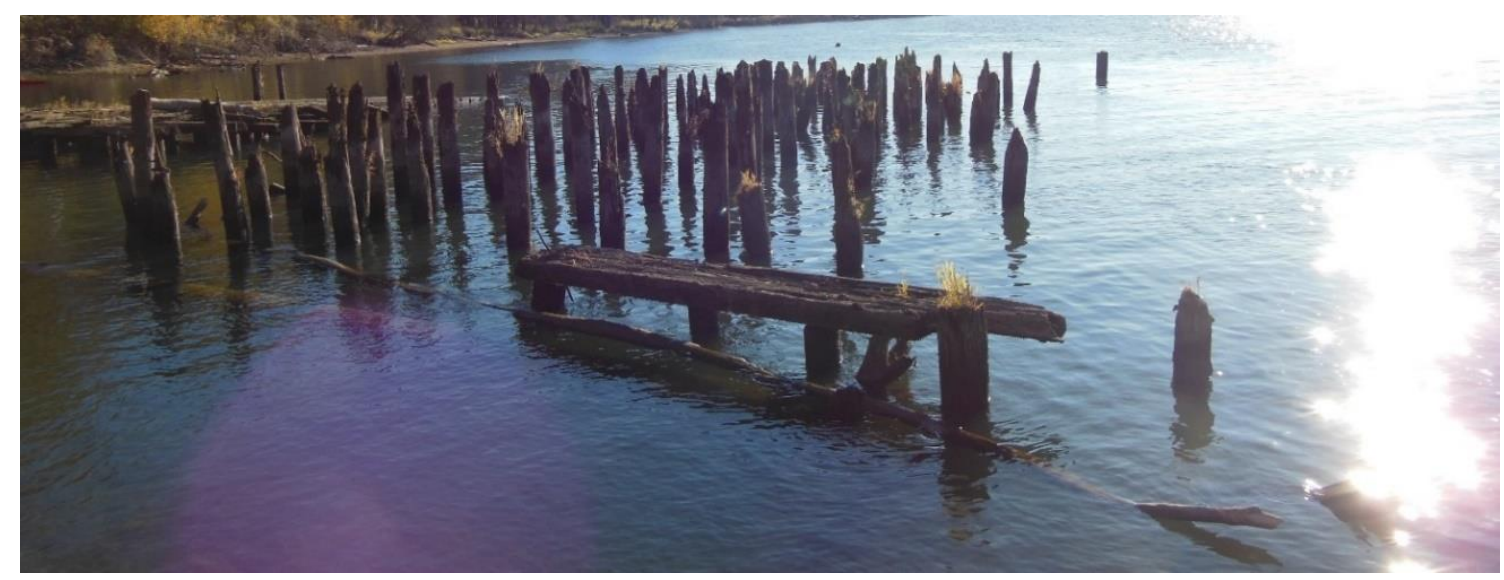

Piling field and structural elements at site 35CO66. 


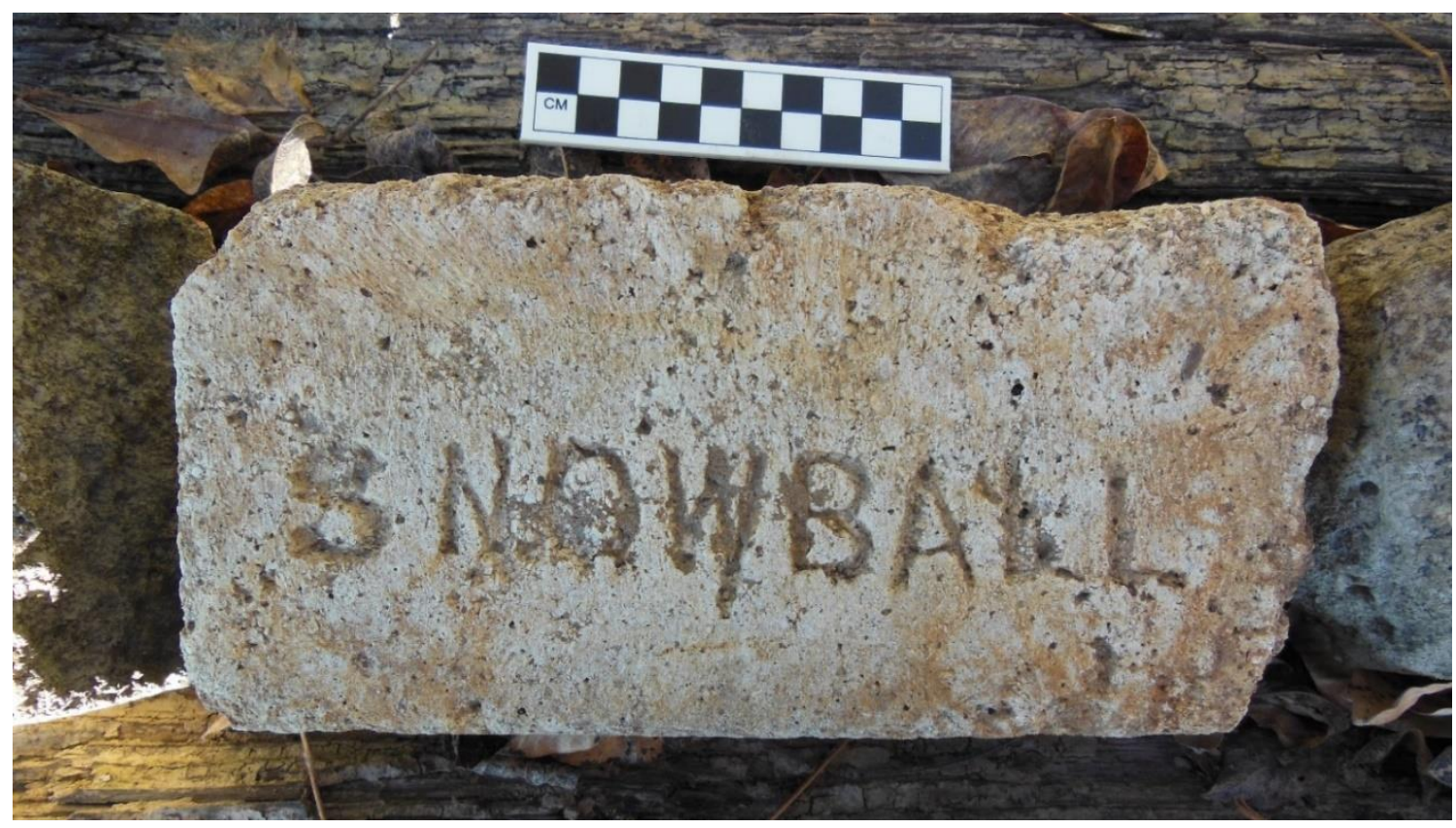

Light yellow-brown complete brick with “Snowball” maker's mark, ca. 1854-1935, from looting pile at $35 \mathrm{CO} 66$. 


\section{$\underline{35 \mathrm{CO} 75}$}

This site is a previously recorded multicomponent fire-cracked rock, lithic, and historic refuse scatter with exposed in situ cultural deposits, on the western Sauvie Island shoreline, along the Multnomah Channel. Upon revisiting, only a small portion of the historic component was relocated; the precontact component is assumed to be destroyed. The site has an area of $1,302 \mathrm{~m}^{2}$ and sits along a partially exposed slumping bank, with a partially vegetated beach with a gradual slope below the waterline. The assemblage is estimated at less than 40 historic refuse fragments, including some with diagnostic markings. No cultural deposits were observed in situ in the eroding bank. The site surface is partially inundated at high-tide, with portions of a stepped beach sitting above high-tide during the summer and early fall months. The site can be accessed by travelling on foot along the beach from access points to the south at low-tide and can also be accessed via boat at or near low tide during the summer and fall months. 


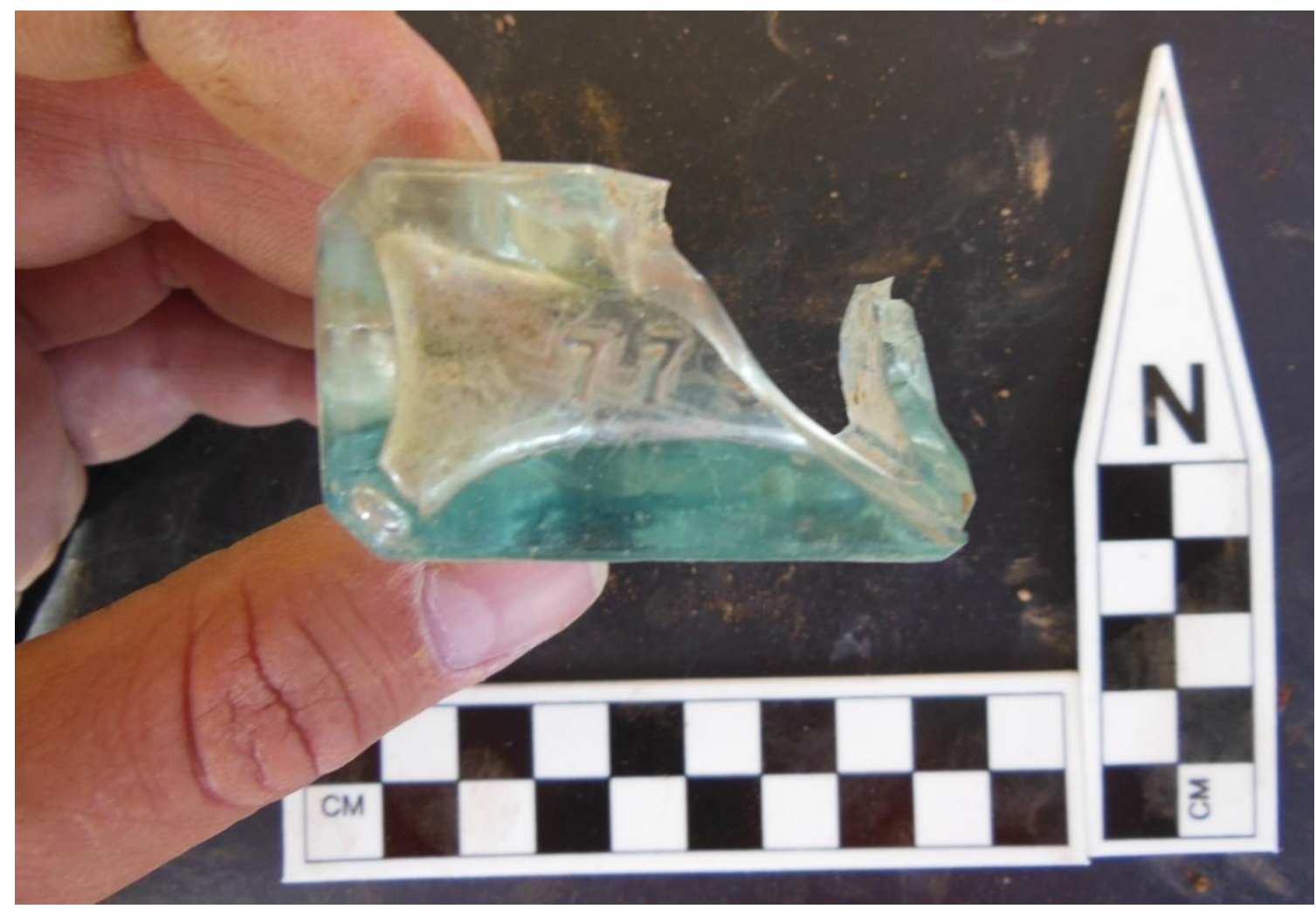

Aqua glass bottle base fragment found at site 35CO75, diagnostic, view of base and "77" numbering.

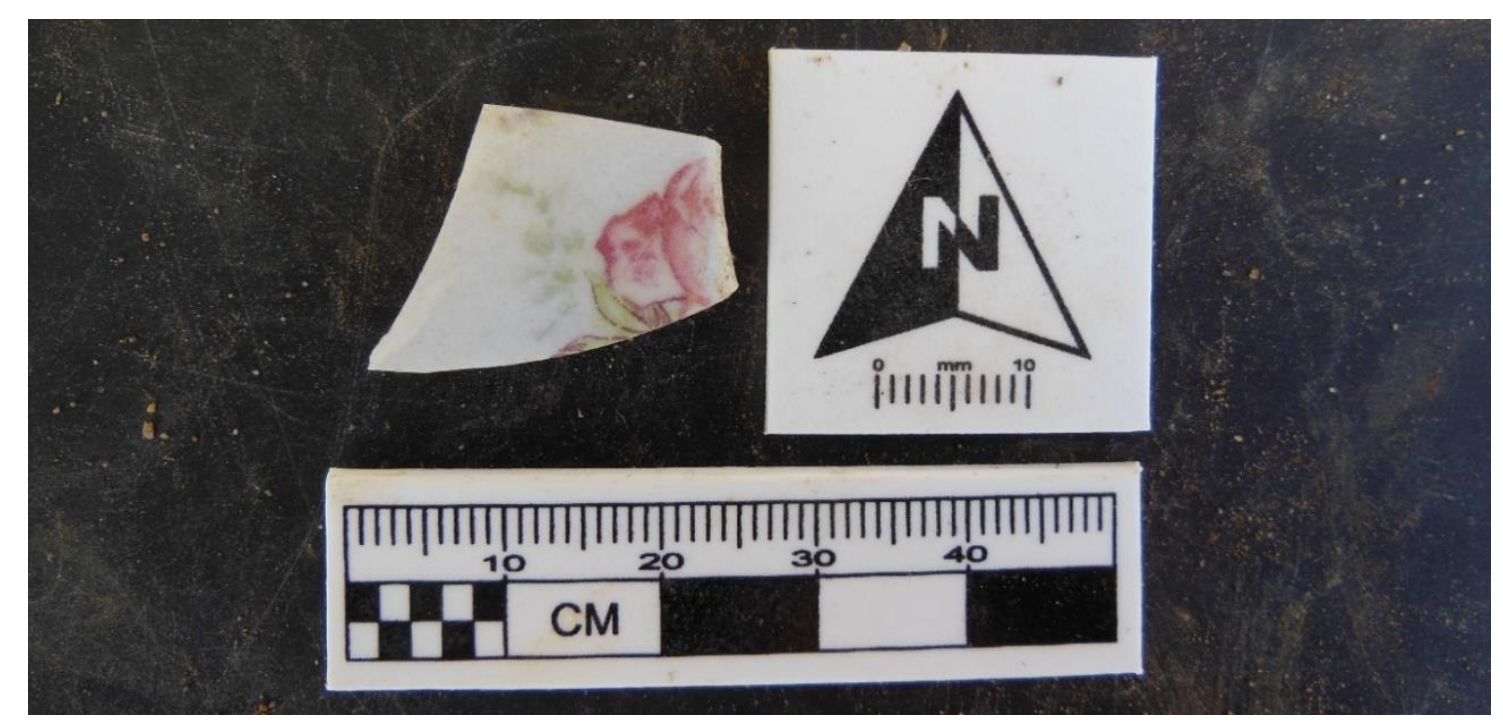

White porcelain ceramic fragment with green/rose floral print found at site $35 \mathrm{CO} 75$. 


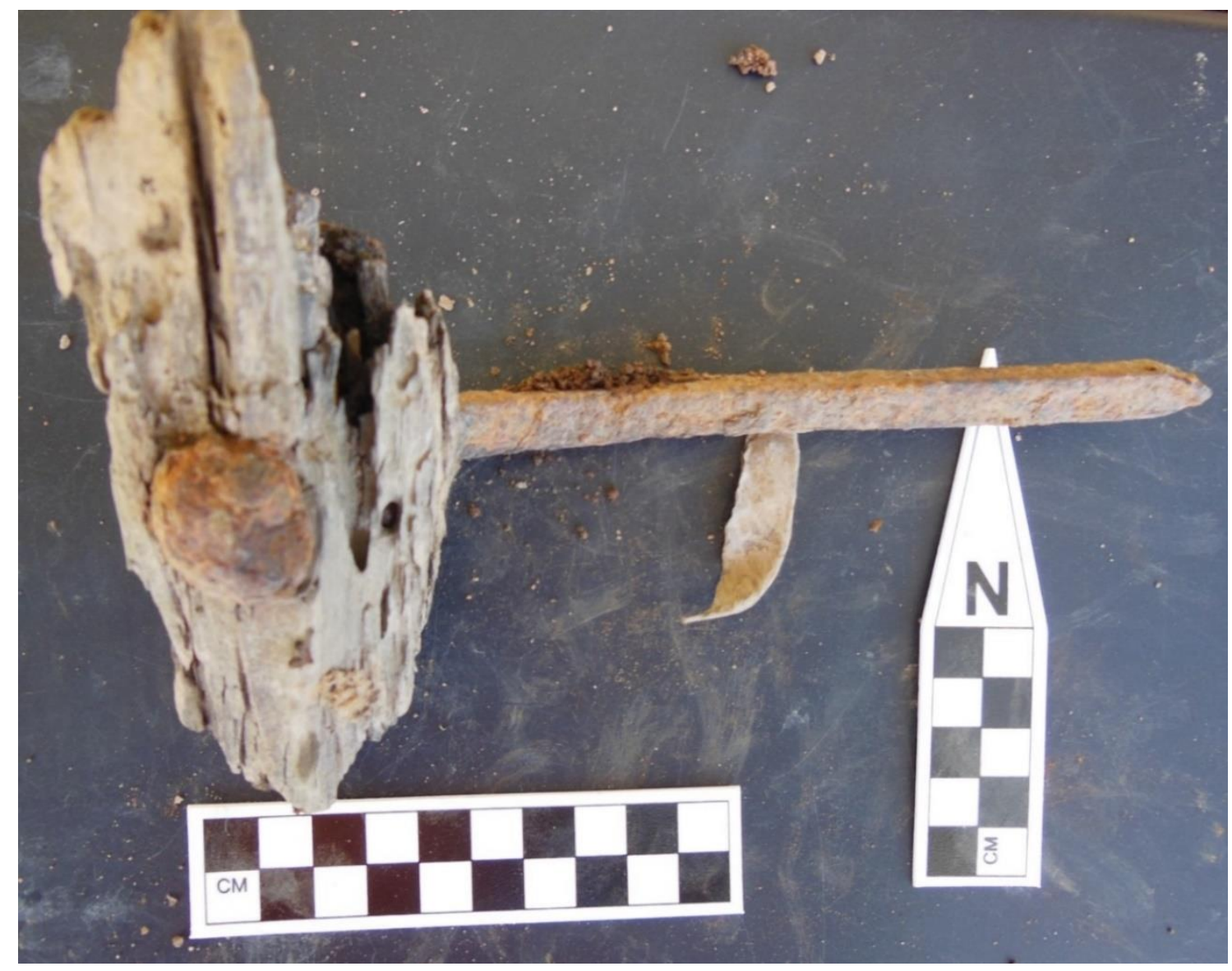

Nail and wood fragment at site $35 \mathrm{CO} 75$. 


\section{$\underline{35 \mathrm{CO} 76}$}

Previously recorded during a 2015 survey, this is a precontact site, on the western Sauvie Island shoreline, along the Multnomah Channel. The site has an area of $162 \mathrm{~m}^{2}$ and sits along an exposed eroding bank, with an unvegetated beach and an abrupt termination below the waterline, a similar profile to the initial recording. The assemblage is estimated at less than 125 artifacts of relatively uniform size and material, also similar to the report from the 2015 recording. However, in addition to at least one distinct concentration of fire-cracked rock the beach surface, rerecording also newly identified an in situ charcoal feature, likely a hearth, with embedded FCR fragments, eroding out of the exposed bank. These newly identified features represent an expansion of the site assemblage due to erosional forces impacting the site since initial recording. The degree of erosion to expose these features, which were revealed only 4 years after initial recording, highlights the speed at which erosion is occurring on Sauvie Island. Additionally, a modern barbed wire fence with metal posts runs across a portion of the bank and is eroding downslope. A pasture sits above the site but is set well back from the edge of the bank by vegetation. The fence is likely the remains of previous enclosures around said pasture, but no evidence of cattle trampling was observed at the site proper, and a thick barrier of vegetation above would prevent cattle from approaching the edge of the bank and contributing to erosion in that manner. 


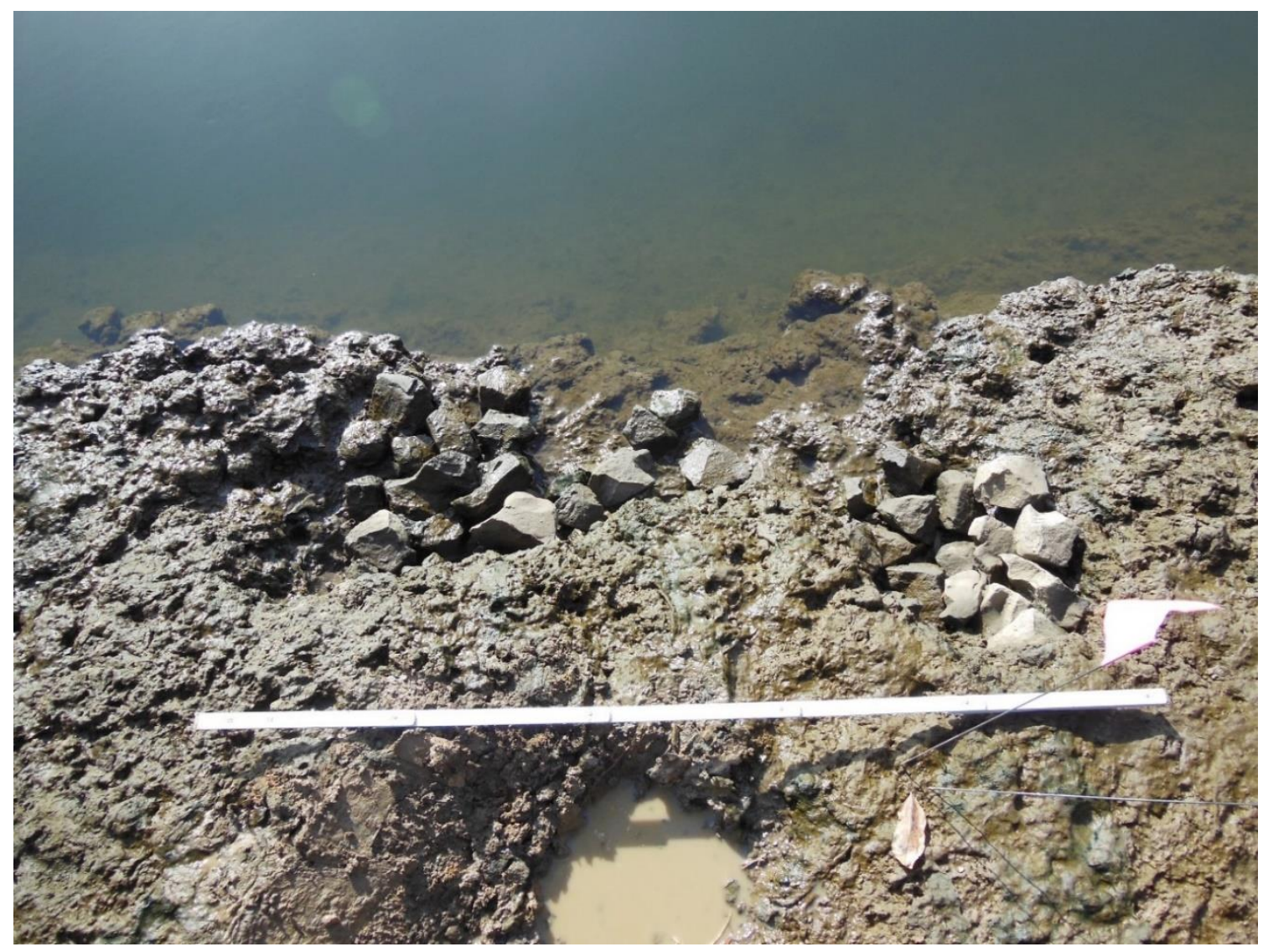

Eroding fire-cracked rock feature at site $35 \mathrm{CO} 76$. 


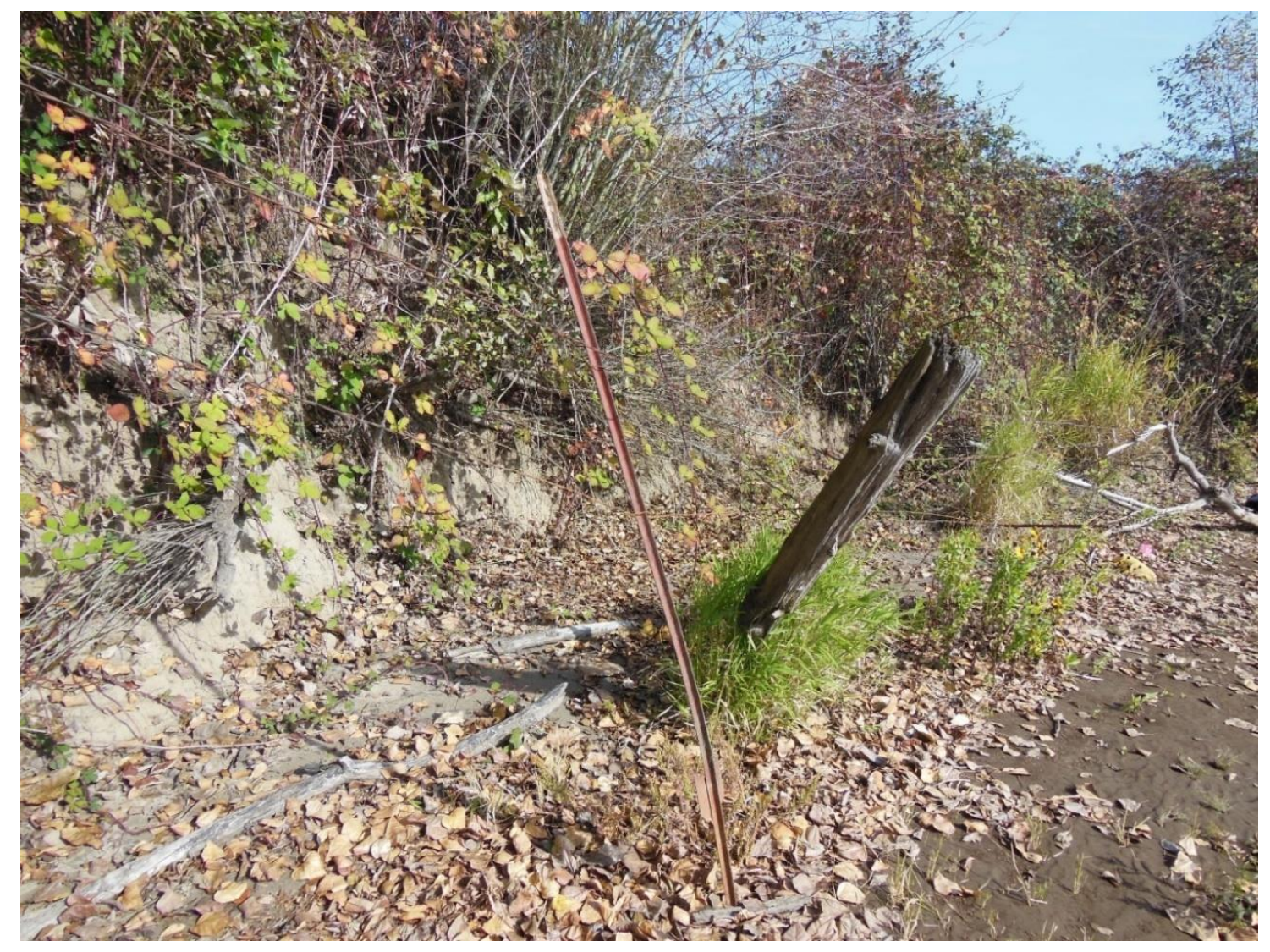

Barbed wire fence eroding out of cut-bank at site 35CO76.

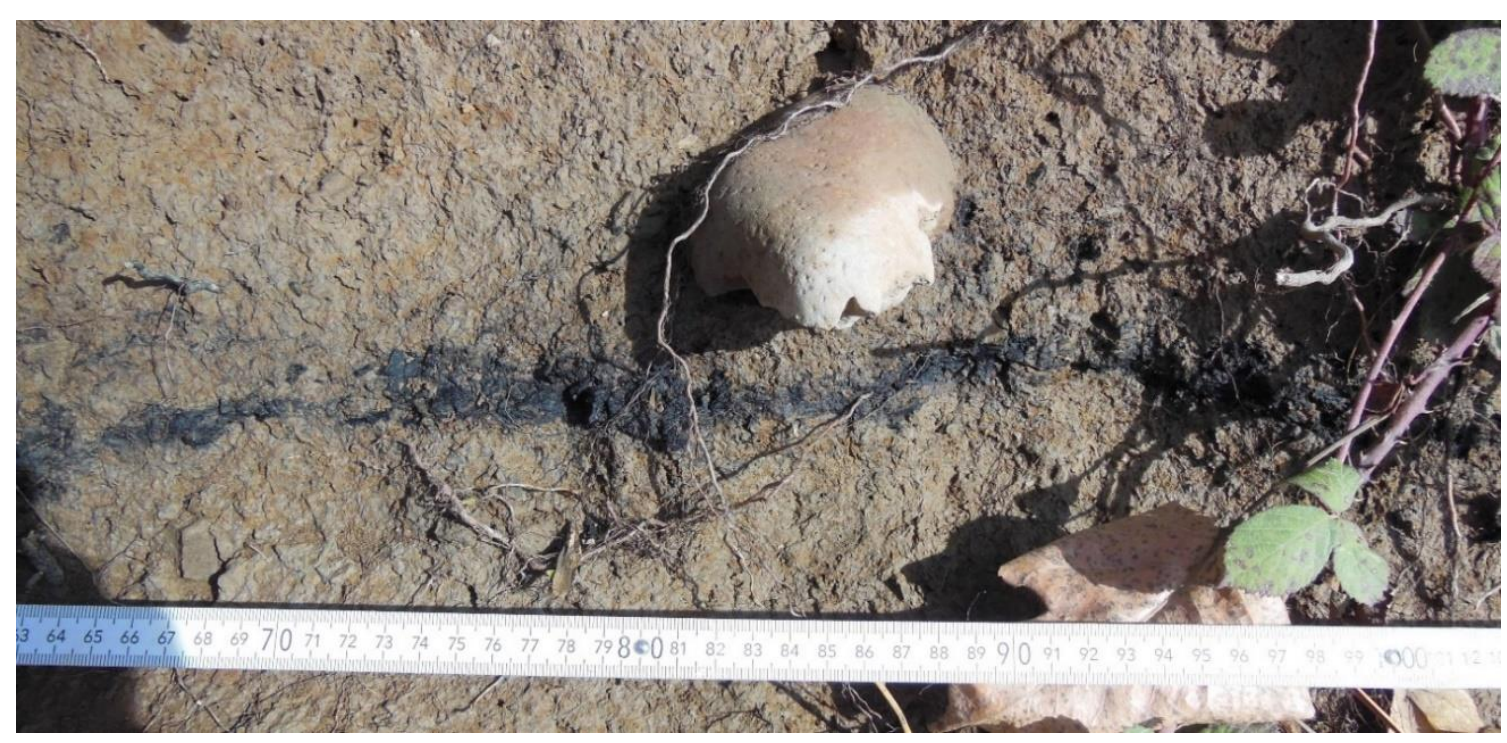

Hearth feature and fire-cracked rock eroding out of cut-bank at site $35 \mathrm{CO} 76$. 


\section{Appendix G: Overview of Collaborative Process to Assess Scores:}

Through multiple meetings with Grand Ronde THPO, using this template process, the final prioritization scoring was developed in a collaborative effort.

\section{Overview of Criteria and Process Used in Assigning Archaeological Value Scores:}

Dateable Features and Materials - Presence (2) or absence (0) of dateable features, which can include hearth features or charcoal.

Diagnostic Artifacts - Presence (2) or absence (0) of temporally distinct artifacts, including historic maker's marks or projectile point types established in regional chronologies.

Proximal Relationship to Ethnographically Documented Indigenous Place - Site is (1) or is not $(0)$ considered in close proximity to a location noted in the ethnographic or ethnohistorical record based on a $1 \mathrm{~km}$ distance. This distinction was made by creating a $1 \mathrm{~km}$ buffer zone around site datum and then determining if buffer passed through the location of any ethnographically identified Indigenous place. In the case of this project, such places are drawn from internal tribal GIS data provided by the Grand Ronde, but other sources could be utilized, including the primary sources that informed Grand Ronde GIS data. Based on this data, $1 \mathrm{~km}$ is roughly the average minimum distance between sites surveyed in this project and ethnographically recorded villages in the Sauvie Island area. This project's determination of proximity does consider GIS mapped locations, but the radial buffer method provides a broader operationalizable means to score for proximity if precise GIS data is not available.

$\underline{\text { Rare Characteristics }}$ - Presence (1) or absence (0) of characteristics that are uncommon in the regional archaeological record. Includes assemblages, features, or site types that contribute in a unique manner to Sauvie Island, Portland Basin, or Lower Columbia archaeology.

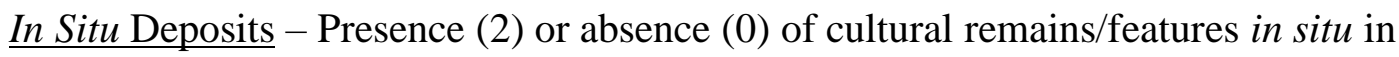
exposed channel bank, which can be above or below the low-tide waterline. These may 
include Indigenous or Euro-American temporal deposits and is not exclusively limited to in situ dateable features or diagnostic artifacts.

Multicomponent Site - This includes the presence (1) or absence (0) of assemblages or features reflecting multiple cultural phases at a site, often reflected in the study area as both Indigenous and Euro-American components being present at a site. 


\section{Overview of Criteria and Process Used in Assigning Tribal Value Scores:}

As part of our collaborative process, the Grand Ronde THPO, Daily and Butler produced a set of questions for each tribal value that helped.

Proximity to Tribally Known Location(s) - This refers to sites that are in close proximity to ethnographically recorded locations important to the Grand Ronde, specifically those drawn from tribal GIS data. For each site surveyed in my project, I created two distance $(\mathrm{km} / \mathrm{m})$ buffer zones and then ran an intersect function to determine if any buffer zone intersected with any part of an ethnographic village polygon. A proximity value here refers to sites within $0.75 \mathrm{~km} / 750 \mathrm{~m}$ (2) and sites within $1.5 \mathrm{~km} / 1500 \mathrm{~m}$ (1) of an ethnographically recorded place, or sites beyond that range (0). These buffers reference the accessibility of sites from village locations, and the ability to easily travel between cultural resources by foot or by water.

Key Questions:

1) What measures of proximity, raw or relative measures of distance, are appropriate for the project area?

Measuring distance via straight line, along shoreline, datum to centroid, via buffer, etc. Using measurements of distance or subjectively observing site proximity.

2) What is the relative distance between cultural properties on the landscape? Average, minimum, maximum distances between sites, villages, etc.

3) What landforms might limit, inhibit, or change travel on the landscape?

To what degree is a site and ethnographic place(s) accessible via land vs. water and what routes connect the two places.

4) How has the landscape around a site changed since initial deposition of cultural materials, how might such changes impact access? What sources provide information on these changes?

Shoreline retreat, inundation, modern agricultural modification, growth/disappearance of wetlands, etc. 
5) What ethnographic data sources inform both the archaeological and tribal perspectives?

GLO maps, geologic surveys, ethnohistorical maps, etc.

6) What GIS resources exist to plot ethnographic locations with greater precision? Do such resources exist in archaeological databases or with tribal partners?

Do tribal partners have GIS shapefiles for important locations, archaeological sites, ethnographic locations, etc. that would inform analysis?

7) How do measurements of proximity change as the characteristics of sites change?

Do early post-contact sites represent overlapping occupations or uses? Do post-contact tribal records include involvement with Euro-American industry?

Presence of (or potential for) Dateable Features or Materials - This refers not only to the presence or absence of dateable features and materials but to their potential (1) or lack thereof $(0)$ for existing at the site, either below the waterline or in vertical/horizontal deposits yet to be exposed. The decreased weight in comparison to archaeological value for dateable features reflects the greater importance of the tribal values of survivability and re-connectivity over the physical archaeology of a site.

Key Questions:

1) What elements of an assemblage might suggest the potential for dateable features? Presence of FCR.

2) What other cultural resources in the vicinity would suggest the potential for dateable features?

Village in close proximity.

3) What does the condition of the site and the nature of risk factors present suggest for the potential of dateable features to exist at the site?

Is the site heavily disturbed by modern activities? To what degree has erosion impacted site? How exposed is the existing cultural component? What is the estimated degree of 
damage? If the site was previously recorded, how much of the assemblage appears to have been lost?

4) Does the site have observable dateable features?

Presence of hearths.

5) How much of the bank is exposed and how large is the exposed portion; is there sheer exposed bank below the waterline?

How many meters high is the exposed bank at the site? Is the bank not exposed and if so, why is that? Has the bank been disturbed by modern earthmoving or other modification?

Rare Characteristics - Presence (1) or absence (0) of characteristics that are considered uncommon in the tribal record and/or in the regional understanding of cultural patterns. Examples may include uncommon artifact assemblages or dateable hearth features.

Key Questions:

1) What characteristics of a site or assemblage are considered rare or uncommon to tribal partners?

A type of artifact? A type of diagnostic artifact? Dateable features? Diverse assemblage? Intangible aspects?

2) Are rare characteristics tangible, intangible, or a mix of both?

3) What cultural resources are ubiquitous in tribal records?

What types of resources would draw tribal attention in a cultural resource management situation? What types of sites are common or represent well understood cultural activities? How does the surrounding context impact rarity?

4) Which of these characteristics, if any, overlap with characteristics considered rare in the archaeological record?

5) How can the context of a site contribute to rarity or lack thereof in tribal records? Site has clear association with nearby village, site has clear association with a cultural activity, etc. 


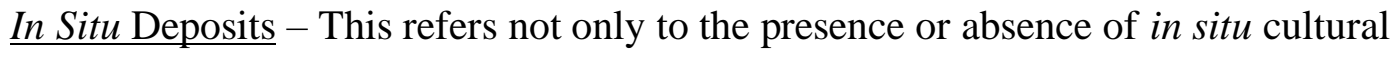
deposits in the bank, but to the potential (1) or lack thereof (0) for deposits to exist at the site, unexposed by erosion or not visible during survey. This considers the broader context of a site, beyond what was observed during site survey. The decreased weight in comparison to archaeological value for dateable features reflects the greater importance of the tribal values of survivability and re-connectivity over the physical archaeology of a site.

Key Questions:

1) What elements of the assemblage suggest the potential for intact cultural deposits?

2) What other cultural resources in the vicinity would suggest the potential for intact cultural deposits?

3) What does the condition of the site and nature of risk factors present suggest for the potential for intact cultural deposits to exist at the site?

4) Does the site have observable in situ deposits already present?

5) How much of the bank is exposed and how large is the exposed portion; is there sheer exposed bank below the waterline?

Survivability - This refers to the distinction between sites where the characteristics of the assemblage or the nature of the loss (anthropogenic vs. natural) warrant efforts to prevent site degradation (1-2) and sites where loss is considered part of the natural cycle (0). Score is determined through an assessment of both the physical element of the site and the element of the site that exists in tribal memory, with each aspect adding (1) point to the overall score.

Key Questions:

1) Are the impacts on the site natural, anthropogenic, or both?

3) Is the site at risk due to exclusively anthropogenic factors, such as recreation, looting, or development?

Modern cultural disturbance such as the fishing trail at site 35MU62. 
4) Is the site at risk due to natural factors accelerated by anthropogenic forces? Accelerated erosion at FCR sites such as PJD006 that have no easy access points and show no sign of exclusively anthropogenic disturbance.

5) Would the site be lost to natural forces such as erosion even if risk factors were not accelerated by anthropogenic forces?

Rapidly eroding sites that have little opportunity for realistic stabilization.

6) What would be the cost/time investment required to stabilize/preserve the site, as opposed to data collection in the face of loss?

Cost and time to do regular site visits, to remove fishing trails, to discourage looting, to block off beach access vs. a single data collection effort, etc.

7) What do tribal partners view as natural vs. anthropogenic forces, what forces are considered part of the natural process of site loss?

Channel erosion from current, wave action vs. wake or the site being accessed by recreationalists, etc.

$\underline{\text { Reconnectivity }}$ - Site retains, on a sliding scale (1-2) or does not retain (0) tribal identity through its broader connection to the cultural landscape (other archaeological or ethnographic sites) or direct affiliation with a cultural resource, story, or activity, through oral histories or assemblage characteristics. The greater weight for this value reflects the tribal prioritization of connection to the cultural resource apart from simple physical archaeology.

Key Questions:

1) Is the site associated with an activity such as resource processing or tool construction?

2) Is the site explicitly mentioned in the ethnographic record?

3) Are elements of the site considered sacred or is the site located near a sacred place?

4) Is the site within the vicinity of ethnographically mentioned places, tribally important landforms/landmarks, first foods, basketry materials, etc.? 
5) Is the site associated with a precontact or historic event, individual, pattern, etc. of tribal importance?

6) Is the site associated with a historic process, movement, or temporal period that is of meaning to tribal partners?

7) Is the site or elements of the site associated with an oral tradition, with religious practices, with ceremonies, with linguistic accounts, or with family stories or mentioned some in other type of tribal record?

8) How accessible is the site for tribal visits or data collection; what means can be used to access the site; is the site on public or private land? What documentation or permitting is necessary to visit site? 


\section{Overview of Criteria and Process Used in Assigning Risk Factor Scores:}

Disturbance - This is a recognition of passive damage from modern cultural activity such as recreational use, in the form of boating or fishing. This does not refer to illegal modifications to trespass, vandalize, or loot the property, or signs of such illegal activity. Disturbance may refer to the presence of modern trash or signs of modern recreational activity.

Estimate \% Damaged - This relies on observations during recording of geomorphological agents negatively impacting or that could negatively impact the integrity of the cultural resource, often through active erosion of cultural materials, either directly into the water or out of the cut-bank. All sites along the Multnomah Channel shore have sustained an estimated degree of damage above $20 \%$ and a scaled score reflects damage estimated between $20-40 \%$ (>20\%), 40-60\% (>40\%), 60-80\% (>60\%), and 80-100\% (>80\%).

Undercutting vs. Sloughing/Slumping - Undercutting is defined as the active creation of an overhang, where bank soil underneath is being removed, or eroded by tidal forces or wave action (see Figure 1). Undercutting often happens on banks where trees hold the upper portion of the bank together, but the lower bank is exposed without supporting plant communities.

Sloughing/Slumping can happen at the same site, but usually occurs on sheer banks with less tree cover, where wedges of soil slide down as bank integrity is compromised from top to bottom. These banks rarely have trees holding the topsoil together, hence the slumping/sloughing. 


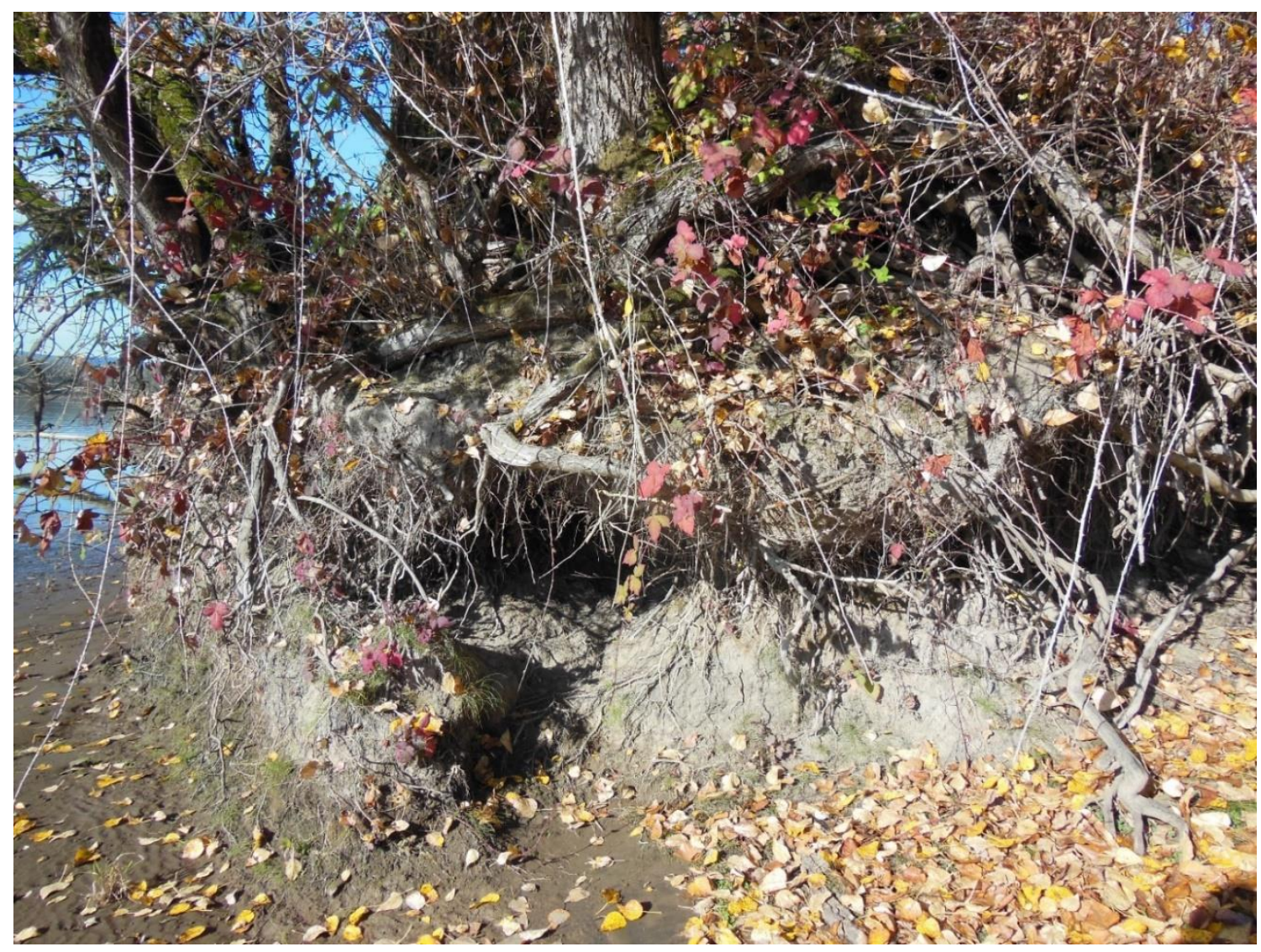

Example of undercutting. 
Sheer Beach Edge - This is a phenomenon noted at several sites, typically located on the inside curves of the island along the channel. As water accelerates around outside curves, it impacts on inside curves at a higher speed, cutting beaches into sheer, terminating drop-offs into deeper water and depositing that sediment on outside curves further along the channel. Where these sheer beach edges occur, parts of the site are actively and rapidly lost to deep water as the beach edge retreats towards the bank, while this rapid erosion can also expose deeply buried, older deposits that site below the waterline. This impact is contrasted against the gradually terminating beaches on sites located on the outside curve of the channel, where deposits are periodically inundated and silted over based on seasonal water levels.

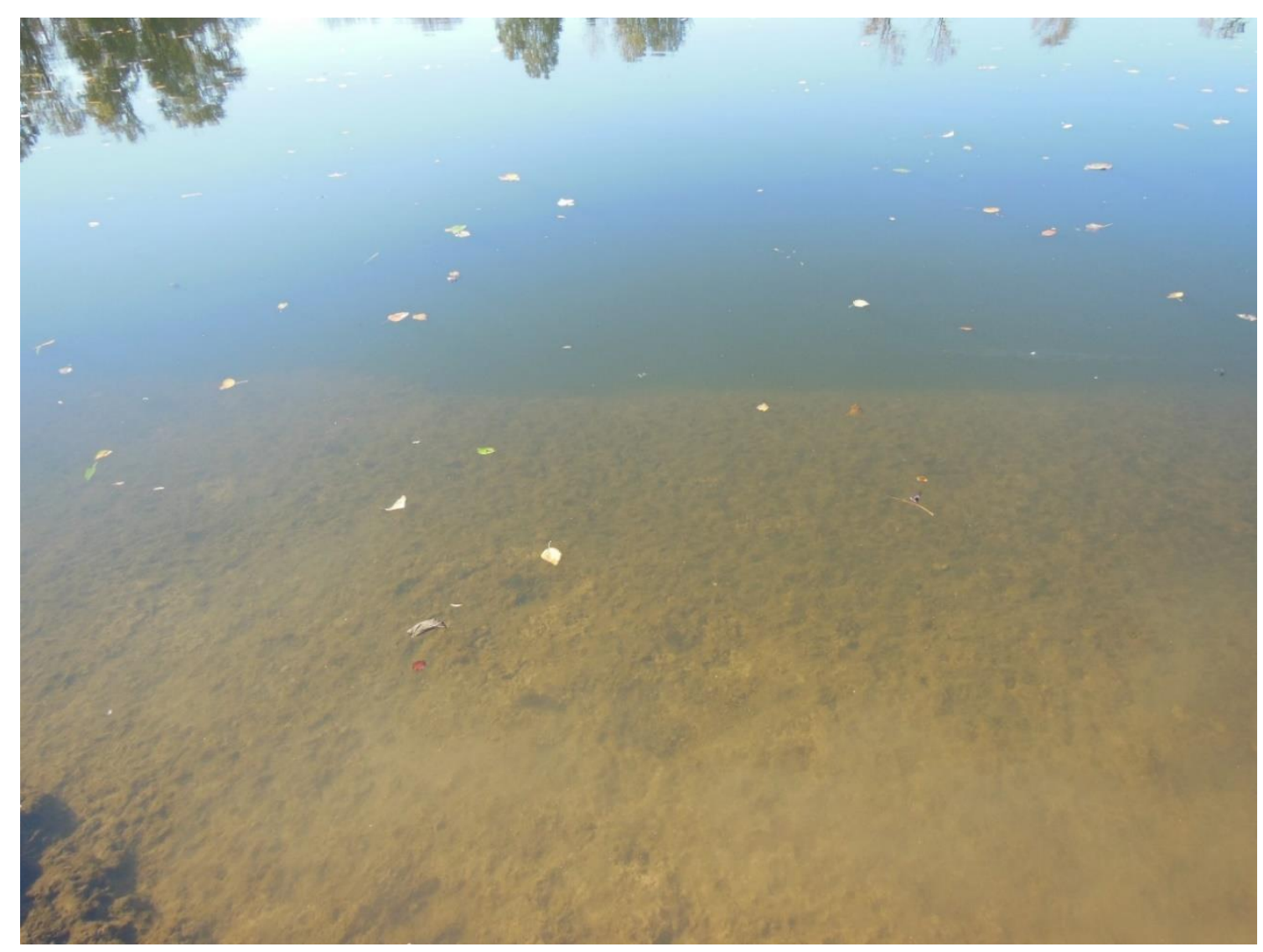

Example of a sheer beach edge. 


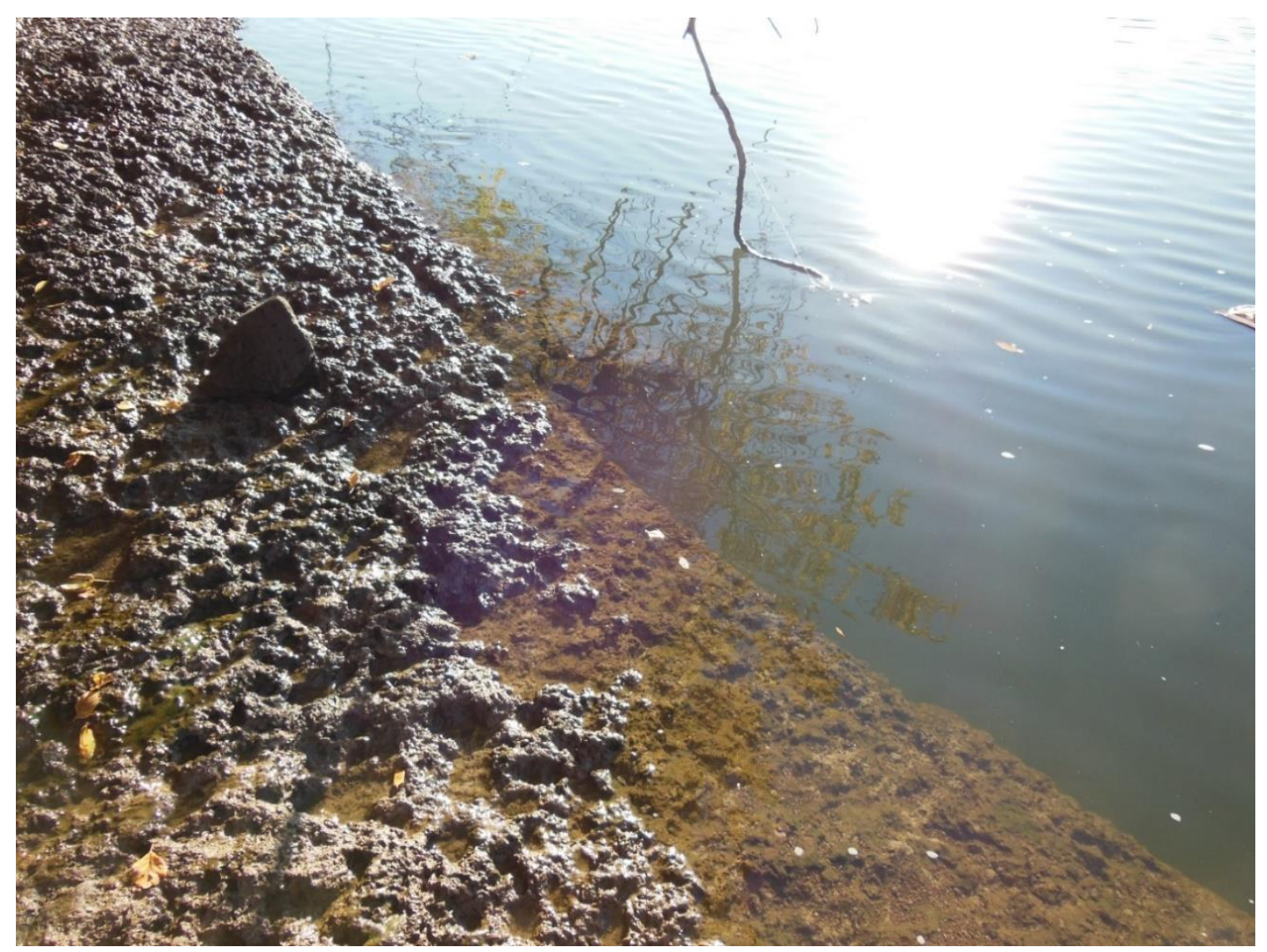

Another example of a sheer beach edge. 


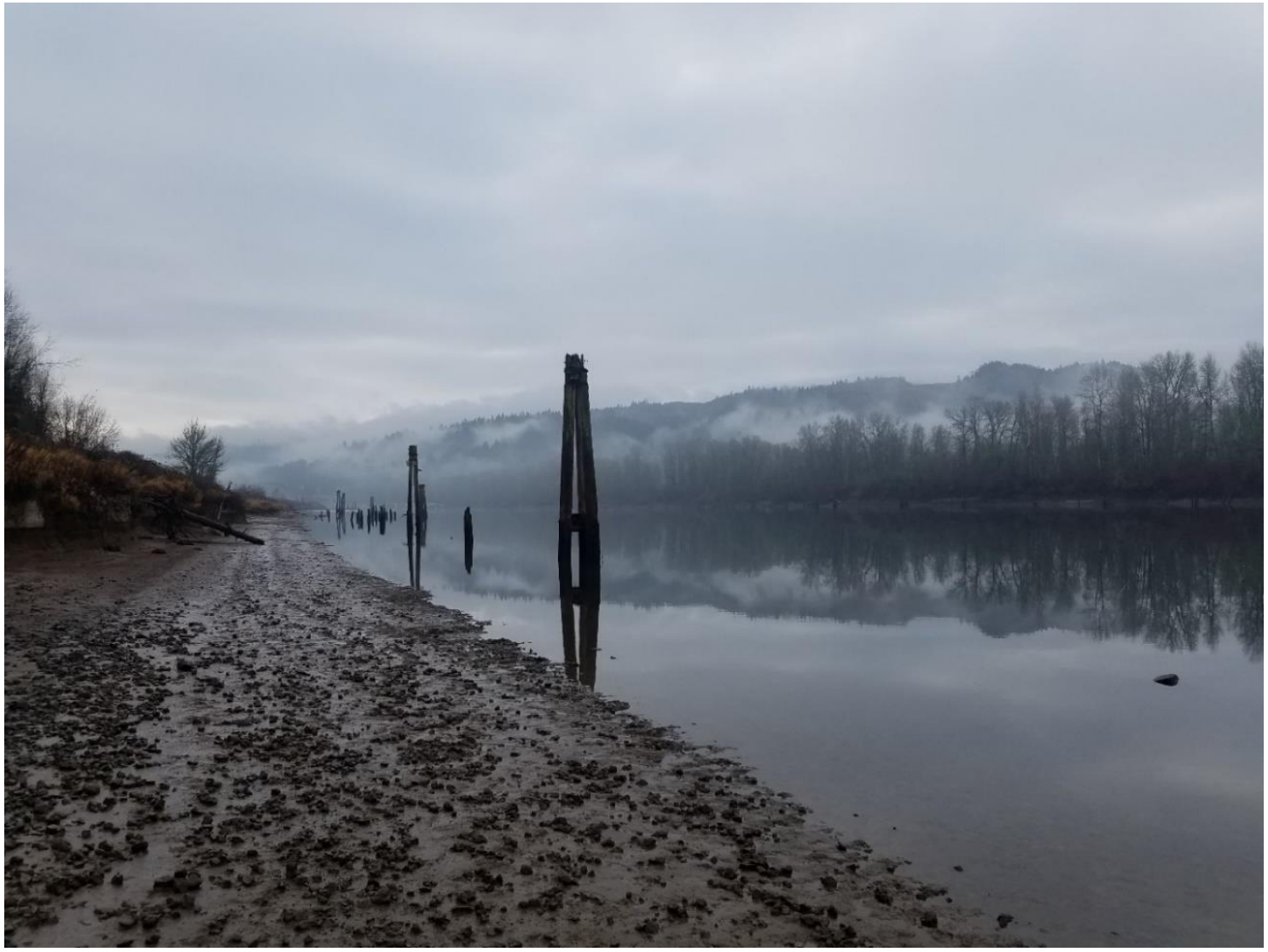

Example of a gradually terminating beach edge. 


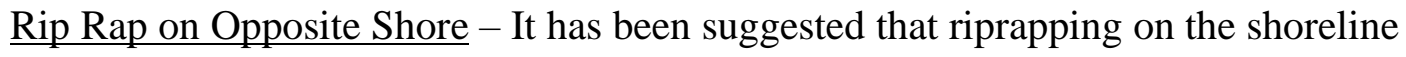
opposite sites may redirect channel currents in a manner that expedites erosion in the site area.

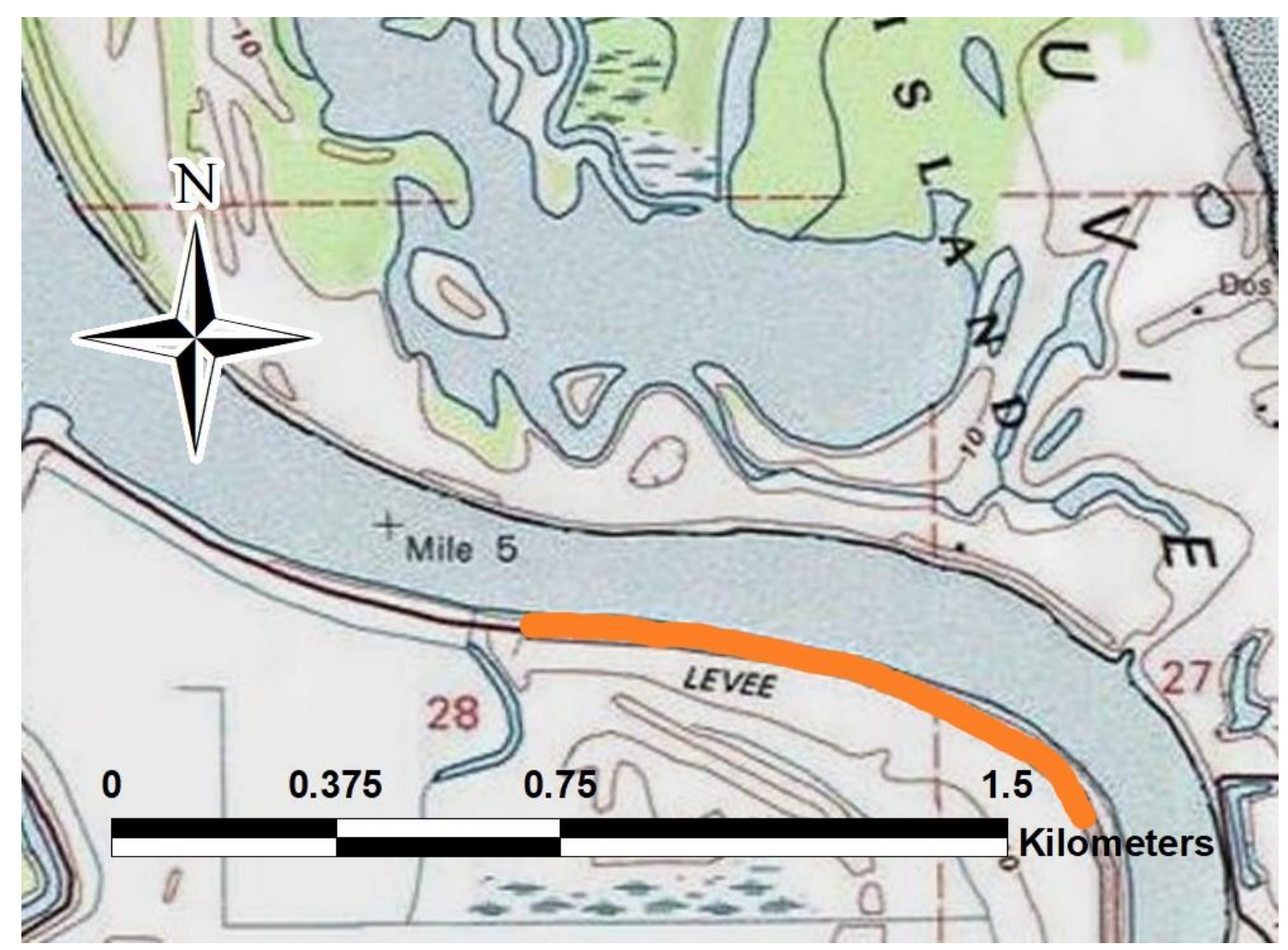

Example of a riprapped levee location across from western shoreline sites. [NOTE: Site locations have been redacted at the request of our tribal partners and to prevent site disturbance. Please refer to the Oregon State Historic Preservation Office records for unredacted version.] 
Exposed Cultural Features - This refers to the presence of exposed cultural features/materials in the bank wall. The active erosion of partially intact and/or in situ deposits (as opposed to deposits on the beach surface that have been fully exposed by a receding bank and that may have been subjected to looting and other modern disturbances) represents a risk factor for the site, while the Deposition portion of archaeological value recognizes the importance and presence of these partially intact deposits for researchers. Exposed geologic features from floods and other events (see Figure 10), may also represent natural features useful for dating cultural deposits.

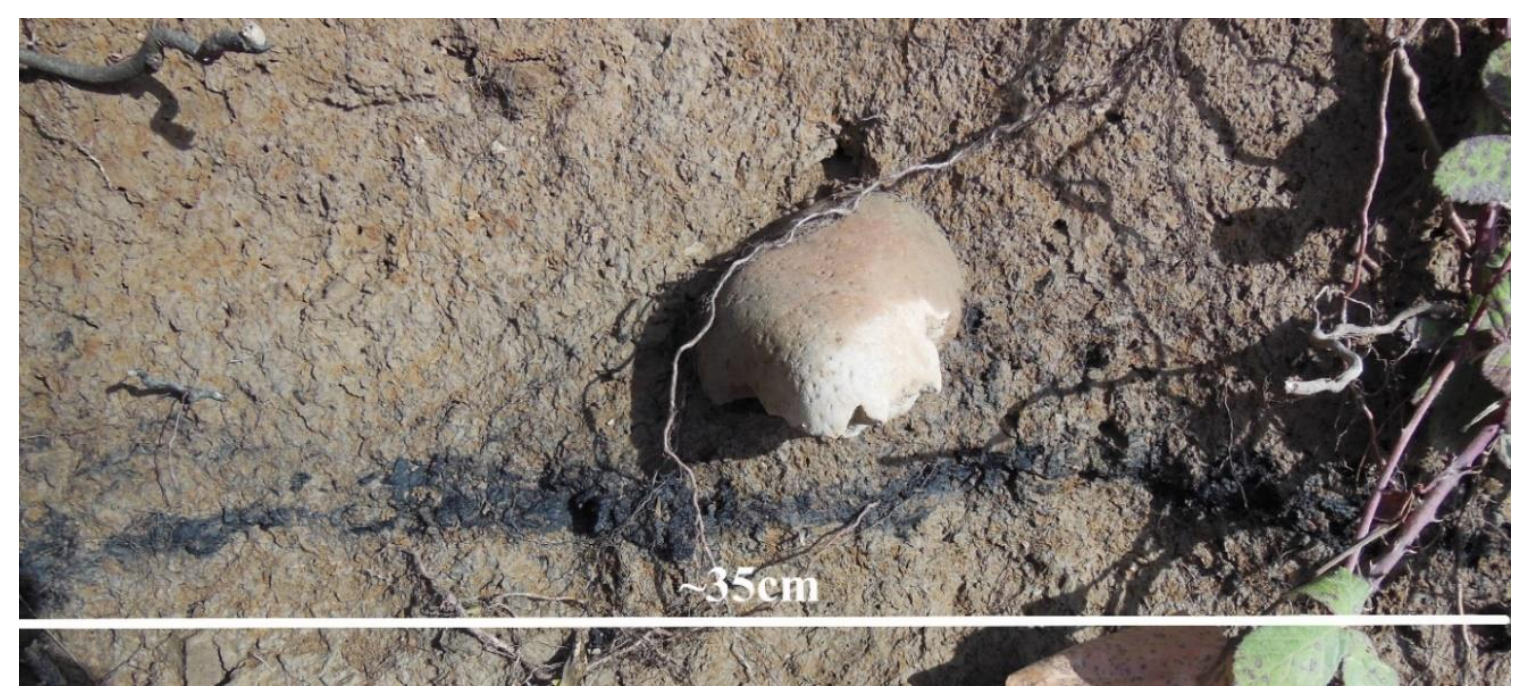

Example of eroding charcoal feature. 


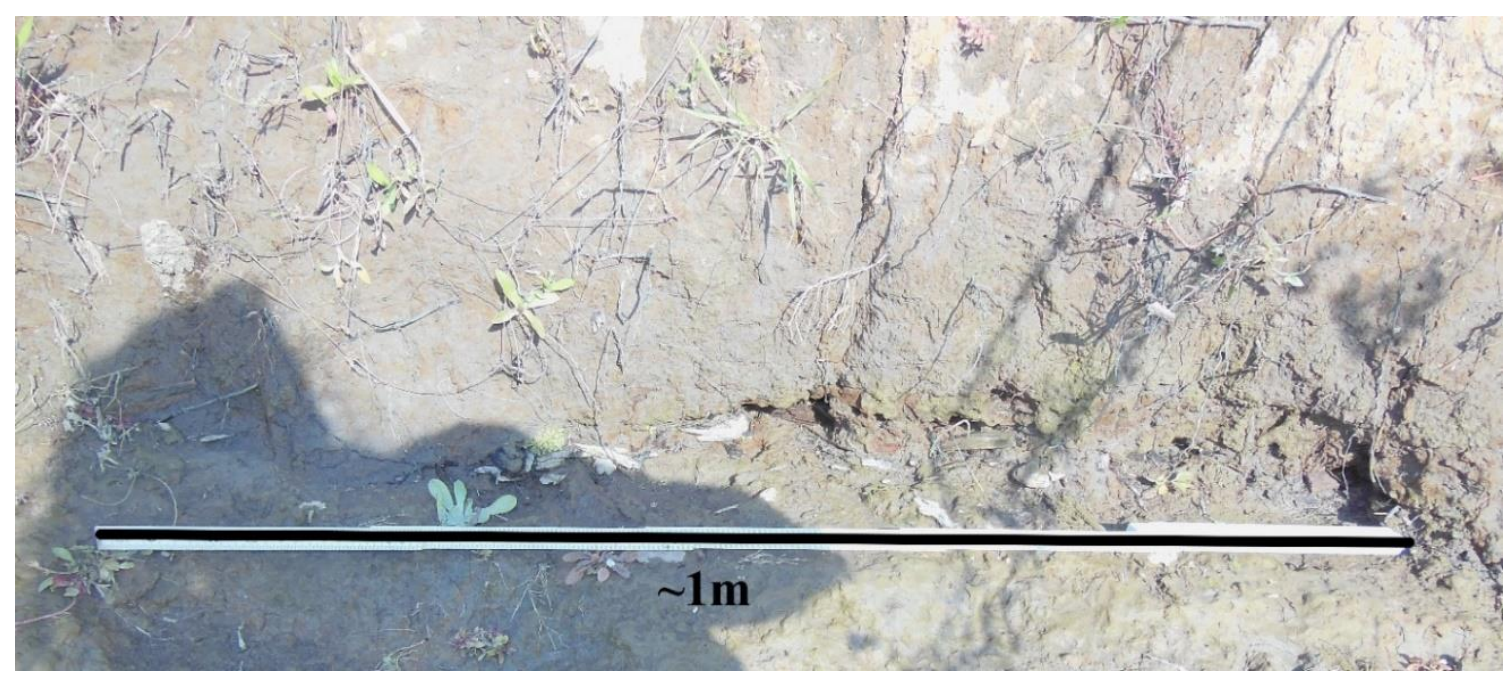

Example of eroding refuse deposit. 
Bank Angle - This refers to the sheerness of the bank slope angle. Excluding gradually sloping banks $\left(<50^{\circ}\right.$, see Figure 11), bank slopes are scored on a scale, with vertical or near vertical banks having the highest risk factor (see Figure 12), although gradually sloped banks may also have risk factors such as Runoff Channeling, while banks with Undercutting may have angles greater than $90^{\circ}$. Additionally, as viewed on the site condition excel table, some sites have variable bank angle across the site. In these cases, the score defaults to the highest risk angle present at the site.

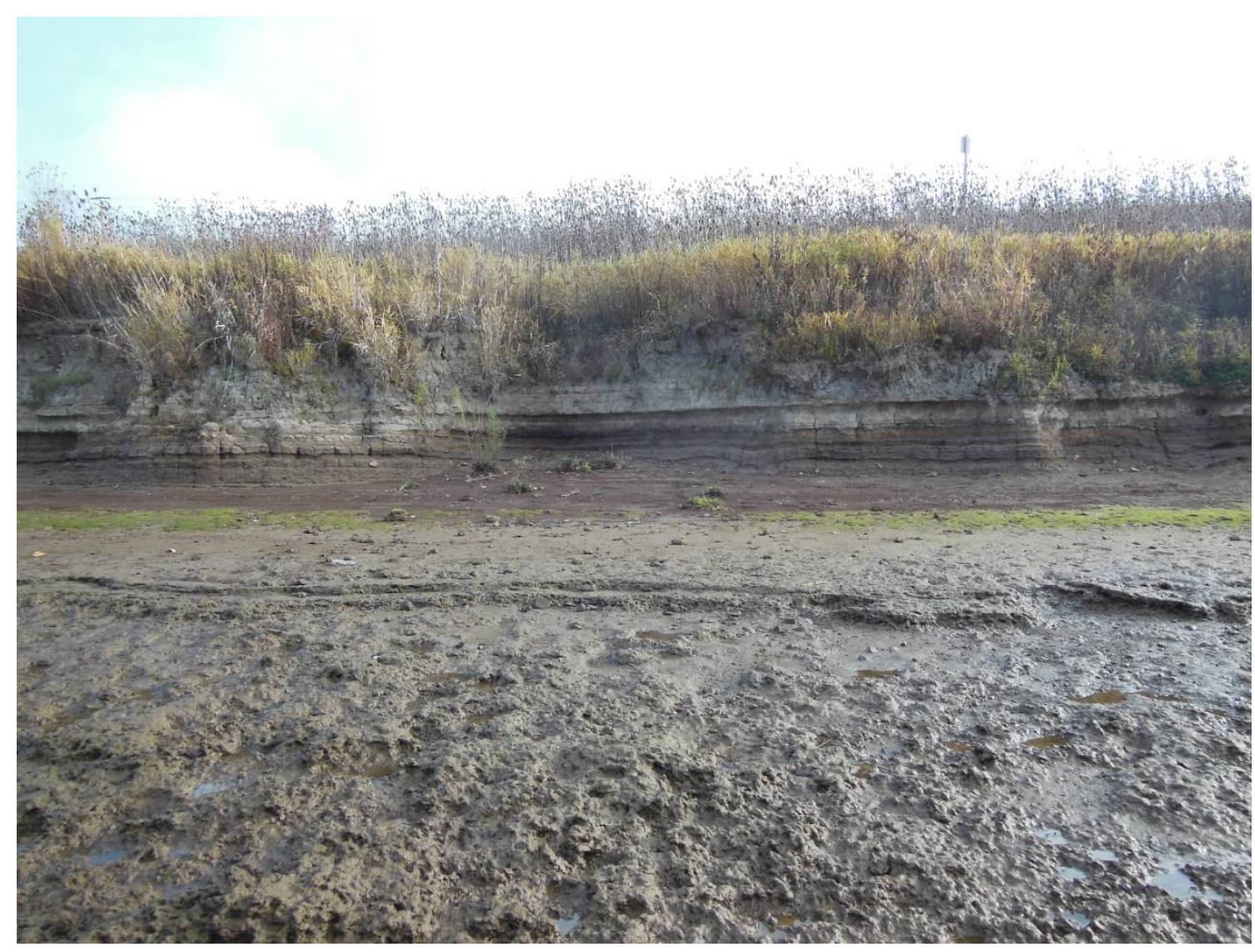

Example of sheer bank edge. 


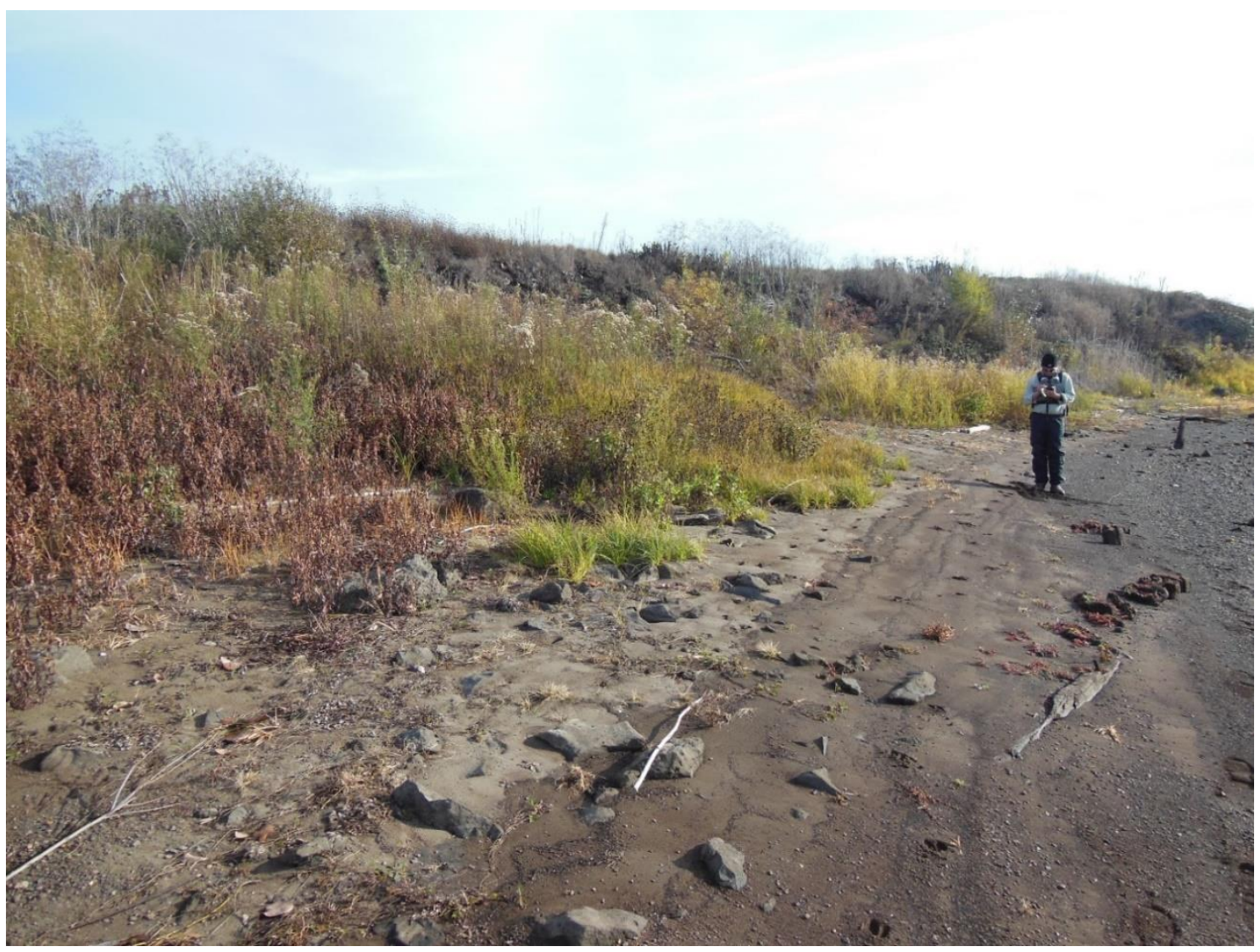

Example of a gradually sloping bank angle. 


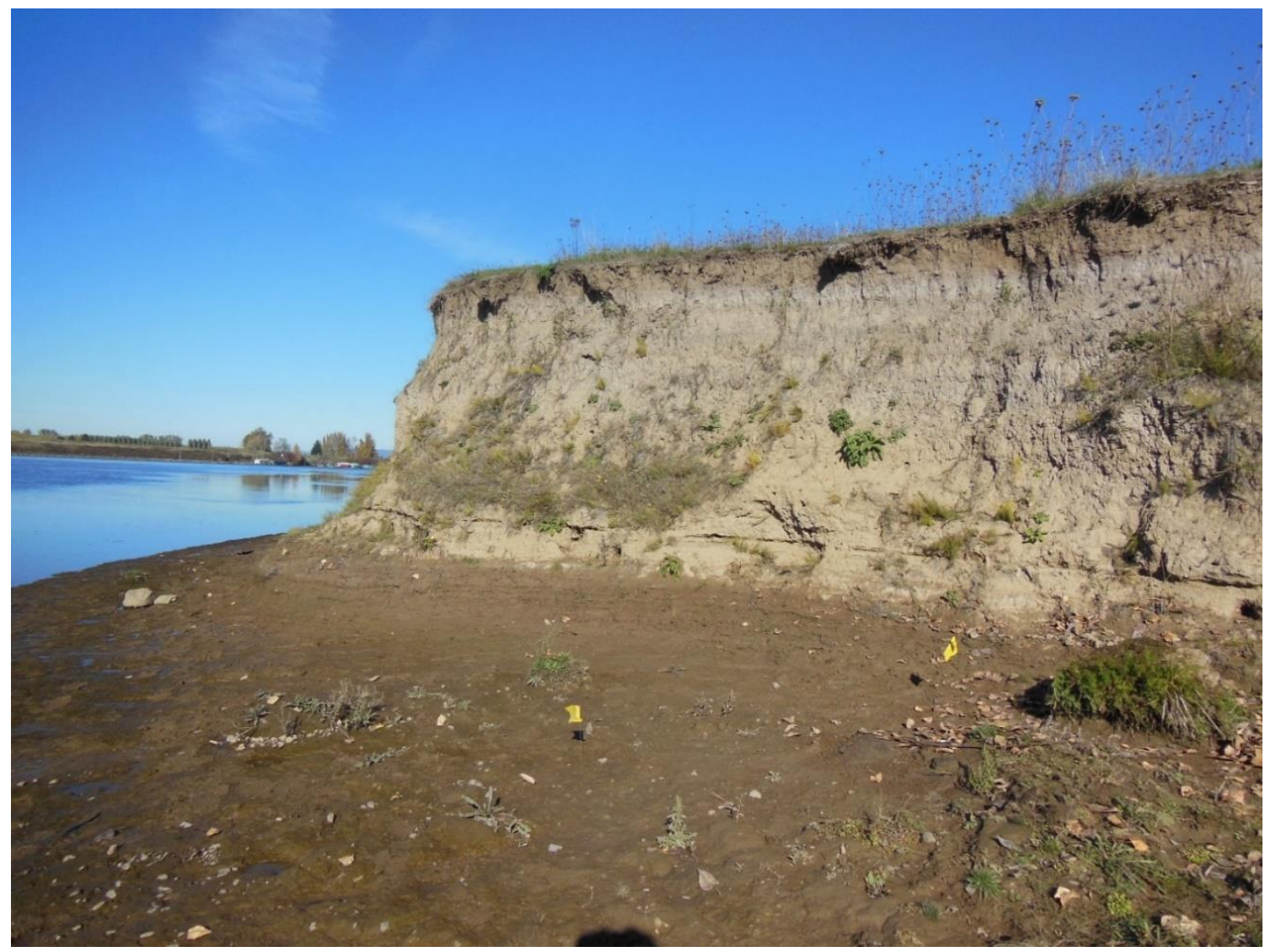

Example of a steep, sheer bank angle. 


\section{Appendix H: Site Condition Overview for Recorded Sites}

\begin{tabular}{|c|c|c|c|c|c|c|}
\hline \multicolumn{7}{|c|}{ 35MU4 (Sunken Village) } \\
\hline Attribute & 1973 & 1987 & 2004 & 2007 & 2019 & $\begin{array}{c}\text { Notes - Additional information from } \\
\text { previous reports, access notes, notes on } \\
\text { modern disturbance/use, etc. }\end{array}$ \\
\hline $\begin{array}{l}\text { Overview - General } \\
\text { description/nature of site }\end{array}$ & $\begin{array}{l}\text { Multicomponent wet-site } \\
\text { with precontact features and } \\
\text { artifacts, historic debris }\end{array}$ & Wet-site & Wet-site & $\begin{array}{l}\text { Large-scale acorn } \\
\text { processing } \\
\text { multicomponent wet- } \\
\text { site }\end{array}$ & Multicomponent site & $\begin{array}{l}2019 \text { survey was strictly along Multnomah } \\
\text { Channel shoreline, site visited in } \\
\text { September/October at low tide, site can be } \\
\text { accessed via beach/overland hiking or boat }\end{array}$ \\
\hline $\begin{array}{l}\text { Vegetation - General } \\
\text { overview of plant } \\
\text { communities at site }\end{array}$ & None mentioned & None mentioned & $\begin{array}{l}\text { Thick grasses on bank } \\
\text { and slump leading to } \\
\text { beach }\end{array}$ & \begin{tabular}{|l|} 
Hazelnut trees, cattail, \\
Oregon white oak, \\
wapato, and agricultural \\
crops
\end{tabular} & $\begin{array}{l}\text { No vegetation cover on beach, bank } \\
\text { vegetation limited to blackberry } \\
\text { thickets and sparse black cottonwood } \\
\text { trees }\end{array}$ & $\begin{array}{l}2007 \text { vegetation report references the overall } \\
\text { area surrounding the site. }\end{array}$ \\
\hline $\begin{array}{l}\text { Culturally Important Plants - } \\
\text { Species indicated as } \\
\text { important in ethnographic } \\
\text { accounts or modern } \\
\text { conversations with tribes }\end{array}$ & None mentioned & None mentioned & None mentioned & \begin{tabular}{|l|} 
Hazelnut trees, cattail, \\
Oregon white oak, \\
wapato
\end{tabular} & None observed & $\begin{array}{l}2007 \text { vegetation report on culturally important } \\
\text { plants references the overall area surrounding } \\
\text { the site. }\end{array}$ \\
\hline $\begin{array}{l}\text { Assemblage - General } \\
\text { overview of artifacts and } \\
\text { features found at site }\end{array}$ & $\begin{array}{l}\text { Basketry, FCR, hearth(s), } \\
\text { shell and wood artifacts, } \\
\text { groundstone, shell layer }\end{array}$ & $\begin{array}{l}\text { Lithic debitage, basketry, } \\
\text { wood, faunal and floral } \\
\text { remains, preserved organic } \\
\text { remains, } \sim 884 \text { total artifacts }\end{array}$ & $\begin{array}{l}\text { Twig lined pit features, } \\
\text { FCR, faunal remains, } \\
\text { lithic debitage }\end{array}$ & $\begin{array}{l}\text { Worked bone and shell, } \\
\text { FCR, wood, lithics, } \\
\text { groundstone, faunal and } \\
\text { floral remains, historic } \\
\text { cans and glass }\end{array}$ & $\begin{array}{l}\text { Few visible artifacts, no shell or } \\
\text { basketry, leaching pits not visible, } \\
\text { possible groundstone and FCR } \\
\text { fragments, }<10 \text { total artifacts }\end{array}$ & \\
\hline $\begin{array}{l}\text { Condition - General } \\
\text { overview of state of site }\end{array}$ & $\begin{array}{l}\text { Series of basins visible at } \\
\text { low-water, cut-bank with } \\
\text { visible features and slumping, } \\
\text { looting pits, log-raft floats } \\
\text { offshore }\end{array}$ & $\begin{array}{l}\text { Largely intact wet-site with } \\
\text { preserved depositional depth } \\
\text { to }<3 \mathrm{~m} \text {, illegal excavation and } \\
\text { collecting reported to land } \\
\text { managers, log-raft floats } \\
\text { offshore }\end{array}$ & \begin{tabular}{|l|} 
Exposed eroding cut- \\
bank with active \\
sloughing, extensive \\
intact cultural deposits \\
at site in natural levee, \\
looter tunneling, intake \\
pipe through cut-bank, \\
artificial levee placed \\
on top of natural levee, \\
possible log-rafts \\
offshore
\end{tabular} & \begin{tabular}{|l|} 
Site condition noted as \\
good, (between $5 \%$ and \\
$40 \%$ of site damaged)
\end{tabular} & $\begin{array}{l}\text { Site set on gradually sloping beach } \\
\text { with moderately steep ( }>65 \text { degrees) } \\
\text { cut-bank protected by riprap layer } \\
\text { along entirety of site boundary, thick } \\
\text { vegetation cover on bank, leaching } \\
\text { pits likely silted over at time of re- } \\
\text { recording, estimated visibility of site } \\
\text { at }<20 \% \text {, estimated condition of site } \\
\text { good ( }<40 \% \text { damaged) }\end{array}$ & $\begin{array}{l}\text { Due to minimal visibility of site during } 2019 \\
\text { rerecording, the <40\% estimated condition of } \\
\text { site is drawn from } 2007 \text { recording. }\end{array}$ \\
\hline $\begin{array}{l}\text { Impacting Agents - Noted or } \\
\text { inferred potential forces that } \\
\text { act negatively on site } \\
\text { condition }\end{array}$ & $\begin{array}{l}\text { Erosion washing, } \\
\text { looting/pothunting }\end{array}$ & Looting & $\begin{array}{l}\text { Erosion, looting, } \\
\text { illegal excavation, } \\
\text { modern agricultural } \\
\text { disturbance }\end{array}$ & $\begin{array}{l}\text { Bioturbation, erosion, } \\
\text { looting, vandalism, } \\
\text { animal trampling }\end{array}$ & $\begin{array}{l}\text { Inundation/degradation of exposed } \\
\text { leaching basketry from leaching pits }\end{array}$ & $\begin{array}{l}\text { Riprap has dramatically reduced the area of } \\
\text { the site accessible to potential looters, while } \\
\text { silting has likely obscured basketry features. } \\
\text { As such, site stability appears to have } \\
\text { improved over time. }\end{array}$ \\
\hline
\end{tabular}




\begin{tabular}{|c|c|c|c|}
\hline \multicolumn{4}{|c|}{ 35MU61 (Marked) } \\
\hline Attribute & 1987 & 2019 & Notes \\
\hline Overview & $\begin{array}{l}\text { Multicomponent scatter with } \\
\text { associated features }\end{array}$ & FCR scatter & $\begin{array}{l}\text { Site can be accessed } \\
\text { via beach/overland } \\
\text { hiking or boat }\end{array}$ \\
\hline Vegetation & $\begin{array}{l}\text { No vegetation cover on beach } \\
\text { w/ exception of sparse } \\
\text { horsetail/weeds, thick } \\
\text { grasses on bank }\end{array}$ & $\begin{array}{l}\text { No vegetation cover on } \\
\text { beach, thick grasses on bank }\end{array}$ & \\
\hline Culturally Important Plants & None mentioned & None observed & \\
\hline Assemblage & $\begin{array}{l}\text { FCR scatter, bone tools, } \\
\text { wood stakes, potential weir } \\
\text { feature, historic metal, glass, } \\
\text { beads, wood-post feature in } \\
\text { cut-bank }\end{array}$ & $\begin{array}{l}\text { FCR scatter, }<50 \text { total } \\
\text { artifacts }\end{array}$ & $\begin{array}{l}\text { Significant reduction in } \\
\text { assemblage observed } \\
\text { in } 2019 \text { re-record, } \\
\text { features not relocated }\end{array}$ \\
\hline Condition & $\begin{array}{l}\text { Sparse beach scatter on } \\
\text { eroding shoreline, land } \\
\text { manager reported artifact } \\
\text { collectors in area }\end{array}$ & $\begin{array}{l}\text { Gradually sloping ( }<50 \\
\text { degrees) eroding cut-bank, } \\
\text { some signs of slumping and } \\
\text { runoff channeling, gradually } \\
\text { sloping beach, estimated } \\
\text { visibility of site at }<80 \%, \\
\text { estimated condition of site is } \\
\text { very poor ( }>80 \% \text { damaged) }\end{array}$ & \\
\hline Impacting Agents & $\begin{array}{l}\text { General erosional forces, } \\
\text { potential looting, gas pipeline } \\
\text { disturbance, occasional cattle } \\
\text { grazing }\end{array}$ & $\begin{array}{l}\text { Erosion via high-water, } \\
\text { runoff, wave-action, high- } \\
\text { water events }\end{array}$ & \\
\hline
\end{tabular}




\begin{tabular}{|c|c|c|c|}
\hline \multicolumn{4}{|c|}{ 35MU62 (Howell) } \\
\hline Attribute & 1987 & 2019 & Notes \\
\hline Overview & $\begin{array}{l}\text { Multicomponent scatter with } \\
\text { associated features }\end{array}$ & $\begin{array}{l}\text { Multicomponent scatter with } \\
\text { associated feature }\end{array}$ & $\begin{array}{l}\text { Site can be accessed } \\
\text { via beach/overland } \\
\text { hiking or boat }\end{array}$ \\
\hline Vegetation & $\begin{array}{l}\text { Dense grass and weed cover } \\
\text { on beach, including ragwort, } \\
\text { thistle, and vetch }\end{array}$ & $\begin{array}{l}\text { No vegetation on beach } \\
\text { proper, thick grasses with } \\
\text { scattered brush on bank and } \\
\text { slump }\end{array}$ & \\
\hline Culturally Important Plants & None mentioned & None observed & \\
\hline Assemblage & $\begin{array}{l}\text { FCR scatter and lithic } \\
\text { debitage, projectile points, } \\
\text { ash/bone layers eroding from } \\
\text { cut-bank, two likely hearth } \\
\text { features, historic ceramics }\end{array}$ & $\begin{array}{l}\text { FCR scatter, hearth feature } \\
\text { eroding out of cut-bank, } \\
\text { historic glass and cans, }<50 \\
\text { total artifacts }\end{array}$ & $\begin{array}{l}\text { As with several sites, } \\
\text { large portions of the } \\
\text { Indigenous record were } \\
\text { not relocated, including } \\
\text { diagnostic artifacts }\end{array}$ \\
\hline Condition & $\begin{array}{l}\text { Bank is undercut, cultural } \\
\text { materials actively eroding out } \\
\text { of exposed bank, log rafts } \\
\text { moored offshore, associated } \\
\text { with dike and roadside } \\
\text { refuse, potential use as } \\
\text { recreational beach }\end{array}$ & $\begin{array}{l}\text { Sheer ( }>80 \text { degrees) exposed } \\
\text { cut-bank with visible } \\
\text { slumping and active erosion } \\
\text { of existing feature, illegal } \\
\text { access trail built into cut- } \\
\text { bank, northern site boundary } \\
\text { terminates near houseboat } \\
\text { moorage, estimated visibility } \\
\text { of site at <80\%, estimated } \\
\text { condition of site is poor } \\
\text { (>60\% damaged) }\end{array}$ & \\
\hline Impacting Agents & $\begin{array}{l}\text { Erosion via wave-action, } \\
\text { pothunting }\end{array}$ & $\begin{array}{l}\text { Erosion via wave-action, } \\
\text { wake, high-water events, } \\
\text { potential vandalism/looting }\end{array}$ & \\
\hline
\end{tabular}




\section{MU63}

\begin{tabular}{|c|c|c|c|}
\hline Attribute & 1987 & 2019 & Notes \\
\hline Overview & $\begin{array}{l}\text { Multicomponent scatter with } \\
\text { associated historic features }\end{array}$ & $\begin{array}{l}\text { Multicomponent scatter with } \\
\text { associated historic features }\end{array}$ & $\begin{array}{l}\text { Site can be accessed } \\
\text { via beach/overland } \\
\text { hiking or boat }\end{array}$ \\
\hline Vegetation & $\begin{array}{l}\text { Sparse weeds and horsetail } \\
\text { on beach, slump from cut- } \\
\text { bank heavily vegetated, } \\
\text { blackberry on bank slope }\end{array}$ & $\begin{array}{l}\text { No vegetation on beach } \\
\text { proper, thick grasses with } \\
\text { scattered brush on bank and } \\
\text { slump }\end{array}$ & \\
\hline Culturally Important Plants & None mentioned & None observed & \\
\hline Assemblage & $\begin{array}{l}\text { FCR and lithic debitage } \\
\text { scatter, historic metal, brick, } \\
\text { glass, ceramics, and other } \\
\text { refuse associated with dock } \\
\text { feature extending into bank }\end{array}$ & $\begin{array}{l}\text { FCR scatter, historic trash } \\
\text { scatter including glass, } \\
\text { ceramics, metal, and dock } \\
\text { remains, with historic trash } \\
\text { midden and dock feature } \\
\text { extending into bank, }<125 \\
\text { total artifacts }\end{array}$ & \\
\hline Condition & $\begin{array}{l}\text { Beach and bank used for } \\
\text { grazing and agriculture, beach } \\
\text { used recreationally, features } \\
\text { actively eroding out of cut- } \\
\text { bank }\end{array}$ & $\begin{array}{l}\text { Exposed cut-bank ranging } \\
\text { from sheer to gradually } \\
\text { sloped, visible slumping, } \\
\text { estimated visibility of site at } \\
<80 \% \text {, estimated condition of } \\
\text { site is poor ( }>60 \% \text { damaged) }\end{array}$ & $\begin{array}{l}\text { Recreational and } \\
\text { agricultural use has } \\
\text { ceased since } 1987 \\
\text { recording }\end{array}$ \\
\hline Impacting Agents & $\begin{array}{l}\text { Looting/vandalism, cattle } \\
\text { trampling, erosion due to } \\
\text { tidal forces, agricultural land } \\
\text { modification (dike } \\
\text { construction) }\end{array}$ & $\begin{array}{l}\text { Erosion by inundation, wave- } \\
\text { action, high water events, } \\
\text { wake, degradation due to } \\
\text { exposure }\end{array}$ & \\
\hline
\end{tabular}


35MU242

\begin{tabular}{|c|c|c|c|}
\hline Attribute & 2013 & 2019 & Notes \\
\hline Overview & $\begin{array}{l}\text { Historic dam and dock } \\
\text { pilings, intake }\end{array}$ & $\begin{array}{l}\text { Historic dam and dock } \\
\text { pilings, intake }\end{array}$ & $\begin{array}{l}\text { Site consists of two } \\
\text { distinct dock/dam } \\
\text { elements, only one of } \\
\text { which was located due } \\
\text { to access issues, } \\
\text { attribute observations } \\
\text { refer to Multnomah } \\
\text { Channel portion, } \\
\text { Multnomah Channel } \\
\text { portion can be } \\
\text { accessed via } \\
\text { beach/overland hiking } \\
\text { or boat }\end{array}$ \\
\hline Vegetation & $\begin{array}{l}\text { No vegetation cover in site } \\
\text { area }\end{array}$ & $\begin{array}{l}\text { No vegetation cover in site } \\
\text { area, some grasses on bank } \\
\text { above site }\end{array}$ & \\
\hline Culturally Important Plants & None mentioned & None observed & \\
\hline Assemblage & $\begin{array}{l}\text { Two rows of historic pilings, } \\
\text { large historic riprap pile, } \\
\text { large angular boulders }\end{array}$ & $\begin{array}{l}\text { Two rows of historic pilings, } \\
\text { large historic riprap pile, } \\
\text { large angular boulders }\end{array}$ & \\
\hline Condition & $\begin{array}{l}\text { Site condition is poor }(>60 \% \\
\text { damaged) }\end{array}$ & $\begin{array}{l}\text { Site sits on shoreline edge of } \\
\text { gradually sloping beach along } \\
\text { a gradually sloping }(<50 \\
\text { degrees) heavily vegetated, } \\
\text { unexposed bank, rock/dam } \\
\text { posts degrading, riprap pile } \\
\text { and boulder fill intact, } \\
\text { estimated site visibility is } \\
>80 \%, \text { estimated site } \\
\text { condition is very good }(<20 \% \\
\text { damaged) }\end{array}$ & $\begin{array}{l}\text { Unable to assess } \\
\text { Willamette River } \\
\text { portion, satellite } \\
\text { imagery shows general } \\
\text { bounds of piling field } \\
\text { is similar to } 2013 \\
\text { recording }\end{array}$ \\
\hline Impacting Agents & $\begin{array}{l}\text { Erosion and decay by } \\
\text { inundation, weathering of } \\
\text { exposed pilings }\end{array}$ & $\begin{array}{l}\text { Erosion and decay by } \\
\text { inundation, weathering of } \\
\text { exposed pilings }\end{array}$ & \\
\hline
\end{tabular}




\begin{tabular}{|c|c|c|c|c|}
\hline \multicolumn{5}{|c|}{$35 \mathrm{CO66}$} \\
\hline Attribute & 2009 & 2014 & 2019 & Notes \\
\hline Overview & $\begin{array}{l}\text { Historical industrial logging } \\
\text { complex }\end{array}$ & $\begin{array}{l}\text { Historical industrial logging } \\
\text { complex }\end{array}$ & $\begin{array}{l}\text { Historical industrial } \\
\text { logging complex with } \\
\text { associated refuse } \\
\text { scatter }\end{array}$ & $\begin{array}{l}\text { Site can be accessed } \\
\text { via beach/overland } \\
\text { hiking or boat }\end{array}$ \\
\hline Vegetation & None mentioned & None mentioned & $\begin{array}{l}\text { Scattered bunchgrass } \\
\text { on beach proper, } \\
\text { slump, and gently } \\
\text { sloping bank, thickly } \\
\text { vegetated bank with } \\
\text { grasses, brush, and } \\
\text { black cottonwoods }\end{array}$ & $\begin{array}{l}2009 \text { and } 2014 \text { reports } \\
\text { center on the pilings } \\
\text { fields, which sit largely } \\
\text { offshore }\end{array}$ \\
\hline Culturally Important Plants & None mentioned & None mentioned & None observed & \\
\hline Assemblage & $\begin{array}{l}\text { Multiple fields of historic } \\
\text { dock pilings, several } \\
\text { concrete structures partially } \\
\text { submerged offshore, milled } \\
\text { lumber, metal, glass, } \\
\text { ceramics, nails, and brick } \\
\text { scatter, } 331 \text { total artifacts }\end{array}$ & $\begin{array}{l}\text { Substantial number of pilings } \\
\text { and associated structures }\end{array}$ & \begin{tabular}{|l|} 
Three distinct dock \\
piling fields stretching \\
into and below the \\
waterline, degrading \\
concrete structure \\
partially submerged in \\
water, historic debris \\
scatter of metal, brick, \\
and glass, large \\
concrete drainage pipe, \\
$<125$ total artifacts
\end{tabular} & $\begin{array}{l}2014 \text { recording was a } \\
\text { brief overview largely } \\
\text { consisting of archival } \\
\text { research }\end{array}$ \\
\hline Condition & $\begin{array}{l}\text { Site damage indicated as } \\
\text { poor }(>60 \% \text { damaged })\end{array}$ & Unclear & $\begin{array}{l}\text { Gradually sloping }(<50 \\
\text { degrees) cut-bank } \\
\text { without significant soil } \\
\text { exposure, some } \\
\text { sloughing visible, } \\
\text { looter's piles found, } \\
\text { pilings remain exposed } \\
\text { at all tide levels, } \\
\text { estimated visibility of } \\
\text { site is }>60 \% \text {, estimated } \\
\text { site condition is poor } \\
\text { in the two northernmost } \\
\text { site sections }(>60 \% \\
\text { damaged) and fair in } \\
\text { the southernmost } \\
\text { section }(>40 \% \\
\text { damaged) }\end{array}$ & $\begin{array}{l}2014 \text { recording does not } \\
\text { appear to have visited } \\
\text { site directly or assessed } \\
\text { the condition, no } \\
\text { estimation of damage is } \\
\text { given }\end{array}$ \\
\hline Impacting Agents & $\begin{array}{l}\text { Erosion and decay by } \\
\text { inundation, weathering of } \\
\text { dock pilings }\end{array}$ & Inundation and decay & $\begin{array}{l}\text { Erosion and decay by } \\
\text { inundation, high-water } \\
\text { events, wave-action, } \\
\text { and wake, weathering } \\
\text { of exposed dock } \\
\text { pilings, looting of } \\
\text { diagnostic artifacts }\end{array}$ & \\
\hline
\end{tabular}




\section{$35 \mathrm{CO} 75$}

\begin{tabular}{|c|c|c|c|}
\hline Attribute & 2015 & 2019 & Notes \\
\hline Overview & $\begin{array}{l}\text { Multicomponent camp and } \\
\text { scatter with associated } \\
\text { features }\end{array}$ & Historic debris scatter & $\begin{array}{l}\text { No indications of } \\
\text { Indigenous artifact } \\
\text { component in } 2019 \text { re- } \\
\text { record, site is } \\
\text { accessible via } \\
\text { overland route } \\
\text { seasonally, can be } \\
\text { accessed via beach } \\
\text { hiking with careful } \\
\text { tidal preparation, or by } \\
\text { boat }\end{array}$ \\
\hline Vegetation & $\begin{array}{l}\text { Cottonwood, willow, } \\
\text { blackberry, and grasses on } \\
\text { bank }\end{array}$ & $\begin{array}{l}\text { Scattered bunchgrass } \\
\text { increasing in frequency closer } \\
\text { to cut-bank, thick blackberry } \\
\text { and occasional cottonwoods } \\
\text { line bank }\end{array}$ & $\begin{array}{l}\text { Vegetation in re-record } \\
\text { appears to be less } \\
\text { diverse, possibly due } \\
\text { to invasive blackberry }\end{array}$ \\
\hline Culturally Important Plants & Willow & None observed & \\
\hline Assemblage & $\begin{array}{l}\text { FCR and lithic debitage } \\
\text { scatter, diagnostic projectile } \\
\text { points, groundstone, with } \\
\text { hearth feature and artifacts } \\
\text { eroding out of bank, historic } \\
\text { glass, metal, and ceramic } \\
\text { fragments, 98 total artifacts }\end{array}$ & $\begin{array}{l}\text { Historic glass and ceramic } \\
\text { fragments, }<40 \text { total artifacts }\end{array}$ & $\begin{array}{l}\text { Significant changes to } \\
\text { the assemblage were } \\
\text { observed at site, } \\
\text { including the absence } \\
\text { of diagnostic } \\
\text { Indigenous artifacts }\end{array}$ \\
\hline Condition & $\begin{array}{l}\text { Site condition is fair }(>40 \% \\
\text { damaged) }\end{array}$ & $\begin{array}{l}\text { Site located on gradually } \\
\text { sloping beach, bank across } \\
\text { site has varying levels of } \\
\text { slope and exposure, some } \\
\text { signs of slumping, secondary } \\
\text { cut-bank forming mid-way } \\
\text { down beach, bank } \\
\text { undercutting at landmark } \\
\text { trees, potential cattle access } \\
\text { with grazing area on bank } \\
\text { above site, estimated site } \\
\text { visibility is }>60 \%, \text { estimated } \\
\text { site condition is very poor } \\
\text { (>80\% damaged) }\end{array}$ & \\
\hline Impacting Agents & Erosion due to inundation & $\begin{array}{l}\text { Erosion by inundation, } \\
\text { undercutting due to high-water } \\
\text { events, wave-action, and } \\
\text { wake, cattle trampling }\end{array}$ & \\
\hline
\end{tabular}




\begin{tabular}{|c|c|c|c|}
\hline \multicolumn{4}{|c|}{ 35СО76 } \\
\hline Attribute & 2015 & 2019 & Notes \\
\hline Overview & Lithic scatter & $\begin{array}{l}\text { FCR scatter with associated } \\
\text { features }\end{array}$ & $\begin{array}{l}\text { Site is accessible via } \\
\text { overland route } \\
\text { seasonally, can be } \\
\text { accessed via beach } \\
\text { hiking with careful } \\
\text { tidal preparation, or by } \\
\text { boat }\end{array}$ \\
\hline Vegetation & $\begin{array}{l}\text { No vegetation on beach, bank } \\
\text { vegetation includes alder, } \\
\text { blackberry, willow, and } \\
\text { grasses }\end{array}$ & $\begin{array}{l}\text { No vegetation on beach, bank } \\
\text { vegetation includes thick } \\
\text { blackberry brush and } \\
\text { scattered black cottonwoods }\end{array}$ & $\begin{array}{l}\text { Significant changes to } \\
\text { vegetation profile } \\
\text { observed in } 2019 \text { re- } \\
\text { record }\end{array}$ \\
\hline Culturally Important Plants & Willow & \begin{tabular}{|l|} 
None observed \\
\end{tabular} & \\
\hline Assemblage & $\begin{array}{l}\text { FCR scatter, } \sim 100 \text { total } \\
\text { artifacts }\end{array}$ & $\begin{array}{l}\text { FCR scatter with surface } \\
\text { hearth feature on beach edge } \\
\text { and additional hearth feature } \\
\text { extending into cut-bank, }<125 \\
\text { total artifacts }\end{array}$ & $\begin{array}{l}\text { Hearth features are } \\
\text { newly located in } 2019 \\
\text { re-record process }\end{array}$ \\
\hline Condition & $\begin{array}{l}\text { Site condition is fair }(>40 \% \\
\text { damaged) }\end{array}$ & $\begin{array}{l}\text { Site set on abruptly } \\
\text { terminating beach with sheer } \\
\text { drop-off into water, beach } \\
\text { feature actively eroding into } \\
\text { water, cut-bank is sheer ( }>80 \\
\text { degrees), with extensive } \\
\text { exposure and actively eroding } \\
\text { feature, estimated site } \\
\text { visibility is }>80 \% \text {, estimated } \\
\text { site condition is very poor } \\
\text { ( }>80 \% \text { damaged) }\end{array}$ & \\
\hline Impacting Agents & Erosion due to inundation & $\begin{array}{l}\text { Erosion due to inundation, } \\
\text { high-water events, wave- } \\
\text { action, and wake }\end{array}$ & \\
\hline
\end{tabular}


PJD001 - Wapato Access

\begin{tabular}{|c|c|c|}
\hline Attribute & 2019 & Notes \\
\hline Overview - General description/nature of site & FCR Scatter & $\begin{array}{l}\text { Site not fully recorded in } 2019 \text { visit due to access issues, site may be } \\
\text { accessible via overland route but could only be reached via boat during } \\
\text { survey }\end{array}$ \\
\hline $\begin{array}{l}\text { Vegetation - General overview of plant communities } \\
\text { at site }\end{array}$ & $\begin{array}{l}\text { Minimal vegetation cover on beach proper, with some } \\
\text { bunchgrass at foot of bank, thick grasses on slump, thick } \\
\text { black cottonwood stands and blackberry brush on top of } \\
\text { bank }\end{array}$ & $\begin{array}{l}\text { Douglas fir visible in the interior, site is just west of Virginia Lake, which } \\
\text { has a significant wapato plant community }\end{array}$ \\
\hline $\begin{array}{l}\text { Culturally Important Plants - Species indicated as } \\
\text { important in ethnographic accounts or modern } \\
\text { conversations with tribes }\end{array}$ & None observed & $\begin{array}{l}\text { Wapato in Virginia Lake (site PJD001 is on NW edge of Wapato Access } \\
\text { Greenway, OPRD) }\end{array}$ \\
\hline $\begin{array}{l}\text { Assemblage - General overview of artifacts and } \\
\text { features found at site }\end{array}$ & FCR Scatter, $<150$ total artifacts & \\
\hline Condition - General overview of state of site & $\begin{array}{l}\text { Site located on a gradually sloping beach against a } \\
\text { majority }>80 \text { degree bank slope with significant } \\
\text { portions of exposed bank, visible heavily vegetated } \\
\text { slumping and large deadfall across site, boundary } \\
\text { crosses fence that extends onto beach, estimated } \\
\text { visibility of site at }>80 \%, \text { estimated condition of site is } \\
\text { poor ( }>60 \% \text { damaged) }\end{array}$ & $\begin{array}{l}\text { Site is situated on the northernmost boundary of OPRD land and private } \\
\text { property beyond that, with a barbed wire fence extending onto the beach } \\
\text { to divide the site and demarcate the property boundary }\end{array}$ \\
\hline $\begin{array}{l}\text { Impacting Agents - Noted or inferred potential forces } \\
\text { that act negatively on site condition }\end{array}$ & $\begin{array}{l}\text { Erosion via high-water events, wave-action, wake, and } \\
\text { tidal forces, modern disturbance from private land } \\
\text { development }\end{array}$ & \\
\hline
\end{tabular}




\begin{tabular}{|c|c|c|}
\hline \multicolumn{3}{|c|}{ PJD002 - Wildlife Refuge } \\
\hline Attribute & 2019 & Notes \\
\hline Overview & Multicomponent scatter with associated features & $\begin{array}{l}\text { Only the historic-era component was observed due to water level during } \\
\text { the } 2019 \text { survey, which occurred the end of October, at low-tide, } \\
\text { indigenous component reported by other visiting researchers, site can be } \\
\text { reached via overland route and boat }\end{array}$ \\
\hline Vegetation & $\begin{array}{l}\text { No vegetation cover on beach proper, slump and bank } \\
\text { covered in thick bunchgrass as well as possible } \\
\text { agricultural crops on top of bank, small stand of black } \\
\text { cottonwoods are the far southern tip of the site }\end{array}$ & $\begin{array}{l}\text { No blackberry brush or trees were observed at on the bank top across } \\
\text { majority of site, likely due to agricultural clearing }\end{array}$ \\
\hline Culturally Important Plants & None observed & \\
\hline Assemblage & $\begin{array}{l}\text { Historic-era glass, metal, and ceramic fragments, } \\
\text { diagnostic ceramic fragments with maker's marks, } \\
\text { unknown number of FCR fragments below waterline, } \\
<75 \text { total artifacts }\end{array}$ & $\begin{array}{l}\text { Hearth and possible FCR reported by other visiting researchers, not } \\
\text { observed in } 2019 \text { recording due to water level }\end{array}$ \\
\hline Condition & $\begin{array}{l}\text { Site located on narrow, gradually sloping beach against } \\
\text { a sheer ( }>80 \text { degrees), exposed bank with significant } \\
\text { slumping at middle of site and steep beach drop-off } \\
\text { along waterline, elements of site sit below waterline at } \\
\text { all but lowest water levels, assemblage mixed with } \\
\text { significant amounts of modern trash, site sits adjacent to } \\
\text { recreation area parking/cattle grazing area, estimated } \\
\text { visibility of site is }>60 \% \text {, estimated condition of site is } \\
\text { very poor ( }>80 \% \text { damaged) }\end{array}$ & $\begin{array}{l}\text { Based on water depth, narrowness of beach, and steepness of bank slope, } \\
\text { it is not thought that cattle have access to site, despite close proximity }\end{array}$ \\
\hline Impacting Agents & $\begin{array}{l}\text { Erosion via high-water events, wave-action, wake, and } \\
\text { tidal forces, vandalism, recreational activity }\end{array}$ & $\begin{array}{l}\text { Site is adjacent to a clearly marked ODFW parking area within the Sauvie } \\
\text { Island Wildlife Refuge and is easily accessed from bank }\end{array}$ \\
\hline
\end{tabular}




\begin{tabular}{|c|c|c|}
\hline \multicolumn{3}{|c|}{ PJD003 - Pulloff } \\
\hline Attribute & 2019 & Notes \\
\hline Overview & FCR Scatter & $\begin{array}{l}\text { Site can be reached via overland hiking, beach hiking from OPRD access } \\
\text { areas, and by boat }\end{array}$ \\
\hline Vegetation & $\begin{array}{l}\text { No vegetation cover on beach proper, minimal grasses } \\
\text { on slump, bank top thickly vegetated with black } \\
\text { cottonwoods, dogwoods, and blackberry brush }\end{array}$ & \\
\hline Culturally Important Plants & None observed & \\
\hline Assemblage & FCR fragments, $<50$ total artifacts & \\
\hline \begin{tabular}{|l|} 
Condition \\
\end{tabular} & $\begin{array}{l}\text { Site is on a gradually sloping beach with a sheer drop- } \\
\text { off into water, sheer ( }>80 \text { degrees) bank is partially } \\
\text { exposed with some visible slumping and undercutting } \\
\text { and significant deadfall throughout, estimated visibility } \\
\text { of site at }>80 \% \text {, estimated condition of site is poor } \\
(>60 \% \text { damaged) }\end{array}$ & \\
\hline Impacting Agents & $\begin{array}{l}\text { Erosion via high-water events, wave-action, wake, and } \\
\text { tidal forces }\end{array}$ & \\
\hline
\end{tabular}




\begin{tabular}{|l|l|l|}
\hline \multicolumn{2}{|c|}{ PJD004 - Coon Island } & \multicolumn{1}{|c|}{$\mathbf{2 0 1 9}$} \\
\hline \multicolumn{2}{|c|}{ Attribute } & \multicolumn{1}{|c|}{ Notes } \\
\hline Overview & FCR Scatter w/ accompanying tools & $\begin{array}{l}\text { Site can only be accessed via boat, dense vegetation makes beach and } \\
\text { overland access impossible }\end{array}$ \\
\hline Vegetation & $\begin{array}{l}\text { No vegetation cover on beach proper, bank top thickly } \\
\text { vegetated with black cottonwood trees and blackberry } \\
\text { brush, with occasional bitter cherry trees }\end{array}$ & \\
\hline Culturally Important Plants & None observed & $\begin{array}{l}\text { FCR fragments, netweight preform, possible } \\
\text { hammerstone, <100 total artifacts }\end{array}$ \\
\hline Assemblage & $\begin{array}{l}\text { Site is located on a gradually sloping beach along a } \\
\text { sheer (>80 degrees), exposed bank with extensive } \\
\text { deadfall throughout site, some signs of runoff } \\
\text { channeling, estimated visibility of site at }>60 \%, \\
\text { estimated condition of site is fair (>40\% damaged) }\end{array}$ & \\
\hline Condition & $\begin{array}{l}\text { Erosion via high-water events, wave-action, wake, tidal } \\
\text { forces, and runoff }\end{array}$ & \\
\hline Impacting Agents & \\
\hline
\end{tabular}




\begin{tabular}{|c|c|c|}
\hline \multicolumn{3}{|c|}{ PJD005 - Crane Lake } \\
\hline Attribute & 2019 & Notes \\
\hline Overview & FCR Scatter & $\begin{array}{l}\text { Site can only be accessed via boat, dense vegetation makes beach and } \\
\text { overland access impossible }\end{array}$ \\
\hline Vegetation & $\begin{array}{l}\text { Minimal vegetation cover on beach proper with some } \\
\text { small grasses against bank edge and on slump, bank top } \\
\text { thickly vegetated with black cottonwoods, dogwoods, } \\
\text { and blackberry brush }\end{array}$ & \\
\hline Culturally Important Plants & None observed & \\
\hline Assemblage & $\begin{array}{l}\text { FCR fragments, possible hammerstone, possible historic } \\
\text { era debris, }<150 \text { total artifacts }\end{array}$ & $\begin{array}{l}\text { Site was recorded near end of daylight hours in early November, } \\
\text { verification of historic-era debris via diagnostic artifacts could not be } \\
\text { completed }\end{array}$ \\
\hline Condition & $\begin{array}{l}\text { Site sits against intermittently exposed bank, both sheer } \\
\text { and gradually sloped, with some slumping and } \\
\text { significant deadfall, beach slopes gradually into water, } \\
\text { significant presence of modern trash, debris, and } \\
\text { potential recreational gear across site, estimated } \\
\text { visibility of site at }>80 \% \text {, estimated condition of site is } \\
\text { fair (>40\% damaged) }\end{array}$ & \\
\hline Impacting Agents & $\begin{array}{l}\text { Erosion via high-water events, wave-action, wake, and } \\
\text { tidal forces, vandalism, recreational activity }\end{array}$ & \\
\hline
\end{tabular}


PJD006 - Crane River

\begin{tabular}{|c|c|c|}
\hline Attribute & 2019 & \begin{tabular}{|c|} 
Notes \\
\end{tabular} \\
\hline Overview & FCR Scatter & $\begin{array}{l}\text { Site can only be accessed via boat, dense vegetation makes beach and } \\
\text { overland access impossible }\end{array}$ \\
\hline Vegetation & $\begin{array}{l}\text { No vegetation cover on beach proper, bank top thickly } \\
\text { vegetated with black cottonwoods, dogwoods, and } \\
\text { blackberry brush, along with some grasses at bank edge }\end{array}$ & \\
\hline Culturally Important Plants & None observed & \\
\hline Assemblage & FCR fragments, $<75$ total artifacts & \\
\hline Condition & $\begin{array}{l}\text { Site located on gradually sloping beach, against sheer } \\
(>80 \text { degrees) exposed bank with occasional small } \\
\text { deadfall, estimated visibility of site at }>80 \% \text {, estimated } \\
\text { condition of site is fair ( }>40 \% \text { damaged) }\end{array}$ & $\begin{array}{l}\text { Although site shows no signs of modern activity, it sits just below and } \\
\text { south of a hunting-related structure situated on bank, within privately } \\
\text { owned property to the north of Crane Lake }\end{array}$ \\
\hline Impacting Agents & $\begin{array}{l}\text { Erosion via high-water events, wave-action, wake, and } \\
\text { tidal forces }\end{array}$ & \\
\hline
\end{tabular}




\begin{tabular}{|c|c|c|}
\hline \multicolumn{3}{|c|}{ PJD007 - Gilbert River } \\
\hline Attribute & 2019 & Notes \\
\hline Overview & FCR Scatter w/ accompanying tools & $\begin{array}{l}\text { Site can only be accessed via boat, dense vegetation makes beach and } \\
\text { overland access impossible }\end{array}$ \\
\hline Vegetation & $\begin{array}{l}\text { No vegetation cover on beach with exception of low- } \\
\text { lying grass patch on western edge against bank, bank top } \\
\text { and slope thickly vegetated with dogwood, blackberry } \\
\text { brush, and other small shrubs and trees }\end{array}$ & \\
\hline Culturally Important Plants & None observed & \\
\hline Assemblage & $\begin{array}{l}\text { FCR fragments, unifacial cobble chopper, possible } \\
\text { hammerstones, }<100 \text { total artifacts }\end{array}$ & \\
\hline Condition & $\begin{array}{l}\text { Site sits along partially exposed, moderately sheer }(>65 \\
\text { degrees) bank with significant vegetation and some } \\
\text { visible slumping, beach terminates in a sheer drop-off } \\
\text { into channel, some small deadfall present at site, } \\
\text { estimated visibility of site at }>60 \% \text {, estimated condition } \\
\text { of site is very poor ( }>80 \% \text { damaged) }\end{array}$ & $\begin{array}{l}\text { Site shows no signs of modern activity, but does sit on the exposed } \\
\text { prominence between Crane Lake outlet and the Gilbert River, within view } \\
\text { of the Gilbert River Boat Ramp and a privately owned dock further into } \\
\text { the island interior }\end{array}$ \\
\hline Impacting Agents & $\begin{array}{l}\text { Erosion via high-water events, wave-action, wake, and } \\
\text { tidal forces }\end{array}$ & \\
\hline
\end{tabular}




\begin{tabular}{|c|c|c|}
\hline \multicolumn{3}{|c|}{ PJD008 - Rocky Point } \\
\hline Attribute & 2019 & Notes \\
\hline Overview & Historic-era dock, trash scatter, and associated feature & Site can be accessed via overland hiking, beach hiking, or by boat \\
\hline Vegetation & $\begin{array}{l}\text { Thick bunchgrass and small dogwoods on bank with } \\
\text { some grasses on beach }\end{array}$ & \\
\hline Culturally Important Plants & None observed & \\
\hline Assemblage & $\begin{array}{l}\text { Historic-era glass, metal, and wood fragments, dock } \\
\text { feature with wood posts and rock fill, dock debris } \\
\text { feature extending into and along bank, }<30 \text { total artifacts }\end{array}$ & \\
\hline Condition & $\begin{array}{l}\text { Site located against gradually sloping ( }<50 \text { degrees), } \\
\text { heavily vegetated bank with visible slump onto } \\
\text { gradually sloping beach and bank deposits exposed by } \\
\text { undercutting, estimated visibility of site at }>80 \% \text {, } \\
\text { estimated condition of site is poor ( }>60 \% \text { damaged) }\end{array}$ & \\
\hline Impacting Agents & $\begin{array}{l}\text { Erosion via high-water events, wave-action, wake, and } \\
\text { tidal forces, degradation due to exposure and inundation }\end{array}$ & \\
\hline
\end{tabular}


PJD009 - Cunningham Lake

\begin{tabular}{|c|c|c|}
\hline Attribute & 2019 & Notes \\
\hline Overview & FCR Scatter with associated tools and feature & $\begin{array}{l}\text { Site can only be accessed via boat, dense vegetation makes beach and } \\
\text { overland access impossible }\end{array}$ \\
\hline Vegetation & $\begin{array}{l}\text { Minimal vegetation on beach proper, scattered low- } \\
\text { lying grasses mid way up beach and tufted hairgrass at } \\
\text { foot of bank, bank top is heavily vegetated with black } \\
\text { cottonwoods and blackberry brush, with some } \\
\text { occasional red-osier dogwood bushes }\end{array}$ & \\
\hline Culturally Important Plants & None observed & \\
\hline Assemblage & $\begin{array}{l}\text { FCR fragments, hammerstone, possible hearth feature, } \\
<175 \text { total artifacts }\end{array}$ & \\
\hline Condition & $\begin{array}{l}\text { Site sits along sheer ( }>80 \text { degrees), exposed bank, } \\
\text { beach is narrow, gradually sloped, with sheer drop-off } \\
\text { into water, deadfall present throughout site, estimated } \\
\text { visibility of site at }>80 \% \text {, estimated condition of site is } \\
\text { very poor ( }>80 \% \text { damaged) }\end{array}$ & \\
\hline Impacting Agents & $\begin{array}{l}\text { Erosion via high-water events, wave-action, wake, and } \\
\text { tidal forces }\end{array}$ & \\
\hline
\end{tabular}




\begin{tabular}{|c|c|c|}
\hline \multicolumn{3}{|c|}{ PJD010 - Polar Star } \\
\hline Attribute & 2019 & Notes \\
\hline Overview & Multicomponent scatter with associated features & $\begin{array}{l}\text { Site can only be accessed via boat, dense vegetation makes beach and } \\
\text { overland access impossible }\end{array}$ \\
\hline Vegetation & $\begin{array}{l}\text { Minimal vegetation on beach proper, increasingly thick } \\
\text { bunchgrass leading up to foot of bank and onto slump, } \\
\text { top of bank is thickly vegetated with dogwood and } \\
\text { blackberry brush }\end{array}$ & \\
\hline Culturally Important Plants & None observed & \\
\hline Assemblage & $\begin{array}{l}\text { FCR and lithic debitage scatter, projectile point, } \\
\text { possible hearth features, historic-era ceramic } \\
\text { concentration and dock feature, }<275 \text { total artifacts }\end{array}$ & \\
\hline Condition & $\begin{array}{l}\text { Site is set on a gradually sloping beach, against a } \\
\text { variably sloping and exposed bank, with significant } \\
\text { undercutting, slumping, runoff channeling, and deadfall } \\
\text { alternating across site, regularly inundated dock feature } \\
\text { is in various stages of decay, modern tugboat anchored } \\
\text { to the northwest of site at a continuously used set of } \\
\text { pilings, estimated visibility of site at }>60 \% \text {, estimated } \\
\text { condition of site is fair ( }>40 \% \text { damaged) }\end{array}$ & $\begin{array}{l}\text { Site is marked at the north end along the Multnomah Channel by a } \\
\text { commercial moorage in use since the } 1990 \text { 's at the latest with barges and } \\
\text { other commercial ships appearing on satellite imagery, current docked } \\
\text { ship is the Polar Star tugboat, which appears abandoned, beach directly in } \\
\text { front of moorage has significant modern debris but site does not appear to } \\
\text { extend into this scatter }\end{array}$ \\
\hline Impacting Agents & $\begin{array}{l}\text { Erosion through high-water events, run-off, wave- } \\
\text { action, inundation, degradation through wind and water } \\
\text { weathering, vandalism and damage from commercial } \\
\text { boat moorage nearby }\end{array}$ & \\
\hline
\end{tabular}

